\title{
Quality management after curative surgery in colorectal cancer patients
}

Citation for published version (APA):

Ramphal, W. (2020). Quality management after curative surgery in colorectal cancer patients. [Doctoral Thesis, Maastricht University]. Trichis Publishing. https://doi.org/10.26481/dis.20201016wr

Document status and date:

Published: 01/01/2020

DOI:

10.26481/dis.20201016wr

Document Version:

Publisher's PDF, also known as Version of record

\section{Please check the document version of this publication:}

- A submitted manuscript is the version of the article upon submission and before peer-review. There can be important differences between the submitted version and the official published version of record.

People interested in the research are advised to contact the author for the final version of the publication, or visit the DOI to the publisher's website.

- The final author version and the galley proof are versions of the publication after peer review.

- The final published version features the final layout of the paper including the volume, issue and page numbers.

Link to publication

\footnotetext{
General rights rights.

- You may freely distribute the URL identifying the publication in the public portal. please follow below link for the End User Agreement:

www.umlib.nl/taverne-license

Take down policy

If you believe that this document breaches copyright please contact us at:

repository@maastrichtuniversity.nl

providing details and we will investigate your claim.
}

Copyright and moral rights for the publications made accessible in the public portal are retained by the authors and/or other copyright owners and it is a condition of accessing publications that users recognise and abide by the legal requirements associated with these

- Users may download and print one copy of any publication from the public portal for the purpose of private study or research.

- You may not further distribute the material or use it for any profit-making activity or commercial gain

If the publication is distributed under the terms of Article $25 \mathrm{fa}$ of the Dutch Copyright Act, indicated by the "Taverne" license above, 


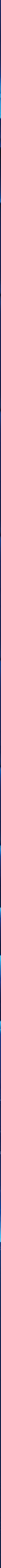


Quality management after curative surgery in colorectal cancer patients

Winesh Ramphal

PhD thesis, Maastricht University, with summary in Dutch

Proefschrift, Universiteit van Maastricht, met een samenvatting in het Nederlands

Cover design: Boyd Coonen (Brand Hero) \& Winesh Ramphal

Layout: Tiny Wouters

Production: Print Link Management

Publisher: Trichis Publishing

ISBN: 9789492881465

(C) W. Ramphal, Maastricht 2020

All rights reserved. No part of this publication may be reproduced, stored in a database or retrieval system, or transmitted, in any form or by any means without prior written permission of the author, or when appropriate, the publisher of the papers

Financial support for the publication of this thesis was financially supported by: ABN AMRO, Amphia Ziekenhuis Breda, Applied Medical, Chipsoft, Convatec, Erbe, Hollister Incorporated, IKNL, Kyowa Kirin Pharma, Norgine, Servier Nederland Farma, Sysmex Nederland, Universiteit van Maastricht en Welland Nederland. 


\title{
Quality Management after Curative Surgery in Colorectal Cancer Patients
}

\author{
PROEFSCHRIFT \\ Ter verkrijging van de graad van doctor aan de Universiteit Maastricht, \\ op gezag van Rector Magnificus prof. dr. Rianne M. Letschert \\ volgens het besluit van het College van Decanen, \\ in het openbaar te verdedigen \\ op vrijdag 24 april 2020 om 14:00 uur \\ door \\ Winesh Ramphal \\ Geboren op 28 augustus 1987 \\ te Eindhoven
}




\section{Promotor}

Prof. dr. H.J.T Rutten

\section{Co-promotores}

Dr. P.D. Gobardhan, Amphia Ziekenhuis Breda, afd. Chirurgie

Dr. J.M.J. Schreinemakers, Amphia Ziekenhuis Breda, afd Chirurgie

\section{Beoordelingscommissie}

Prof. dr. L.P.S. Stassen (voorzitter)

Prof. dr. I.H.J.T. de Hingh

Prof. dr. I.H.M. Borel Rinkes, Universitair Medisch Centrum Utrecht

Dr. D.K. Wasowicz-Kemps, Elisabeth-TweeSteden Ziekenhuis, Tilburg

\section{Paranimfen}

dhr. Tim C. Kuijpers

dhr. Joeri van Boxtel 


\section{Table of contents}

Chapter 1 General introduction and outline of this thesis 7

PART I Endoscopic follow-up after uncomplicated diverticulitis $\quad 18$

Chapter 2 What is the risk of colorectal cancer after an episode of acute 20 diverticulitis in conservatively treated patients?

Chapter 3 Tumour characteristics of patients with colorectal cancer after $\quad 35$ a first episode of acute uncomplicated diverticulitis

PART II Follow-up after curative surgery in colorectal cancer patients $\quad 49$

Chapter $4 \quad$ lleus caused by obstructing colorectal cancer: Impact on long 51 term survival

Chapter 5 Colonoscopy surveillance after colorectal cancer: The optimal 65 interval for follow-up

Chapter 6 Serum carcinoembryonic antigen to predict recurrence in the follow-up of patients with colorectal cancer

Chapter 7 Oncologic outcome and recurrence rate following anastomotic leakage after curative resection for colorectal cancer

Chapter 8 Fluorescence imaging with indocyanine green during robot-assisted surgery in rectal cancer patients

$\begin{array}{ll}\text { PART III General discussion, future perspectives and summary } & 133\end{array}$

$\begin{array}{lll}\text { Chapter } 9 \text { General discussion and future perspectives } & 135\end{array}$

$\begin{array}{lll}\text { Chapter } 10 & \text { Summary } & 147\end{array}$

Chapter 11 Summary in Dutch/Samenvatting in het Nederlands 153

$\begin{array}{lll}\text { Chapter } 12 \text { Valorisation } & 163\end{array}$

$\begin{array}{lll}\text { PART IV } & 169\end{array}$

$\begin{array}{lll}\text { Chapter } 13 \text { List of publications } & 171\end{array}$

Acknowledgements / Dankwoord $\quad 175$

$\begin{array}{ll}\text { Curriculum Vitae } & 185\end{array}$ 



\section{Chapter 1}

General introduction and outline of this thesis 



\section{General introduction}

\section{Diverticular disease}

Diverticular disease is one of the most common, yet benign condition of the large intestines in the Western world and one of the most common findings identified at colonoscopy with an increase in prevalence with increasing age ${ }^{1}$. Two-thirds of the population in western countries will develop this disease by the age of $85^{2}$. The pathogenesis of diverticular disease is thought to be multifactorial and include both environmental and genetic factors in addition to the historically accepted aetiology of dietary fibre deficiency ${ }^{3}$. Inflammation of a diverticulum leads to diverticulitis. It can present as either an acute or chronic process. Diverticulitis is the most common complication of diverticulosis, which occurs in about $10-25 \%$ of patients ${ }^{4}$. The pathophysiology of diverticulitis is the obstruction of the diverticulum sac by faecalith, which by irritation of the mucosa causes low-grade inflammation, congestion and further obstruction ${ }^{5}$.

The diagnosis of acute diverticulitis is a clinical diagnosis and is based on left lower quadrant pain, C-reactive protein (CRP) $>50 \mathrm{mg} / \mathrm{L}$ and the absence of vomiting ${ }^{6,7}$. This clinical diagnosis can be confirmed by characteristic findings on a computed tomography (CT) scan and/or ultrasound (US) of the abdomen ${ }^{8,9}$. Diverticulitis is classified as simple (uncomplicated) or complicated. Complicated diverticulitis refers to abscess, fistula, stricture, or free perforation, and simple diverticulitis describes inflammation without these features ${ }^{10}$. The complicated group requires intervention (percutaneous drainage or surgical therapy) more often ${ }^{11,12}$. The most widely used classification to diagnose the severity of acute diverticulitis is the Hinchey classification. Hinchey 0 and $I$ are defined as mild clinical diverticulitis and as the presence of a pericolic abscess or phlegmon, respectively. Hinchey II is defined as a pelvic, intraabdominal or retroperitoneal abscess. Hinchey III and IV are defined as purulent peritonitis and the presence of faecal peritonitis, respectively ${ }^{9}$.

In the Western world, the localization of both diverticular disease and colorectal cancer (CRC) occurs most commonly on the left side of the colon. Therefore, it is generally accepted practice to perform colonoscopy after the resolution of acute diverticulitis in candidates for whom an examination of the colon has not recently been performed to exclude a misdiagnosis of colonic neoplasm ${ }^{13}$. Although no clear data are present, it is common practice in many hospitals in the Netherlands to perform a colonoscopy after an episode of uncomplicated diverticulitis after several weeks to exclude $\mathrm{CRC}^{14}$. However, according to the Dutch guidelines "Diagnostic and treatment of acute diverticulitis of the colon," after an episode of uncomplicated acute diverticulitis of the colon, patients should not be offered a colonoscopy on a routine basis. However, the evidence supporting these recommendations is poor ${ }^{15}$. Based on the available 
evidence, the question remains whether all patients who were treated conservatively or only patients who have alarm symptoms such as rectal bleeding, weight loss, or abdominal pain should undergo a colonoscopy to rule out CRC.

Nevertheless, there are conflicting reports on whether diverticular disease is associated with CRC. Burkitt was the first to formulate this hypothesis; however, this association is not entirely proven ${ }^{16}$. Some studies have found an increased risk for CRC after diverticulitis ${ }^{17-20}$ while others did not ${ }^{21-25}$. If CRC is diagnosed in such cases, it is unclear what the (tumour) characteristics are for those patients after an episode of uncomplicated acute diverticulitis. Synchronous colorectal tumours might be incidental findings. Perhaps these cancers are located in a different segment of the colon other than the diverticulitis.

\section{Colorectal cancer}

CRC is a common and lethal disease if left untreated. The mortality and incidence rates vary markedly around the world. Globally, CRC is the third most commonly diagnosed cancer in males and second in females with 1.65 million new cases and almost 835,000 deaths in $2016^{26}$. Due to an improved screening program and multidisciplinary treatment, survival rates of CRC patients in the Netherlands have improved, with a current 5-year overall survival rate of $65 \%$. This results in the high prevalence of 75,878 CRC patients in the Netherlands in $2017^{27}$. CRC is a malignant disease of the aged and modernity: the highest rates of incidence are in developed countries. As the world becomes richer, and more people shift to Western diets and lifestyles, the incidence of CRC is likely to increase ${ }^{28}$. The highest incidence rates are in Australia, New Zealand, Europe and North America, and the lowest rates are found in Africa and South-Central Asia ${ }^{29}$.

CRC incidence in the Netherlands increased to 13,597 new patients in 2017, which is almost double the incidence of 7,046 CRC patients in $1990^{27}$. Aging of the Dutch population is one reason why the incidence has increased. Another prevailing explanation is an improved screening program. This screening consists of an occult blood loss faces test every two years in persons between 55 and 75 years old. In cases of a positive test on occult blood loss, a subsequent colonoscopy must be performed to prove or rule out $\mathrm{CRC}^{29}$. It is globally accepted that most colorectal malignancies arise from adenomas, and early screening colonoscopy is recommended for the early detection of these premalignant adenomas or polyps. Such screening leads to the detection of endoscopically curable stages of these lesions and avoid second operations $^{31,32}$.

Prior to performing a colonoscopy to exclude a malignancy in patients who are suspected for CRC, patients are often analysed because of abdominal symptoms such as 
bowel habit changes, bloody stool, unintentional weight loss and unexplained iron deficiency anaemia ${ }^{32-34}$. Less common presenting symptoms include abdominal distention, and/or nausea and vomiting, which could be indicators of obstruction. Approximately $10-28 \%$ of patients with CRC present with symptoms of an acute obstruction $^{35}$. Symptoms of colorectal obstruction are abdominal (cramping) pain and severe constipation ${ }^{36}$. Obstruction symptoms are more common in left-sided tumours than in right-sided tumours. Faecal contents are liquid in the proximal colon, and the lumen calibre is larger; therefore, right-sided tumours will cause less likely obstructive symptoms. Obstruction leads to distension of the colorectal wall, which could cause insufficient circulation that in some cases leads to ischaemia and perforation. These patients deteriorate within days after the acute obstruction with poor intake, vomiting and weight loss. In some cases, this is accompanied by severe abdominal pain and sepsis requiring emergency surgery ${ }^{37}$. The short-term results after emergency surgery in obstructing CRC show higher morbidity and mortality rates ${ }^{38,39}$. Emergency surgery is an independent risk factor for mortality, which might increase to $41 \%$ in elderly patients with two or more additional risk factors ${ }^{40,41}$. Limited data are available regarding long-term survival between cases of obstructing and non-obstructing CRCs.

Patients who have undergone a curative resection because of CRC have a higher risk of developing a metachronous colorectal tumour. The risk of second primary tumour is approximately $2.5 \%$ within the first 5 years ${ }^{42}$. The risk of developing metachronous CRC is highest within the first 2-3 years after diagnosis ${ }^{43,44}$. Therefore, Dutch guidelines were adapted in 2014 to advise that the first colonoscopy surveillance should occur approximately one year after curative resection rather than at 2-3 years. This recommendation complies with international guidelines, which clearly state that a follow-up colonoscopy is indicated after surgery for CRC. However, the guidelines differ regarding the time interval for monitoring the colon and rectum both for the first postoperative colonoscopy and for subsequent colonoscopies. The intervals for prearranged follow-up colonoscopies vary among different clinics and institutions, with both overuse and underuse being reported after resection for CRC. In general, patients who have undergone surgical resection for stage I-III and/or intentional curable stage IV CRC are potential patients for surveillance colonoscopy. Patients with stage IV CRC that is unresectable for cure are generally not candidates for surveillance, because of the poor survival benefit. Preoperative colonoscopy can be incomplete due to tumour obstruction, or absent in some patients. These patients mostly present with an acute bowel obstruction requiring emergency surgical intervention. According to Dutch guidelines, such patients must undergo a completing colonoscopy within 3 months after resection to detect synchronous neoplasia ${ }^{45}$.

Another diagnostic tool in the follow-up of patients after curative surgery for CRC is carcinoembryonic antigen (CEA), a tumour marker found in serum. In most patients who are diagnosed with CRC, CEA blood levels are elevated and tend to decrease after successful curative surgery and/or adjuvant treatment. Elevated preoperative serum 
CEA levels have been found to be associated with poor oncologic prognosis in patients with $\mathrm{CRC}^{46-48}$. Measuring CEA during postoperative follow-up is common because CEA levels can rise with cancer recurrence, which is important for early detection and treatment at a curable stage and therefore to survival ${ }^{49,50}$. In the Netherlands, the follow-up program for CRC consists of a physical examination, imaging with an abdominal ultrasound and chest $\mathrm{x}$-ray and serum testing for the tumour marker CEA ${ }^{51}$. International guidelines recommend measuring CEA in intervals of 3-6 months after surgical treatment for CRC. When CEA levels are elevated, further investigation is typically indicated with a CT scan of the chest, abdomen and/or pelvis, or a positron emission tomography (PET)-CT scan. Some authors suggest that CEA levels appear to be the most sensitive for identifying hepatic and retroperitoneal located metastases and the least sensitive for local recurrence and peritoneal or pulmonary metastases ${ }^{52}$. Therefore, during the follow-up period, CEA is used as a diagnostic screening tool; when the CEA blood level is elevated, the physician is alerted to initiate further investigation through imaging ${ }^{53}$. Given the inconsistencies of CEA levels between tumour stage and tumour grade, it remains unclear if preoperative serum CEA levels provide accurate information regarding locoregional and distant recurrence during follow-up.

Like other patients with cancer, those with colorectal cancer should be assessed by a multidisciplinary team. The multidisciplinary team should include a colorectal surgeon, a medical oncologist, a gastroenterologist, a radiotherapist, a radiologist, and a pathologist. Patients with rectal cancer for whom a decision must be made about need for neoadjuvant therapy and all patients with distant metastases should be assessed before treatment is started. For patients with colon cancer without signs of distant metastases, assessment of the need for adjuvant therapy after surgery is usually sufficient ${ }^{54}$. The assessment by a multidisciplinary team has been associated with a reduced rate of positive circumferential resection margins for rectal cancer and increased rates of adjuvant therapy for patients with colon cancer and of metastasis surgery for patients with stage IV disease ${ }^{55-57}$.

Surgery remains the cornerstone in the treatment of patients with CRC. In colon cancer surgery, the tumour and the corresponding lymph vessels are removed. The extent of surgery is predetermined by the tumour localisation and the supplying blood vessels $\mathrm{s}^{54}$. The standard surgical procedure for the treatment of rectal cancer is total mesorectal excision-i.e., removal of the rectum together with the mesorectum around it and the surrounding envelope, the mesorectal fascia ${ }^{58}$. Complete removal of the mesorectum is important because it contains most of the involved lymph nodes and tumour deposits. Open surgery used to be the only option available; however, laparoscopic resection has developed as an alternative. Several meta-analyses have shown that laparoscopic resection of colorectal cancer achieves the same long-term results as open surgery, and is associated with a reduced number of patients requiring blood transfusions $(3.4 \%$ vs. $12.2 \%$ ), faster return of bowel function (first bowel movement after 3.3 days vs. 
4.6 days), and a shorter duration of hospital stay ${ }^{59,60}$. Despite these advances in surgical management, surgery will always be accompanied with risks and complications. Anastomotic leakage $(\mathrm{AL})$ is one of the most severe early complications after colorectal surgery. Because of the recent increase in sphincter preserving surgery for rectal cancer, the likelihood of AL will increase as well, and patients with a low anastomosis have a higher risk of leakage ${ }^{61}$. AL is associated with a high reoperation rate, increases in the severity of short-term morbidity and mortality rates, poor functional outcomes and higher healthcare costs ${ }^{62-64}$. Incidence rates of AL vary in the current literature but are dependent on several factors, such as tumour location (colon or rectum), type of operation, and patient characteristics ${ }^{65,66}$. Another explanation for the broad range of reported cases of $A L$ is the wide variability in the definition of $A L$. Some articles only included patients with symptomatic AL, whereas other authors also included asymptomatic $\mathrm{AL}$, the diagnosis of which was based on radiologic findings. In general, AL patients have a poor prognosis. In the literature, there have been conflicting studies of the oncologic outcomes and long-term mortality in patients with $A L$ after curative surgery for CRC. The relation with the occurrence of local recurrence and/or distant metastases have been studied, and contradictory results have been found. It remains unclear whether $A L$ is associated with poor oncologic outcomes in patients who had undergone curative surgery for CRC.

Prevention of $\mathrm{AL}$ must be based on understanding pathophysiology of $\mathrm{AL}$ and on knowledge of risk factors. Unfortunately, the pathophysiology of AL is not completely understood and multifactorial. Factors involved are mechanical, ischaemic, bacterial and inflammatory ${ }^{67-69}$. Many risk factors are known such as male gender, high body mass index (BMI), malnutrition, use of non-steroidal anti-inflammatory (NSAIDs) drugs, chronic steroid use, preoperative radiation therapy, perioperative blood transfusion, prolonged operation time, distal colorectal anastomosis and surgeon ${ }^{70-72}$. Strategies to reduce the incidence of $A L$ often focus on reducing the risk factors before, during and after the operation. During the operation, the surgeon can reduce the risk of AL with measures that reduce tension of the anastomoses, which ascertain an adequate bowel perfusion and diversion of the faecal passage by creating a temporary ileostomy. Assessment of the bowel perfusion and the indication for a diverting ileostomy are not very well defined and depend on the judgment of the surgeon. An adequately perfused bowel on the level of the anastomosis is important to obtain enough oxygen supply for optimal healing ${ }^{73,74}$. During surgery, several checks are performed to determine perfusion such as examination of the colour of the bowel wall, visible peristalsis, palpable pulsation and bleeding from the marginal arteries. However, these are subjective checks and based on experience of the surgeon and can lead to misinterpretation. Only recently, fluorescence angiography with indocyanine green (ICG) under near-infrared (NIR) light has been introduced in colorectal surgery. ICG can become fluorescent under NIR light, which provides a real-time confirmation of 
intestinal perfusion. It is very interesting to determine whether intraoperative ICG-NIR fluorescence imaging affects the rates of $A L$ and diverting ileostomies.

In conclusion, improving outcomes in CRC patients is an important and challenging topic in today's medicine, which is characterized by individual patient awareness, increased costs, the introduction of numerous diagnostic modalities and surgical (as well as non-surgical) strategies. These results can be used to evaluate old and new treatment modalities, detect shortcomings and initiate new research projects. This will eventually increase transparency for physicians and hospitals to compare clinical results in order to optimize quality management in colorectal cancer patients. 


\section{Aims and outline of this thesis}

The aim of this thesis is to evaluate the outcome of various clinical situations in colorectal cancer patients. The first part investigates the roll of endoscopic follow-up in patients who were treated conservatively for uncomplicated diverticulitis, to prevent clinical invasive follow-up by means of colonoscopy, to rule out colorectal cancer. The focus of the second part of this thesis is to study patients with colorectal cancer after curative surgery, with interpretations of clinical results to optimize quality management.

Chapter 2 evaluates the necessity of colonoscopy to exclude colorectal cancer in patients who have had an uncomplicated episode of acute diverticulitis and have been treated conservatively, with or without antibiotics. In Chapter 3, specific tumour characteristics are aimed to investigate patients who were diagnosed with colorectal cancer found by colonoscopy, after being treated conservatively for acute uncomplicated diverticulitis.

A retrospective observational cohort study is conducted in Chapter 4 to assess the long term survival of patients with obstructive colorectal cancer causing an ileus. This group was then compared to patients without obstructing colorectal cancer. In Chapter 5, the results of 11 years of endoscopic follow-up after curative surgery for colorectal cancer are presented. Based on the findings, a recommendation is provided regarding the optimal interval for performing the first colonoscopy surveillance after curative resection. In Chapter 6, the role of preoperative CEA levels as an independent predictor for locoregional and systemic recurrence are evaluated in patients who previously underwent curative surgery for colorectal cancer. Secondly, the role of postoperative CEA level measurement during follow-up in this patient group is determined. The impact of anastomotic leakage on local recurrence, distant recurrence, disease-free survival and overall mortality after curative surgery for colorectal cancer are determined in Chapter 7. Chapter 8 investigates whether intraoperative imaging with indocyanine green in combination with near-infrared light to asses bowel perfusion during robot-assisted laparoscopic surgery affects the rates of anastomotic leakage and diverting ileostomies in patients with rectal cancer.

Chapter 9 provides a general discussion and future perspectives with recommendations and suggestions for future research. Chapter 10 provides a summary of the most important findings of this thesis. In Chapter 11, a summary in Dutch is provided. 


\section{References}

1. Everhart JE, Ruhl CE. Burden of digestive diseases in the United States part II: lower gastrointestinal diseases. Gastroenterology. 2009;136:741-754.

2. Lahat A, Yanai H, Sakhnini E, Menachem Y, Bar-Meir S. Role of colonoscopy in patients with persistent acute diverticulitis. World J Gastroenterol. 2008;14:2763-2766.

3. Rezapour M, Ali S, Stollman N. Diverticular Disease: An Update on Pathogenesis and Management. Gut and Liver. 2018;12: 125-132.

4. Parks TG. Natural history of diverticular disease of the colon. Clin Gastroenterol. 1975;4:53-69.

5. Bhucket TP, Stollman NH. Diverticular disease of the colon. In: Feldman M, Friedman LS, Brandt L, eds. Sleisenger and Fordtran's gastrointestinal and liver disease: pathophysiology, diagnosis, management. Volume 2. 10th ed. Philadelphia: Elsevier, 2014:1-15.

6. Andeweg CS, Knobben L, Henkdriks JC, Bleichrodt RP, van Goor H. How to diagnose acute colonic diverticulitis. Proposal for a clinical scoring system. Ann Surg. 2011;253:940-946.

7. Lameris W, van Randen A, van Gulik TM, Busch OR, Winkelhagen J, Bossuyt PM, Stoker J and Boermeester MA. A clinical decision rule to establish the diagnosis of acute diverticulitis at the emergency department. Dis Colon Rectum. 2010;53:896-904.

8. Lahat A, Yanai H, Menachem Y, Avidan B, Bar-Meir S. Feasibility and risk of early colonoscopy in acute diverticulitis: a prospective controlled study. Endoscopy. 2007;39:521-524.

9. Kaiser AM, Jiang JK, Lake JP, Ault G, Artinyan A, Gonzalez-Ruiz C, Essani R and Beart RW Jr. The management of complicated diverticulitis and the role of computed tomography. Am J Gastroenterol. 2005;100:910-917.

10. Solomon CG. Diverticulitis. N EngI J Med. 2018;379:1635-42.

11. Farrell RJ, Farrell JJ, Morrin MM. Diverticular disease in the elderly. Gastroenterol Clin North Am. 2001;30:475-496.

12. Wong WD, Wexner SD, Lowry A, Vernava A 3rd, Burnstein M, Denstman F, Fazio V, Kerner B, Moore R, Oliver G, Peters W, Ross T, Senatore P, Simmang C. Practice parameters for the treatment of sigmoid diverticulitis-supporting documentation. The Standards Task Force. The American Society of Colon and Rectal Surgeons. Dis Colon Rectum. 2000;43:290-297.

13. Stollman N, Smalley W, Hirano I; AGA Institute Clinical Guidelines Committee. American Gastroenterological Association Institute guideline on the management of acute diverticulitis. Gastroenterology. 2015;149:1944-1949.

14. Schout PJ, Spillenaar Bilgen EJ, Groenen MJ. Routine screening for colon cancer after conservative treatment of diverticulitis. Dig Surg. 2012;29:408-411.

15. Dutch Society of Surgery. Diagnostic and treatment of acute diverticulitis of the colon. Dutch guidelines diagnostics and treatment of acute colonic diverticulitis. 2012. Available at: http://www.mdl.nl/ uploads/240/1137/Acute-diverticulitis-van-hetcolon-2012.pdf.

16. Ekbom A: Is diverticular disease associated with colonic malignancy? Dig Dis 2012;30:46-50.

17. Stefánsson T, Ekbom A, Sparèn P, Påhlman L: Association between sigmoid diverticulitis and left-sided colon cancer: a nested, population- based, case control study. Scand J Gastroenterol. 2004;39:743-747.

18. Lau KC, Spilsbury K, Farooque Y, Kariyawasam, SB, Owen RG, Wallace MH, Makin GB: Is colonoscopy still mandatory after a CT diagnosis of left-sided diverticulitis: can colorectal cancer be confidently excluded? Dis Colon Rectum. 2011;54:1265-1270.

19. Soran A, Harlak A, Wilson JW, Nesbitt L, Lembersky BC, Wienad HS, O'Connell MJ: Diverticular disease in patients with colon cancer: subgroup analysis of national surgical adjuvant breast and bowel project protocol C-06. Clin Colorectal Cancer. 2006;6:140-145.

20. Stefánsson T, Ekbom A, Sparén P, Påhlman L: Cancers among patients diagnosed as having diverticular disease of the colon. Eur J Surg. 1995;161:755-760.

21. Krones CJ, Klinge U, Butz N, Junge K, Stumpf, M, Rosch R, Hermanns B, Heussen N, Schumpelick V: The rare epidemiologic coincidence of diverticular disease and advanced colonic neoplasia. Int J Colorectal Dis. 2006;21:18-24.

22. Lam TJ, Meurs-Szojda MM, Gundlach L, Belien JA, Meijer GA, Mulder CJ, Felt-Bersma RJ: There is no increased risk for colorectal cancer and adenomas in patients with diverticulitis: a retrospective longitudinal study. Colorectal Dis. 2010;12:1122-1126. 
23. Granlund J, Svensson T, Granath F, Hjern F, Ekbom A, Blomqvist P, Schmidt PT: Diverticular disease and the risk of colon cancer - a population-based case-control study. Aliment Pharmacol Ther. 2011;34: $675-681$.

24. Sallinen $V$, Mentula $P$, Leppäniemi A: Risk of colon cancer after computed tomography-diagnosed acute diverticulitis: is routine colonoscopy necessary? Surg Endosc. 2014;28:961-966.

25. Van de Wall BJ, Reuling EM, Consten EC, van Grinsven JH, Schwartz MP, Broeders IA, Draaisma WA: Endoscopic evaluation of the colon after an episode of diverticulitis: a call for a more selective approach. Int J Colorectal Dis. 2012;27:1145-1150.

26. Fitzmaurice C, Allen C, et al. Global Burden of Disease Cancer Collaboration. Global, Regional, and National Cancer Incidence, Mortality, Years of Life Lost, Years Lived With Disability, and DisabilityAdjusted Life-years for 32 Cancer Groups, 1990 to 2015: A Systematic Analysis for the Global Burden of Disease Study. JAMA Oncol. 2017;3:524-548.

27. https://www.cijfersoverkanker.nl/ consulted on 3 June 2019.

28. Brody H. Colorectal cancer. Nature 2015;521:S1.

29. https://www.mlds.nl/kanker/darmkanker/bevolkingsonderzoekdarmkanker/?gclid=CjwKCAiAgrfhBRA3EiwAnfF4tnxQxPI7kShVzTu33jLjFk2mx2gMB7lqAOp4YMxA6NQ MO8M2i7T2-BoCRYIQAvD_BwE consulted on 6 June 2019.

30. Arditi C, Gonvers J, Burnand B, Minoli G, Oertli D, Lacaine F, Dubois RW, Vader JP, Schusselé Filliettaz S, Peytremann-Bridevaux I, Pittet V, Juillerat P, Froehlich F, and the EPAGE II Study Group. Appropriateness of colonoscopy in Europe (EPAGE II) Surveillance after polypectomy and after resection of colorectal cancer. Endoscopy. 2009;41:209-217.

31. Rex DK, Kahi CJ, Levin B, Smith RA, Bond JH, Brooks D, Burt RW, Byers T, Fletcher RH, Hyman N, Johnson D, Kirk L, Lieberman DA, Levin TR, O’Brien MJ, Simmang C, Thorson AG, Winawer SJ. Guidelines for Colonoscopy Surveillance after Cancer Resection: A Consensus Update by the American Cancer Society and US Multi-Society Task Force on Colorectal Cancer. CA Cancer J Clin. 2006;56:160-167.

32. Hamilton W, Round A, Sharp D, Peters TJ. Clinical features of colorectal cancer before diagnosis: a population-based case-control study. Br J Cancer. 2005;93:399-405.

33. Majumdar SR, Fletcher RH and Evans AT. How does colorectal cancer present? Symptoms, duration, and clues to location. Am J Gastroenterol. 1999;94(10):3039-3045.

34. Thompson MR, O'Leary DP, Flashman K, Asiimwe A, Ellis BG, Senapati A. Clinical assessment to determine the risk of bowel cancer using Symptoms, Age, Mass and Iron deficiency anaemia (SAMI). Br J Surg. 2017;104:1393-1404.

35. Ripamonti C, Bruera E. Palliative management of malignant bowel obstruction. Int J Gynecol Cancer. 2002;12(2):135-143.

36. Phillips RK, Hittinger R, Fry JS, Fielding. Malignant large bowel obstruction. Br J Surg. 1985;72:296-302.

37. DeBernardo R. Surgical management of malignant bowel obstruction: strategies toward palliation of patients with advanced cancer. Curr Oncol Rep. 2009;11:287-292.

38. Smothers L, Hynan L, Fleming J, Turnage R, Simmang C, Anthony T. Emergency surgery for colon carcinoma. Dis Colon Rectum. 2003;46:24-30.

39. Sjo $\mathrm{OH}$, Larsen S, Lunde OC, Nesbakken. A Short term outcome after emergency and elective surgery for colon cancer. Colorectal Dis. 2009;11:733-739.

40. Alves A, Panis Y, Mathieu P, Mantion G, Kwiatkowski F, Slim K. French Surgical Association. Postoperative mortality and morbidity in French patients undergoing colorectal surgery: results of a prospective multicenter study. Arch Surg. 2005;140:278-283.

41. Kolfschoten NE, Wouters MW, Gooiker GA, Eddes EH, Kievit J, Tollenaar RA. Nonelective colon cancer resections in elderly patients: results from the Dutch Surgical Colorectal Audit. Dig Surg. 2012;29: 412-419.

42. le Clercq, C, Bouwens, M, Riedl, R, Beets GL, Winkens B, Hameeteman W. Incidence and potential causes for metachronous colorectal cancer: a 10-year retrospective survey. Gastroenterology. 2012;142: S-81.

43. Rex DK, Kahi CJ, Levin B, Smith RA, Bond JH, Brooks D. Guidelines for colonoscopy surveillance after cancer resection: a consensus update by the American Cancer Society and the US Multi-Society Task Force on Colorectal Cancer. Gastroenterology. 2006;130: 1865-1871.

44. Couch DG, Bullen N, Ward-Booth SE, Adams C. What interval between colorectal cancer resection and first surveillance colonoscopy? An audit of practice and yield. Colorectal Dis. 2013;15:317-322. 
45. Dutch Guidelines colonoscopy surveillance. Nederlandse Vereninging van Maag-, Darm en Leverartsen in samenwerking met Nederlandse Vereniging van Pathologie. https://www.mdl.nl/sites/ www.mdl.nl/files/richlijnen/Richtlijn_Coloscopie_Surveillance_definitief_2013.pdf.

46. Chapman MA, Buckley D, Henson DB, Armitage NC. Preoperative carcinoembryonic antigen is related to tumour stage and long-term survival in colorectal cancer. Br J Cancer. 1998;78:1346-1349.

47. Reiter W, Stieber P, Reuter C, Nagel D, Lau-Werner U, Lamerz R. Multivariate analysis of the prognostic value of CEA and CA 19-9 serum levels in colorectal cancer. Anticancer Res. 2000;20:5195-5198.

48. Stelzner S, Hellmich G, Koch R, Ludwig K. Factors predicting survival in stage IV colorectal carcinoma patients after palliative treatment: a multivariate analysis. J Surg Oncol. 2005;89:211-217.

49. Goldstein MJ and Mitchell EP. Carcinoembryonic antigen in the staging and follow-up of patients with colorectal cancer. Cancer Invest. 2005;23:338-351.

50. Nordic Gastrointestinal Tumor Adjuvant Therapy Group. Expectancy or primary chemotherapy in patients with advanced asymptomatic colorectal cancer: a randomized trial. J Clin Onco. 1992;10: 904-911.

51. Dutch National Guidelines Workgroup Gastro-intestinal Tumours, type: national guidelines, http://www.oncoline.nl/colorectaalcarcinoom. Consulted on 4 January 2019.

52. Moertel CG, Fleming TR, Macdonald JS, Haller DG, Laurie JA, Tangen C. An evaluation of the carcinoembryonic antigen (CEA) test for monitoring patients with resected colon cancer. JAMA. 1993; 270:943-947.

53. Verberne CJ, Zhan Z, van den Heuvel E, Grossmann I, Doornbos PM, Havenga K, et al. Intensified followup in colorectal cancer patients using frequent carcino-embryonic antigen (CEA) measurements and CEA triggered imaging: results of the randomized "CEAwatch" trial. Eur J Surg Oncol. 2015;41: 1188-1196.

54. Brenner H, Kloor M, Pax CP. Colorectal cancer. Lancet 2014;383:1490-1502.

55. Burton S, Brown G, Daniels IR, Norman AR, Mason B, Cunningham D, and the Royal Marsden Hospital, Colorectal Cancer Network. MRI directed multidisciplinary team preoperative treatment strategy: the way to eliminate positive circumferential margins? Br J Cancer. 2006;94:351-357.

56. MacDermid E, Hooton G, MacDonald M, McKay G, Grose D, Mohammed N, Porteous C. Improving patient survival with the colorectal cancer multi-disciplinary team. Colorectal Dis. 2009;11:291-295.

57. Segelman J, Singnomklao T, Hellborg H, Martling A. Differences in multidisciplinary team assessment and treatment between patients with stage IV colon and rectal cancer. Colorectal Dis. 2009;11: 768-774.

58. Heald RJ, Ryall RD. Recurrence and survival after total mesorectal excision for rectal cancer. Lancet. 1986;1:1479-1482.

59. Liang Y, Li G, Chen P, Yu J. Laparoscopic versus open colorectal resection for cancer: a meta-analysis of results of randomized controlled trials on recurrence. Eur J Surg Oncol. 2008;34:1217-1224.

60. Trastulli S, Cirocchi R, Listorti C, Cavaliere D, Avenia N, Gullà N, Giustozzi G, Sciannameo F, Noya G, Boselli C. Laparoscopic vs open resection for rectal cancer: a meta-analysis of randomized clinical trials. Colorectal Dis. 2012;14:e277-296.

61. E. Rullier, C. Laurent, J.L. Garrelon, P. Michel, J. Saric, M. Parneix, Risk factors for anastomotic leakage after resection of rectal cancer, Br. J. Surg. 1998;85:355-358.

62. Kube R, Mroczkowski P, Granowski D, Benedix F, Sahm M, Schmidt U. Anastomotic leakage after colon cancer surgery: a predictor of significant morbidity and hospital mortality, and diminished tumour-free survival, Eur. J. Surg. Oncol. 2010;36:120-124.

63. Matthiessen P, Hallböök O, Rutegård J, Sjödahl R. Population-based study of risk factors for postoperative death after anterior resection of the rectum, Br J Surg. 2006;96:498-503.

64. McDermott FD, Heeney A, Kelly ME, Steele RJ, Carlson GL, Winter DC. Systematic review of preoperative, intraoperative and postoperative risk factors for colorectal anastomotic leaks, Br J Surg. 2015;102:462-479.

65. Bruce J, Krukowski ZH, Al-Khairy G, Russell EM, Park KG. Systematic review of the definition and measurement of anastomotic leak after gastrointestinal surgery, Br J Surg. 2001;88: 1157-1168.

66. Mirnezami A, Mirnezami R, Chandrakumaran K, Sasapu K, Sagar P, Finan P. Increased local recurrence and reduced survival from colorectal cancer following anastomotic leak: systematic review and metaanalysis, Ann Surg. 2011;253:890-899. 
67. Park JS, Choi GS, Kim SH, Kim HR, Kim NK, Lee KY, Kang SB, Kim JY, Lee KY, Kim BC, Bae BN, Son GM, Lee $\mathrm{SI}$, Kang $\mathrm{H}$. Multicenter analysis of risk factors for anastomotic leakageafter laparoscopic rectal cancer excision: the Korean laparoscopic colorectal surgery study group. Ann Surg. 2013;257:665-671

68. Peeters KC, Tollenaar RA, Marijnen CA, Klein Kranenbarg E, Steup WH, Wiggers T, Rutten HJ, van de Velde CJ; Dutch Colorectal Cancer Group. Risk factors for anastomotic failure after total mesorectal excision of rectal cancer. Br J Surg. 2005;92:211-216.

69. Karanjia ND, Corder AP, Bearn P, Heald RJ. Leakage from stapled low anastomosis after total mesorectal excision for carcinoma of the rectum. Br J Surg. 1994;81:1224-1226.

70. Frouws MA, Snijders HS, Malm SH, Liefers GJ, Van de Velde CJH, Neijenhuis PA, Kroon HM. Clinical Relevance of a Grading System for Anastomotic Leakage After Low Anterior Resection: Analysis From a National Cohort Database. Dis Colon Rectum. 2017;60:706-713

71. García-Granero E, Navarro F, Cerdán Santacruz C, Frasson M, García-Granero A, Marinello F, FlorLorente B, Espí A. Individual surgeon is an independent risk factor for leak after double-stapled colorectal anastomosis: An institutional analysis of 800 patients. Surgery. 2017;162:1006-1016.

72. Qu H, Liu Y, Bi DS. Clinical risk factors for anastomotic leakage after laparoscopic anterior resection for rectal cancer: a systematic review and meta-analysis. Surg Endosc. 2015;29:3608-3617.

73. Trencheva K, Morrissey KP, Wells M, Mancuso CA, Lee SW, Sonoda T, Michelassi F, Charlson ME, Milsom JW. Identifying important predictors for anastomotic leak after colon and rectal resection: prospective study on 616 patients. Ann Surg. 2013;257:108-113.

74. Kologlu M, Yorganci K, Renda N, Sayek I. Effect of local and remote ischemia-reperfusion injury on healing of colonic anastomoses. Surgery. 2000:128;99-104. 



\section{Part}

Endoscopic follow-up after uncomplicated diverticulitis 



\section{Chapter}

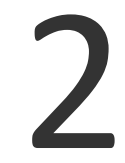

What is the risk of colorectal cancer after an episode of acute diverticulitis in conservatively

treated patients?

\section{Winesh Ramphal}

Jennifer M.J. Schreinemakers

Tom C.J. Seerden

Rogier M.P.H. Crolla

Arjen M. Rijken

Paul D. Gobardhan

Journal of Clinical Gastroenterology. 2016;50(4):35-39. 


\section{Abstract}

\section{Goals}

The goal is to find the risk of colorectal cancer after an episode of acute diverticulitis in conservatively treated patients. Secondly, to determine the benefit of colonoscopy in these patients

\section{Background}

In the Netherlands, it is a common practice to routinely perform a colonoscopy after an episode of conservatively treated diverticulitis to exclude a malignancy. Yet according to the Dutch guidelines, these patients should not undergo a colonoscopy on a routine basis. The aim of this study is to determine the benefit of a colonoscopy in patients who have been treated for diverticulitis conservatively.

\section{Study}

This retrospective study includes patients who were diagnosed with acute diverticulitis (Hinchey 0 and I) and were treated conservatively, with or without antibiotics. Only patients who underwent colonoscopy were included for analysis. In addition, the outcome (yes or no colorectal cancer) of colonoscopy was analyzed according to patients' presentation of alarm symptoms for colorectal cancer.

\section{Results}

Between January 2008 and June 2013, 977 patients were treated conservatively for an episode of acute diverticulitis. Of those, 645 underwent colonoscopy during follow-up. Alarm symptoms for colorectal cancer were present in 205 patients. Nine of them were diagnosed with colorectal cancer $(4.4 \%)$ versus 1 patient $(0.2 \%, \mathrm{P}=0.0002)$ in the group without alarm symptoms $(\mathrm{N}=440)$.

\section{Conclusions}

This study confirms that routine colonoscopy is not indicated after acute diverticulitis which has been treated conservatively in a large series. Only in case of alarm symptoms a colonoscopy is mandatory, but even then the actual finding of a colorectal cancer is rare. 


\section{Introduction}

The incidence of diverticulitis or diverticular disease of the colon is increasing, especially in western industrialized countries and the prevalence rises with age. Two third of the population in western countries will develop this disease by the age of $85^{1}$. The diagnosis of acute diverticulitis is a clinical diagnosis and is based on left lower quadrant pain, C-reactive protein $>50 \mathrm{mg} / \mathrm{L}$ and the absence of vomiting ${ }^{2,3}$. This clinical diagnosis can be confirmed by characteristic findings on computed tomography (CT) scan and/or ultrasound (US) of the abdomen ${ }^{4,5}$. Most patients will remain uncomplicated and recover uneventfully, but a small group will develop complications (e.g., abscess formation, perforation, or stenosis) or will not respond to conservative therapy (with or without antibiotics). This complicated group requires intervention (percutaneous drainage or surgical therapy) more often ${ }^{6,7}$. After an episode of uncomplicated diverticulitis, a colonoscopy is frequently performed after several weeks to exclude colorectal cancer. Although no clear data are present, we believe this is common practice in many hospitals in The Netherlands. However, according to the Dutch guidelines "Diagnostic and treatment of acute diverticulitis of the colon" after an episode of uncomplicated acute diverticulitis of the colon, patients should not be offered a colonoscopy on a routine basis. Yet, the evidence supporting these recommendations is poor ${ }^{9}$. On the basis of the available evidence, the question remains whether all patients who were treated conservatively or only patients who have alarm symptoms as rectal bleeding, weight loss, or abdominal pain, should undergo a colonoscopy.

The aim of this study is to evaluate the value of a colonoscopy in patients who have had an uncomplicated episode of acute diverticulitis and have been treated conservatively to exclude colorectal cancer.

\section{Materials and methods}

In our hospital, patients who were diagnosed with acute diverticulitis and were treated conservatively (with or without antibiotics) were offered colonoscopy (on discretion of the supervising specialist) to rule out a malignancy of the colon. We retrospectively reviewed all these patients treated between January 2008 and July 2013. Conservative treatment could consist of a course of oral or intravenous antibiotics or no antibiotics at all.

We selected patients through the hospital administration system. Patients were identified if they had been registered for a first episode of diverticular disease and/or diverticulitis based on the diagnosis treatment combination system (official health care system in The Netherlands, Diagnose Behandel Combinatie based on International 
Classification of Diseases-9). Medical charts were reviewed for demographic and clinical data (signs and symptoms) radiologic findings, treatment, and whether or not they underwent a colonoscopy and the outcome of colonoscopy.

All patients underwent laboratory evaluation and had to be diagnosed with diverticulitis on radiologic studies. The Hinchey classification was used to exclude complicated cases of diverticulitis from our study. The classification of diverticulitis was based on the Hinchey classification based on radiologic findings (CT scan or US) ${ }^{5}$; mild clinical diverticulitis without confirmation by imaging or surgery (Hinchey 0); or pericolic abscess or phlegmon (Hinchey I). Patients with a pelvic, intra-abdominal, or retroperitoneal abscess (Hinchey II) purulent (Hinchey III) or fecal peritonitis (Hinchey IV), and who were treated with percutaneous drainage or surgery were excluded from the analysis. Also patients with previous colorectal surgery were excluded from the analysis.

Alarm symptoms for colorectal cancer were defined as unintentional weight loss, a change in bowel habits, bloody stool, and/or persistent abdominal pain ${ }^{10-13}$. These symptoms had to be present within 3 months after the moment of first presentation until colonoscopy was performed.

We divided patients into 2 groups, those who did and those who did not undergo colonoscopy. The patients who underwent colonoscopy were included in our analysis. We compared the results of colonoscopy of patients with and those without alarm symptoms. All patients underwent colonoscopy after the acute episode of diverticulitis, between 6 weeks and 3 months after presentation.

No institutional review board approval was required for this retrospective single-centre study according to national law. We consulted the institutional review board (AMOA) of the Amphia hospital and they confirmed that no formal written waiver for the need of ethics approval was required, because of the retrospective design of the study.

\section{Statistics}

Data are depicted as means and SD for normally distributed data and median and interquartile range for not normally distributed data. We used the w2 test to compare dichotomous variables. We calculated the percentage of colorectal cancers diagnosed by colonoscopy and subsequent pathologic examination of suspect lesions, after being treated conservatively for an episode of acute diverticulitis. We compared the frequency of colorectal cancer between patients with and without alarm symptoms for colorectal cancer. We used IBM SPSS Statistics program, version 20. 


\section{Results}

In our hospital 1130 patients were treated for a first episode of acute diverticulitis. We retrospectively reviewed all these patients treated between January 2008 and July 2013. Of these patients, 153 (13.4\%) patients were excluded because they had a complicated course of diverticulitis (Hinchey II to IV). These patients underwent radiologic or surgical treatment for perforation, (fecal) peritonitis, ileus, or an abscess. The definitive diagnosis of all these complicated cases was confirmed by means of a CT scan. A total of 977 patients were treated conservatively with or without antibiotics, 151 (13\%) versus 826 (73\%) patients, respectively. Of these conservatively treated patients, 645 (66\%) underwent a colonoscopy (Figure 1).

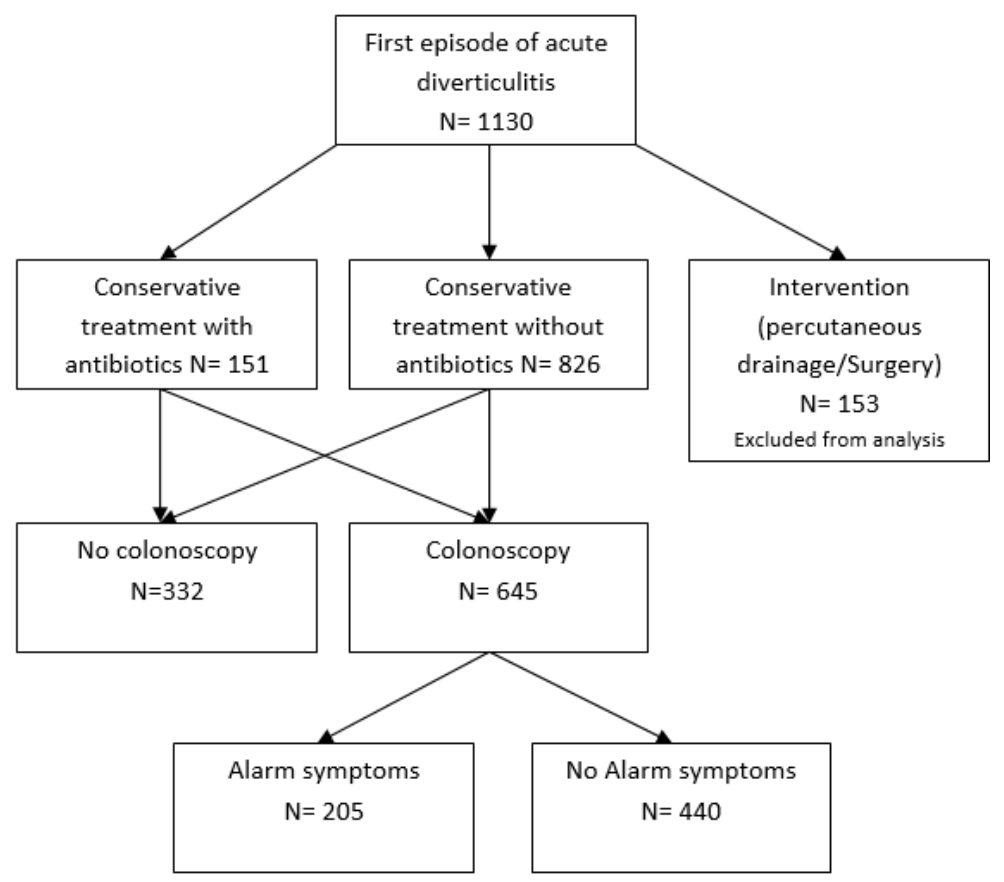

Figure $1 \quad$ Flowchart of 1130 patients with diverticulitis.

*Alarm symptoms were defined as bloody stools, unintentional weight loss, and/or persistent abdominal pain.

Three hundred and thirty-two patients did not undergo a colonoscopy, because of the following reasons: some of them were lost to follow up. In some cases the patient rejected the offer to undergo a colonoscopy for diagnostic purposes. However, in most cases, it was the physicians' choice and expertise to offer a colonoscopy to the patient. Sometimes there were no clinical signs or symptoms to rule out a malignancy of the 
colon within the first 3 months after a first episode of acute diverticulitis. Approximately a third of the patients (32\%) who underwent a colonoscopy, had alarm symptoms potentially indicating a colorectal cancer, whereas the majority of the patients did not have any alarm symptoms (68\%). The mean age of patients who did undergo colonoscopy compared with the patients who did not was 63 and 59 years, respectively $(\mathrm{P}<0.0001$, Table 1$)$.

Table 1 Baseline characteristics and outcome of colonoscopy for uncomplicated acute diverticulitis in patients with or without alarm symptoms.

\begin{tabular}{lccc}
\hline Colonoscopy group & $\begin{array}{c}\text { Alarm symptoms present } \\
(\mathbf{n = 2 0 5 )}\end{array}$ & $\begin{array}{c}\text { No alarm symptoms } \\
(\mathbf{n = 4 4 0 )}\end{array}$ & P-value \\
\hline Sex (Male N=\%) & $67(33 \%)$ & $192(44 \%)$ & n.a. \\
Mean Age (years) \pm SD & $66.3 \pm 11.5$ & $61.7 \pm 13.2$ & $\mathrm{P}=0.0001$ \\
Colon cancer (N= (\%) & $9(4.4 \%)$ & $1(0.2 \%)$ & $\mathrm{P}=0.0002$ \\
Finding of diverticulosis during & $179(87.3 \%)$ & $388(88.2 \%)$ & n.s. \\
colonoscopy ( $=(\%)$ & & & \\
\hline
\end{tabular}

NA: not applicable

NS: not significant different.

Of the 10 diagnosed cancers, 2 were treated with antibiotics initially; the other 8 were treated conservatively without antibiotics in the beginning. One hundred and fiftythree patients were excluded because they underwent a surgical or radiologic intervention like operation or percutaneous drain positioning in an abscess. Twentythree of these cases were Hinchey IV, 27 cases were classified as Hinchey III and IV, and 9 as Hinchey II. None of the surgical resection were malignant after research of the pathologist. In patients without any alarm symptoms $(n=440)$, only 1 patient $(0.2 \%)$ had a colorectal cancer versus $9(4.4 \%)$ patients in the group with alarm symptoms (Table 1). The alarm symptoms were rectal bleeding $(n=3,33.3 \%)$, persisting abdominal pain ( $n=5,55.6 \%)$, and unintentional weight loss ( $n=2,22.2 \%)$.

Of those 10 patients diagnosed with colorectal cancer, 1 patient had stage I disease, 4 had stage II disease, and 5 had stage III disease. One patient with colorectal cancer had 2 alarm symptoms, persistent abdominal pain and unintentional weight loss. All patients who had alarm symptoms had persistent complaints after discharge for their acute diverticulitis. The mean age of patients who had a colon cancer was 68 years (range, 42 to $94 \mathrm{y}$ ). Of the 205 patients with alarm symptoms, 104 presented with bloody stools, 82 with persistent abdominal pain, and 24 patients with unintentional weight loss. Five patients had 2 alarm symptoms at the same time. One of them turned out to have a sigmoidal cancer.

Table 2 shows that there is no difference in patients who did go for colonoscopy and patients who did not go for colonoscopy. Only 17 patients showed alarm symptoms versus 315 without alarm symptoms for colorectal cancer. 
Baseline characteristics of patients for uncomplicated acute diverticulitis who did not undergo colonoscopy.

\begin{tabular}{lccc}
\hline No Colonoscopy group & $\begin{array}{c}\text { Alarm symptoms } \\
\text { present }(\mathbf{N}=\mathbf{1 7})\end{array}$ & $\begin{array}{c}\text { No alarm symptoms } \\
(\mathbf{N}=\mathbf{3 1 5})\end{array}$ & P-value \\
\hline Sex (Male N=\%) & $8(47 \%)$ & $131(41 \%)$ & n.a. \\
Mean Age (years) \pm SD & $64.3 \pm 9.4$ & $62.9 \pm 12.3$ & $\mathrm{P}=0.16$ \\
Colorectal carcinoma (N=\%) & $0(0 \%)$ & $0(0 \%)$ & n.a. \\
\hline
\end{tabular}

NA: not applicable.

Other diagnoses that were found after colonoscopy were benign polyps in 117 patients and inflammation in 94 patients. These finding includes, 1 with ulcerative colitis, 1 with ischemic colitis, 4 patients with lipomas, 1 patient a post infectious episode of Giardia lamblia, 1 pseudomelanosis, and 1 hemosiderosis. No patients were diagnosed with Crohn disease. No malignancies were found in the 153 patients who were excluded because of a radiologic or surgical intervention. Forty-two patients were classified as Hinchey II, 24 patients were classified as Hinchey III, and 15 patients were classified as Hinchey IV. These findings are based on peroperative findings of the surgeon and/or postoperative findings by the pathologist after examining the specimen. All patients underwent laboratory evaluation and had to be diagnosed with diverticulitis on radiologic studies (US or CT scan). The 10 patients who were diagnosed with a colorectal cancer during follow-up had radiologic studies at their first presentation when diagnosed with diverticulitis. These imaging studies showed that in 2 patients there was a suspicion on a malignancy, requiring further examination.

\section{Discussion}

In this large study on the role of colonoscopy in uncomplicated diverticulitis, we found that a colonoscopy, performed on a routine basis is not indicated to rule out colorectal cancer. Especially in patients without alarm symptoms the risk of an actual colorectal cancer was very low (0.2\%) but significantly higher than in patients who did have alarm symptoms $(4.4 \%, \mathrm{P}=0.0002)$. To the best of our knowledge, our series is the largest in current literature. Previous studies recommended that colonoscopy on a routine basis should be performed several weeks after an acute episode of uncomplicated diverticulitis $^{14-19}$.

However, there are contradicting recommendations in different studies. Some advocate a colonoscopy following an episode of acute diverticulitis routinely, whereas others advise to not routinely perform a colonoscopy. The risk for colorectal cancer in these patients seems to depend on whether they have alarm symptoms or not. O'Neill et al. ${ }^{20}$ found a very low risk for colorectal cancer of $0.2 \%$ to $0.5 \%$ in patients without symptoms. However, in patients with alarm symptoms as weight loss, changed bowel 
habits, bloody stool, and/or persistent abdominal pain, the incidence of colorectal cancer is between $2.1 \%$ and $4.4 \%{ }^{8,21}$. Several authors recommend a colonoscopy several weeks after resolution of symptoms to confirm the diagnosis of diverticular disease and rule out other pathology of the colon such as a malignancy. However, this was not based on actual evidence ${ }^{14-16}$. Lau and colleagues recommended a routine colonoscopy after an attack of presumed left-sided diverticulitis based on their findings in 319 patients. Only 9 patients (2.8\%) were diagnosed with colorectal cancer. In this study clinical alarm symptoms were not used to decide whether a patient should undergo a colonoscopy afterwards, but complicated CT findings like pelvic mass, perforation, or fistulas were used.15 In studies that evaluated early (after 6 wks) versus late colonoscopy (after $8 \mathrm{wks}$ ), after an episode of acute diverticulitis, late colonoscopy was complete (coecal valuation) more often ${ }^{1,4}$.

Another relatively large series was published by Schout and colleagues. In a population of 378 patients who underwent colonoscopy 6 to 10 weeks after discharge, they revealed a malignant tumor in $8(2.1 \%)$ patients. Six of these 8 patients reported either rectal bleeding, significant weight loss, or persistent abdominal pain or a combination of these alarm symptoms after initial treatment. They advised to screen for colorectal cancer after conservative treatment of diverticulitis only in symptomatic patients. On the basis of our study, we concur with these recommendations ${ }^{8}$. Although the number of colorectal cancers is low in our study, the numbers are significantly different $(4.4 \%$ vs. $0.2 \%$ ) and should not be ignored. The fact that patients with alarm symptoms are significantly older in case of alarm symptoms is probably not clinically relevant. Two other studies concluded only offering colonic evaluation to patients with only persisting abdominal complaints after an episode of diverticulitis. There appears to be no benefit in performing colonoscopy on a routine basis because the incidence of colorectal cancer is almost equal to that of the general population ${ }^{22,23}$.

A different study that included patients who had acute uncomplicated diverticulitis and the indication for subsequent colonoscopy or CT colonography showed that 11 patients (5.4\%) had advanced colonic neoplasia and one of them was diagnosed with a colorectal cancer $(0.5 \%)$. The proportion of patients with colonic neoplasia (tubular adenoma $>10 \mathrm{~mm}$ and adenomas with high-grade dysplasia included) in this cohort was equivalent to, or less than detected on screening asymptomatic average-risk individuals. In the absence of other indications, subsequent evaluation of the colon may not be required to confirm the diagnosis of diverticulitis ${ }^{20}$. Unfortunately, in this study again no statistical data were available to confirm their conclusion.

The Dutch guidelines and Dutch society of Surgeons in The Netherlands recommends to limit the indication for colonoscopy only to symptomatic patients ${ }^{9,24}$. In contrast the guidelines of the European Association for Endoscopic Surgery and the American Society of Colon and Rectal Surgeons recommend routine colonoscopy ${ }^{14,20}$. Not only the 
Dutch guidelines advise not to perform a colonoscopy on a routine basis, other studies also have shown that colonoscopy is only indicated when diagnosis is uncertain on CT scan, in case the patient present with alarm symptoms and/or has risk factors for colorectal cancer, like a positive family history ${ }^{25}$. In addition, 2 recently published studies, a meta-analysis, and a review concluded that colonoscopy is only indicated when the patient presents with alarm symptoms, or has a complicated episode of acute diverticulitis $^{26,27}$. In these high-risk patients, the benefits of potentially diagnosing neoplasia or malignancy would most definitely outweigh the risks of colonoscopy ${ }^{26}$. The risk of colorectal cancer after a radiologically proven episode of acute uncomplicated diverticulitis is $l o w^{25}$.

It appears that despite the guidelines, colonoscopy is performed often (66\%) after uncomplicated diverticulitis. This may be harmful to patients, as colonoscopy is not without risk, let alone, the discomfort of the preparation and the procedure itself for the patient. Complications that may occur may be mild, but can be severe. Of the 645 patients who underwent a colonoscopy in our series, 4 patients developed a bleeding after the procedure and 2 patients a perforation. The first patient underwent immediate emergency surgery, a primary resection of the sigmoid was performed. The second patient had a more complicated course after the colonoscopy. Four days after the colonoscopy was performed, the patient was presented at the emergency room with a severe abdominal sepsis based on a sigmoidal perforation (which required resection).

One hundred and twenty-six patients developed a mild to complete obstruction. In these cases, the physician was not able to complete the colonoscopy and objectify the whole colon including the coecum and/or terminal ileum. Eight of these patients with obstruction during colonoscopy had a malignancy of the colon confirmed by the pathologist after biopsy. These are well-known complications ${ }^{28}$.

The main limitation of our study is the retrospective nature of this cohort. Colonoscopy was performed at the discretion of the treating physician and this may have led to bias. Although laboratory evaluation was done in all patients, specific information about the laboratory values was not included in the database. Furthermore, we are uncertain if the follow-up in the group who did not undergo colonoscopy is complete. We share the conclusion of an updated systematic review. It would be ideal to compare both groups in a randomized trial ${ }^{29}$.

\section{Conclusions}

Until now, there was limited evidence to perform a colonoscopy on a routine basis after an episode of acute diverticulitis in asymptomatic patients to exclude other pathology of the colon. We conclude that after an episode of uncomplicated diverticulitis, a 
colonoscopy is not indicated routinely as the risk of colorectal cancer is very low. Only in case of alarm symptoms, a colonoscopy may be justified. Yet, the chance of finding an actual colorectal cancer is relatively low. 


\section{References}

1. Lahat A, Yanai H, Sakhnini E, et al. Role of colonoscopy in patients with persistent acute diverticulitis. World J Gastroenterol. 2008;14:2763-2766.

2. Andeweg CS, Knobben L, Henkdriks JC, et al. How to diagnose acute colonic diverticulitis. Proposal for a clinical scoring system. Ann Surg. 2011;253:940-946.

3. Lameris W, van Randen A, van Gulik TM, et al. A clinical decision rule to establish the diagnosis of acute diverticulitis at the emergency department. Dis Colon Rectum. 2010;53:896-904.

4. Lahat A, Yanai H, Menachem Y, et al. Feasibility and risk of early colonoscopy in acute diverticulitis: a prospective controlled study. Endoscopy. 2007;39:521-524.

5. Kaiser AM, Jiang JK, Lake JP, et al. The management of complicated diverticulitis and the role of computed tomography. Am J Gastroenterol. 2005;100:910-917.

6. Farrell RJ, Farrell JJ, Morrin MM. Diverticular disease in the elderly. Gastroenterol Clin North Am. 2001;30:475-496.

7. Wong WD, Wexner SD, Lowry A, et al. Practice parameters for the treatment of sigmoid diverticulitissupporting documentation. The Standards Task Force. The American Society of Colon and Rectal Surgeons. Dis Colon Rectum. 2000;43:290-297.

8. Schout PJ, Spillenaar Bilgen EJ, Groenen MJ. Routine screening for colon cancer after conservative treatment of diverticulitis. Dig Surg. 2012;29:408-411.

9. Dutch Society of Surgery. Diagnostic and treatment of acute diverticulitis of the colon. Dutch guidelines diagnostics and treatment of acute colonic diverticulitis. 2012. Available at: http://www.mdl.nl/ uploads/240/1137/Acute-diverticulitis-van-hetcolon- 2012.pdf.

10. Majumdar SR, Fletcher RH, Evans AT. How does colorectal cancer present? Symptoms, duration, and clues to location. Am J Gastroenterol. 1999;94:3039-3045.

11. Hamilton W, Round A, Sharp D, et al. Clinical features of colorectal cancer before diagnosis: a population-based casecontrol study. Br J Cancer. 2005;93:399-405.

12. Jones R, Latinovic R, Charlton J, et al. Alarm symptoms in early diagnosis of cancer in primary care: cohort study using General Practice Research Database. BMJ. 2007;334:1040.

13. Clinical Guideline. Colorectal cancer: the diagnosis and management of colorectal cancer. Full Guideline. 2011. Available at: http://www.nice.org.uk/guidance/cg131/resources/colorectal- cancerfull-guideline2.

14. Stollman NH, Raskin JB. Diagnosis and management of diverticular disease of the colon in adults. Ad Hoc Practice Parameters Committee of the American College of Gastroenterology. Am J Gastroenterol. 1999;94:3110-3121.

15. Westwood DA, Eglinton TW, Frizelle FA. Routine colonoscopy following acute uncomplicated diverticulitis. Br J Surg. 2011;98:1630-1634.

16. Beckham $\mathrm{H}$, Whitlow $\mathrm{CB}$. The medical and non operative treatment of diverticulitis. Clin Colon Rectal Surg. 2009;22:156-160.

17. Rafferty J, Shellito P, Hyman NH, et al. Practice parameters for sigmoid diverticulitis. Dis Colon Rectum. 2006;49:939-944.

18. Jacobs DO. Clinical practice. Diverticulitis. N Engl J Med. 2007;357:2057-2066.

19. Biondo S, Lopez Borao J, Millan M, et al. Current status of the treatment of acute colonic diverticulitis: a systematic review. Colorectal Dis. 2012;14:1-11.

20. O'Neill S, Ross P, McGarry P, et al. Latest diagnosis and management of diverticulitis. Br J Med Pract. 2011;4:a443-a450.

21. Lau KC, Spilsbury K, Farooque Y, et al. Is colonoscopy still mandatory after a CT diagnosis of left-sided diverticulitis: can colorectal cancer be confidently excluded? Dis Colon Rectum. 2011;21: 541265-541270.

22. van de Wall BJ, Reuling EM, Consten EC, et al. Endoscopic evaluation of the colon after an episode of diverticulitis: a call for a more selective approach. Int J Colorectal Dis. 2012;27:1145-1150.

23. Schmilovitz-Weiss $H$, Yalunin E, Boaz M, et al. Does a colonoscopy after acute diverticulitis affect its management?: a single center experience. J Clin Gastroenterol. 2012;46:317-320.

24. Vennix S, Morton DG, Hahnloser D, et al. Systematic review of evidence and consensus on diverticulitis: an analysis of national and international guidelines. Colorectal Dis. 2014;24:866-878. 
25. Lecleire S, Nahon S, Alatawi A, et al. Diagnostic impact of routine colonoscopy following acute diverticulitis: a multicenter study in 808 patients and controls. United European Gastroenterol J. 2014;2:301-306.

26. Sharma PV, Eglinton T, Hider P, et al. Systematic review and meta-analysis of the role of routine colonic evaluation after radiologically confirmed acute diverticulits. Ann Surg. 2014;256:263-272.

27. Agarwal AK, Karanjawala BE, Maykel JA, et al. Routine colonic endoscopic evaluation following resolution of acute diverticulitis: is it necessary? World J Gastroenterol. 2014;20:12509-12516.

28. Chukmaitov A, Bradley CJ, Dahman B, et al. Association of polypectomy techniques, endoscopist volume, and facility type with colonoscopy complications. Gastrointest Endosc. 2013;77: 436-446.

29. Daniels L, Unlü C, de Wijkerslooth TR, et al. Routine colonoscopy after left-sided acute uncomplicated diverticulitis: a systematic review. Gastroint Endosc. 2013;79:378-389. 


\section{Chapter}

\section{Tumour characteristics of patients with colorectal cancer after acute uncomplicated diverticulitis}

Winesh Ramphal

Jennifer M.J. Schreinemakers

Tom C.J. Seerden

Paul D. Gobardhan

Digestive diseases. 2018;36(5):362-368. 


\section{Abstract}

\section{Background}

The association between diverticulitis and colorectal cancer (CRC) remains unclear, though both share epidemiological characteristics. The aim of this study was to investigate whether there is higher risk for CRC after an episode of uncomplicated diverticulitis. Furthermore, in cases of CRC, we sought to determine specific tumour characteristics.

\section{Methods}

This retrospective observational study includes patients with acute diverticulitis (Hinchey 0 and 1 ) who were conservatively treated with or without antibiotics between 2008 and 2013. Patients with endoscopic follow up were included for analysis. Tumour characteristics of patients diagnosed with CRC during colonoscopic follow-up according to patients' presentation of alarm symptoms were considered to be the primary endpoint.

\section{Results}

A total of 977 patients were conservatively treated for an episode of acute diverticulitis, 645 of whom underwent colonoscopy during follow-up. Ten patients were diagnosed with CRC, nine of whom exhibited alarm symptoms. One patient was diagnosed with stage I disease, 4 had stage II, and 5 had stage III disease.

\section{Conclusions}

This study strongly suggests that even though CRC is rare after uncomplicated diverticulitis, in cases of alarm symptoms, a colonoscopy is indicated. In cases where $\mathrm{CRC}$ is diagnosed, it is often advanced with a higher TNM stage and poor prognosis. 


\section{Introduction}

Colorectal cancer (CRC) and diverticular disease share multiple epidemiological characteristics. Both are common in the Western world, the incidence increases with advancing age, and prevalence is higher in men. In the last decade, the hospitalizations for patients with diverticulitis have increased. In 2009, 18,355 patients were admitted compared to only 13,655 patients in $2006^{1}$. In contrast, 11,541 patients were diagnosed with CRC in $2015\left(8,301\right.$ colon and 3,240 rectal) ${ }^{2}$. In the Western world, the localization of both diverticular disease and CRC occurs most commonly on the left side of the colon. There are conflicting reports on whether diverticular disease is associated with CRC. Burkitt was the first to formulate this hypothesis; however, this association is not entirely proven ${ }^{3}$. Some studies have found an increased risk for CRC after diverticulitis $^{4-7}$, while others did not ${ }^{8-13}$. In 1993, Stefánsson et al suggested that positive associations could be explained by high concentrations of bacteria in the colon, some of which produce carcinogens ${ }^{14}$. Additionally, increases in cell turnover during longstanding chronic inflammation could play a role, but these assumptions lack strong evidence. Patients with longstanding chronic inflammation of the colon or with frequent episodes of diverticulitis might have an increased risk for developing CRC. Routine use of colonoscopy after acute uncomplicated diverticulitis is controversial and seems unnecessary ${ }^{15-19}$. In our previous study, we advocated that routine colonoscopy not be performed after an episode of acute uncomplicated diverticulitis. The risk for CRC in patients after acute uncomplicated diverticulitis with alarm symptoms is 4.4 vs. $0.2 \%$ without alarm symptoms. Colonoscopy appears to be indicated in patients only with alarm symptoms for CRC such as rectal blood loss, unintentional weight loss and/or persistent abdominal pain ${ }^{8}$. If CRC is diagnosed in such cases, it is unclear what the (tumour) characteristics are of those patients after an episode of uncomplicated acute diverticulitis. Synchronous colorectal tumours may be incidental findings. Perhaps these cancers are located in a different segment of the colon other than the diverticulitis. Therefore, in this subsequent study, based on the same cohort, we aimed to investigate the (tumour) characteristics of patients with CRC diagnosed after an uncomplicated episode of diverticulitis.

\section{Methods}

All patients treated between January 2008 and July 2013 were retrospectively reviewed. Patients were selected through the hospital administration system and were identified if they had been registered for an episode of diverticular disease and/or diverticulitis based on the diagnoses treatment combination system (official health care system in the Netherlands, Diagnose Behandel Combinatie based on International Classification of Disease-9). Demographic and medical data was retrieved from their medical charts and consisted of signs and symptoms, radiologic findings, medical 
treatment and whether or not colonoscopy was performed Conservative treatment could consist of oral or intravenous antibiotics or no antibiotics at all. Patients who were treated conservatively for acute diverticulitis were offered colonoscopy to rule out CRC. The outcome of these colonoscopies was ascertained as well.

Diverticulitis was defined by the presence of the following 3 symptoms: fever (bodytemperature above 38.5 degrees Celsius), blood level of C-reactive protein $>50 \mathrm{mg} / \mathrm{L}$ (ref $0-10 \mathrm{mg} / \mathrm{L}$ ) and abdominal pain in the left lower quadrant ${ }^{1}$. The diagnosis of diverticulitis was then confirmed and classified by radiologic findings (by computed tomography scan [CT-scan] or ultrasound) based on the Hinchey classification ${ }^{20}$. Hinchey 0 and I classifications were included for analysis and are defined as mild clinical diverticulitis with confirmation by imaging or surgery and as the presence of a pericolic abscess or phlegmon respectively. Hinchey II was defined as a pelvic, intra-abdominal or retroperitoneal abscess. Hinchey III and IV were defined as purulent peritonitis and the presence of faecal peritonitis respectively. Patients with a Hinchey II-IV diverticulitis who were treated with percutaneous drainage or surgery were excluded from analysis because of a different follow-up strategy compared to patients who were treated conservatively. Excluding a malignancy would not be the primary goal of a postoperative colonoscopy because the potential colorectal tumour would already have been resected during surgery. Patients with previous colorectal surgery were excluded as well to maintain a homogeneous study population.

According to Dutch guidelines, antibiotics are only administered in cases where the patient has a fever and is suspected of having bacteraemia or (severe) sepsis, if the patient is immunocompromised, or in cases of chronic non-steroidal anti-inflammatory drug use. Alarm symptoms for CRC were defined as unintentional weight loss, a change in bowel habits, bloody stool and/or persistent abdominal pain ${ }^{8}$. These symptoms had to be present within 3 months after first presentation until the time at which colonoscopy was performed. Patients were divided into 2 groups, those who did and those who did not undergo colonoscopy. The patients who underwent colonoscopy between 6 weeks and 3 months after their acute episode of diverticulitis were eligible for analysis. We compared the results of colonoscopy for patients with and without alarm symptoms. Data regarding surgery, pathology and colonoscopy outcome was retrieved to determine the characteristics of patients and tumours. Specific data regarding the type of surgical resection, location of the tumour, histological characteristics and follow-up was ascertained as well. Information on overall- and disease-free survival is presented in months. As subsequent follow-up on our earlier study regarding the risk of CRC after acute uncomplicated diverticulitis, part of these research methods match those from our earlier study ${ }^{8}$. 


\section{Ethical approval}

We consulted the institutional review board of the Amphia hospital and they confirmed that no formal written waiver or informed consent for the need of ethics approval was required, due to the retrospective design of the study.

\section{Statistics}

The $\chi^{2}$ test was used to compare dichotomous variables such as the presence of alarm symptoms and whether or not colonoscopy was performed. We calculated the percentage of CRCs diagnosed by colonoscopy and subsequent pathologic examination of suspect lesions, after being conservatively treated for an episode of acute uncomplicated diverticulitis. A comparison was made between frequencies of CRC in patients with and without alarm symptoms for $C R C^{8}$. We used the IBM SPSS Statistics program, version 20 for statistical calculations.

\section{Results}

\section{Patients}

Between January 2008 and July 2013, 1,272 patients were treated for acute diverticulitis in the Amphia hospital. Ninety-six patients had one or more previous episodes of diverticulitis before 2008 and were therefore excluded. Another 46 patients were excluded because they underwent colorectal surgery, 13 patients due to CRC, 32 patients because of diverticulitis and one patient because of benign polyps. The remaining 1,130 patients were treated for an initial episode of acute diverticulitis. One hundred fifty-three patients were excluded because of a complicated course in their first episode of diverticulitis (Hinchey II-IV). Nine hundred seventy-seven patients were conservatively treated with or without antibiotics, comprising 151 and 826 patients respectively. Of those patients treated conservatively, 645 (66\%) underwent colonoscopy, 440 patients had no alarm symptoms (68\%) and 205 patients had alarm symptoms (32\%). Only one patient $(0.2 \%)$ from those with no alarm symptoms presented with CRC versus $9(4.4 \%)$ patients in the group with alarm symptoms $(P=0.0002$; Figure 1). 


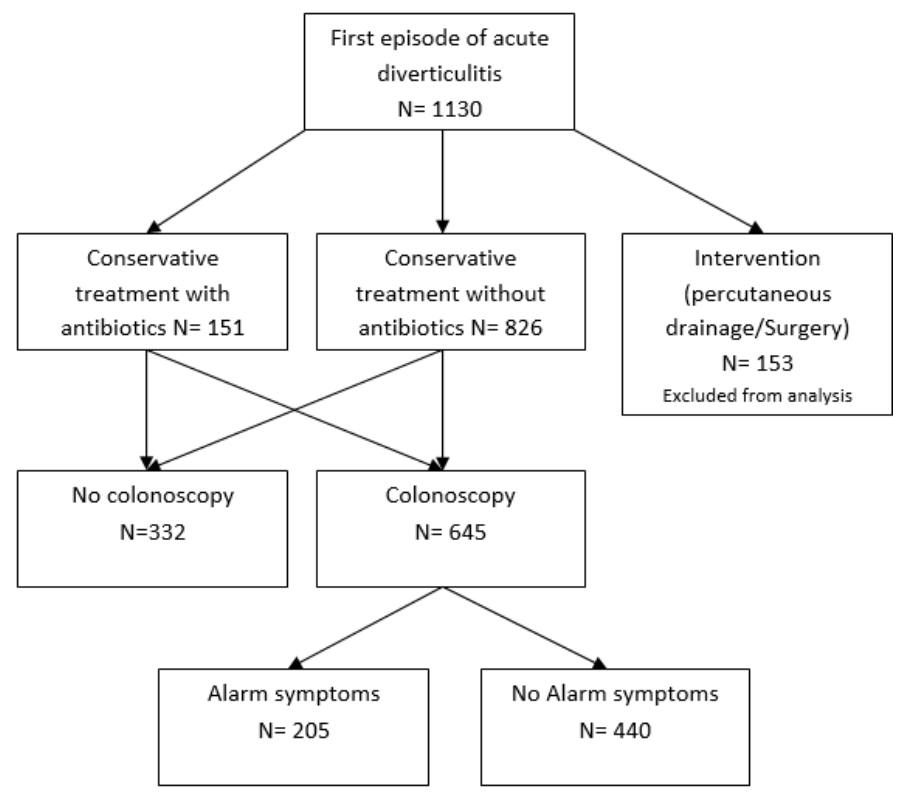

Figure $1 \quad$ Flowchart of 1,130 patients with diverticulitis. Ramphal et al ${ }^{8}$.

* Alarm symptoms were defined as bloody stools, unintentional weight loss and/or persistent abdominal pain.

\section{Tumour characteristics}

Of the 10 patients diagnosed with CRC, 1 patient had stage I disease, 4 patients had stage II disease and 5 patients had stage III disease (Table 1).

Table 1 Characteristics of patients who had CRC diagnosis after colonoscopy for acute diverticulitis.

\begin{tabular}{|c|c|c|c|c|c|}
\hline $\begin{array}{l}\text { Patients } \\
\text { Number/Sex } \\
\text { (M/F)/Age (years) }\end{array}$ & $\begin{array}{c}\text { Alarm } \\
\text { symptoms } \\
\text { present yes/no }\end{array}$ & $\begin{array}{c}\text { Type of } \\
\text { symptoms }\end{array}$ & Tumor location & Surgery & TNM stage \\
\hline 1. $\mathrm{M} / 64$ & No & - & Sigmoid & Resection & T4bN2Mx \\
\hline 2. $F / 94$ & Yes & Weight loss & Sigmoid & $\begin{array}{l}\text { Irresectable, } \\
\text { diverting stoma only }\end{array}$ & T4aN1M0* \\
\hline 3. $M / 72$ & Yes & Abdominal pain & Sigmoid & Resection & T1N0M0 \\
\hline 4. $F / 42$ & Yes & $\begin{array}{l}\text { Weight loss and } \\
\text { abdominal pain }\end{array}$ & Sigmoid & Resection & T4aN2M0 \\
\hline 5. $\mathrm{F} / 80$ & Yes & Abdominal pain & Hepatic flexure & Resection & T3NOMO \\
\hline 6. $M / 56$ & Yes & Abdominal pain & Rectal-Sigmoid & Resection & T3NOMO \\
\hline 7. $F / 64$ & Yes & Bloody stool & $\begin{array}{l}\text { Sigmoid and } \\
\text { splenic flexure }\end{array}$ & Resection & T3NOMO \\
\hline 8. $F / 83$ & Yes & Bloody stool & Sigmoid & $\begin{array}{c}\text { Irresectable, } \\
\text { diverting stoma only }\end{array}$ & T4NxMx* \\
\hline 9. $\mathrm{F} / 70$ & Yes & Bloody stool & Sigmoid & Resection & T3N1M0 \\
\hline 10. $\mathrm{M} / 57$ & Yes & Abdominal pain & Sigmoid & Resection & T3N2MO \\
\hline
\end{tabular}

TNM stage (TNM classification $5^{\text {th }}$ edition ${ }^{34}{ }^{*}$ cTNM-classification. The tumours of remaining patients were classified as pTNM). M/F: male/female. CRC: colorectal cancer. 
Alarm symptoms included rectal bleeding $(n=3,33.3 \%)$, persistent abdominal pain $(n=5$, $55.6 \%)$, and unintentional weight loss $(n=2,22.2 \%)$. One patient with CRC had both persistent abdominal pain and unintentional weight loss. The mean age of patients with CRC was 68 years (range 42-94 years). An overview of the patients' characteristics, including the presence of specific alarm symptoms, tumour location, type of surgery and TNM (primary tumour, lymph nodes and metastasis) classification, is shown in Table 1. Four of the ten patients diagnosed with CRC were men. Nine of the ten tumours were found in the left colon (sigmoid) compared to one tumour in the hepatic flexure (diverticulitis in this patient was seen in the left colon). On the other hand, only one patient was diagnosed with right side diverticulitis located in the ascending colon, but the malignancy was located in the left colon (sigmoid). In these 2 patients, no alarm symptoms for CRC were present in the weeks or months prior to the episode of acute diverticulitis. Most tumours had an advanced T stage (T1 $n=1, T 3 n=5, T 4 n=4)$. Five patients were lymph node positive, three of whom possessed a T4 tumour and two a T3 tumour.

Table 2 shows an additional overview of specific tumour characteristics, such as the histological outcome, pre-operative carcinoembryonic antigen and risk factors for colon cancer including predisposing family history. Only one patient had no serum carcinoembryonic antigen assay. In case numbers 2 and 8, lymphangio invasion was unknown because the tumour was irresectable due to growth of the tumour into the abdominal wall and only biopsies were taken for histological confirmation. Two patients had a family history of CRC, one of whom exhibited positive microsatellite instability after molecular determination (patient 4). One patient developed a tumour perforation during work-up. One patient had a positive family history for Crohn's disease. None of the patients had synchronous metastasis. Only case number 9 had recurrent and progressive disease with peritoneal carcinomatosis 11 months after the diagnosis of CRC. Three patients were treated with adjuvant systemic therapy, two of whom are still disease free at this time. Half of the patients died during follow-up, and median followup was 39 months (range 2-64 months).

Between January 2008 and July 2013, 135 patients had 2 or more episodes of diverticulitis; also none of these patients were diagnosed with CRC during follow-up. 


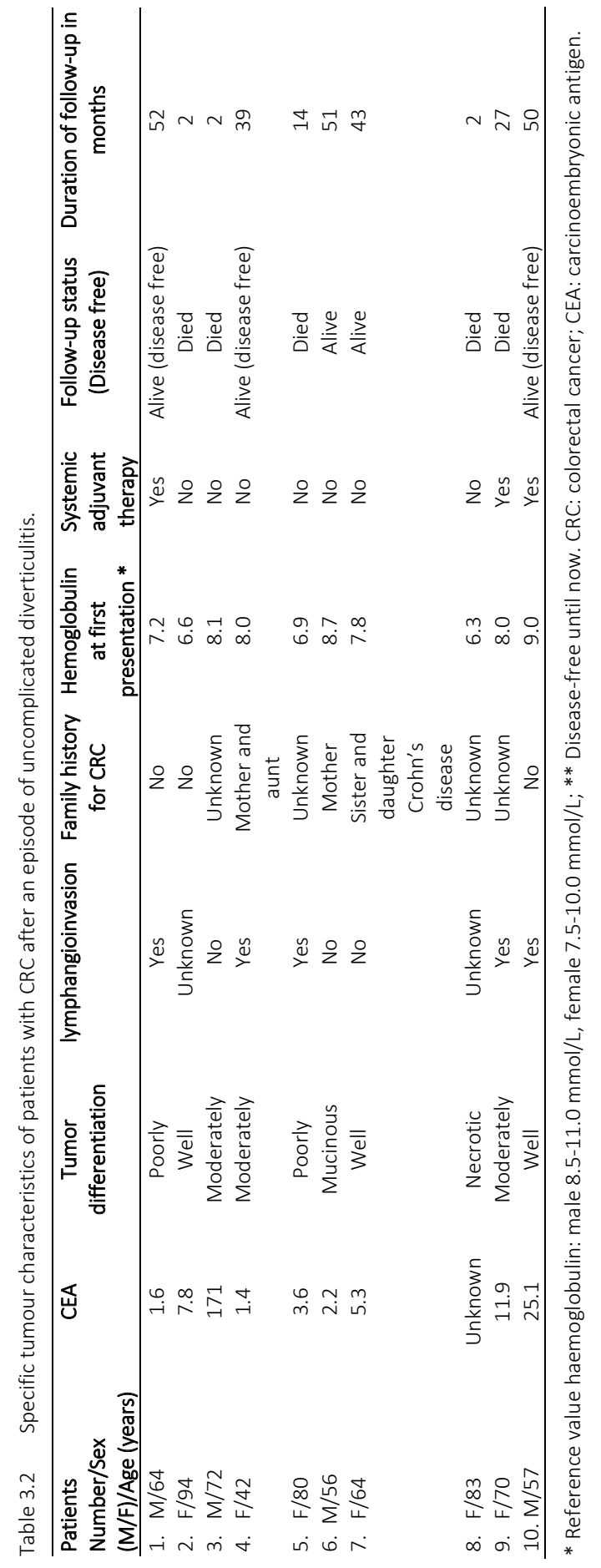




\section{Alarm symptoms}

All patients presenting with alarm symptoms had persistent complaints after discharge for their acute diverticulitis. Of the 205 patients with alarm symptoms, 104 presented with bloody stools, 82 with persistent abdominal pain, and 24 patients with unintentional weight loss. Five patients had 2 alarm symptoms simultaneously, one of whom turned out to have sigmoidal cancer. Of these 205 patients with alarm symptoms, a total of 73 patients had undergone a CT-scan at the time of first presentation. In 21 cases $(28.7 \%)$, the radiologist could not differentiate between a colorectal malignancy and diverticulitis, requiring further examination by means of colonoscopy. In the remaining 52 cases, diverticulitis was the primary diagnosis and the radiologist excluded a colorectal malignancy based on the CT-scan. In 5 out of 10 patients with CRC, an ultrasound was performed during their first visit and a CT-scan was performed in the remaining 5 patients. In 2 out of these 5 patients, the initial CTscan was suspicious of CRC.

\section{Excluded patients and patients without colonoscopy}

One hundred fifty-three patients were excluded because they underwent surgery or percutaneous drain positioning in an abscess (Hinchey II-IV). Fifty-nine of these patients underwent surgery. Twenty-three of these cases were classified as Hinchey IV, 27 were Hinchey III, and 9 were Hinchey II. None of these resected specimens were malignant after examination by the pathologist. Ninety-four patients had a radiologic intervention. A total of 332 patients did not undergo colonoscopy for several reasons, mostly due to physicians' choice and non-availability of expertise to offer colonoscopy to the patient because there were no clinical signs or symptoms to rule out a malignancy. Two hundred sixty-eight patients returned for a scheduled check-up after their episode of diverticulitis. The remaining 64 patients did not have a check-up after discharge at the emergency department due to successive therapy with pain killers, life style advice and lack of symptoms during follow-up. Seventeen patients did have alarm symptoms (persisting abdominal pain, no rectal blood loss or unintentional weight loss). Fifteen of them had no symptoms after a second check-up. The remaining 2 patients were offered colonoscopy, but both patients declined. Due to comorbidity and age, a diagnostic colonoscopy would not have therapeutic consequences. In both cases, physicians agreed not to perform further diagnostic studies. In 93 of 332 patients, colonoscopy was performed in the context of population screening for CRC. No colorectal malignancies malignancies were found during these colonoscopies, despite all 93 patients having diverticulosis during colonoscopy. 


\section{Discussion}

The aim of this study was to determine tumour characteristics of patients diagnosed with CRC during colonoscopic follow-up after an episode of uncomplicated diverticulitis. From the data in this retrospective study, we reached some interesting conclusions. First, the finding of CRC after an episode of uncomplicated diverticulitis is often located in the sigmoid and matches with the location of diverticulitis in $80 \%$ of the cases in in our study. Furthermore, the T-stage is most often advanced, that is, T3 or frequently T4 with positive lymph nodes (stage III CRC; Table 1). To our knowledge, this is the first and only series showing that CRC after experiencing uncomplicated diverticulitis are in general high-risk CRCs. Different authors described the association between diverticulosis or diverticulitis and CRC and the benefit of colonoscopy to exclude malignancy afterwards ${ }^{4-7}$. Limited data is available concerning the risk of finding CRC in patients with an episode of uncomplicated diverticulitis.

The Dutch national guidelines do not recommend routine colonoscopy; however, this advice is based on a small series and lack strong evidence ${ }^{1,15-17}$. In the case of alarm symptoms, a colonoscopy does appear to be indicated to rule out $\mathrm{CRC}^{8,21}$. This is in line with the study of Daniels et al. $^{22}$ who showed that detection of advanced colonic neoplasia by colonoscopy after CT proven uncomplicated acute diverticulitis is comparable to randomly picked asymptomatic CRC screening participants. The authors draw similar conclusions compared to our previous study. Follow-up with colonoscopy may be beneficial only for high-risk patients ${ }^{22}$. Several other studies regarding the necessity of diagnostic colonoscopy after proven diverticulitis are in line with our study. They only suggest a colonoscopy when there are potential clues on CT findings that could lead to CRC, such as an increase in intestinal wall thickness more than $6 \mathrm{~mm}$, abscess, obstruction or lymph node abnormalities. When a CT-confirmed diverticulitis is in the absence of other concerning or intermediate findings, there is no benefit in a follow-up colonoscopy ${ }^{23-26}$.

Recently, 3 meta-analyses were published concerning the risk of CRC after a radiologic confirmed diagnosis of acute diverticulitis. The first meta-analysis included, just as in our study, patients with uncomplicated diverticulitis. In 1,796 patients, the prevalence of CRC was $1.5 \%{ }^{27}$. The second meta-analysis was performed by Sharma et al. ${ }^{28}$ more recently and they included 1,970 patients who received endoscopic evaluation. The prevalence of CRC is this group was $1.6 \%$. In contrast to our study, this study uses all patients with diverticulitis, meaning patients with complicated diverticulitis including patients without conformation by imaging and patients with persisting diverticulitis ${ }^{28}$. Because we only included patients experiencing their first uncomplicated episode of diverticulitis, this meta-analysis is not comparable to the one conducted on our study population. The third meta-analysis had a smaller cohort of 771 patients with CT proven diagnosis of diverticulitis. The prevalence of CRC was $2.1 \%$ compared to $0.68 \%$ 
in adults older than 55 years old who are at average risk ${ }^{29}$. Just like in the first 2 metaanalyses, the authors concluded that the risk of CRC after a radiologic proven episode of uncomplicated acute diverticulitis is low and there is limited data to support the recommendation to perform a colonoscopy. The similar location between diverticulitis and colonic cancer may insinuate that these 2 entities are not completely unrelated to each other. However, the association between diverticular disease and CRC remains unclear. The results from these several studies were not consistent and selection bias and confounding were underlying factors that prevented us from arriving at firm conclusions of direct causality ${ }^{30-32}$.

Another reason why the association between these 2 diseases could not be made is due to the lack of long-term observations. Nevertheless, 2 studies examining the association between diverticular disease and CRC using large databases showed that risk for diagnosis of CRC after diverticulitis increased in the first year following the first episode of diverticulitis ${ }^{11,33}$. The first important study was performed in Sweden by Granlund et al. ${ }^{11}$ and was a huge nation-wide case control study involving 41,037 patients with CRC identified by the Swedish Cancer Registry. Cases and controls were searched for an episode of hospitalizations with the diagnosis of diverticular disease. Among patients with colon cancer, mortality was not significantly different between patients with and without diverticular disease. Based on this finding, the authors highly recommend that patients with diverticular disease should have a diagnostic work-up within the first 12 months after the initial episode of diverticular disease. The second large study was performed in Taiwan and the methodology for this study differs from that of the Swedish study ${ }^{33}$. These authors first retrieved a database of 41,359 patients with diverticular disease from the National Health Research Institute database. These patients were matched with 4 controls each, comprising 165,436 individuals without diverticular disease. The authors drew similar conclusions as in the Swedish study: The risk of colon cancer is only increased within the first year after diagnosis of diverticular disease. These 2 large cohorts differ from each other. The Swedish study makes no distinction between diverticulosis and diverticulitis, and cases were divided by the number of admissions, not by the severity of disease ranked using the Hinchey classification, which is a limitation of this study. The Taiwanese study does make a distinction between diverticulosis and/or diverticulitis. Similar to our study, we only included patients with a first episode of uncomplicated diverticulitis and who had a colonoscopy during follow-up. To differentiate for CRC, our advice would be, based on our own cohort, that only patients with alarm symptoms for CRC should have the diagnostic work-up through colonoscopy [8]. This would result in less patient burden and possibly less colonoscopy-related risks and complications. Besides, national health care costs could be reduced.

Limitations of our series are the small number of patients and the retrospective nature. However, there are few large colonoscopy series and no previous series to describe 
tumour characteristics for these patients. Another potential drawback that should be acknowledged is that we did not include patients with complicated diverticulitis (Hinchey II-IV). The results cannot be extrapolated to the group that did not receive conservative treatment but rather underwent surgery or radiologic intervention.

\section{Conclusions}

In conclusion, from this observational study, we can conclude that in the case of alarm symptoms, a diagnostic colonoscopy appears to be indicated after a first episode of uncomplicated diverticulitis. If a concomitant CRC is found, it is often an advanced Tstage and located on the left colon and sigmoid. 


\section{References}

1. Dutch Society of Surgery: Diagnostic and Treatment of Acute Diverticulitis of the Colon. Dutch Guidelines Diagnostics and Treatment of Acute Colonic Diverticulitis. http://www.mdl.nl/uploads/ 240/1137/Acute-diverticulitis-van-hetcolon-2012.pdf, 2012.

2. Dutch Institute for Clilnical Auditing: Dutch Surgical Colorectal Audit. https://www.dica.nl/ jaarrapportage-2015/dsca.

3. Ekbom A: Is diverticular disease associated with colonic malignancy? Dig Dis. 2012;30:46-50.

4. Stefánsson T, Ekbom A, Sparèn P, Påhlman L. Association between sigmoid diverticulitis and left-sided colon cancer: a nested, population-based, case control study. Scand J Gastroenterol. 2004;39:743-747.

5. Lau KC, Spilsbury K, Farooque Y, Kariyawasam SB, Owen RG, Wallace MH, Makin GB. Is colonoscopy still mandatory after a CT diagnosis of left-sided diverticulitis: can colorectal cancer be confidently excluded? Dis Colon Rectum. 2011; 54: 1265-1270.

6. Soran A, Harlak A, Wilson JW, Nesbitt L, Lembersky BC, Wienad HS, O'Connell MJ. Diverticular disease in patients with colon cancer: subgroup analysis of national surgical adjuvant breast and bowel project protocol C-06. Clin Colorectal Cancer. 2006; 6: 140-145.

7. Stefánsson T, Ekbom A, Sparén P, Påhlman L. Cancers among patients diagnosed as having diverticular disease of the colon. Eur J Surg. 1995; 161: 755-760.

8. Ramphal W, Schreinemakers JM, Seerden TC, Crolla RM, Rijken AM, Gobardhan PD. What is the risk of colorectal cancer after an episode of acute diverticulitis in conservatively treated patients? J Clin Gastroenterol 2016; 50:e35-e39.

9. Krones CJ, Klinge U, Butz N, Junge K, Stumpf M, Rosch R, Hermanns B, Heussen N, Schumpelick V. The rare epidemiologic coincidence of diverticular disease and advanced colonic neoplasia. Int J Colorectal Dis 2006;21: 18-24.

10. Lam TJ, Meurs-Szojda MM, Gundlach L, Belien JA, Meijer GA, Mulder CJ, Felt-Bersma RJ. There is no increased risk for colorectal cancer and adenomas in patients with diverticulitis: a retrospective longitudinal study. Colorectal Dis. 2010; 12: 1122-1126.

11. Granlund J, Svensson T, Granath F, Hjern F, Ekbom A, Blomqvist P, Schmidt PT: Diverticular disease and the risk of colon cancer - a population-based case-control study. Aliment Pharmacol Ther. 2011;34: 675-681.

12. Sallinen V, Mentula P, Leppäniemi A. Risk of colon cancer after computed tomography-diagnosed acute diverticulitis: is routine colonoscopy necessary? Surg Endosc. 2014;28:961-966.

13. Van de Wall BJ, Reuling EM, Consten EC, van Grinsven JH, Schwartz MP, Broeders IA, Draaisma WA. Endoscopic evaluation of the colon after an episode of diverticulitis: a call for a more selective approach. Int J Colorectal Dis. 2012; 27: 1145-1150.

14. Stefánsson T, Ekbom A, Sparèn P, Påhlman L. Increased risk of left sided colon cancer in patients with diverticular disease. Gut. 1993; 34: 499-502.

15. Hjern F, Jonas E, Holmström B, Josephson T, Mellgren A, Johansson C. CT colonography versus colonoscopy in the follow-up of patients after diverticulitis - a prospective, comparative study. Clin Radiol. 2007; 62: 645-650.

16. Lahat A, Yanai H, Menachem Y, Avidan B, Bar-Meir S. The feasibility and risk of early colonoscopy in acute diverticulitis: a prospective controlled study. Endoscopy. 2007; 39:521-524.

17. Lahat A, Yanai H, Sakhnini E, Menachem Y, Bar-Meir S. Role of colonoscopy in patients with persistent acute diverticulitis. World J Gastroenterol. 2008; 14: 2763-2766.

18. Brar MS, Roxin G, Yaffe PB, Stanger J, MacLean AR, Buie WD. Colonoscopy following nonoperative management of uncomplicated diverticulitis may not be warranted. Dis Colon Rectum. 2013; 56: 1259-1264.

19. Westwood DA, Eglinton TW, Frizelle FA. Routine colonoscopy following acute uncomplicated diverticulitis. Br J Surg. 2011; 98: 1630-1634.

20. Kaiser AM, Jiang JK, Lake JP, Ault G, Artinyan A, Gonzalez-Ruiz C, Essani R, Beart RW Jr. The management of complicated diverticulitis and the role of computed tomography. Am J Gastroenterol. 2005; 100: 910-917.

21. Schout PJ, Spillenaar Bilgen EJ, Groenen MJ. Routine screening for colon cancer after conservative treatment of diverticulitis. Dig Surg. 2012; 29: 408-411. 
22. Daniels L, Ünlü Ç, de Wijkerslooth TR, Stockmann HB, Kuipers EJ, Boermeester MA, Dekker E. Yield of colonoscopy after recent CT-proven uncomplicated acute diverticulitis: a comparative cohort study. Surg Endosc. 2015; 29: 2605-2613.

23. Andrade $P$, Ribeiro A, Ramalho $R$, Lopes $S$, Macedo $G$. Routine colonoscopy after acute uncomplicated diverticulitis - challenging a putative indication. Dig Surg. 2017; 34: 197-202.

24. Elmi A, Hedgire SS, Pargaonkar V, Cao K, McDermott S, Harisinghani M. Is early colonoscopy beneficial in patients with CT-diagnosed diverticulitis? AJR Am J Roentgenol. 2013; 200:1269-1274.

25. Walker AS, Bingham JR, Janssen KM, Johnson EK, Maykel JA, Ocampo O, Gonzalez JP, Steele SR. Colonoscopy after Hinchey I and II left-sided diverticulitis: utility or futility? Am J Surg. 2016; 212: 837-843.

26. Ou G, Rosenfeld G, Brown J, Chan N, HongT, Lim H, Bressler B. Colonoscopy after CT diagnosed acute diverticulitis: is it really necessary? Can J Surg. 2015; 58: 226-231.

27. Daniels L, Unlü C, de Wijkerslooth TR, Dekker E, Boermeester MA. Routine colonoscopy after left-sided acute uncomplicated diverticulitis: a systematic review. Gastrointest Endosc. 2014; 79: 378-389.

28. Sharma PV, Eglinton T, Hider P, Frizelle F. Systematic review and meta-analysis of the role of routine colonic evaluation after radiologically confirmed acute diverticulitis. Ann Surg. 2014; 259: 263-272.

29. Sai VF, Velayos F, Neuhaus J, Westphalen AC. Colonoscopy after CT diagnosis of diverticulitis to exclude colon cancer: a systematic literature review. Radiology. 2012; 263: 383-390.

30 Kieff BJ, Eckert GJ, Imperiale TF. Is diverticulosis associated with colorectal neoplasia? A cross-sectional colonoscopic study. Am J Gastroenterol. 2004; 99: 2007-2011.

31. Meurs-Szojda MM, Terhaar sive Droste JS, Kuik DJ, Mulder CJ, Felt-Bersma RJ. Diverticulosis and diverticulitis form no risk for polyps and colorectal neoplasia in 4,241 colonoscopies. Int J Colorectal Dis. 2008; 23: 979-984.

32. Morini S, Zullo A, Hassan C, Tomao S, Campo SM. Diverticulosis and colorectal cancer: between lights and shadows. J Clin Gastroenterol. 2008; 42: 763-770.

33. Huang WY, Lin CC, Jen YM, Chang YJ, Hsiao CW, Yang MH, Lin CS, Sung FC, Liang JA, Kao CH. Association between colonic diverticular disease and colorectal cancer: a nationwide population-based study. Clin Gastroenterol Hepatol. 2014; 12: 1288-1294.

34 Clinical Guideline: Colorectal Cancer: The Diagnosis and Management of ColorectalCancer. Full Guideline. http://www.nice.org.uk/guidance/cg131/resources/colorectalcancer- full-guideline2, 2011. 


\section{Part II}

Follow-up after curative surgery in colorectal cancer patients 



\section{Chapter 4}

\section{Ileus caused by obstructing colorectal cancer:}

Impact on long term survival

Jeske R.E. Boeding

Winesh Ramphal

Rogier M.P.H. Crolla

Leandra J.M. Boonman - de Winter

Paul D. Gobardhan

Jennifer M.J. Schreinemakers

International Journal of Colorectal Disease. 2018 Oct;33(10):1393-1400 


\section{Abstract}

\section{Purpose}

It is unclear whether obstructing colorectal cancer (CRC) has a worse prognosis than non-obstructing CRC. Of CRC patients, $10-28 \%$ present with symptoms of acute obstruction. Previous studies regarding obstruction have been primarily based on shortterm outcomes, risk factors and treatment modalities. With this study, we want to determine the long-term survival of patients presenting with acute obstructive CRC.

\section{Methods}

This single-centre observational retrospective cohort study includes all CRC patients who underwent surgery between December 2004 and 2010. Patients were divided into two groups: ileus and no ileus. Survival analyses were performed for both groups. Additional survival analyses were performed in patients with and without synchronous metastases. The primary outcome was survival in months.

\section{Results}

A total of 1236 patients were included in the analyses. Ileus occurred in 178 patients $(14.4 \%)$. The 5 -year survival for patients with an ileus was $32 \%$ and without $60 \%$ $(\mathrm{P}<0.01)$. In patients without synchronous metastases, survival with and without an ileus was 40.9 and $68.4 \%$, respectively $(P<0.01)$. If ileus presentation was complicated by a colon blowout, 5 -year survival decreased to $29 \%$. No significant difference was found in patients with synchronous metastases. Survival at 5 years in this subgroup was 10 and $12 \%$ for patients with and without an ileus, respectively $(P=0.705)$.

\section{Conclusions}

Patients with obstructive CRC have a reduced short-term overall survival. Also, longterm overall survival is impaired in patients who present with acute obstructive CRC compared to patients without obstruction. 


\section{Introduction}

Colorectal cancer (CRC) is the third most common type of cancer in the Netherlands ${ }^{1}$. Patients with CRC are often analysed because of abdominal symptoms such as bowel habit changes, bloody stool, unintentional weight loss and anaemia. Approximately $10-28 \%$ of the patients with CRC present with symptoms of an acute obstruction ${ }^{2}$. Symptoms of colorectal obstruction are abdominal (cramping) pain and severe constipation $^{3}$. Obstruction leads to distension of the colorectal wall, which may cause insufficient circulation that in some cases leads to ischaemia and perforation. These patients deteriorate within days after the acute obstruction with poor intake, vomiting and weight loss. In some cases, this is accompanied by severe abdominal pain and sepsis $^{4}$. In cases with obstructing CRC, several treatment modalities can be used. The Dutch Colorectal Audit (DCRA), a nationwide database consisting of all CRCs, shows that the most common treatment options are emergency resection of the tumour (82\%), followed by stenting prior to surgery (11\%) and two-staged surgery (first decompressing colostomy followed by elective resection, $7 \%)^{5}$. These surgical treatment options are mainly applied for obstructive left-sided CRC.

The short-term results after emergency surgery in obstructing CRC show higher morbidity and mortality rates ${ }^{6,7}$. Emergency surgery is an independent risk factor for mortality, which may increase to $41 \%$ in elderly patients with two or more additional risk factors ${ }^{8,9}$. The long-term results show a lower 5-year disease-free survival rate for patients who had emergency colorectal resections versus elective resections ${ }^{10}$. Disease recurrence in patients with obstructing CRC seems to be higher ${ }^{11}$. From the fact that the recurrence rate is significantly higher and the 5-year disease-free survival rate is lower, one may speculate that the overall survival is also impaired in the obstructing CRC group. Limited data is available regarding long-term survival between cases of obstructing and non-obstructing $\mathrm{CRCs}^{12}$. The aim of this study is to assess the long-term survival of patients with acute obstructive CRC causing an ileus compared to patients without obstructing CRC.

\section{Material and methods}

\section{Database and definitions}

This is a single-centre retrospective observational cohort study. The database consisted of patients who underwent surgery for CRC in our hospital between December 2004 and December 2010. This included surgery with curative intent or palliative resections. Patients who underwent oncologic colorectal resection because of an appendix carcinoma or pseudomyxoma peritonei (PMP) were excluded. Demographic-, clinicaland tumour-related data were ascertained from patients' medical charts. Surgical data 
consisted of resection type; these were classified as emergency or elective. In case of an emergency, surgery was performed within $24 \mathrm{~h}$ after diagnoses of acute obstruction. Additionally, follow-up data on systemic metastases and duration of follow-up were collected. Metastases could be diagnosed preoperatively, perioperatively, and during follow-up by imaging and, whenever possible, with histologic confirmation or when described in autopsy reports. Metastases diagnosed before, during and 6 weeks after surgery were defined as synchronous metastases. Metastases diagnosed after 6 weeks were classified as metachronous.

Surgery-related mortality was defined as death within 30 days after surgery. Pathological classification was based on the fifth edition of the TNM classification ${ }^{13}$. The date of death was ascertained by using the Social Security number of the patient in the Municipal Personal Records Database (Gemeentelijke basisadministratie persoonsgegevens (GBA)). Follow-up time was determined from the date of surgery until the date of death or the last date of follow-up. Patients were divided into two groups: ileus and no ileus. Ileus was defined as clinical obstruction and distension of the abdomen. In some cases, this clinical finding could be confirmed by the presence of a dilated colon with computed tomography (CT-scan) or an X-ray of the abdomen; the presence of a dilated colon could also be determined perioperatively. A blowout was diagnosed on a CT-scan showing a perforation of the colon with pneumoperitoneum and/or free fluid or intraabdominal fluid and signs of tumour perforation of the colon during surgery.

\section{Statistics}

We analysed patients' demographics by using the Kolmogorov-Smirnov model to determine if the variables were normally distributed. Data are presented as the means and SD for normally distributed data and as the medians and interquartile ranges (IQR) for non-normally distributed data. The relationships between categorical variables were analysed by a $\chi^{2}$ test. Kaplan-Meier curves were constructed to compare the survival rates between patients with and without an ileus. The statistical outcome between these groups was determined by using the log-rank test. The Mann-Whitney $U$ test was performed to determine the survival rates between patients with and without an ileus at 5 years after surgery. Additional survival analyses were performed in patients with an ileus complicated by a blowout and in patients without synchronous metastases. The primary outcome was overall survival in months. A P value of less than 0.05 was used to indicate significance. We used IBM SPSS Statistics program, version 24.

\section{Compliance with ethical standards}

The Medical Research Ethics Committees United (MEC-U) was consulted for ethical approval. They confirmed that this study (reference number W17,073), the Medical Research Involving Human Subject Act (WMO), does not apply. The institutional review 
board (AMOA) of Amphia Hospital confirmed that no formal written waiver for ethics approval was required.

\section{Results}

A total of 1249 patients underwent surgery for CRC between December 2004 and December 2010. Nine patients were excluded because of incorrect or missing Social Security number.

Four patients were excluded because of appendix carcinoma or PMP. The remaining 1236 patients were included in the analysis (Figure 1).

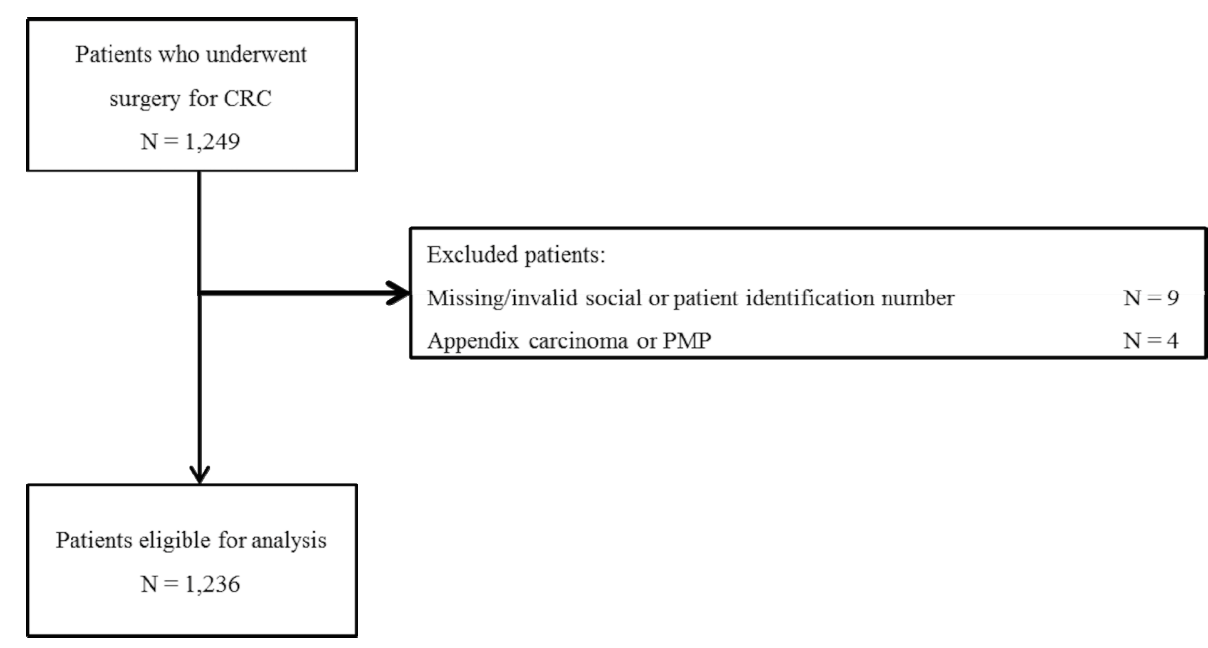

Figure 1. Flowchart of included patients.

CRC: Colorectal cancer; PMP: Pseudomyxoma Peritonei.

\section{Demographics}

Of the 1236 patients, 688 were male (55.6\%) (Table 1). The median age of the patients at the time of diagnosis was 71 years (IQR 62-78 years); median follow-up time was 72 months (IQR 21-97 months). The incidence of patients presenting with an ileus was 178 (14.4\%). 
Table 1 Patient characteristics of 1,236 included patients with colorectal carcinoma.

\begin{tabular}{|c|c|c|c|}
\hline $\begin{array}{l}\text { Patient characteristics } \\
(\mathrm{N}=1,236)\end{array}$ & $\begin{array}{c}\text { No ileus } \\
(\mathrm{N}=1,058)\end{array}$ & $\begin{array}{c}\text { Ileus } \\
(\mathrm{N}=178)\end{array}$ & P-value \\
\hline Gender & & & 0.54 \\
\hline Male & $593(56.0 \%)$ & $95(53.4 \%)$ & \\
\hline Female & 465 (44.0\%) & 83 (46.6\%) & \\
\hline Median age years $\left(\mathrm{IQR}^{1}\right)$ & $70(62-77)$ & $74(65-80)$ & $<0.01$ \\
\hline Surgery $<24$ hours & $44(4.2 \%)$ & $144(80.9 \%)$ & $<0.01$ \\
\hline Re-operation & $150(14.8 \%)$ & 30 (16.9\%) & 0.35 \\
\hline $\mathrm{R} 1 / \mathrm{R} 2$ resection & $14(1.3 \%)$ & $11(6.2 \%)$ & $<0.01$ \\
\hline \multicolumn{4}{|l|}{ Comorbidity (ASA $\left.{ }^{2}\right)$} \\
\hline 1 & $142(13.4 \%)$ & $10(5.6 \%)$ & $<0.01$ \\
\hline II & 577 (54.5\%) & $72(40.4 \%)$ & $<0.01$ \\
\hline III & $325(30.7 \%)$ & $82(46.1 \%)$ & $<0.01$ \\
\hline IV & 14 (1.4\%) & $14(7.9 \%)$ & $<0.01$ \\
\hline \multicolumn{4}{|l|}{ Metastases } \\
\hline Synchronous & $161(15.2 \%)$ & $51(28.7 \%)$ & $<0.01$ \\
\hline Metachronous & $143(13.5 \%)$ & $38(21.3 \%)$ & $<0.01$ \\
\hline No metastases & $754(71.3 \%)$ & $89(50.0 \%)$ & $<0.01$ \\
\hline
\end{tabular}

${ }^{1}$ IQR: Interquartile range; ${ }^{2}$ ASA: American Society of Anaesthesiologists

The most frequently reported location of the tumour was the rectum, followed by the sigmoid and the caecum (Table 2). Metastases were found in 393 patients (32\%), of which 212 (54\%) were synchronous metastases (Table 1). pTNM stadium was missing in 90 (7.3\%) patients because of numerous reasons. In 69 patients, no resection was performed $(76.7 \%)$; in these patients, only colostomy $(\mathrm{N}=58,64.4 \%)$, exploratory laparotomy $(\mathrm{N}=3,3.3 \%)$ or palliative bypass $(\mathrm{N}=8,8.9 \%)$ was performed. In 16 patients $(17.8 \%)$, no vital tumour cells were found. In the remaining five (5.6\%) patients, a preventive colostomy was performed. However, no curative resection could occur because of postoperative death in two patients and progressive disease in the other three patients.

The median age of patients presenting with an ileus was 74 years (IQR 65-80 years) compared to 70 years (IQR 62-77 years) for patients without an ileus $(P<0.01)$. In the patients with ileus, emergency surgery was performed in $144(81.0 \%)$ of the cases compared to $44(4.0 \%)$ patients without ileus $(P<0.01)$. The median follow-up time for patients with and without an ileus was 21 months (IQR 3-77 months) and 76 months (IQR 27-100 months), respectively $(\mathrm{P}<0.01)$. A statistical difference in tumour location was found for the sigmoid colon, hepatic and splenic flexures. Adjuvant chemotherapy was administered in 274 patients (25.6\%). Patients with an ileus received chemotherapy more frequently than patients without an ileus. Palliative chemotherapy was indicated in 20 of the 50 patients (40\%) with an ileus. For the patients without an ileus, in 76 out of the 224 patients (33.9\%), palliative chemotherapy was indicated ( $P=0.06$; Table 2). 
Table 2 Tumour characteristics of included patients categorised as ileus and no ileus.

\begin{tabular}{|c|c|c|c|}
\hline $\begin{array}{l}\text { Tumour characteristics } \\
(\mathrm{N}=1,236)\end{array}$ & $\begin{array}{c}\text { No ileus } \\
(\mathrm{N}=1,058)\end{array}$ & $\begin{array}{c}\text { Ileus } \\
(\mathrm{N}=178)\end{array}$ & P-value \\
\hline \multicolumn{4}{|l|}{ Tumour location } \\
\hline Caecum & $128(12.1 \%)$ & $31(17.4 \%)$ & 0.05 \\
\hline Ascending colon & $118(11.2 \%)$ & $12(6.7 \%)$ & 0.08 \\
\hline Hepatic flexure & 57 (5.4\%) & $17(9.7 \%)$ & 0.03 \\
\hline Transversal colon & $38(3.6 \%)$ & 7 (3.9\%) & 0.82 \\
\hline Splenic flexure & $31(2.9 \%)$ & $15(8.4 \%)$ & $<0.01$ \\
\hline Descending colon & $35(3.3 \%)$ & $6(3.4 \%)$ & 0.96 \\
\hline Sigmoidal colon & $237(22.4 \%)$ & $67(37.6 \%)$ & $<0.01$ \\
\hline Rectum & $374(35.3 \%)$ & $16(9.0 \%)$ & $<0.01$ \\
\hline Double tumour & 40 (3.8\%) & 7 (3.9\%) & 0.92 \\
\hline \multicolumn{4}{|l|}{ Tumour stage } \\
\hline $\mathrm{T} 1$ & $76(7.2 \%)$ & $4(2.2 \%)$ & $<0.01$ \\
\hline $\mathrm{T} 2$ & 247 (23.3\%) & $20(11.3 \%)$ & $<0.01$ \\
\hline T3 & $589(55.7 \%)$ & $98(55.1 \%)$ & 0.79 \\
\hline $\mathrm{T} 4$ & 79 (7.5\%) & $33(18.5 \%)$ & $<0.01$ \\
\hline T missing* & $67(6.3 \%)$ & $23(12.9 \%)$ & $<0.01$ \\
\hline \multicolumn{4}{|l|}{ Nodal stage } \\
\hline NO & 649 (61.3\%) & $79(44.4 \%)$ & $<0.01$ \\
\hline N1 & 209 (19.8\%) & $50(28.1 \%)$ & 0.02 \\
\hline N2 & $133(12.6 \%)$ & $26(14.6 \%)$ & 0.48 \\
\hline $\mathrm{N}$ missing & 67 (6.3\%) & $23(12.9 \%)$ & $<0.01$ \\
\hline \multicolumn{4}{|l|}{ M stage } \\
\hline MO & $863(81.6 \%)$ & 117 (65.7\%) & $<0.01$ \\
\hline M1 & $162(15.3 \%)$ & $53(29.8 \%)$ & $<0.01$ \\
\hline M missing & 33 (3.1\%) & $8(4.5 \%)$ & $<0.01$ \\
\hline \multicolumn{4}{|l|}{ Tumour stadium AJCC** } \\
\hline Stage I & $260(24.6 \%)$ & $14(7.9 \%)$ & $<0.01$ \\
\hline Stage II & $360(34.0 \%)$ & $55(30.8 \%)$ & 0.38 \\
\hline Stage III & $243(23.0 \%)$ & $48(27.0 \%)$ & 0.39 \\
\hline Stage IV & $162(15.3 \%)$ & $53(29.8 \%)$ & $<0.01$ \\
\hline Missing & 33 (3.1\%) & $8(4.5 \%)$ & $<0.34$ \\
\hline 30-day mortality & $47(4.4 \%)$ & $28(15.7 \%)$ & $<0.01$ \\
\hline Adjuvant chemotherapy & & & 0.04 \\
\hline Yes & $224(21.2 \%)$ & $50(28.1 \%)$ & \\
\hline No & $834(78.8 \%)$ & $128(71.9 \%)$ & \\
\hline Palliative chemotherapy & 76 (33.9\%) & 20 (40.0\%) & 0.06 \\
\hline Neo adjuvant therapy & $277(26.2 \%)$ & $12(6.7 \%)$ & $<0.01$ \\
\hline
\end{tabular}

* cT4

** AJCC: American Joint Committee on Cancer.

\section{Survival}

The median overall survival was 82 months (95\% Cl 72-92), and 5-year overall survival was $56 \%$. Five-year overall survival was significantly decreased in patients with an ileus compared to patients without ( 32.0 versus $59.8 \%$, respectively, $\mathrm{P}<0.01$ ) (Figure 2 ). 


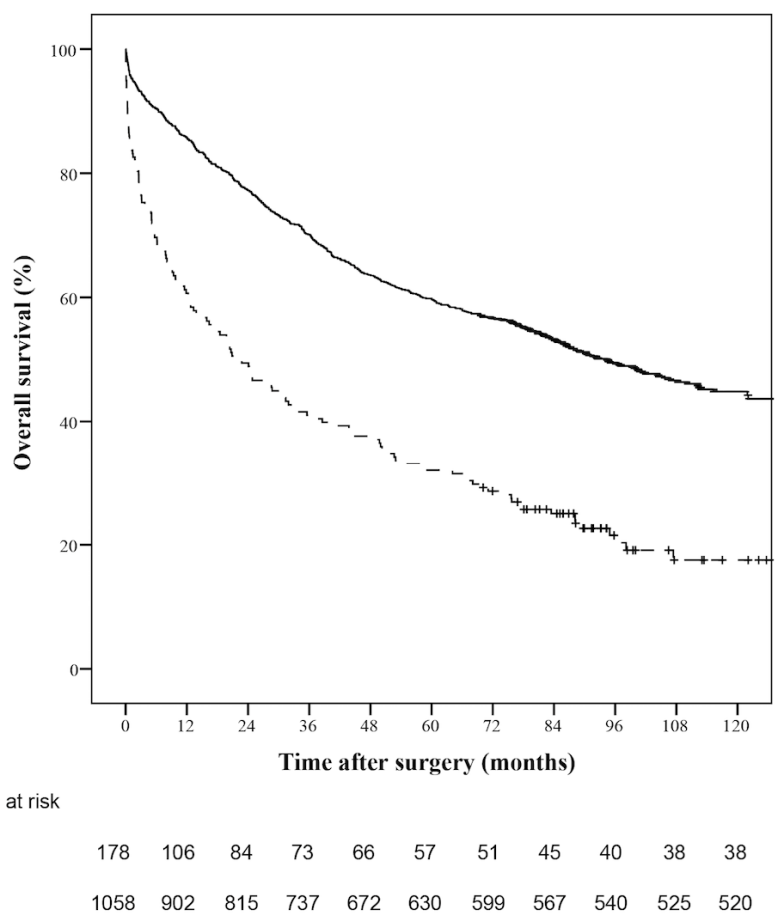

Figure 2 Overall survival (ileus versus no ileus). Kaplan-Meier curve of patients with (dashed line) and without (solid line) an ileus caused by colorectal carcinoma (log-rank test $\mathrm{P}<0.01)$.

Median overall survival for patients with and without an ileus was 22 months $(95 \% \mathrm{Cl}$ 13-31) and 95 months $(95 \% \mathrm{Cl} 82-107)$, respectively. When ileus presentation was complicated by a blowout ( $\mathrm{N}=28)$, 5 -year overall survival decreased to $28.6 \%$ with a median overall survival of 6 months $(95 \% \mathrm{Cl} 0-18)$ (Table 3$)$.

In an additional subgroup analysis, patients with synchronous metastases were excluded. Overall survival was improved in both groups. The 5-year overall survival rates of patients with $(\mathrm{N}=127)$ and without an ileus $(\mathrm{N}=897)$ were 40.9 and $68.4 \%$, respectively $(P<0.01)$. The median overall survival was 128 months $(95 \% \mathrm{Cl} 116-140)$ in the patients without an ileus and 40 months (95\% Cl 21-59) in patients with an ileus. When ileus presentation was complicated by a blowout, 5-year overall survival was $32 \%$ with a median overall survival of 9 months (95\% Cl 0-34) (Figure 3; Table 3). 

Overall survival of included patients, with- and without synchronous metastases.

\begin{tabular}{lccc}
\hline & $\begin{array}{c}\text { 5-yr survival } \\
\text { (\%) }\end{array}$ & $\begin{array}{c}\text { Median overall } \\
\text { survival (months) }\end{array}$ & $\begin{array}{c}\mathbf{9 5 \%} \mathbf{C l} \\
\text { (months) }\end{array}$ \\
\hline Complete group (N=1,236) & 55.8 & 82 & $72-91$ \\
No ileus (N=1,058) & 59.8 & 95 & $82-107$ \\
Ileus (N=178) & 32.0 & 22 & $13-31$ \\
$\quad$ Complicated by blow-out ( $=28)$ & 28.6 & 6 & $0-18$ \\
Patients without synchronous metastases (N=1,024) & $65.0 \%$ & 107 & $93-121$ \\
No ileus (N=897) & $68.4 \%$ & 128 & $116-140$ \\
Ileus (N=127) & $40.9 \%$ & 40 & $21-59$ \\
Complicated by a blow-out ( $=22)$ & $31.8 \%$ & 9 & 034 \\
Patients with synchronous metastases. (N=212) & $11.3 \%$ & 16 & $12-20$ \\
No ileus (N=161) & $11.7 \%$ & 19 & $15-23$ \\
lleus ( $=51$ ) & $9.8 \%$ & 6 & $4-9$ \\
\hline
\end{tabular}

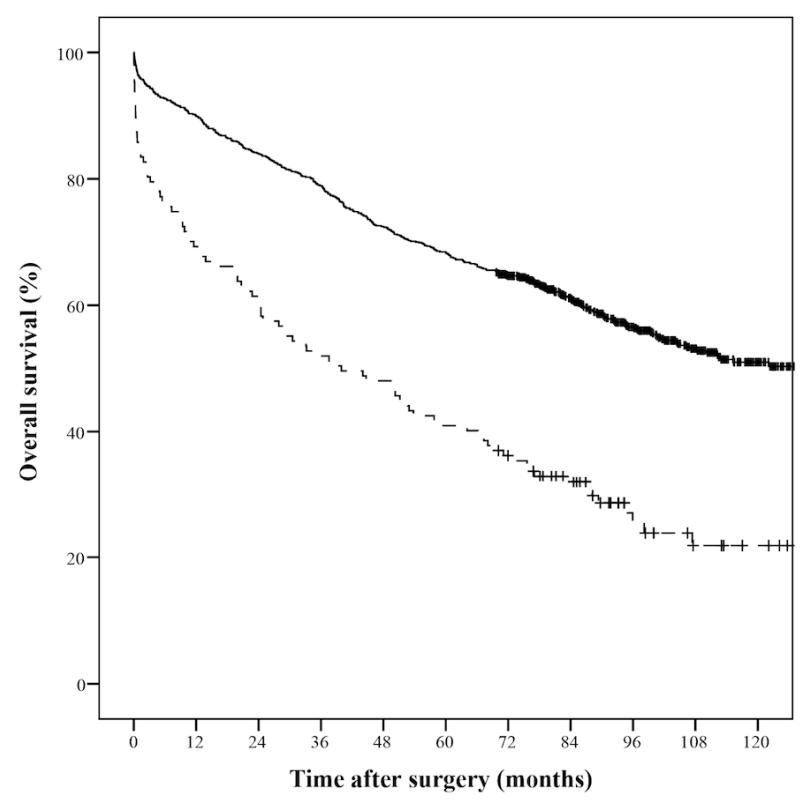

Numbers at risk

$\begin{array}{lrrrrrrrrrrr}\text { lleus } & 127 & 87 & 74 & 66 & 61 & 52 & 46 & 41 & 36 & 34 & 34 \\ \text { No ileus } & 897 & 804 & 756 & 708 & 653 & 615 & 584 & 555 & 528 & 513 & 508\end{array}$

Figure 3 Overall survival in patients without synchronous metastases (ileus versus no ileus). KaplanMeier curve of patients with (dashed line) and without (solid line) an ileus caused by colorectal carcinoma (log-rank test $\mathrm{P}<0.01$ ).

In a second subsequent analysis, only patients with synchronous metastases were included. Survival rates at 5 years with $(\mathrm{N}=51)$ and without an ileus $(\mathrm{N}=161)$ were 9.8 and $11.7 \%$, respectively ( $P=0.705$; Figure 4). The median overall survival was 6 months 
(95\% Cl 4-9) in patients with an ileus compared to a median overall survival of 19 months $(95 \% \mathrm{Cl} 15-23)$ in patients without an ileus (Table 3).

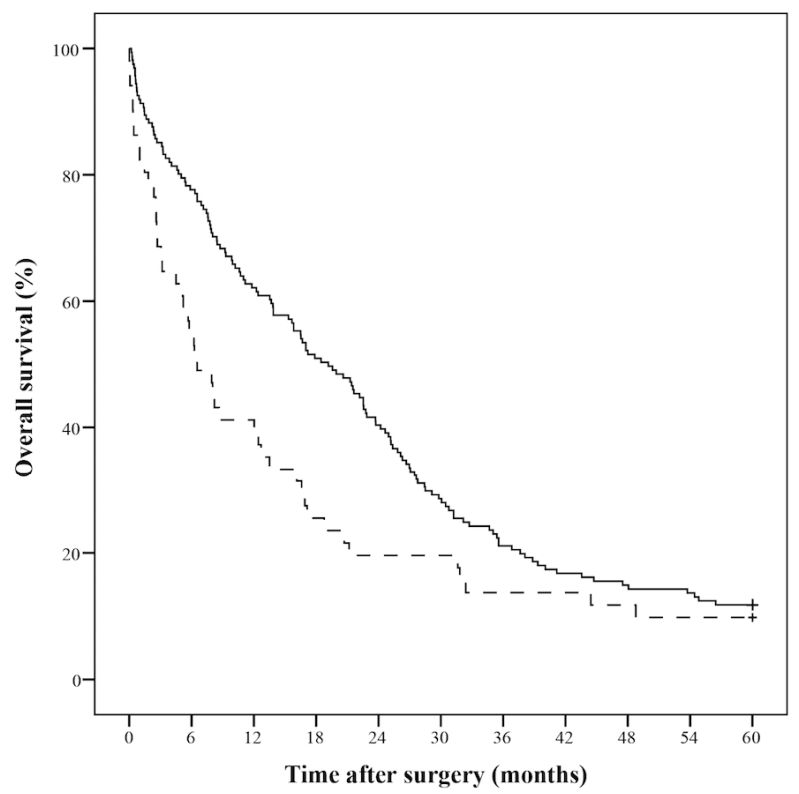

Numbers at risk

$\begin{array}{lccccccccccc}\text { lleus } & 51 & 25 & 19 & 12 & 10 & 10 & 7 & 7 & 5 & 5 & 5 \\ \text { No ileus } & 161 & 122 & 98 & 81 & 63 & 43 & 33 & 27 & 23 & 20 & 19\end{array}$

Figure 4 Overall survival in patients with synchronous metastases (ileus versus no ileus). Kaplan-Meier curve of patients with synchronous metastases categorized as patients with (dashed line) and without (solid line) an ileus caused by colorectal carcinoma (log rank test $\mathrm{P}=0.02$ ).

\section{Discussion}

This single-centre retrospective observational study compared the long-term survival of patients with obstructing CRC to patients without obstructing CRC. We found a lower 5year overall survival rate in patients with obstructing CRC. If obstruction was complicated by a blowout, survival was even worse with a 5 -year survival rate of $28.6 \%$. A significant difference was found in median survival between patients with and without an ileus.

It is already known that the morbidity and mortality rates in patients with obstructing $\mathrm{CRC}$ is worse than in patients with non-obstructing $\mathrm{CRC}^{6,7,9}$. From our large series with a 
follow-up longer than 5 years, it has become clear that the overall survival of patients with acute obstructing CRC is half that of patients without an acute obstruction. Limited data are available in the current literature regarding long-term survival in obstructing CRC. One study showed no difference in long-term survival between obstructing or non-obstructing CRC. In this small cohort, there was a non-significant difference in survival rate in patients with $(\mathrm{N}=80)$ and without $(\mathrm{N}=171)$ an ileus ${ }^{12}$. Patients who underwent emergency surgery for other reasons than blowout were excluded (perforation or abscess). This might be the reason why their study demonstrated a higher 5-year survival rate in the patients with obstruction compared with our series. In addition, patients with middle or low rectal carcinomas were excluded because none of them presented with large bowel obstruction at the time of diagnosis, which can induce selection bias. Wang et al. showed that obstruction is an independent prognostic factor for long-term survival. The 5-year cancer-specific survival rate was significantly lower in patients with an obstruction (46\%) than in patients without an obstruction (83\%) $(P=0.0001)^{14}$. Poor survival outcomes were also found in a recently published retrospective study from Japan. They analysed 234 patients with obstructive CRC with similar tumour locations as those found in our study. The 5-year disease-free survival and cancer-specific survival rates were 50.6 and $80.3 \%$, respectively ${ }^{15}$. They excluded all patients with stage I disease and patients who did not undergo primary resection.

The low survival rate in patients with a blowout was different from the study by Biondo et al. In this small cohort, they specifically determined a difference in outcome between patients with obstructive $(\mathrm{N}=117)$ and perforated colonic cancer $(\mathrm{N}=38)$ who were managed with emergency curative surgery. No differences were found in overall- and cancer-related survival at 5 years ${ }^{16}$. However, they excluded all patients with rectal cancer $<15 \mathrm{~cm}$ from the anal verge and patients who underwent palliative surgery. In our study, three locations (sigmoidal colon, the hepatic and splenic flexures) were more frequently reported in patients with an ileus compared to patients without an ileus; the caecum location was borderline significant. These results are partly in line with those described by Moolla et al. in the South African study; only the sigmoid colon was the most common site ${ }^{17}$. Other authors suggest that the splenic flexure is at greatest risk of obstruction because of angulation ${ }^{3}$. Findings of our study confirm this suggestion. In recent literature, some studies demonstrate no difference between the overall incidences of left- and right sided obstructing $\mathrm{CRC}^{18,19}$.

The definition of ileus varies in published literature, and without a universally accepted definition, tumour locations causing an ileus will continue to vary in future publications. In this study, an ileus was defined as a clinical finding that could be confirmed with radiological findings. Other authors define an ileus as a clinical finding, and when symptoms are vague, obstruction is then defined as colorectal disease requiring emergency surgery ${ }^{17}$. Differences in definition lead to misunderstanding and heterogeneous study populations. Previous studies have shown that obstructing CRC is 
associated with increased rates of distant metastases; this is confirmed in our data $^{6,11,20}$. The overall incidence of both synchronous and metachronous metastases was significantly higher in patients with an ileus. Patient characteristics, subsequent patient and doctor delays, tumour biology and patient immune factors may contribute to this difference. Second, surgery quality may be impaired in patients who undergo emergency surgery compared to patients who undergo elective surgery. Emergency surgery has, as its priority, preserving life and is based on 'damage control'; this could lead to irradical resection margins that cause further tumour proliferation and a higher probability of tumour spread. Emergency surgery could lead to inaccuracy in preoperative staging compared to elective operation patients. In these patients, occult metastases may already be present at the time of emergency surgery, causing a higher incidence rate in patients presenting with obstructive $C R C^{21}$. These theories are based on assumptions and are not evidence-based.

Surveillance of patients after obstructing CRC, however, has a specific importance because of the higher incidence in distant metastases. Patients with obstructive CRC after curative surgery may benefit from a more intensive surveillance programme. Several authors have determined and shown the advantage of an intensive surveillance programme $22-25$.

The strength of our study is the large population with a median follow-up of longer than 5 years. This retrospective study has several limitations. First, we used a database from patients who underwent surgery within a specific time period prior to 2011 . It is important to realize that perioperative morbidity and 30-day mortality have decreased significantly ever since in the Netherlands and in our hospital. Second, patient demographics were significantly different between the ileus and no ileus groups. For example, patients presenting with an ileus were significantly older. Although the difference was only 4 years, this might have influenced the long-term survival in this group negatively because of their lower overall survival profit. In addition, a higher ASA status was found in the ileus group, i.e. their physical condition was more critical than in patients without an ileus, and they were therefore more vulnerable to possible longterm and preoperative and postoperative complications.

\section{Conclusion}

This study provides evidence that patients with obstructive CRC not only have worse short-term survival but also have decreased long-term survival compared to patients who do not present with acute obstruction of the colon. 


\section{References}

1. Elferink MAG, Koopman M, Rütten H, Van de Velde $\mathrm{CJH}$. Colorectaal carcinoom. Kankerzorg in beeld. Amsterdam: 2014 Integraal Kankercentrum Nederland.

2. Ripamonti C, Bruera E. Palliative management of malignant bowel obstruction. Int J Gynecol Cancer. 2002;12:135-143.

3. Phillips RK, Hittinger R, Fry JS, Fielding LP. Malignant large bowel obstruction. Br J Surg 1985;72: 296-302.

4. DeBernardo R. Surgical management of malignant bowel obstruction: strategies toward palliation of patients with advanced cancer. Curr Oncol Rep. 2009;11:287-292.

5. Pieter J. Tanis, Nuno R. Paulino Pereira, Jeanin E. van Hooft, Esther C.J. Consten, Willem A. Bemelman. Resection of Obstructive Left-Sided Colon Cancer at a National Level: A Prospective Analysis of ShortTerm Outcomes in 1,816 Patients. Digestive Surgery. 2015;32 (5):317-324.

6. Smothers L, Hynan L, Fleming J, Turnage R, Simmang C, Anthony T. Emergency surgery for colon carcinoma. Dis Colon Rectum. 2003;46:24-30.

7. Sjo $\mathrm{OH}$, Larsen S, Lunde $\mathrm{OC}$, Nesbakken A. Short term outcome after emergency and elective surgery for colon cancer. Color Dis. 2009;11:733-739.

8. Alves A, Panis Y,Mathieu P,Mantion G, Kwiatkowski F, Slim K. Postoperative mortality and morbidity in French patients undergoing colorectal surgery: results of a prospective multicenter study. Arch Surg. 2005;140:278-283.

9. Kolfschoten NE, Wouters MW, Gooiker GA, Eddes EH, Kievit J, Tollenaar RA. Nonelective colon cancer resections in elderly patients: results from the Dutch Surgical Colorectal Audit. Dig Surg. 2012;29: 412-419.

10. Paulson EC, Mahmoud NN, Wirtalla C, Armstrong K. Acuity and survival in colon cancer surgery. Dis Colon Rectum. 2010;53:385-392.

11. CortetM, Grimault A, Cheynel N, Lepage C, Bouvier AM, Faivre J. Patterns of recurrence of obstructing colon cancers after surgery for cure: a population-based study. Color Dis. 2013;15:1100-1106.

12. Tentes AA, Mirelis CG, Kakoliris S, Korakianitis OS, Bougioukas IG, Tsalkidou EG. Results of surgery for colorectal carcinoma with obstruction. Langenbeck's Arch Surg. 2009;394:49-53.

13. National Collaborating Centre for Cancer (UK). Colorectal cancer: the diagnosis and management of colorectal cancer. National Collaborating Centre for Cancer (UK), National Institute for Health and Clinical Excellence: Guidance, Cardiff. 2011.

14. Wang HS, Lin JK,Mou CY, Lin TC, ChenWS, Jiang JK, Yang SH. Long-term prognosis of patients with obstructing carcinoma of the right colon. Am J Surg. 2004;187:497-500.

15. Atsushi I, Mitsuyoshi O, Kazuya Y, Syuhei K, Noriyuki K, Masashi M. Long-term outcomes and prognostic factors of patients with obstructive colorectal cancer: a multicenter retrospective cohort study. World J Gastroenterol. 2016;22:5237-5245.

16. Biondo S, Kreisler E, Millan M, Fraccalvieri D, Golda T, Marti Rague J et al. Differences in patient postoperative and long-term outcomes between obstructive and perforated colonic cancer. Am J Surg. 2008;195:427-432.

17. Moolla Z,Madiba TE. Trends in demographics and management of obstructing colorectal cancer. World J Surg. 2014;38:2466-2470.

18. Serpell JW, McDermott FT, Katrivessis H, Hughes ES. Obstructing carcinomas of the colon. Br J Surg. 198976:965-969.

19. Lee YM, Law WL, Chu KW, Poon RT. Emergency surgery for obstructing colorectal cancers: a comparison between right sided and left-sided lesions. J Am Coll Surg. 2001;192:719-725,

20. Umpleby HC,Williamson RC. Survival in acute obstructing colorectal carcinoma. Dis Colon Rectum. 1984;27:299-304.

21. McArdle CS, McMillan DC, Hole DJ. The impact of blood loss, obstruction and perforation on survival in patients undergoing curative resection for colon cancer. Br J Surg. 2006;93:483-488

22. Renehan AG, Egger M, Saunders MP, O’Dwyer ST. Impact on survival of intensive follow up after curative resection for colorectal cancer: systematic review and meta-analysis of randomized trials. BMJ. 2002;324:813. 
23. Scholefield JH, Robinson MH, Mangham CM, Hardcastle JD. Screening for colorectal cancer reduces emergency admissions. Eur J Surg Oncol. 1998;24:47-50.

24. Rosati G, Ambrosini G, Barni S, Andreoni B, Corradini G, Luchena G, Daniele B, Gaion F, Oliverio G, Duro M, Martignoni G, Pinna N, Sozzi P, Pancera G, Solina G, Pavia G, Pignata S, Johnson F, Labianca R, Apolone G, Zaniboni A, Monteforte M, Negri E, Torri V, Mosconi P, Fossati R. A randomized trial of intensive versus minimal surveillance of patients with resected Dukes B2-C colorectal carcinoma. Ann Oncol. 2016;27:274-280.

25. Glover C, Douse P, Kane P, Karani J,Meire H, Mohammadtaghi S, Allen-Mersh TG. Accuracy of investigations for asymptomatic colorectal liver metastases. Dis Colon Rectum. 2002;45:476-484. 


\section{Chapter 5}

\section{Colonoscopy surveillance after colorectal cancer: \\ The optimal interval for follow-up}

Winesh Ramphal

Jeske R.E. Boeding

Jennifer M.J. Schreinemakers

Paul D. Gobardhan

Harm J.T. Rutten

Rogier M.P.H. Crolla

Journal of Gastrointestinal Cancer. 2019 Jun 3. [Epub ahead of print].

doi: 10.1007/s12029-019-00254-5 


\section{Abstract}

\section{Purpose}

Patients who have undergone curative surgery for colorectal cancer are at risk of developing a metachronous colorectal tumour or anastomotic recurrence. The aim of this study was to determine the incidence of recurrent colorectal cancer in a cohort of patients who participated in a colonoscopy surveillance programme.

\section{Methods}

This single-centre retrospective observational cohort study included patients who underwent curative surgery for colorectal cancer between 2005 and 2015. All reports of postoperative colonoscopies were retrieved to calculate the incidence rates of recurrence and metachronous colorectal cancer.

\section{Results}

Of 2420 patients, 1644 (67.9\%) underwent at least one postoperative colonoscopy and 776 (32.1\%) did not. In 1087 patients, colonoscopy was performed in the first 18 months after surgery, which detected 34 (3.1\%) instances of metachronous colorectal tumours or anastomotic recurrence. Thirty-three additional patients were also diagnosed with recurrent colorectal cancer, but the tumours were detected by other diagnostic modalities or detected perioperatively, rather than by colonoscopy.

\section{Conclusions}

Patients with a history of colorectal cancer have an increased risk for a second colorectal tumour. Therefore, we recommend a colonoscopic surveillance programme with the first colonoscopy performed 1 year after curative surgery, which is in accordance with national guidelines. 


\section{Introduction}

Patients who have undergone a colorectal resection because of malignancy have a higher risk of developing a metachronous colorectal tumour. These tumours can involve either a second primary colorectal cancer (CRC) or anastomotic recurrence. In the current literature, the reported incidence rates of metachronous CRC after previous curative resection are between 0.6 and $9 \%^{1,2}$. The risk of second primary tumour is approximately $2.5 \%$ within the first 5 years ${ }^{3}$. There are studies that show increasing incidence of metachronous tumours with time in general population and in patients with specified genetic predisposition ${ }^{4,5}$. However, other studies show that the risk of developing metachronous CRC is highest within the first 2 to 3 years after diagnosis ${ }^{6-8}$. Mulder et al. found a cumulative incidence rate of metachronous CRC of $1.1 \%$ after 3 years. This is 1.4 times the incidence rate of CRC in the Netherlands ${ }^{2}$. Therefore, Dutch guidelines were adapted in 2014 to advise that the first colonoscopy surveillance should occur approximately 1 year after curative resection rather than at 2 to 3 years. However, this is a recommendation based on weak evidence ${ }^{8}$. This recommendation complies with international guidelines, which clearly state that a follow-up colonoscopy is indicated after surgery for $\mathrm{CRC}^{9-12}$.

However, the guidelines differ regarding the time interval for monitoring the colon and rectum both for the first postoperative colonoscopy and for subsequent colonoscopies. Furthermore, some studies suggest that early endoscopy does not contribute to the detection of recurrence or metachronous tumours ${ }^{13-15}$. The intervals for prearranged follow-up colonoscopies vary among different clinics and institutions, with both overuse and underuse being reported after resection for $\mathrm{CRC}^{16,17}$. In general, patients who have undergone surgical resection for stage I-III and/or intentional curable stage IV CRC are potential patients for surveillance colonoscopy. Patients with stage IV CRC that is unresectable for cure are generally not candidates for surveillance, because of the poor survival benefit. Preoperative colonoscopy can be incomplete due to tumour obstruction or be absent in some patients. These patients mostly present with an acute bowel obstruction requiring emergency surgical intervention. According to Dutch guidelines, such patients must undergo a completing colonoscopy within 3 months after resection to detect synchronous neoplasia ${ }^{8}$.

To date, no study has analysed the ability of 1-year postoperative surveillance colonoscopy to detect metachronous colorectal tumours or anastomotic recurrences. Since 2005 but before the implementation of routine colonoscopies as per the 2014 guidelines, we had performed the first follow up colonoscopy 1 year after colorectal resection in the majority of our patients. The main aim of this study is to present the results of 11 years of endoscopic follow-up after surgery for CRC. In addition, based on our findings, we provide a recommendation regarding the optimal interval for first colonoscopy surveillance after curative resection. 


\section{Methods}

\section{Data and definitions}

At Amphia Hospital, patients diagnosed with CRC and treated with curative surgery were offered colonoscopy to detect recurrent disease. Patients who were diagnosed and treated between January 2005 and December 2015 were retrospectively reviewed. Our surgical team prospectively collected data on all CRC patients undergoing colorectal surgery because of a malignancy between 2005 and 2010. From 2011 onwards, trained personnel of the National Cancer Registration Centre (Integraal Kanker Centrum Nederland, IKNL) entered the data of CRC patients into the National Dutch Colorectal Audit database (DCRA). Data consisted of patient characteristics, preoperative imaging diagnostics, location of the tumour within the colon and/or rectum and whether or not a complete preoperative colonoscopy was performed. Data regarding surgery included curative surgical treatment. The results regarding postoperative colonoscopies as a part of the surveillance programme, completion colonoscopies, or other imaging techniques that were used to detect colorectal recurrence were retrospectively retrieved from medical charts. Major complications after colonoscopy requiring surgery or postponing colonoscopy were also ascertained. Colonoscopies were deemed complete if the bottom of caecum, ileocaecal valve, or terminal ileum was visualized and reported. Anastomotic recurrence was defined as tumour growth in the previous anastomotic suture line, irrespective of synchronous metastatic or other local recurrence ${ }^{18}$.

Local recurrence was defined as tumour growth outside or inside the colonic/rectal wall, which can extend through this wall with perforation and/or invasion of adjacent organs or structures ${ }^{19}$. Metachronous tumours or second primary tumours were defined as luminal tumours located elsewhere in the colon or rectum at least 6 months after curative surgery for the primary tumour. Preoperative colonoscopy had to be complete in these patients for them to classify a new luminal tumour as metachronous. During follow-up interval, most of the patients were seen by the surgeon every 3 months during the first year and every 6 months thereafter. In the Netherlands, each follow-up visit includes a physical examination, measurement of the serum carcinoembryonic antigen (CEA), ultrasound of the abdomen and chest X-ray. Chest CT, abdominopelvic $\mathrm{CT}$, or positron emission tomography (PET) was performed when there was high suspicion of recurrence of disease on routine imaging studies. Recurrence of disease did not include distant metastases to other organs.

\section{Inclusion and exclusion criteria}

Patients were included if they had undergone surgery for their index CRC between 2005 and 2015. Patients were excluded if they had a previous history of CRC, an appendix carcinoma or pseudomyxoma peritonei (PMP). Patients were also excluded if they had undergone surgery for palliative purposes (palliative resection or debulking, palliative 
bypass, or palliative colostomy/ileostomy due to of obstructing symptoms). Amphia Hospital is a referral centre for (colorectal) liver metastases. Patients who were referred to Amphia Hospital by another hospital because of liver metastasis were also excluded.

\section{Ethical approval}

For ethical approval, we consulted the national institutional review board's Medical research Ethics Committees United (MEC-U). Referring to this study (reference number W17.073), confirmation was received that the Medical Research Involving Human Subject Act (WMO) does not apply; therefore, official approval of this study by the MEC-U was not required under the WMO. We also consulted the institutional review board of Amphia Hospital (AMOA), and they confirmed that no formal written waiver of ethics approval was required, because of the retrospective design of the study.

\section{Statistical analysis}

The Kolmogorov-Smirnov test was used to determine whether the variables were normally distributed. Data are presented as the means and SD for normally distributed data and as medians and interquartile ranges (IQR) for non-normally distributed data. Differences in continuous variables between and among groups were tested using independent $t$ tests and oneway ANOVA, respectively. A two-sided $P$ value of less than 0.05 indicated statistical significance. All of the data analyses were performed with IBM SPSS software, version 24 .

\section{Results}

Between 2005 and 2015, 2750 patients underwent surgery for CRC. In this patient group, 330 patients (12.0\%) were excluded because of non-curative treatment (Table 1). The Remaining 2420 patients (88.0\%) were eligible for analysis (Figure 1). A total of 1340 patients were male.

Table $1 \quad$ Number of excluded patients presented as N (\%).

\begin{tabular}{lc}
\hline Exclusion criteria & $\begin{array}{c}\text { Excluded patients } \\
\mathbf{N = 3 3 0 ~ ( \% * ) ~}\end{array}$ \\
\hline Palliative colostomy/ileostomy & $125(37.9 \%)$ \\
Palliative resection/debulking & $57(17.3 \%)$ \\
Referred liver patient & $42(12.7 \%)$ \\
History of Colorectal cancer & $41(12.4 \%)$ \\
Palliative bypass & $33(10.0 \%)$ \\
Appendix carcinoma/PMP & $17(5.2 \%)$ \\
No surgical intervention & $11(3.3 \%)$ \\
Liver first & $4(1.2 \%)$ \\
\hline
\end{tabular}

\footnotetext{
* Percentage of patients who were excluded
} 


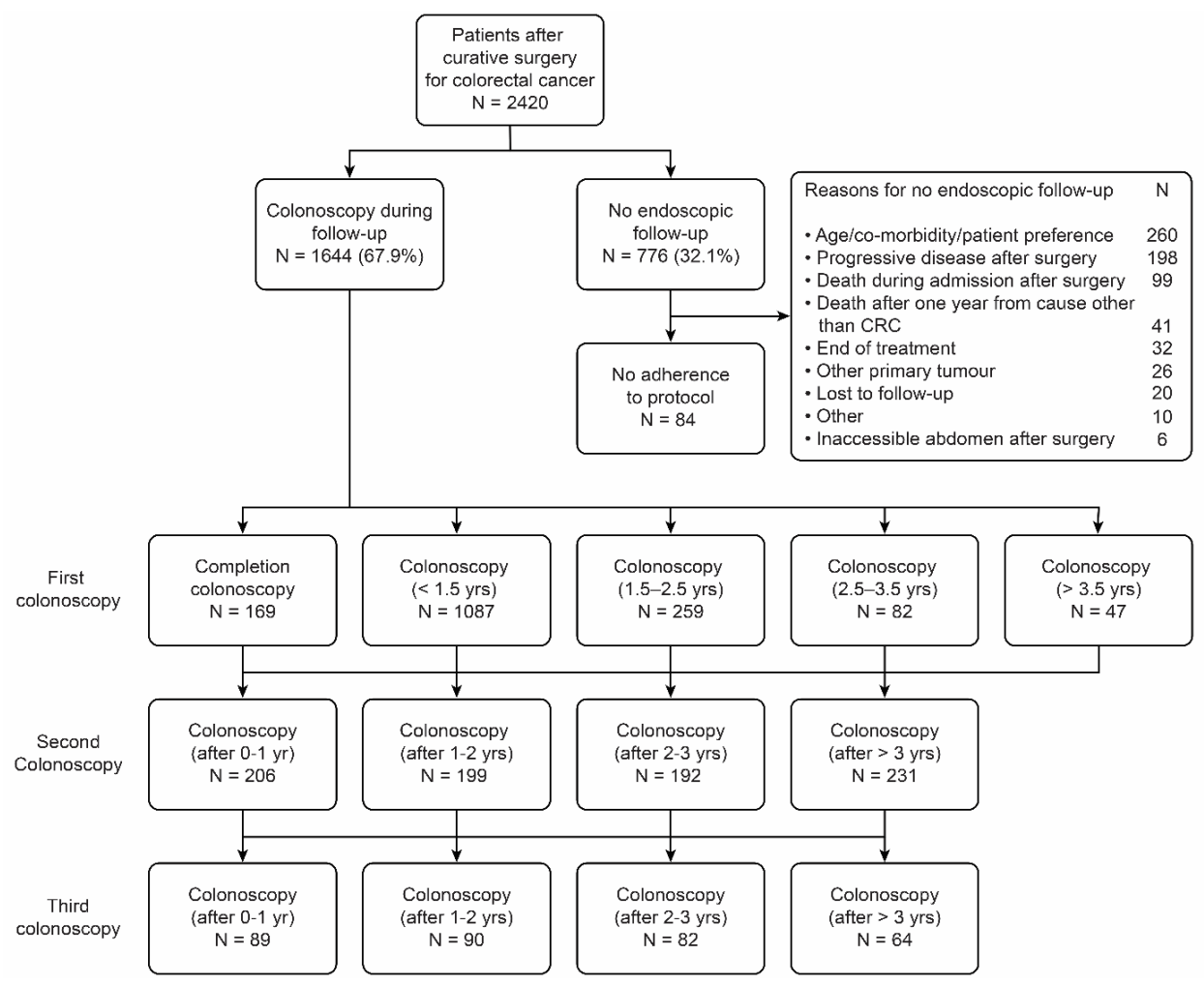

Figure 1 Flowchart of 2420 patients attending follow-up after surgery for colorectal cancer.

Preoperative colonoscopies were complete in 1332 patients (55.0\%). In 279 (11.6\%) patients, no preoperative colonoscopy had been performed. In the remaining 809 (33.4\%) patients, colonoscopy was incomplete mostly due to tumour obstruction. The rectum was the most common tumour location, followed by the sigmoid and caecum. Several types of resections were performed as outlined in Table 2. Among these resections, right hemicolectomy was performed most frequently, followed by low anterior resection and (recto) sigmoidal resection. Among the 2420 patients who had undergone surgery for $\mathrm{CRC}$, eight patients had hereditary nonpolyposis colorectal cancer syndrome (HNPCC), and ten patients had IBD (seven patients with ulcerative colitis and three patients with Crohn's disease). 

resections.

\begin{tabular}{|c|c|}
\hline Type of resection & $\begin{array}{c}\text { Number of patients } \\
\mathrm{N}=\mathbf{2 4 2 0}(\%)\end{array}$ \\
\hline Ileocaecal resection & $36(1.5 \%)$ \\
\hline Right hemicolectomy & $723(29.9 \%)$ \\
\hline Transversal resection & $62(2.6 \%)$ \\
\hline Left hemicolectomy & $167(6.9 \%)$ \\
\hline (Recto)sigmoidal resection & $346(14.3 \%)$ \\
\hline Anterior resection & 117 (4.8\%) \\
\hline Hartmann procedure & $174(7.2 \%)$ \\
\hline Low anterior resection & 495 (20.4\%) \\
\hline Abdominal perineal resection & $230(9.5 \%)$ \\
\hline Subtotal colectomy & $31(1.3 \%)$ \\
\hline Transanal endoscopic microsurgery & $31(1.3 \%)$ \\
\hline Total colectomy with pouch & $1(0.04 \%)$ \\
\hline Total colectomy with ileostomy & $5(0.2 \%)$ \\
\hline Abdominal polypectomy & $2(0.1 \%)$ \\
\hline
\end{tabular}

Of the 2420 patients who had undergone curative surgery, 1644 (67.9\%) had at least one colonoscopy during follow-up. A flowchart is provided in Figure 1. The remaining 776 (32.1\%) patients did not undergo surveillance colonoscopy. The median age was statistical significant lower in het colonoscopy group (67 years (IQR 60-74) vs. 76 years (IQR 68-82), $\mathrm{P}<0.0001$ ). The main reasons for not participating in the colonoscopy surveillance programme were patient related factors, such as advanced age, comorbidity and patient preference.

Follow-up colonoscopy was not performed in patients after a total colectomy with a permanent ileostomy or in patients after trans-anal endoscopic microsurgery (TEM), who underwent endoscopic ultrasound surveillance instead of normal colonoscopy surveillance. These patients are referred to as "other" in Figure 1.

In the first 6 months after resection, 240 patients underwent their first follow-up colonoscopy. One hundred and forty-three (59.6\%) of these patients were subjected to a completing colonoscopy. During these procedures, a total of five synchronous tumours (3.5\%) were detected ( $\mathrm{T} 1$ stadium $\mathrm{N}=3, \mathrm{~T} 3$ stadium $\mathrm{N}=2$ ). In the remaining 97 patients $(40.4 \%)$, colonoscopy was performed as a part of the surveillance programme, and four tumours (4.1\%) were detected, two of them were classified as T1 and the other two tumours as T2. One of these four tumours was an anastomotic recurrence, and the remaining three were primary tumours. In these first 6 months, there were nine patients (3.6\%) who did not participate in the colonoscopy surveillance programme but developed anastomotic recurrence $(N=1)$, local recurrence $(N=7)$, or a second primary tumour $(\mathrm{N}=1)$. These tumours were diagnosed with PET-CT or CT. Most patients had their first follow-up colonoscopy between 6 and 18 months postoperatively $(\mathrm{N}=1016,61.8 \%)$. Twenty-six patients underwent completing colonoscopy, which revealed no additional synchronous tumours. So in the first 
18 months in 169 completing colonoscopies, five synchronous tumours were found (3.0\%). Thirty colorectal tumours were found with colonoscopy in the remaining 990 patients between the first 6 and 18 months (3.0\%). Twenty-four patients were diagnosed with recurrent disease without colonoscopy $(2.3 \%), 22$ patients had local recurrence, one patient had anastomotic recurrence and one patient had a second primary tumour. The results for later time intervals regarding the first postoperative colonoscopy and their findings are given in Table 3. In total, at the first postoperative surveillance endoscopic follow-up, 50 tumours were found among 1475 patients who attended to the colonoscopy surveillance programme and 47 patients in which tumours were detected by other diagnostic imaging modalities (PET-CT, CT, or MRI) or perioperatively (during laparotomy), rather than by colonoscopy $(2.9 \%)$.

Including completing colonoscopies, in 1644 patients who underwent a first follow-up colonoscopy, 55 (3.3\%) colorectal tumours were found (Table 3; Figure 1). The results for later time intervals regarding the second and third postoperative colonoscopy are given in Tables 4 and 5 in the Appendices.

latrogenic perforation that required acute surgery was found in three $(0.14 \%)$ out of 2141 patients who underwent preoperative colonoscopy in this series. Two patients had a right hemicolectomy and one had a transversal resection. In the 2797 postoperative colonoscopies, iatrogenic perforation occurred in four patients, which was followed by emergency surgery $(0.14 \%)$. One patient underwent a sigmoid resection, one patient underwent a right hemicolectomy, and two patients had revision of their colostomy due to a perforation near the colostomy. One of these latter two patients had a complicated course after colonoscopy, with severe abdominal sepsis due to intra-abdominal abscesses and underwent multiple laparotomies requiring prolonged stay at the intensive care unit.

In one case, colonoscopy had to be postponed because of a significant decrease in oxygen levels to below $85 \%$ after sedation was administered. 


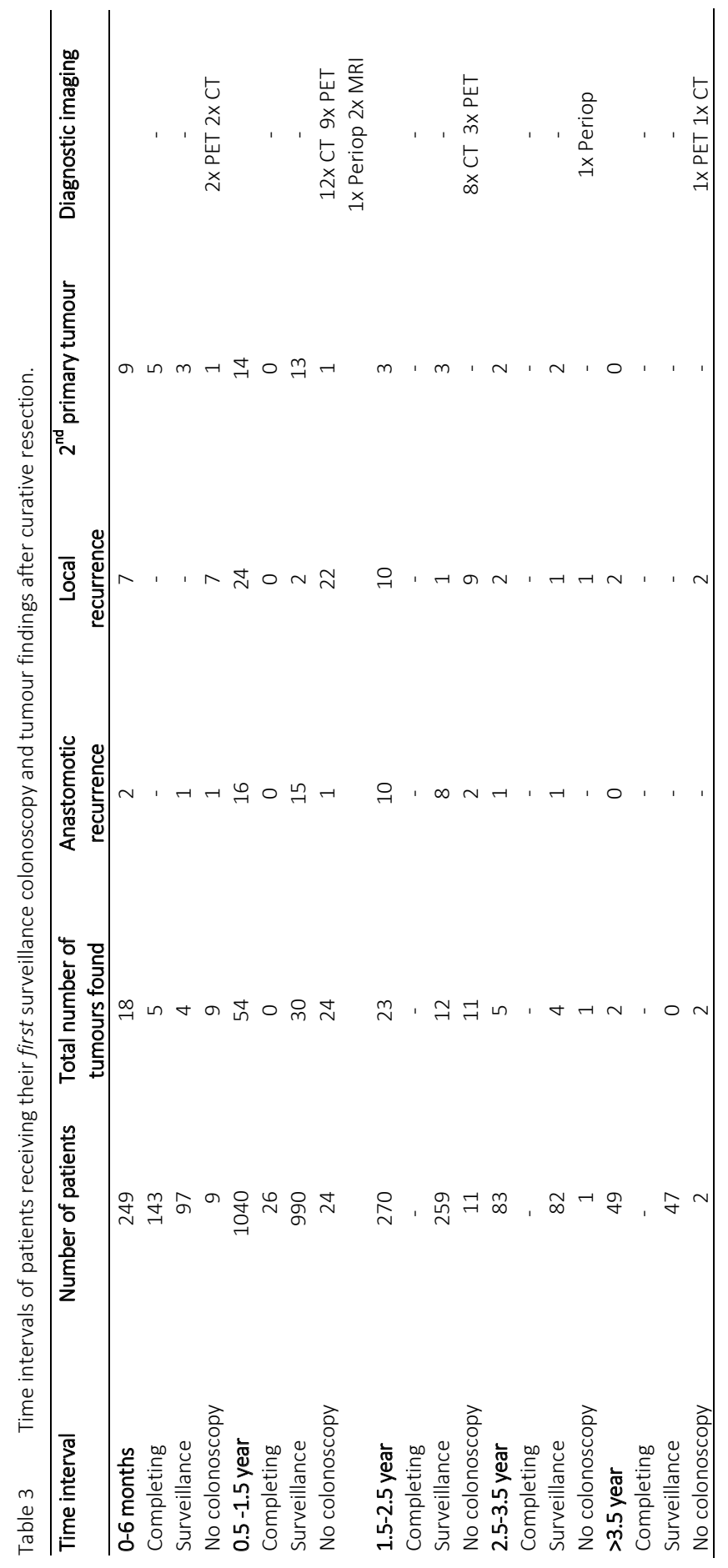




\section{Discussion}

The aim of this study was to determine the incidence of CRC recurrence found by means of endoscopic surveillance after curative resection. We found an incidence of $3.1 \%$ between the first 6 and 18 months postoperative, which is similar to rates in some other cohorts ${ }^{20-22}$, although higher incidence rates between $6.3 \%$ and $41 \%{ }^{23-27}$ and much lower incidence rates between 0.6 and $1.3 \%{ }^{28-30}$ have also been reported.

A comparison of our results with the current literature is challenging for several reasons. First, there is no consensus definition of metachronous and synchronous tumours. In the literature, the time interval used to distinguish between these tumours ranges from 6 months to 3 years after curative surgery. In most reports, metachronous cases are defined as a second CRC at a site other than that of the anastomosis that appeared at least 6 months after primary surgery ${ }^{31}$. However, there are reports that use a different time interval $\left(12\right.$ months $\left.^{30}\right)$ or do not define the time interval ${ }^{20,32}$. Second, there is heterogeneity in the duration of follow-up among different reports, and there are differences among studies in the study population. Some cohorts are based on national CRC databases or patients from multicentre studies, whereas other studies only included patients operated on in a single centre, as with our cohort.

Ninety-seven patients had their first postoperative colonoscopy within 6 months, and four metachronous CRC cases were detected. Remarkably, preoperative colonoscopies in these patients were classified as complete. These tumours were labelled metachronous CRC but could alternatively be considered as synchronous because these lesions might have been undetected and therefore not removed during preoperative colonoscopy. If appropriate endoscopic removal of premalignant lesions is performed at the time of diagnosis of the primary tumour, any lesions found during following colonoscopies are categorized as Metachronous ${ }^{6}$. However, it is possible that some of these synchronous lesions were missed during preoperative colonoscopy, meaning this index colonoscopy should be classified as incomplete. These colonoscopies could be of questionable quality due to poor intestinal preparation. Flat adenomas or depressed lesions have a fairly high malignant potential ${ }^{33,34}$. These adenomas are considered difficult to trace during diagnostic or surveillance colonoscopy, especially when the bowel is poorly prepared.

Another potential explanation for the detection of metachronous CRC in these patients is that the development of CRC was accelerated and aggressive.

In this study, most of the patients received their first postoperative colonoscopy approximately 18 months after curative surgery; this is consistent with Cooper et al. ${ }^{21}$. However, a third of the patients had no surveillance; this might be explained by comorbidity, age, or disease related factors. Unfortunately, in 84 patients $(10.8 \%)$, surveillance was not fulfilled for unknown reasons. Seven of these patients $(8.3 \%)$ 
developed a second CRC with a median time interval of 30 months (range 3-60 months) after curative surgery. These tumours were all classified as local recurrence and were found with PET-CT or CT scan.

The survival benefit to these patients likely would have improved if they had continued to attend at the colonoscopy surveillance programme.

Unfortunately, because of the retrospective nature of this study, no survival analyses could be made because of the high risk of selection bias, as physicians might have discouraged surveillance colonoscopy in patients for whom the potential benefit of surveillance was low.

Such patients have more co-morbidities that other patients or have progressive disease, which increases the risk of death relative to that of healthier patients who did undergo surveillance colonoscopy. Moreover, the patients who were offered colonoscopy were significantly younger than the patients in the no-colonoscopy group. However, there are studies that found a survival benefit compared to patients who did not attend to an endoscopic follow-up programme $e^{30,35-37}$. Three published randomized controlled trials (RCTs) involving intensive follow-up found no benefit compared to a normal surveillance programme $26,27,38$. Three systematic reviews found a higher 5 -year survival with a reduction of mortality of $9-13 \%$ in intensive follow-up group compared with the control group ${ }^{39-41}$. However, in these reviews, intensive follow-up involved all diagnostic modalities within the full follow-up schedule (imaging, CEA and colonoscopy) and do not consider the effects of colonoscopy alone. In one published RCT, comparison among surveillance schedules was performed, with other diagnostic modalities (CEA and imaging) held constant. This trial showed no better survival in patients who attended to an intensive follow-up schedule ${ }^{42}$.

In this study, local recurrences were included, which do not necessarily grow intraluminally. Endoscopic surveillance alone would not be useful enough for patients with local recurrence; therefore, other imaging techniques should be part of a surveillance programme ${ }^{43,44}$. In the first 18 months after curative surgery, we detected 33 tumours with imaging (PET-CT, CT and MRI) and one CRC perioperatively. This case concerns an 89-year-old male who presented with an ileus and underwent emergency surgery because of a pelvic tumour which was grown into the small intestines. After the total follow-up time, 77 tumours were found with other imaging modalities (Tables 3, 4 and 5).

In general, it is recommended to perform a preoperative diagnostic colonoscopy and a colonoscopy after curative surgery for CRC during follow-up. Unfortunately, colonoscopy entails some risk of complications, as well as patient discomfort during preparation and the procedure itself. Complications can be mild, such as a minor bleeding, which can be solved with clipping and/or local adrenaline injections, but they can also be severe, requiring emergency surgery. The incidence of iatrogenic 
perforation was $0.14 \%$ for both preoperative and surveillance colonoscopies. This is near the complication norm of the Dutch guidelines $(<0.1 \%)^{8,45}$.

Early surveillance colonoscopy 1 year after curative surgery can be a cost-effective measure and thereby reduce medical costs ${ }^{46,47}$. However, to evaluate the optimal frequency and interval for surveillance colonoscopy, a prospective multicentre study should be performed to evaluate the results of colonoscopy after surgery. To evaluate and determine efficient surveillance colonoscopy intervals, current colonoscopy guidelines should be evaluated by an RCT in which patients, who undergo colonoscopy early after 3 or 6 months postoperatively, are compared with those undergoing normal surveillance colonoscopy after 1,3 and 5 years.

There are several biases in this retrospective observational cohort. Because of the retrospective design of this cohort, there was no randomization of patients. In addition, no distinction was made between colon and rectum among different age groups. Furthermore, no reliable distinction could be made between colonoscopies that were routine procedures in asymptomatic surveillance patients and those that were indicated based on developed symptoms or physical or laboratory findings. Additionally, the frequency and intervals of subsequent follow-up colonoscopy varied in our study population. Finally, it is globally accepted that most colorectal malignancies arise from adenomas and that screening or surveillance colonoscopy is recommended for the early detection of these adenomas or polyps. Such screening could lead to the detection of endoscopically curable stages of these lesions and avoid second operations. In this study, only malignant findings were analysed. Unfortunately, data regarding the numbers of detected advanced adenomas or polypectomies and their polyp characteristics including histology and size are not present in our database.

In conclusion, the results of this study indicate that it is relevant to perform colonoscopy for CRC to screen for anastomotic recurrence and metachronous tumours. We recommend a short-term surveillance colonoscopy approximately 1 year after curative surgery. 


\section{Appendices}
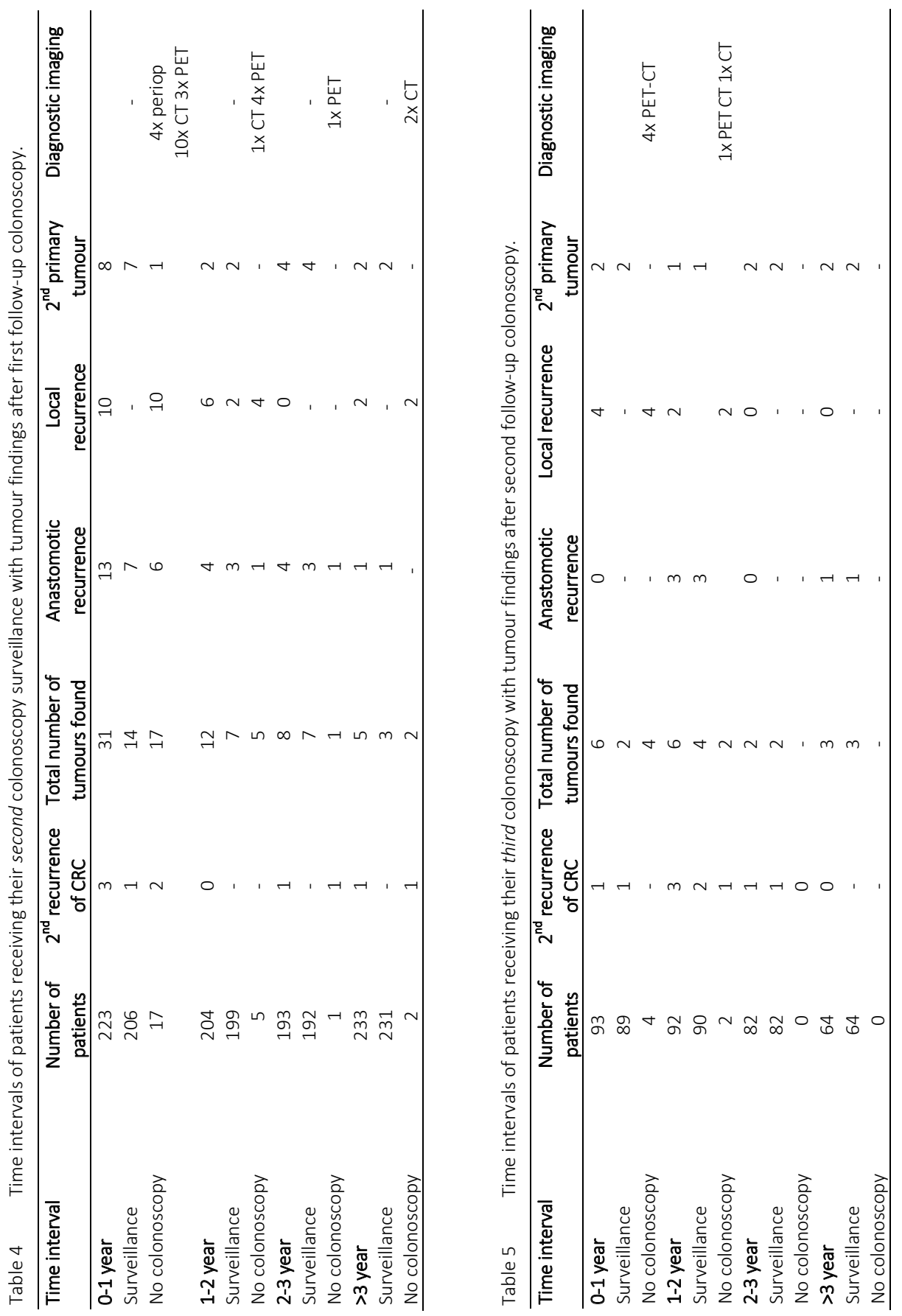


\section{References}

1. Bouvier AM, Latournerie M, Jooste V, Lepage C, Cottet V, Faivre J. The lifelong risk of metachronous colorectal cancer justifies long-term colonoscopic follow-up. Eur J Cancer. 2008;44:522-527.

2. Mulder SA, Kranse R, Damhuis RA, Ouwendijk RJ, Kuipers EJ, van Leerdam ME. The incidence and risk factors of metachronous colorectal cancer: an indication for follow-up. Dis Colon Rectum. 2012;55: 522-531.

3. le Clercq C, Bouwens M, Riedl R, Beets GL, Winkens B, Hameeteman W, et al. Incidence and potential causes for metachronous colorectal cancer: a 10-year retrospective survey. Gastroenterology. 2012;142:S-81.

4. Jayasekara H, Reece JC, Buchanan DD, Rosty C, Dashti SG, Ait Ouakrim D, et al. Risk factors for metachronous colorectal cancer following a primary colorectal cancer: a prospective cohort study. Int J Cancer. 2016;139:1081-1090.

5. Parry S, Win AK, Parry B, Macrae FA, Gurrin LC, Church JM, et al. Metachronous colorectal cancer risk for mismatch repair gene mutation carriers: the advantage of more extensive colon surgery. Gut. 2011;60:950-957.

6. Rex DK, Kahi CJ, Levin B, Smith RA, Bond JH, Brooks D, et al. Guidelines for colonoscopy surveillance after cancer resection: a consensus update by the American Cancer Society and the US Multi-Society Task Force on Colorectal Cancer. Gastroenterology. 2006;130:1865-1871.

7. Couch DG, Bullen N, Ward-Booth SE, Adams C. What interval between colorectal cancer resection and first surveillance colonoscopy? An audit of practice and yield. Color Dis. 2013;15:317-322.

8. Dutch Guidelines colonoscopy surveillance. Nederlandse Vereninging van Maag-, Darm en Leverartsen in samenwerking met Nederlandse Vereniging van Pathologie. https://www.mdl.nl/sites/www.mdl.nl/ files/richlijnen/Richtlijn_Coloscopie_Surveillance_definitief_2013.pdf.

9. Engstrom, PF., Arnoletti, JP., Benson, AB 3rd., Chen, YJ., Choti, MA., Cooper HS et al. National Comprehensive Cancer Network. NCCN clinical practice guidelines in oncology: colon cancer. J Natl Compr Cancer Netw. 2009;7:778-831.

10. Cairns SR, Scholefield JH, Steele RJ, Dunlop MG, Thomas HJ, Evans GD, et al. Guidelines for colorectal cancer screening and surveillance in moderate and high risk groups (update from 2002). Gut. 2010; 59:666-689.

11. Labianca, R., Nordlinger, B., Beretta, GD., Brouquet, A., Cervantes, A. ESMO Guidelines Working Group. Primary colon cancer: ESMO clinical practice guidelines for diagnosis, adjuvant treatment and followup. Ann Oncol. 2010;21:70-77.

12. Poston GJ, Tait D, O'Connell S, Bennett A, Berendse S. Guideline Development Group. Diagnosis and management of colorectal cancer: summary of NICE guidance. Br Med J. 2011;343: d6751.

13. Khoury DA, Opelka FG, Beck DE, Hicks TC, Timmcke AE, Gathright JB. Colon surveillance after colorectal cancer surgery. Dis Colon Rectum. 1996;39:252-256.

14. Patchett SE, Mulcahy HE, O'Donoghue DP. Colonoscopic surveillance after curative resection for colorectal cancer. Br J Surg. 1993;80:1330-1332.

15. Barrier A, Houry S, Huguier M. The appropriate use of colonoscopy in the curative management of colorectal cancer. Int J Color Dis. 1998;13:93-98.

16. Singh A, Kuo YF, Goodwin JS. Many patients who undergo surgery for colorectal cancer receive surveillance colonoscopies earlier than recommended by guidelines. Clin Gastroenterol Hepatol. 2013;11:65-72.

17. Cooper GS, Doug Kou T. Underuse of colorectal cancer screening in a cohort of Medicare beneficiaries. Cancer. 2008;112:293-299.

18. Jung WB, Yu CS, Lim SB, Park IJ, Yoon YS, Kim JC. Anastomotic recurrence after curative resection for colorectal cancer. World J Surg. 2017;41:285-294.

19. Landmann RG, Weiser MR. Surgical management of locally advanced and locally recurren colon cancer. Clin Colon Rect Surg. 2005;18:182-189.

20. Bülow S, Svendsen LB, Mellemgaard A. Metachronous colorectal carcinoma. Br J Surg. 1990;77: 502-505.

21. Cooper GS, Yuan Z, Chak A, Rimm AA. Patterns of endoscopic follow-up after surgery for nonmetastatic colorectal cancer. Gastrointest Endosc. 2000;52:33-38. 
22. Lee SY, Kim BC, Han KS, Hong CW, Sohn DK, Park SC, et al. Incidence and risk factors of metachronous colorectal neoplasm after curative resection of colorectal cancer in Korean patients. J Dig Dis. 2014;15:367-376.

23. Barillari P, Ramacciato G, Manetti G, Bovino A, Sammartino P, Stipa V. Surveillance of colorectal cancer: effectiveness of early detection of intraluminal recurrences on prognosis and survival of patients treated for cure. Dis Colon Rectum. 1996;39:388-393.

24. Granqvist S, Karlsson T. Postoperative follow-up of patients with colorectal carcinoma by colonoscopy. Eur J Surg. 1992;158:307-312.

25. Cali RL, Pitsch RM, Thorson AG, Watson P, Tapia P, Blatchford GJ, et al. Cumulative incidence of metachronous colorectal cancer. Dis Colon Rectum. 1993;36:388-393.

26. Schoemaker D, Black R, Giles L, Toouli J. Yearly colonoscopy, liver CT, and chest radiography do not influence 5-year survival of colorectal cancer patients. Gastroenterology. 1998;114:7-14.

27. Mäkelä JT, Laitinen SO, Kairaluoma MI. Five-year follow-up after radical surgery for colorectal cancer. Results of a prospective randomized trial. Arch Surg. 1995;130:1062-1067.

28. Cianchi F, Messerini L, Palomba A, Boddi V, Perigli G, Pucciani F, et al. Character of the invasive margin in colorectal cancer: does it improve prognostic information of Dukes staging? Dis Colon Rectum. 1997;40:1170-1175.

29. Green RJ, Metlay JP, Propert K, Catalano PJ,Macdonald JS, Mayer RJ, et al. Surveillance for second primary colorectal cancer after adjuvant chemotherapy: an analysis of Intergroup 0089. Ann Intern Med. 2002;136:261-269.

30. Sakamoto T, Matsuda T, Nakajima T, Saito Y. How often should we perform surveillance colonoscopy after surgery for colorectal cancer? Int J Color Dis. 2013;28:835-840.

31. Moertel CG, Bargen JA, Dockerty MB. Multiple carcinomas of the large intestine: a review of the literature and a study of 261 cases. Gastroenterology. 1958;34:85-98.

32. Fukutomi Y, Moriwaki H, Nagase S, Tajika M, Naito T, Miwa Y, et al. Metachronous colon tumors: risk factors and rationale for the surveillance colonoscopy after initial polypectomy. J Cancer Res Clin Oncol. 2002;128:569-574.

33. Soetikno RM, Kaltenbach T, Rouse RV, Park W, Maheshwari A, Sato T, et al. Prevalence of non polypoid (flat and depressed) colorectal neoplasms in asymptomatic and symptomatic adults. JAMA. 2008; 299:1027-1035.

34. Matsuda T, Saito Y, Hotta K, Sano Y, Fujii T. Prevalence and clinicopathological features of nonpolypoid colorectal neoplasms: should we pay more attention to identifying flat and depressed lesions? Dig Endosc. 2010;22:57-62.

35. Winawer SJ, Zauber AG, Ho MN, O’Brien MJ, Gottlieb LS, Sternberg SS, et al. Prevention of colorectal cancer by colonoscopic polypectomy. The National Polyp Study Workgroup. N Engl J Med. 1993;329:1977-1981.

36. Zauber AG, Winawer SJ, O’Brien MJ, Lansdorp-Vogelaar I, van Ballegooijen M, Hankey BF, et al. Colonoscopic polypectomy and long-term prevention of colorectal-cancer deaths. N Engl J Med. 2012;366:687-696.

37. Citarda, F., Tomaselli, G., Capocaccia, R., Barcherini, S, and Crespi, M. Italian Multicentre Study Group. Efficacy in standard clinical practice of colonoscopic polypectomy in reducing colorectal cancer incidence. Gut. 2001;48:812-815.

38. Kjeldsen BJ, Kronborg O, Fenger C, Jørgensen OD. A prospective randomized study of follow- up after radical surgery for colorectal cancer. Br J Surg. 1997;84:666-669.

39. Renehan AG, Egger M, Saunders MP, O’Dwyer ST. Impact on survival of intensive follow up after curative resection for colorectal cancer: systematic review and meta-analysis of randomised trials. BMJ. 2002;324:813.

40. Figueredo A, Rumble RB, Maroun J, Earle CC, Cummings B, McLeod R, et al. Follow-up of patients with curatively resected colorectal cancer: a practice guideline. BMC Cancer. 2003;3:26.

41. Jeffery M, Hickey BE, Hider PN. Follow-up strategies for patients treated for non-metastatic colorectal cancer. Cochrane Database Syst Rev. 2007;(1). https://doi.org/10. 1002/14651858.CD002200.pub2.

42. Wang T, Cui Y, Huang WS, Deng YH, Gong W, Li CJ, et al. The role of postoperative colonoscopic surveillance after radical surgery for colorectal cancer: a prospective, randomized clinical study. Gastrointest Endosc. 2009;69:609-615. 
43. Barkin JS, Cohen ME, Flaxman M, Lindblad AS,Mayer RJ, Kalser MH, et al. Value of a routine follow-up endoscopy programfor the detection of recurrent colorectal carcinoma. Am J Gastroenterol. 1988;83: 1355-1360.

44. Kronborg O. Optimal follow-up in colorectal cancer patients: what tests and how often? Semin Surg Oncol. 1994;10:217-224.

45. BCSPQuality Assurance Endoscopy Group. Quality assurance guidelines for colonoscopy. NHS Cancer Screening Programmes 2011.

46. Hassan C, Pickhardt PJ, Zullo A, Di Giulio E, Laghi A, Kim DH, et al. Cost-effectiveness of early colonoscopy surveillance after cancer resection. Dig Liver Dis. 2009;41:881-885.

47. Lan YT, Lin JK, Li AF, Lin TC, Chen WS, Jiang JK, et al. Metachronous colorectal cancer: necessity of postoperative colonoscopic surveillance. Int J Color Dis. 2005;20:121-125. 


\section{Chapter}

Serum carcinoembryonic antigen to predict recurrence in the follow-up of patients with

colorectal cancer

Winesh Ramphal

Jeske R.E. Boeding

Maartje van Iwaarden

Jennifer M.J. Schreinemakers

Harm J.T. Rutten

Rogier M.P.H. Crolla

Paul D. Gobardhan

International Journal of Biological Markers. 2019;34(1):60-6 


\begin{abstract}
Introduction

Serum carcinoembryonic (CEA) antigen is used as a diagnostic screening tool during follow-up in colorectal cancer patients. However, it remains unclear whether preoperative serum CEA is a reliable marker in the follow-up to predict recurrence. The aim of the study is to determine the value of elevated pre- and postoperative serum carcinoembryonic antigen levels (CEA > $5 \mu \mathrm{g} / \mathrm{L}$ ) as an independent prognostic factor for locoregional and distant recurrence in patients who underwent curative surgery for colorectal cancer.
\end{abstract}

\title{
Methods
}

This single centre retrospective observational cohort study includes patients who underwent curative surgery for colorectal cancer between 2005 and 2015 and had preand postoperative serum CEA measurements. Five-year disease-free survival and multivariate Cox regression analyses were performed to adjust for confounding factors.

\section{Results}

Preoperative serum CEA level was measured in 2093 patients with colorectal cancer. No significant association was found between an elevated preoperative serum CEA and locoregional recurrence (adjusted hazard ratio (HR) 1.29 (95\% confidence interval (CI) $0.91,1.84 ; \mathrm{P}=0.26)$ ). However, a significant association was found between an elevated preoperative serum CEA and systemic recurrence (adjusted HR 1.58 (95\% Cl 1.25, 2.00; $P<0.01)]$. The five-year disease-free survival was lower in patients with elevated preoperative serum CEA levels $(P<0.01)$. Postoperative serum CEA level was the most sensitive for hepatic metastases during follow-up (73.3\%).

\section{Conclusions}

The preoperative serum CEA level is an independent prognostic factor for systemic metastasis after curative surgery for colorectal cancer in patients with stage I-III disease. The level is the most sensitive for hepatic metastasis compared to metastasis to other anatomic sites. 


\section{Introduction}

Serum carcinoembryonic (CEA) is a set of glycoproteins involved in cell adhesion ${ }^{1}$. CEA levels can be elevated not only in patients with malignancies, such as colorectal cancer (CRC), but also in patients with breast, lung, and pancreatic cancer. Increased levels of CEA are also detected in patients with chronic renal failure, colitis, diverticulitis, and pneumonia, and in smokers ${ }^{2,3}$.

In most patients who are diagnosed with CRC, CEA blood levels are elevated and tend to decrease after successfully curative surgery and/or adjuvant treatment. Elevated preoperative serum CEA levels have been found to be associated with poor oncologic prognosis in patients with $\mathrm{CRC}^{4-11}$ An early study on CEA showed an association between tumor stage and elevated CEA. On the other hand, there is an inverse relationship between CEA levels and tumor grade: well-differentiated tumors tend to produce more CEA than poorly differentiated tumours ${ }^{12}$.

CEA has no value in screening for bowel cancer as the positive predictive value is too low $^{13}$. However, measuring CEA during postoperative follow-up is common because CEA levels may rise with cancer recurrence, which is important for early detection, treatment at a curable stage, and therefor to improve survival ${ }^{14,15}$. In the Netherlands, the follow-up program for CRC consists of a physical examination, imaging with an abdominal ultrasound and chest $x$-ray and serum testing for the tumor marker CEA ${ }^{16}$. International guidelines recommend measuring CEA in intervals of 3 to 6 months after surgical treatment for $\mathrm{CRC}^{17-21}$. When CEA levels are elevated, further investigation is indicated typically with a computed Tomography (CT) scan of the chest, abdomen and/or pelvis, or a positron emission tomography (PET)-CT scan.

Some authors suggest that CEA levels appear to be the most sensitive for identifying hepatic and retroperitoneal located metastases and the least sensitive for local recurrence and peritoneal or pulmonary metastases ${ }^{22-24}$. Therefore, during the followup period, CEA is used as a diagnostic screening tool; when the CEA blood level is elevated, the physician is alerted to initiate further investigation through imaging ${ }^{17,25}$.

Given the inconsistencies of CEA levels between tumor stage and tumor grade, it remains unclear if preoperative serum CEA levels provide accurate information regarding locoregional and distant recurrence during follow-up. The main aim of this study was to evaluate the role of preoperative CEA levels as an independent predictor for locoregional and systemic recurrence in patients who previously underwent curative surgery for CRC. The secondary aim was to determine the role of postoperative serum CEA level measurement during follow-up in patients who had undergone curative surgery for CRC. 


\section{Material and methods}

This is a single centre retrospective observational cohort study of patients with CRC. Data of patients who underwent curative surgery between January 2005 and December 2015 were retrospectively reviewed. Data of CRC patients between 2005 and 2010 were assembled by the surgical team. Data of patients who underwent surgery in the Amphia Hospital for CRC between 2011 and 2015 were retrieved from the National Cancer Registration Centre (Integraal Kanker Centrum Nederland, IKNL). Demographic data and data regarding surgery (type of resection and location) were obtained from medical charts.

Preoperative serum CEA levels and CEA levels at the time of diagnosis of cancer recurrence were retrieved. Before July 2015, all CEA samples were analyzed with the Siemens Immulite ${ }^{\circledR} 2000$ CEA assay (Siemens Healthcare Diagnostics Ltd, Llanberis, Wales). After July 2015, all CEA samples were analyzed with the Roche Diagnostics CEA Elecsys $^{\circledR}$ cobas e601 (Roche Diagnostics Ltd, Rotkreuz, Switzerland). Method comparison showed that the two methods agree, with nonsignificant bias between them (data not shown). Serum CEA levels between 0 and $5 \mu \mathrm{g} / \mathrm{L}$ were considered as normal.

Pathology results were retrieved to obtain tumor grade and whether a radical resection of the tumor was achieved (R0 resection). Pathological classification was based on the fifth edition of the tumor-node-metastasis (TNM) classification ${ }^{26}$. All patients with recurrent disease were confirmed with histological examination whenever possible, or otherwise by diagnostic imaging or with surgery. Locoregional recurrence was defined as tumor growth inside (luminal) or outside the colonic/rectal wall, which can extend through the wall to cause perforation and/or invasion of adjacent organs or structures ${ }^{27}$. Recurrences in other anatomic sites were defined as systemic recurrence or distant metastases. Patients were followed up every 3 to 6 months for 5 years by the surgeon. Each follow-up visit included a physical examination, a CEA blood level, an ultrasound of the abdomen, and a chest x-ray. A chest CT, abdominopelvic CT, or PETCT scan was performed when there was high suspicion of recurrence of disease on routine studies. Colonoscopy surveillance was performed approximately 1 year after curative resection and 3 years after the first postoperative colonoscopy. In case of incomplete preoperative visualization of the colon, a completing colonoscopy was performed within 3 months postoperatively. Date of death was confirmed in the Dutch Municipal Personal Records Database (Gemeentelijkebasisadministratie persoonsgegevens, GBA with their software program CompeT\&TEindhoven) using the patient's social security number. 


\section{Inclusion and exclusion criteria}

Patients were included if they underwent colorectal surgery for a malignancy between 2005 and 2015. Patients were excluded if they had an oncologic resection of an appendix carcinoma or pseudomyxoma peritonei (PMP). Patients were also excluded when they had surgery for palliative purposes (palliative resection or debulking, palliative bypass, and palliative colostomies/ileostomies because of obstructing symptoms). Patients with no preoperative serum CEA measurements were also excluded.

\section{Ethical approval}

Ethical approval was obtained from the National Institutional Review Board Medical Research Ethics Committees United (MEC-U). Official approval of this study by the MEC$\mathrm{U}$ was not required because the Medical Research Involving Human Subject Act under the wet medisch-wetenschappelijk onderzoek (WMO) does not apply to this study (reference number W17.073). The Institutional Review Board of Amphia Hospital (AMOA) confirmed that no formal written waiver for an ethics approval was required.

\section{Statistics}

The Kolmogorov-Smirnov test was used to determine if the data were normally distributed. Data were depicted as the mean and SD for normally distributed data, and median and interquartile range (IQR) for non-normal distributions. The $\chi^{2}$ test was used to compare categorical variables. Five-year disease-free survival analysis was performed with Kaplan-Meier curves for elevated and non-elevated preoperative serum CEA levels. The log rank test was used to test statistical outcomes between these two groups. Cox proportional hazard models were used to estimate independent effect of covariates on locoregional and distant recurrence as measured by adjusted hazard ratio (HR) with a $95 \%$ confidence interval $(\mathrm{Cl})$. Variables that were statistically significant in the univariate Cox regression and/or had clinical relevance were included in the multivariate analysis. A two-sided P-value of less than 0.05 was used to indicate statistical significance. All data analyses were performed with IBM SPSS Statistics Program, version 24.

\section{Results}

Between 2005 and 2015, 2704 patients underwent oncologic colorectal surgery. Of this patient group, 284 patients were excluded. A total of 2420 patients underwent curative resection for $C R C$ and 327 patients were excluded because of the absence of preoperative serum CEA measurements. The remaining 2093 patients were eligible for 
analysis (Figure 6.1). The median age was 69 years (IQR 62-76) and 1209 of them were male (57.8\%, Table 6.1). Median follow-up duration was 43 months (IQR 24-76).

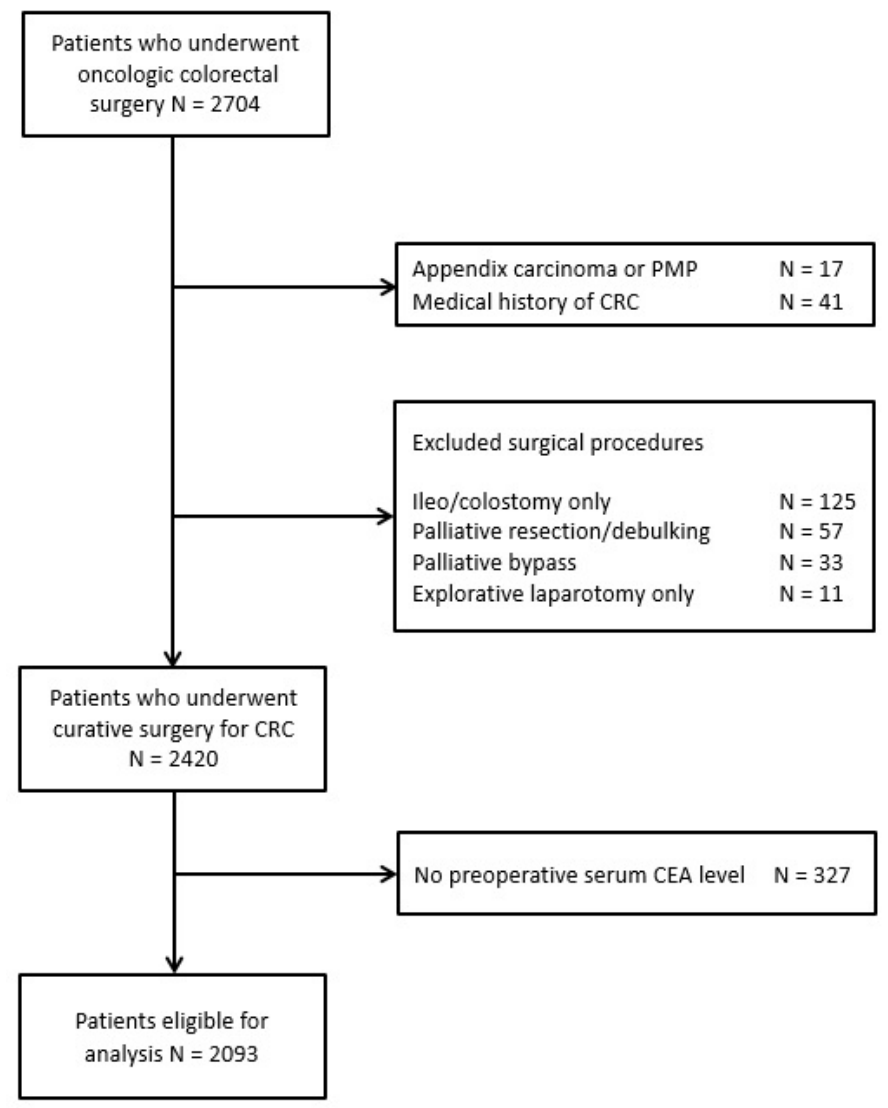

Figure 1 Flowchart of included patients who underwent curative surgery for CRC and had preoperative serum CEA level measurements.

CEA: carcinoembryonic antigen; CRC: colorectal cancer; PMP: Pseudomyxoma Peritonei. 
Table 1 Clinicopathologic characteristics of patients with normal $(\leq 5 \mu \mathrm{g} / \mathrm{L})$ and elevated $(>5 \mu \mathrm{g} / \mathrm{L})$ preoperative serum CEA.

\begin{tabular}{|c|c|c|c|}
\hline & $\begin{array}{c}\text { Preoperative CEA } \\
\text { level } \leq 5 \mu \mathrm{g} / \mathrm{L}\end{array}$ & $\begin{array}{c}\text { Preoperative CEA } \\
\text { level }>5 \mu \mathrm{g} / \mathrm{L}\end{array}$ & P-value \\
\hline Patients (N=2093) & 1256 & 837 & \\
\hline Gender & & & 0.03 \\
\hline Male & $750(62 \%)$ & 459 (38\%) & \\
\hline Female & $506(57.2 \%)$ & $378(42.8 \%)$ & \\
\hline Median age in years (IQR) & $69(62-76)$ & $69(62-76)$ & 0.97 \\
\hline Comorbidity & & & 0.35 \\
\hline ASA I & $152(63 \%)$ & $89(37 \%)$ & \\
\hline ASA II & $686(60.7 \%)$ & $444(39.3 \%)$ & \\
\hline ASA III & $398(58.3 \%)$ & $285(41.7 \%)$ & \\
\hline ASA IV & $20(51.3 \%)$ & $19(48.7 \%)$ & \\
\hline Location & & & $<0.01$ \\
\hline Colon & $720(56.2 \%)$ & $562(43.8 \%)$ & \\
\hline Rectum & $481(67.6 \%)$ & $230(32.4 \%)$ & \\
\hline$\geq 2$ tumours & $55(55 \%)$ & $45(45 \%)$ & \\
\hline Neoadjuvant therapy & & & 0.36 \\
\hline Chemotherapy and radiotherapy & $125(61.3 \%)$ & $79(38.7 \%)$ & \\
\hline Chemotherapy & $10(34.4 \%)$ & $19(65.5 \%)$ & \\
\hline Radiotherapy & $241(66.6 \%)$ & $121(33.4 \%)$ & \\
\hline Tumour grade & & & $<0.01$ \\
\hline Well & $193(38.6 \%)$ & 307 (61.4\%) & \\
\hline Moderate & $784(64.8 \%)$ & $425(35.2 \%)$ & \\
\hline Poor & $263(74.3 \%)$ & $91(25.7 \%)$ & \\
\hline Missing & $16(53.3 \%)$ & $14(46.7 \%)$ & \\
\hline T-stage & & & $<0.01$ \\
\hline $\mathrm{T} 1$ & $184(86.4 \%)$ & $29(13.6 \%)$ & \\
\hline $\mathrm{T} 2$ & $322(72 \%)$ & $125(28 \%)$ & \\
\hline T3 & $679(54.2 \%)$ & $573(45.8 \%)$ & \\
\hline T4 & $71(39.2 \%)$ & $110(60.8 \%)$ & \\
\hline $\mathrm{N}$-stage & & & 0.23 \\
\hline Lymph node-negative & $883(67.5 \%)$ & $425(32.5 \%)$ & \\
\hline Lymph node-positive & $362(47 \%)$ & $411(53 \%)$ & \\
\hline Missing & $11(91.7 \%)$ & $1(8.3 \%)$ & \\
\hline M-stage & & & 0.02 \\
\hline MO & 1060 (63.3\%) & $615(36.7 \%)$ & \\
\hline M1 & 57 (30\%) & $133(70 \%)$ & \\
\hline Missing & $139(62.6 \%)$ & $83(37.4 \%)$ & \\
\hline UICC Stadium & & & $<0.01$ \\
\hline Stage I & $392(79.5 \%)$ & $101(20.5 \%)$ & \\
\hline Stage II & $437(59.8 \%)$ & $294(40.2 \%)$ & \\
\hline Stage III & $330(52.1 \%)$ & $304(47.9 \%)$ & \\
\hline Stage IV & $57(30 \%)$ & $133(70 \%)$ & \\
\hline Missing* & $40(88.9 \%)$ & $5(11.1 \%)$ & \\
\hline Locoregional recurrence & $75(52.8 \%)$ & $67(47.2 \%)$ & 0.89 \\
\hline
\end{tabular}

ASA: American Society of Anesthesiologists; CEA: carcinoembryonic antigen; IQR: Interquartile range; UICC: Union for International Cancer Control. * No vital tumour cells after neo-adjuvant therapy. 


\section{Preoperative serum CEA}

Preoperative serum CEA was elevated in 837 patients (40\%), which corresponds to the sensitivity of the tumor marker for detecting CRC. Of the 2093 patients, 190 (9.1\%) had distant metastases at the time of diagnosis (M1) (Table 6.1). Of these patients with M1 disease at presentation, 133 patients had preoperative serum CEA levels greater than $5 \mu \mathrm{g} / \mathrm{L}$, and 57 patients had CEA levels less than $5 \mu \mathrm{g} / \mathrm{L}$. The median CEA level was $11 \mu \mathrm{g} / \mathrm{L}$ (IQR 4.1-38.5 $\mathrm{\mu g} / \mathrm{L}$ ) in this M1 group. Of the 1903 patients without metastases at the time of diagnosis (MO), 704 patients had CEA levels greater than $5 \mu \mathrm{g} / \mathrm{L}$, and 1199 patients had CEA levels less than $5 \mu \mathrm{g} / \mathrm{L}$. The median CEA level was $3.4 \mu \mathrm{g} / \mathrm{L}$ (IQR 1.9-7.9 $\mathrm{\mu g} / \mathrm{L}$ ) in the MO group. The overall sensitivity and specificity of CEA in detecting metastasis at the time of diagnosing of CRC were $70 \%$ and $63 \%$, respectively. In $25.7 \%$ of patients with a tumor with poorly differentiated cells, the CEA level was $>5 \mu \mathrm{g} / \mathrm{L}$; the CEA level was elevated in $35.2 \%$ of patients with moderate differentiation and in $61.4 \%$ of patients with well differentiated tumors (Table 6.1).

\section{Recurrence}

Of the 2093 patients who underwent curative surgery for CRC, 142 (6.8\%) developed locoregional recurrence during follow-up with a median time to recurrence of 11 months (IQR 6-18 months). There were 1903 patients with stage I-III disease, and 336 $(19.1 \%)$ of them developed systemic recurrence during follow-up. The median time to systemic recurrence was 12 months (IQR 5-24 months). The median time between a CEA increase and the actual confirmation of cancer recurrence through histologic examination or diagnostic imaging or with surgery was 12 days (IQR 10-14). In the univariate analysis, an elevated preoperative serum CEA was associated with locoregional recurrence (hazard ratio (HR) 1.47 (95\% confidence interval ( $\mathrm{Cl}$ ) 1.06, 2.04; $\mathrm{P}=0.02)$ ). However, in the multivariate analysis, no significant association between preoperative serum CEA and locoregional recurrence was found (adjusted HR 1.29 (95\% $\mathrm{Cl} 0.91,1.84 ; \mathrm{P}=0.26)$ ). Covariates with a significant association with locoregional recurrence were poorly differentiated tumors, T-stadium, tumor stage, and tumors that were not radically removed. In contrast to locoregional recurrence, there was a significant association between an elevated preoperative serum CEA level and systemic recurrence in patients with stage I-III disease. This finding was significant in the univariate analysis ( $\mathrm{HR} 1.97(95 \% \mathrm{Cl} 1.58,2.45 ; \mathrm{P}<0.01)$ ) and confirmed in the multivariate analysis (adjusted HR $1.58(95 \% \mathrm{Cl} 1.25,2.00 ; \mathrm{P}<0.01)$ ). In addition, rectal tumors, T-stadium, nodal stage, surgical approach, tumor-stage, and tumors not radically removed were significantly associated with distant recurrence (Table 6.2). The 5-year disease-free survival was significantly lower in patients with an elevated preoperative serum CEA level than in those without $(P<0.01$, Figure 6.2). 
Table 2 Multivariate Cox Regression analysis of locoregional and systemic recurrence in patients who underwent curative surgery for colorectal cancer.

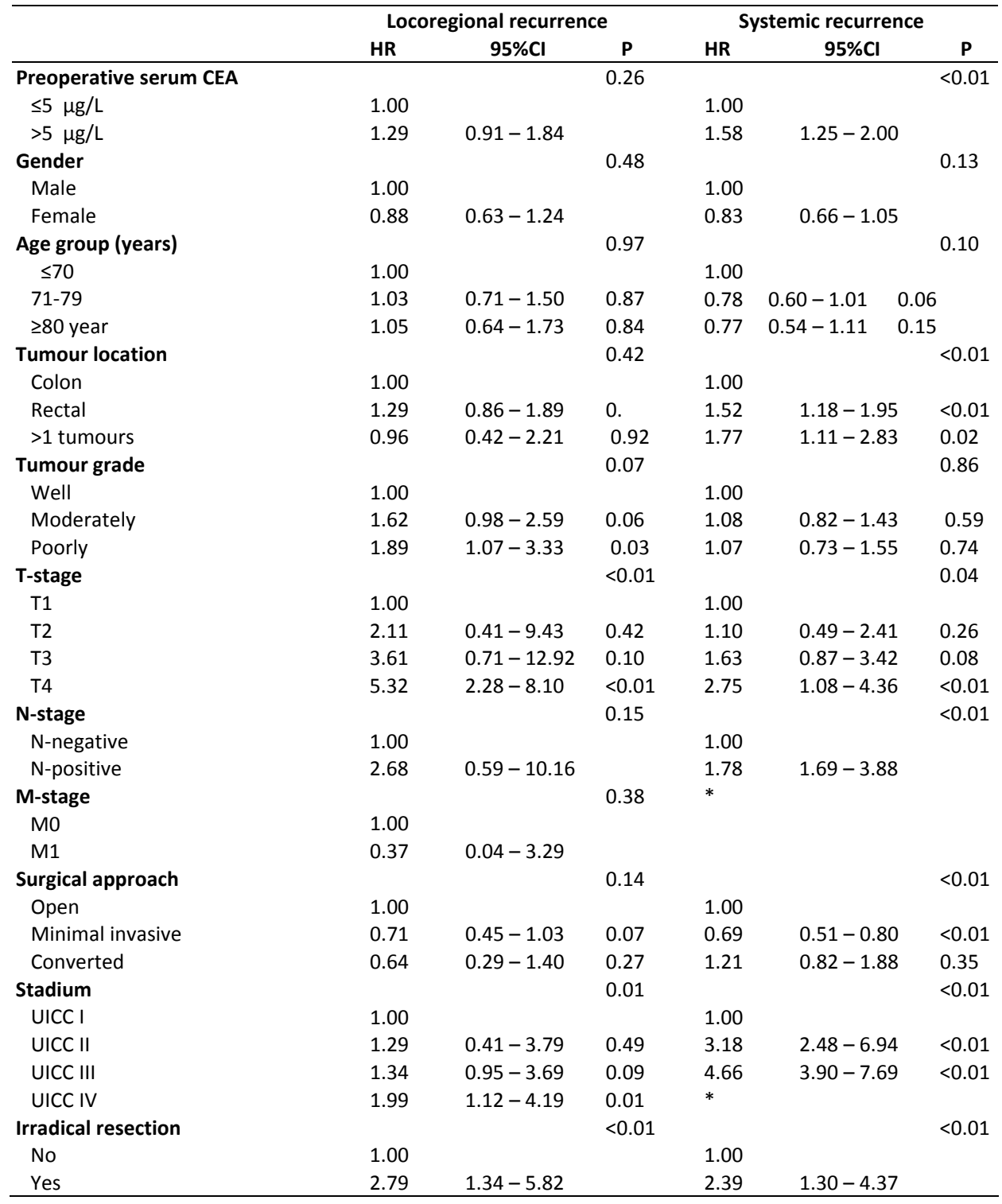

CEA: carcinoembryonic antigen; $\mathrm{Cl}$ : confidence interval; HR: hazard ratio; UICC: Union for International Cancer Control. 


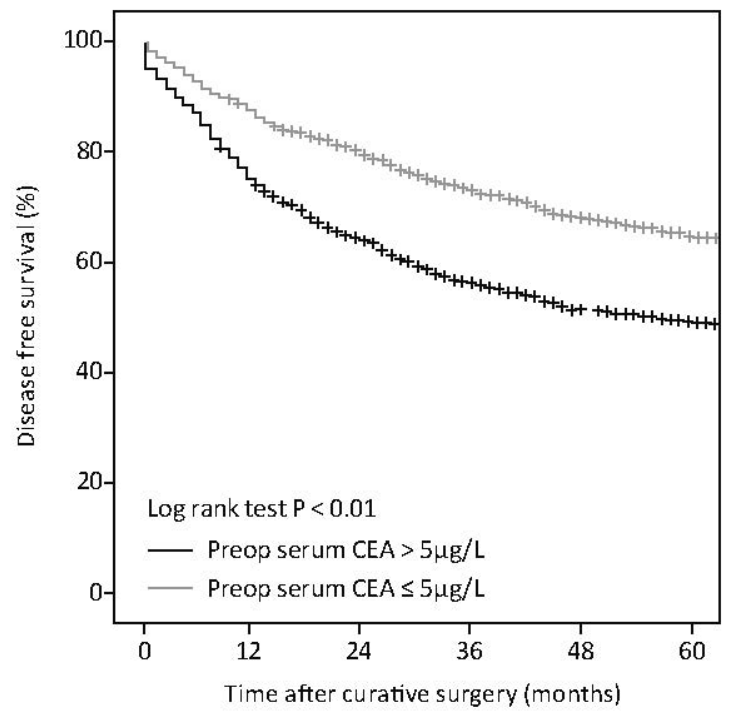

Numbers at risk

$\begin{array}{lllllll}\text { Preop serum CEA } \leq 5 \mu \mathrm{g} / \mathrm{L} & 1256 & 1083 & 1001 & 936 & 892 & 868\end{array}$

$\begin{array}{lllllll}\text { Preop serum CEA }>5 \mu \mathrm{g} / \mathrm{L} & 837 & 619 & 537 & 485 & 458 & 449\end{array}$

Figure 2 Five-year disease-free survival of patients with and without elevated preoperative serum CEA level. CEA: carcinoembryonic antigen.

\section{CEA during follow-up}

Follow-up CEA was elevated in 95 of 142 patients with locoregional recurrence (66.9\%). The median CEA level of patients with locoregional recurrence was $9.1 \mu \mathrm{g} / \mathrm{L}$ (IQR 4.9-13.3 $\mu \mathrm{g} / \mathrm{L}$ ). Follow-up serum CEA levels were measured in 332 of the 336 patients with stage I-III disease who developed systemic metastasis. Follow-up CEA was elevated in 121 of 165 patients with hepatic metastasis. The sensitivity of CEA levels in detecting hepatic metastasis was $73.3 \%$. The median serum CEA level was the highest for hepatic metastasis and the lowest for pulmonary metastasis (Table 6.3.)

Of the 1903 patients with stage I-III disease, postoperative serum CEA levels were measured in 1727 (90.8\%) patients. An elevated CEA was found in 351 patients, but only 221 of them had distant metastasis confirmed with histological examination or by diagnostic imaging. The false positive rate for postoperative CEA measurements was $37.0 \%$ and the true positive rate was $63.0 \%$. On the other hand, a normal CEA was found in 1376 patients during follow-up. In 111 of them, distant metastasis was found through imaging or with histological examination.

The false negative rate for postoperative CEA measurement was $8.1 \%$ and the true negative rate was $91.9 \%$. 
Follow-up serum CEA measurements in patients with stage I-III disease who developed locoregional or systemic recurrence.

\begin{tabular}{lccc}
\hline & CEA $\leq \mathbf{5} \boldsymbol{\mu g} / \mathrm{L}$ & CEA $>\mathbf{5} \boldsymbol{\mu g} / \mathrm{L}$ & Median CEA $\boldsymbol{\mu g} / \mathrm{L}$ (IQR) \\
\hline Locoregional recurrence & $47(33.1 \%)$ & $95(66.9 \%)$ & $9.1(4.9-13.3)$ \\
Systemic recurrence & $\mathrm{N}=111$ & $\mathrm{~N}=221$ & $\mathrm{~N}=332$ \\
Hepatic & $44(26.7 \%)$ & $121(73.3 \%)$ & $14(4.9-45.6)$ \\
Pulmonary & $27(39.1 \%)$ & $42(60.9 \%)$ & $7.2(2.9-24)$ \\
Peritoneal & $8(36.4 \%)$ & $14(63.6 \%)$ & $7.9(2.7-12.3)$ \\
Lymphatic & $21(35.3 \%)$ & $33(64.7 \%)$ & $7.5(3.1-23)$ \\
Other* & $11(50.0 \%)$ & $11(50.0 \%)$ & $9.0(3.6-27.6)$ \\
\hline
\end{tabular}

CEA: carcinoembryonic antigen; IQR: Interquartile range. * Other anatomic sites included brain, bone, adrenal glands, abdominal wall, adnexa, skin and bladder.

\section{Discussion}

This single centre retrospective observational study shows that the preoperative serum CEA level is not an independent prognostic factor for predicting locoregional recurrence.

However, even after adjusting for confounding variables in the multivariate analysis, an elevated preoperative serum CEA level is a prognostic factor for systemic recurrence in patients who previously had curative surgery for CRC. Our findings confirm the results of previous studies, which also found that an elevated preoperative serum CEA level is a prognostic marker for poor oncological outcome $e^{4,24,28-36}$. The sample size of these studies varied between 124 and 2230 patients, with only three studies with more than 1000 patients. Moreover, the definition of an elevated CEA ranged from 2.5 and $10 \mu \mathrm{g} / \mathrm{L}$, leading to heterogeneity among these studies. The major inconsistency in the definition of an elevated CEA generates a broad range of values for the sensitivity and specificity of CEA as a preoperative diagnostic tool. In this study, a preoperative elevated CEA measurement of $>5 \mu \mathrm{g} / \mathrm{L}$ has a sensitivity of $40 \%$ for detecting CRC. Lowering this threshold would cause a higher rate of false positives. On the other hand, increasing the threshold would cause a higher rate of false negatives.

Patients with an elevated preoperative serum CEA level have a decreased 5-year disease-free survival compared to patients with a normal preoperative serum CEA level. Takagawa et al. also evaluated the prognostic value of preoperative serum CEA levels in 638 patients with $\mathrm{CRC}^{36}$. They found a significant difference in disease-free survival with a threshold value of $10 \mu \mathrm{g} / \mathrm{L}$. However, a significant difference was only observed in patients with stage II and stage III disease, whereas stage I only included six patients ${ }^{36}$. Our findings are similar for patients with stage I-III disease with a CEA threshold of $5 \mu \mathrm{g} / \mathrm{L}$, which is used as a cut-off point in the Netherlands ${ }^{16}$. Park et al. found similar results in a larger retrospective cohort of 212 patients with stage I CRC out of a total of 1236 CRC patients, although only 14 of 212 patients with stage I disease had elevated 
preoperative serum CEA levels ${ }^{37}$. The only limitation of this study from South Korea is that they did not evaluate the value of postoperative serum CEA measurements for detecting recurrent disease ${ }^{35}$. Our database contained follow-up data regarding postoperative CEA levels in patients with systemic recurrence, which provides more comprehensive insight into the value of obtaining follow-up serum CEA measurements. Disease-free survival is also significantly lower in patients with stage II and stage III disease $^{35}$. Patients with stage II or stage III disease and elevated preoperative serum CEA levels may have occult systemic disease at the time of curative surgery. Lloyd et al. proved that $32.8 \%$ of patients with stage I and II disease test positive for disseminated tumor cells after surgery ${ }^{38}$. Therefore, even after curative resection, residual malignant cells can remain in situ ${ }^{38}$. Several authors have attempted to determine the correlation between histological characteristics and vascular or perineural invasion ${ }^{35,36}$. However, no convincingly significant differences have been found in these retrospective Asian studies. This study found a significant association between preoperative serum CEA level and tumor grade, which is consistent with previous reports ${ }^{12}$. In this study, an elevated preoperative serum CEA level was associated with systemic recurrence in patients with stage I-III disease.

In the Netherlands, serum CEA monitoring is conducted every 3 to 6 months in the first 3 years and every 6 months thereafter until 5 years after the initial surgical treatment ${ }^{16}$. In some patients, it remains unclear how to interpret an elevated follow-up serum CEA level and its accuracy in detecting metastatic disease. It is also unclear whether postoperative CEA levels should be monitored in patients with recurrence who had normal preoperative serum CEA levels. In this cohort, 332 patients with stage I-III disease were diagnosed with distant metastases. In 221 of them, serum CEA was elevated during follow-up (66.5\%), which appears to be an accurate indicator for further imaging. However, only 221 of the 351 patients with elevated follow-up serum CEA levels actually had distant metastases. Therefore 130 (37\%) patients had false positive elevated serum CEA levels, causing unnecessary additional imaging, radiation exposure, and longer waiting lists. Along with serum CEA, information from the patient's medical history and physical examination are needed to decide whether or not to perform additional imaging. A recently published randomized controlled trial (RCT) evaluated the role of CEA in predicting recurrence and outcomes of surgical treatment with curative intent. The Follow-up after Colorectal Surgery (FACS) trial concluded that CEA testing should not be used as a single triage test ${ }^{39}$. The correlation between follow-up elevated serum CEA levels and recurrence to distant sites has been reported, and is the greatest for hepatic metastases compared to metastases at other organs or structures ${ }^{24,40}$. The results of the current study strengthen this finding. We found that $73.3 \%$ of patients with liver metastasis had elevated follow-up serum CEA levels. The serum level was not as sensitive for detecting distant metastases in other sites. Pulmonary metastasis and peritoneal metastasis had the lowest sensitivity rate of $60.9 \%$ and $63.6 \%$, respectively, which is in line with previous studies ${ }^{22-24}$. These findings 
indicate that postoperative serum CEA levels are more effective in predicting hepatic metastasis than for other types of metastases. There are also studies that suggest the benefit of an intensive follow-up schedule with more frequent CEA monitoring to improve survival in patients with hepatic metastasis ${ }^{41-43}$.

There are several limitations of the present study. First is the retrospective design, although we attempted to reduce this bias with a multivariate Cox regression analysis. Unfortunately, there were 327 (13.5\%) patients with missing preoperative serum CEA measurements. This relatively large number of missing data points negatively influences the power of this study. One reason for the high number of missing preoperative serum CEA measurements is that a preoperative CEA measurement is not considered standard of care in the Dutch guidelines because of its low diagnostic value. The Dutch guidelines only recommend serum CEA monitoring in patients who enter a follow-up program to detect metastatic disease after curative surgery for $\mathrm{CRC}^{16}$. However, serum CEA is a minimally invasive diagnostic tool that provides information of a patient's normal range of CEA while having active CRC, which is especially valuable during follow- up to monitor for CRC recurrence. A second limitation of the study concerns patients who presented with obstructive CRC and underwent emergency surgery. In these patients, the diagnosis of CRC is unclear until it is histologically confirmed; therefore, a preoperative serum CEA level is not typically measured in this specific patient group. In the near future, it is possible that physicians will have a more complete panel of clinical biomarkers in addition to CEA to obtain more information regarding prognosis and to guide treatment. Recently, advancements from molecular studies have provided the opportunity to test novel tumor markers ${ }^{44}$. Additional methods for authentication of new tumor biomarkers and multicentre RCTs are necessary.

In conclusion, in this large study cohort, we show that the preoperative serum CEA level is an independent prognostic factor for systemic recurrence but not for locoregional recurrence after curative surgery for CRC. Patients with hepatic metastasis are more likely to have elevated postoperative serum CEA levels than patients with metastasis involving other anatomic sites.

\section{Acknowledgements}

The authors would like to thank Dr. Marc Thelen (clinical chemist) and Dr. Judith M.A. Emmen (clinical chemist) for extracting pre- and postoperative serum CEA data from the database, and for providing technical information regarding both CEA assay methods of the Clinical Chemistry and Haematology Department (Amphia Hospital Breda, the Netherlands). 


\section{References}

1. Gold P and Freedman SO. Demonstration of tumor-specific antigens in human colonic carcinomata by immunological tolerance and absorption techniques. J Exp Med. 1965;121:439-462.

2. Sturgeon CM, Lai LC and Duffy MJ. Serum tumour markers: how to order and interpret them. BMJ 2009. 339: b3527.doi.org/10.1136/bmj.b3527.

3. Newton KF, Newman W and Hill J. Review of biomarkers in colorectal cancer. Colorectal Dis. 2012;14: 3-17.

4. Chapman MA, Buckley D, Henson DB, et al. Preoperative carcinoembryonic antigen is related to tumour stage and long-term survival in colorectal cancer. Br J Cancer. 1998;78:1346-1349.

5. Morales-Gutiérrez C, Vegh I, Colina F, et al. Survival of patients with colorectal carcinoma: possible prognostic value of tissular carbohydrate antigen 19.9 determination. Cancer. 1999;86:1675-1681.

6. Reiter W, Stieber P, Reuter C, et al. Multivariate analysis of the prognostic value of CEA and CA 19-9 serum levels in colorectal cancer. Anticancer Res. 2000;20:5195-5198.

7. Stelzner S, Hellmich G, Koch R, et al. Factors predicting survival in stage IV colorectal carcinoma patients after palliative treatment: a multivariate analysis. J Surg Oncol. 2005;89:211-217.

8. Takahashi Y, Mai M and Nakazato $H$. Preoperative CEA and PPD values as prognostic factors for immunochemotherapy using PSK and 5-FU. Anticancer Res. 2005;25:1377-1384.

9. Weissenberger C, Von Plehn G, Otto F, et al. Adjuvant radiochemotherapy of stage II and III rectal adenocarcinoma: role of CEA and CA 19-9. Anticancer Res. 2005;25:1787-1793.

10. Wu ZY, Wan J, Zhao G, et al. Risk factors for local recurrence of middle and lower rectal carcinoma after curative resection. World J Gastroenterol. 2008;14:4805-4809.

11. Wang WS, Lin JK, Chiou TJ, et al. Preoperative carcinoembryonic antigen level as an independent prognostic factor in colorectal cancer: Taiwan experience. Jpn J Clin Oncol. 2000;30:12-16.

12. Goslin R, O'Brien MJ, Steele G, et al. Correlation of plasma CEA and CEA tissue staining in poorly differentiated colorectal cancer. Am J Med. 1981;71:246-253.

13. Moertel CG, O'Fallon JR, Go VL, et al. The preoperative carcinoembryonic antigen test in the diagnosis, staging, and prognosis of colorectal cancer. Cancer. 1986;58:603-610.

14. Goldstein MJ and Mitchell EP. Carcinoembryonic antigen in the staging and follow-up of patients with colorectal cancer. Cancer Invest. 2005;23:338-351.

15. Nordic Gastrointestinal Tumor Adjuvant Therapy Group. Expectancy or primary chemotherapy in patients with advanced asymptomatic colorectal cancer: a randomized trial. J Clin Onco. 1992;10: 904-911.

16. Dutch National Guidelines Workgroup Gastro-intestinal Tumours, type: national guidelines, http://www.oncoline. $\mathrm{nl} /$ colorectaalcarcinoom (accessed 25 September 2018). (Dutch)

17. Duffy MJ, Lamerz R, Haglund C, et al. Tumor markers in colorectal cancer, gastric cancer and gastrointestinal stromal cancers: European group on tumor markers 2014 guidelines update. Int J Cancer. 2014;134:2513-2522.

18. Labianca R, Nordlinger B, Beretta GD, et al. Primary colon cancer: ESMO Clinical Practice Guidelines for diagnosis, adjuvant treatment and follow-up. Ann Oncol. 2010;21:70-77.

19. Locker GY, Hamilton S, Harris J, et al. ASCO 2006 update of recommendations for the use of tumor markers in gastrointestinal cancer. J Clin Oncol. 2006;24:5313-5327.

20. Freedman-Cass D and Gregory KM. Clinical practice guidelines in oncology (NCCN guidelines): colon cancer. Fort Washington: National Comprehensive Cancer Network Foundation. 2016.

21. National Institute for Health and Care Excellence. Colorectal Cancer: Diagnosis and Management. NICE Clinical Guideline 131, www.nice.org.uk/guidance/cg131/chapter/ 1-recommendations 2011 (2011, accessed 15 December 2018).

22. Scheer A and Auer RA. Surveillance after curative resection of colorectal cancer. Clin Colon Rect Surg. 2009;22:242-250.

23. Tsikitis VL, Malireddy K, Green EA, et al. Postoperative surveillance recommendations for early stage colon cancer based on results from the clinical outcomes of surgical therapy trial. J Clin Oncol. 2009;27:3671-3676.

24. Moertel CG, Fleming TR, Macdonald JS, et al. An evaluation of the carcinoembryonic antigen (CEA) test for monitoring patients with resected colon cancer. JAMA. 1993;70:943-947. 
25. Verberne CJ, Zhan Z, van den Heuvel E, et al. Intensified follow-up in colorectal cancer patients using frequent carcino-embryonic antigen (CEA) measurements and CEA triggered imaging: results of the randomized "CEAwatch" trial. Eur J Surg Oncol. 2015;41:1188-1196.

26. NICE Guidelines. Colorectal cancer diagnosis and management. Clinical Guideline Colorectal Cancer (CG131). 2011.

27. Landmann RG and Weiser MR. Surgical management of locally advanced and locally recurrent colon cancer. Clin Colon Rect Surg. 2005;18:182-189.

28. Chen CC, Yang SH, Lin JK, et al. Is it reasonable to add preoperative serum level of CEA and CA19-9 to staging for colorectal cancer? J Surg Res. 2005;124:169-174.

29. Park YJ, Park KJ, Park JG, et al. Prognostic factors in 2230 Korean colorectal cancer patients: analysis of consecutively operated cases. World J Surg. 1999;23:721-726.

30. Wichmann MW, Lau-Werner U, Müller C, et al. Carcinoembryonic antigen for the detection of recurrent disease following curative resection of colorectal cancer. Anticancer Res. 2000;20:4953-4955.

31. Carriquiry LA and Piñeyro A. Should carcinoembryonic antigen be used in the management of patients with colorectal cancer? Dis Colon Rectum. 1999;42:921-929.

32. Sener SF, Imperato JP, Chmiel J, et al. The use of cancer registry data to study preoperative carcinoembryonic antigen level as an indicator of survival in colorectal cancer. CA Cancer J Clin. 1989;39:50-57.

33. Wanebo HJ, Rao B, Pinsky CM, et al. Preoperative carcinoembryonic antigen level as a prognostic indicator in colorectal cancer. N Engl J Med. 1978;299:448-451.

34. Tsuchiya A, Ando Y, Kikuchi Y, et al. Reappraisal of preoperative carcinoembryonic antigen levels as a prognostic factor in resectable colorectal cancer. Fukushima J Med Sci. 1994;40:9-17.

35 Park IJ, Choi GS, Lim KH, et al. Serum carcinoembryonic antigen monitoring after curative resection for colorectal cancer: clinical significance of the preoperative level. Ann Surg Oncol. 2009;16:3087-3093.

36. Takagawa R, Fujii S, Ohta M, et al. Preoperative serum carcinoembryonic antigen level as a predictive factor of recurrence after curative resection of colorectal cancer. Ann Surg Oncol. 2008;15:3433-3439.

37. Park YJ, Youk EG, Choi HS, et al. Experience of 1446 rectal cancer patients in Korea and analysis ofprognostic factors. Int J Colorectal Dis. 1999;14:101-106.

38. Lloyd JM, Mclver CM, Stephenson SA, et al. Identification of early-stage colorectal cancer patients at risk of relapse post-resection by immunobead reverse transcription-PCR analysis of peritoneal lavage fluid for malignant cells. Clin Cancer Res. 2006;12:417-423.

39. Shinkins $B$, Nicholson BD, James $T$, et al. What carcinoembryonic antigen level should trigger further investigation during colorectal cancer follow-up? A systematic review and secondary analysis of a randomised controlled trial. Health Technol Assess. 2017;21:1-60.

40. McCall JL, Black RB, Rich CA, et al. The value of serum carcinoembryonic antigen in predicting recurrent disease following curative resection of colorectal cancer. Dis Colon Rectum. 1994;37:875-881.

41 Renehan AG, Egger M, Saunders MP, et al. Impact on survival of intensive follow up after curative resection for colorectal cancer: systematic review and meta-analysis of randomised trials. BMJ. 2002;324:813.

42. Glover $C$, Douse $P$, Kane $P$, et al. Accuracy of investigations for asymptomatic colorectal liver metastases. Dis Colon Rectum. 2002;45:476-484.

43. Scholefield JH, Robinson MH, Mangham CM, et al. Screening for colorectal cancer reduces emergency admissions. Eur J Surg Oncol. 1998;24:47-50.

44. Berretta $M$, Alessandrini $L$, de Divitiis $C$, et al. Serum and tissue markers in colorectal cancer: state of art. Crit Rev Oncol Hematol. 2017;111:103-116. 



\section{Chapter

Oncologic outcome and recurrence rate following anastomotic leakage after curative resection for

colorectal cancer

Winesh Ramphal

Jeske R.E. Boeding

Paul D. Gobardhan

Harm J.T. Rutten

Leandra J.M. Boonman - de Winter

Rogier M.P.H. Crolla

Jennifer M.J. Schreinemakers

Surgical Oncology. 2018;27:730-736 


\begin{abstract}
Introduction

Anastomotic leakage is one of the most severe early complications after colorectal surgery, and it is associated with a high reoperation rate-, and increased in short-term morbidity and mortality rates. It remains unclear whether anastomotic leakage is associated with poor oncologic outcomes. The aim of this study was to determine the impacts of anastomotic leakage on long-term oncologic outcomes, disease-free survival and overall mortality in patients who underwent curative surgery for colorectal cancer.
\end{abstract}

\title{
Methods
}

This single-centre, retrospective, observational cohort study included patients who underwent curative surgery for colorectal cancer between 2005 and 2015 and who had a primary anastomosis. Survival- and multivariate cox regression analyses were performed to adjust for confounding.

\section{Results}

A total of 1984 patients had a primary anastomosis after surgery. The overall incidence of anastomotic leakage was $7.5 \% ; 19$ patients were excluded because they were lost to follow-up. Of the remaining 1965 patients, 41 (2.1\%) developed local recurrence associated with anastomotic leakage [adjusted hazard ratio $(H R)=2.25 ; 95 \%$ confidence interval (Cl) 1.14-5.29; $\mathrm{P}=0.03$ ]. Distant recurrence developed in 291(14.8\%) patients with no association with anastomotic leakage [adjusted $\mathrm{HR}=1.30$ (95\% Cl: 0.85-1.97) $\mathrm{P}=0.23$. Anastomotic leakage was associated with increased long-term mortality [adjusted $\mathrm{HR}=1.69(95 \% \mathrm{Cl} 1.32-2.18) \mathrm{P}<0.01$ ]. Five year disease-free survival was significantly decreased in patients with anastomotic leakage, (log rank test $\mathrm{P}<0.01)$.

\section{Conclusion}

Anastomotic leakage was significantly associated with increased rates of local recurrence, disease free-survival and overall mortality. Associations of anastomotic leakage with distant recurrence was not found. 


\section{Introduction}

Anastomotic leakage $(A L)$ is one of the most severe early complications after colorectal surgery. AL is associated with a high reoperation rate, increases in the severity of shortterm morbidity and mortality rates, poor functional outcomes and higher healthcare costs $^{1-7}$.

Incidence rates of AL vary from 0.5 to $34 \%$ but are dependent on several factors, such as tumour location (colon or rectum), type of operation, and patient characteristics ${ }^{4,8-10}$. Another explanation for the broad range of reported cases of $A L$ is the wide variability in the definition of AL. Some articles only included patients with symptomatic AL, whereas other authors also included asymptomatic $A L$, the diagnosis of which was based on radiologic findings. Because of the recent increase in sphincter preserving surgery for rectal cancer, the likelihood of AL will increase as well, and patients with a low anastomosis have a higher risk of leakage ${ }^{11-14}$. In general, AL is related to poor prognosis. In the literature, there have been conflicting studies of the oncologic outcomes and long-term mortality in patients with $\mathrm{AL}$ after curative surgery for colorectal carcinoma (CRC). Several studies have reported increased rates of local tumour recurrence ${ }^{15-23}$, while other studies have not ${ }^{24-30}$.

The relation with the occurrence of distant metastases has also been studied. In these studies, contradictory results have been found ${ }^{9,21,22,30-32}$. It remains unclear whether $\mathrm{AL}$ is associated with poor oncologic outcomes. The aim of this study was to determine the impact of $A L$ on local recurrence and distant recurrence rates, -disease-free survival and overall mortality in patients who underwent curative surgery for CRC.

\section{Materials and methods}

\section{Database and definitions}

This was a single-centre retrospective observational study with data on eleven years of colorectal surgeries. We retrospectively reviewed all of the patients who were treated between January 2005 and December 2015. Data regarding patients between 2005 and 2010 were prospectively collected by the surgical team. Data from patients who underwent surgery in our hospital because of colorectal cancer between 2011 and 2015 were retrieved at the National Cancer Registration centre (Integraal Kanker Centrum Nederland, IKNL).

Medical and demographic data were ascertained from medical charts. Data regarding surgery included the location of the tumour within the colon and/or rectum, type of resection that was performed and surgical approach (open or laparoscopic surgery). Laparoscopic surgery also included robotic surgery. Pathology results were classified according to The TNM classification, 5 th edition ${ }^{33}$. Postoperative data consisted of surgical complications, including anastomotic leakage, oncologic outcomes and 
postoperative mortality. Anastomotic leakage was defined as communication between the intra- and extraluminal compartments, determined by clinical evidence and/or confirmed by radiologic imaging. Clinical evidence was based on symptomatic anastomotic leaks, defined by the presence of peritonitis or fever (temperature greater than $38.5^{\circ} \mathrm{C}$ ), or the discharge of pus or faeces from the abdominal drain. Clinical and/or biochemical suspicion (increased leucocytes and C-reactive protein (CRP)) of anastomotic leakage led to early CT assessment.

Additionally, anastomotic dehiscences with leakage into the peritoneum or pelvic cavity, leakage from the efferent or afferent limb and anastomotic abscesses were also considered as anastomotic leakage. Asymptomatic anastomotic leakage was considered when leakage was assessed on CT-scan, without any relevant clinical symptoms or laboratory examination findings during the postoperative course. The oncological outcome measures were local recurrence, distant recurrence, disease free survival and overall survival. All patients with recurrent disease were confirmed histologically whenever possible, or otherwise by diagnostic imaging or surgery. Local recurrence was defined as recurrent tumour growth intra-abdominally or within the pelvic cavity. Other tumour recurrence events were categorized as distant recurrence, including peritoneal metastasis/carcinomatosis. Disease-free survival was defined as the period from the date of curative surgery to the date of detection of local recurrence and/or distant recurrence, date of last follow-up or death. Overall survival was defined as the time from the date of curative surgery to the date of death or last follow-up. Date of death was confirmed using the social security numbers of patients in the Dutch Municipal Personal Records Database (Gemeentelijkebasisadministratie persoonsgegevens, GBA with their software program CompeT\&TEindhoven). The follow-up strategies for patients with and without anastomotic leakage were identical. Most of the patients had a follow-up interval by the surgeon of three months during the first year and every six months thereafter. Each follow-up visit included a physical examination, measurement of the serum carcinoembryonic antigen (CEA) ultrasound of the abdomen and chest Xray. Chest $\mathrm{CT}$, abdominopelvic $\mathrm{CT}$, or positron emission tomography (PET) were performed when there was high suspicion of recurrence of disease on routine imaging studies with or without increased CEA levels.

\section{Inclusion and exclusion criteria}

Patients were included if they underwent colorectal surgery for a colorectal tumour between 2005 and 2015. Patients with appendix carcinomas or pseudomyxoma peritonei (PMP) were excluded. Patient who underwent palliative surgical procedures were also excluded. Surgical procedures with permanent colostomy or no primary anastomosis were excluded as well (Hartmann procedure, abdominoperineal resection (APR) or trans-anal endoscopic microsurgery (TEM)). 


\section{Ethical approval}

For ethical approval, we consulted the national institutional review board Medical Research Ethics Committees United (MEC-U). Referring to this study (reference number W17.073) confirmation was received that the Medical Research Involving Human Subject Act (WMO) does not apply; therefore, official approval of this study by the MEC-U was not required under the WMO. We also consulted the institutional review board of the Amphia Hospital (AMOA) and it confirmed that no formal written waiver for the need of ethics approval was required, because of the retrospective design of the study.

\section{Statistics}

The Kolmogorov-Smirnov test was used to define whether data was normally distributed. Data are reported as means and SDs for normally distributed data and medians and interquartile ranges (IQRs) for non normally distributed data. We used the $\chi^{2}$ test to compare dichotomous variables. Overall survival and disease free survival analyses were performed with Kaplan-Meier curves between anastomotic leakage and no anastomotic leakage. The log-rank test was used to test outcomes between these two groups. Cox proportional hazard models were used to estimate the independent effects of covariates on oncologic outcomes and overall mortality measured by the adjusted hazard ratio (HR) with a 95\% confidence interval $(\mathrm{Cl})$. Variables that were statistically significant in the univariate Cox regression and/or had clinical relevance were included in the multivariate analysis. A two sided P-value less than 0.05 was used to indicate statistical significance. All of the data analyses were performed with the IBM SPSS statistics software program, version 24.

\section{Results}

A total of 2703 patients underwent surgery for CRC between 2005 and 2015 in this cohort. After exclusion, 1984 patients were eligible (73.4\%) (Figure 1).

The overall incidence of AL was 148 out of 1984 patients (7.5\%). Nineteen patients were lost to follow-up because of emigration or follow-up in another hospital. A total of 1965 patients were included for the analysis. The median age was 70.0 years old (IQR 62-77), and the median follow-up time was 4.1 years (IQR 2.0-6.4). The patient and clinical characteristics are shown in Table 1. 


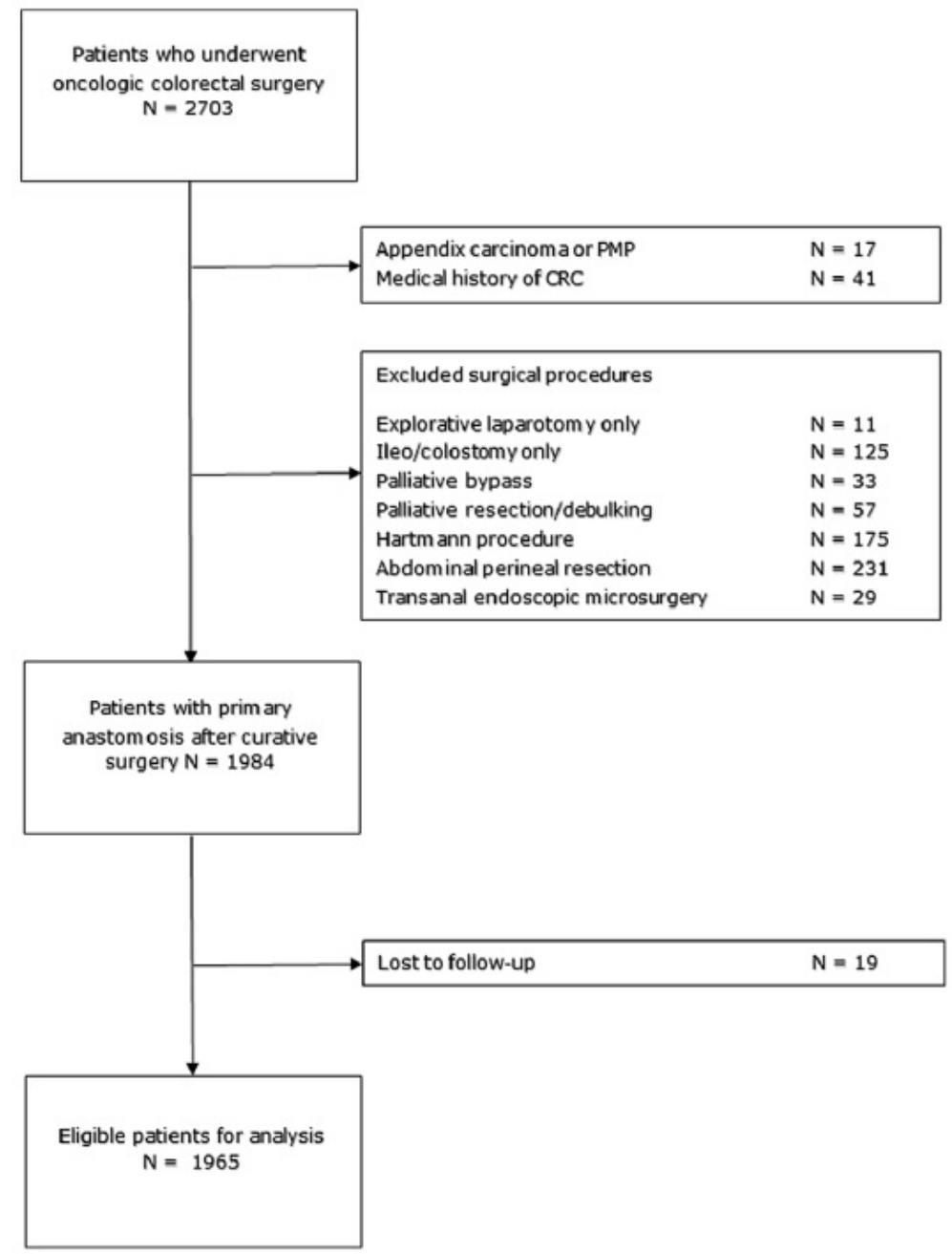

Figure $1 \quad$ Flow-chart of included patients.

CRC: colorectal cancer; PMP: pseudomyxoma peritonei.

\section{Disease recurrence}

The overall local recurrence rate was $2.1 \%$ (41 of 1965) and the overall distant recurrence rate was $14.8 \%$ (291 of 1965). The incidence of local recurrence at the end of follow-up was significantly higher in the AL group compared to the no AL group (4.7\% vs. $1.9 \%, \mathrm{P}=0.019$ ).

However, there was no significant difference in the incidence of distant recurrence at the end of follow-up in the AL group (17.6\% vs. $14.6 \%, P=0.326$, Table 2 ). 
Table 1 Patient and clinical characteristics of colorectal cancer patients who underwent surgery.

\begin{tabular}{|c|c|c|}
\hline & Anastomotic leakage & No anastomotic leakage \\
\hline$N=1965$ & $148(7.5 \%)$ & $1817(92.5 \%)$ \\
\hline \multicolumn{3}{|l|}{ Gender } \\
\hline Male & $96(64.9 \%)$ & $1005(55.3 \%)$ \\
\hline Female & $52(35.1 \%)$ & $812(44.7 \%)$ \\
\hline Median age in years (IQR) & $69(63-77)$ & $70(62-77)$ \\
\hline \multicolumn{3}{|l|}{ Co-morbidity } \\
\hline ASA-I & $12(8.1 \%)$ & $212(11.7 \%)$ \\
\hline ASA-II & $82(55.4 \%)$ & $966(53.1 \%)$ \\
\hline ASA-III & $52(35.2 \%)$ & $607(33.4 \%)$ \\
\hline ASA-IV & $2(1.3 \%)$ & $32(1.8 \%)$ \\
\hline \multicolumn{3}{|l|}{ Tumour stadium (UICC) } \\
\hline Stage I & $25(16.9 \%)$ & $398(21.9 \%)$ \\
\hline Stage II & $58(39.2 \%)$ & $659(36.3 \%)$ \\
\hline Stage III & $43(29.1 \%)$ & $559(30.8 \%)$ \\
\hline Stage IV & $19(12.8 \%)$ & $172(9.4 \%)$ \\
\hline Missing & $3(2.0 \%)$ & $29(1.6 \%)$ \\
\hline \multicolumn{3}{|l|}{ Surgical procedure } \\
\hline Ileocaecal resection & $2(1.4 \%)$ & 34 (1.9\%) \\
\hline Right hemicolectomy & $46(31.1 \%)$ & $669(36.8 \%)$ \\
\hline Left hemicolectomy & $19(12.8 \%)$ & $148(8.1 \%)$ \\
\hline Transverse colectomy & $7(4.7 \%)$ & $54(3.0 \%)$ \\
\hline Sigmoidal resection & $32(21.6 \%)$ & 309 (17.0\%) \\
\hline Low anterior resection & $36(24.3 \%)$ & $572(31.5 \%)$ \\
\hline (Sub)total colectomy & $6(4.1 \%)$ & 31 (1.7\%) \\
\hline \multicolumn{3}{|l|}{ Bowel obstruction } \\
\hline Yes & $16(10.8 \%)$ & $170(9.4 \%)$ \\
\hline No & $132(89.2 \%)$ & $1647(90.6 \%)$ \\
\hline \multicolumn{3}{|l|}{ Surgical approach } \\
\hline Open surgery & 88 (59.5\%) & 952 (52.4\%) \\
\hline Laparoscopic surgery & $52(35.1 \%)$ & 762 (41.9\%) \\
\hline Conversion & $8(5.4 \%)$ & $103(5.7 \%)$ \\
\hline \multicolumn{3}{|l|}{ Additional therapy } \\
\hline Neoadjuvant therapy & $28(19.9 \%)$ & $344(18.9 \%)$ \\
\hline Adjuvant chemotherapy & $39(26.4 \%)$ & $464(25.5 \%)$ \\
\hline
\end{tabular}

ASA: American society of anesthesiologists; UICC: Union for International Cancer Control.

Table 2 Numbers of patients with local recurrence and distant metastases.

\begin{tabular}{lccc}
\hline & Anastomotic leakage & $\begin{array}{c}\text { No anastomotic } \\
\text { leakage }\end{array}$ & P-value \\
\hline $\begin{array}{l}\mathrm{N}=1965 \\
\text { Local recurrence }\end{array}$ & $148(7.5 \%)$ & $1817(92.5 \%)$ & 0.019 \\
$\quad$ Present & $7(4.7 \%)$ & $34(1.9 \%)$ & $1783(98.1 \%)$ \\
$\quad \begin{array}{l}\text { Absent } \\
\text { Systemic recurrence }\end{array}$ & $141(95.3 \%)$ & $192(10.6 \%)$ & 0.326 \\
$\quad$ Synchronous metastasis & $18(12.2 \%)$ & $265(14.6 \%)$ & $1360(74.8 \%)$ \\
$\quad$ Present after surgery for CRC & $26(17.6 \%)$ & & \\
Absent & $104(70.2 \%)$ & & \\
\hline
\end{tabular}

CRC: colorectal cancer 
Local and distant recurrences were diagnosed in twenty patients (1.0\%), three patients in the $A L$ group and seventeen patients in the no $A L$ group. The median time to diagnosis of local recurrence was 1.1 years (IQR $0.7-2.1$ years). The median time to diagnosis of distant recurrence was 1.1 year (IQR $0.6-2.2$ years). No significant difference was found in the median time to local recurrence in the anastomotic leakage group compared to the group without anastomotic leakage (1.1 years (IQR $0.7-1.8$ ) vs. 1.0 year (IQR -0.7-2.3), P=0.86). Likewise, no significant difference was found in the median time to distant recurrence in the anastomotic leakage group compared to the group without anastomotic leakage (0.5 year (IQR 0-1.1) vs. 0.4 year (IQR 0-1.4) $\mathrm{P}=0.73$ ). In the univariate analyses, $\mathrm{Al}$ was associated with local recurrence $[\mathrm{HR}=2.93$ (95\% Cl: 1.30-6.60) $\mathrm{P}=0.01$ ] (Figure 2A), as confirmed in the multivariate analysis [HR=2.25 (95\% Cl:1.14-5.29) $\mathrm{P}=0.03]$.

A total of 14 patients (9.5\%) were defined as asymptomatic and 134 patients developed symptomatic anastomotic leakage (90.5\%). One patient developed local recurrence in the asymptomatic leakage group and six patients in the symptomatic anastomotic leakage group (7.1\% vs. $4.5 \%)$. However no significant difference was found regarding the development of local recurrences between patients with asymptomatic and symptomatic anastomotic leakage $(P=0.51)$. In contrast to local recurrence, no significant association between $A L$ and distant recurrence was found in either the univariate [HR=1.40 (95\% Cl: 0.94-2.10) $\mathrm{P}=0.10$ ] (Figure 2B) or multivariate analysis [HR=1.30 (95\% Cl: 0.85-1.97) $\mathrm{P}=0.23$ ].

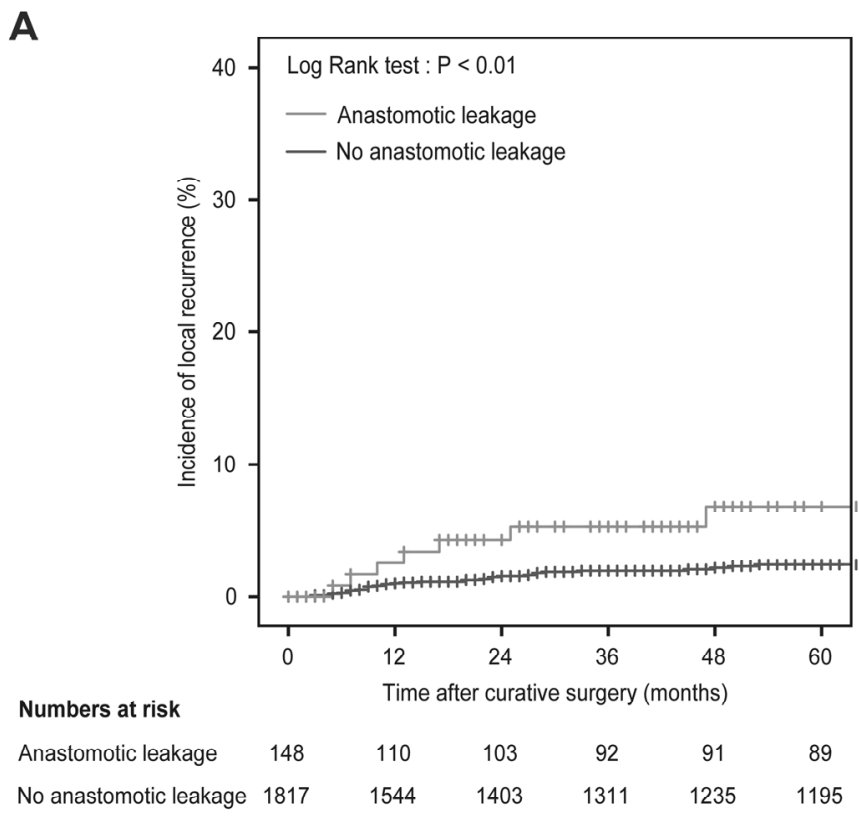


B

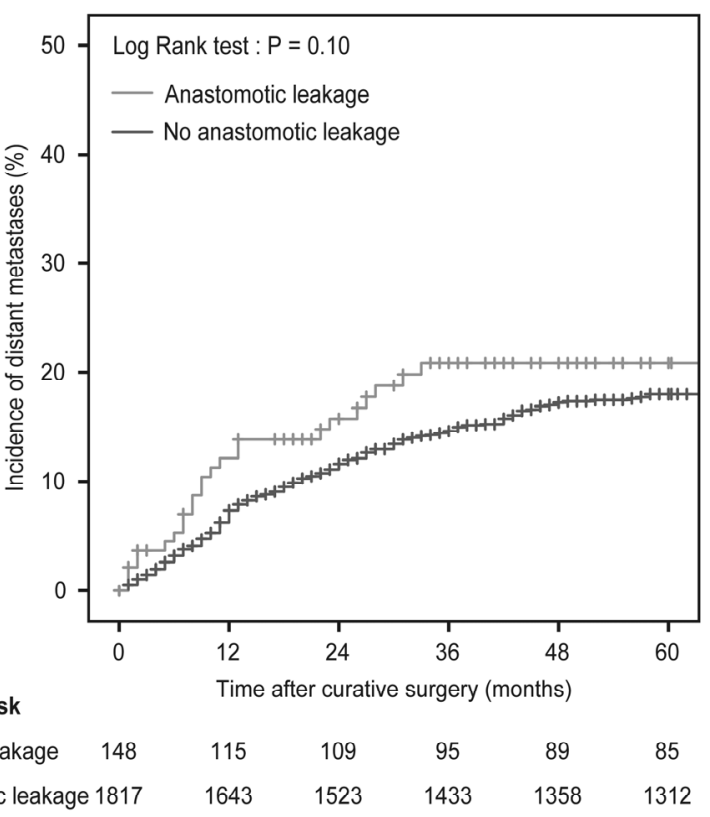

Figure 2 Kaplan Meier plots illustrating the association between $A L$ and the rates of local recurrence (A. log rank test: $\mathrm{P}<0.01$ ) and distant recurrence (B. log rank test: $\mathrm{P}=0.10$ ) in patients after curative surgery for CRC. (grey line: AL group, black line: no AL group).

The covariates with significant influences on distant recurrence were age, tumour stage and bowel obstruction (Table 3). For patients with rectal cancer, receiving neoadjuvant therapy was associated with significant reduction in local recurrence rates in both the univariate analyses [ $\mathrm{HR}=0.44(95 \% \mathrm{Cl}: 0.21-0.85) \mathrm{P}<0.01]$, and the multivariate analyses [HR=0.62 (95\% Cl: 0.41-0.92) P=0.02].

\section{Disease-free survival and overall survival}

Five-year overall survival was significantly decreased in patients with AL after surgery, compared to patients without $\mathrm{AL}(57.4 \%$ vs. $72.0 \%$ respectively $\mathrm{P}<0.01$ (Figure 3 ). The 30-day mortality was significant higher in the anastomotic leakage group compared to the group without anastomotic leakage ( $8.8 \%$ vs. $2.5 \% \mathrm{P}<0.001)$. This significant difference even increases when the 60 -day mortality was investigated (17.6\% vs. $2.8 \%$ $\mathrm{P}<0.00001)$. Similarly, the five year disease-free survival rate was significantly lower in patients with $\mathrm{AL}$ ( $48.0 \%$ vs. $64.1 \% \mathrm{P}<0.01$, (Figure 4 )). 
Table 3 Multivariate Cox Regression analyses of local recurrence, distant recurrence and overall mortality.

\begin{tabular}{|c|c|c|c|c|c|c|c|c|c|}
\hline & \multicolumn{3}{|c|}{ Local recurrence } & \multicolumn{3}{|c|}{ Distant recurrence } & \multicolumn{3}{|c|}{ Overall mortality } \\
\hline & HR & $95 \% \mathrm{Cl}$ & P-value & HR & $95 \% \mathrm{Cl}$ & P-value & HR & $95 \% \mathrm{Cl}$ & P-value \\
\hline Anastomotic leakage & & & 0.03 & & & 0.23 & & & $<0.01$ \\
\hline \multicolumn{10}{|l|}{ No } \\
\hline \multirow[t]{2}{*}{ Yes } & 1.00 & & & 1.00 & & & 1.00 & & \\
\hline & 2.25 & $1.14-5.29$ & & 1.30 & $0.85-1.97$ & & 1.69 & $1.32-2.18$ & \\
\hline Sex & & & 0.54 & & & 0.41 & & & 0.12 \\
\hline Female & 1.00 & & & 1.00 & & & 1.00 & & \\
\hline Male & 0.82 & $0.43-1.57$ & & 0.90 & $0.71-1.15$ & & 0.88 & $0.75-1.03$ & \\
\hline Age group (years) & & & 0.89 & & & 0.03 & & & $<0.01$ \\
\hline$\leq 70$ & 1.00 & & & 1.00 & & & 1.00 & & \\
\hline $71-79$ & 0.84 & $0.40-1.77$ & 0.64 & 0.67 & $0.52-0.92$ & 0.01 & 1.55 & $1.29-1.87$ & $<0.01$ \\
\hline$\geq 80$ & 0.97 & $0.36-2.58$ & 0.95 & 0.74 & $0.50-1.10$ & 0.14 & 2.76 & $2.23-3.42$ & $<0.01$ \\
\hline Comorbidity & & & 0.46 & & & 0.18 & & & $<0.01$ \\
\hline ASA I & 1.00 & & & 1.00 & & & 1.00 & & \\
\hline ASA II & 2.15 & $0.50-9.32$ & 0.31 & 1.28 & $0.86-1.91$ & 0.22 & 1.49 & $1.06-2.08$ & 0.02 \\
\hline ASA III & 3.10 & $0.68-14.04$ & 0.14 & 1.40 & $0.91-2.17$ & 0.13 & 2.56 & $1.81-3.62$ & $<0.01$ \\
\hline ASA IV & na & & & 2.80 & $1.05-7.46$ & 0.04 & 4.81 & $2.86-8.01$ & $<0.01$ \\
\hline Tumour location & & & 0.85 & & & 0.11 & & & 0.64 \\
\hline Colon & 1.00 & & & 1.00 & & & 1.00 & & \\
\hline Rectal & 1.12 & $0.37-3.32$ & & 1.40 & $0.93-2.12$ & & 1.07 & $0.80-1.43$ & \\
\hline Surgical procedure & & & 0.63 & & & 0.15 & & & $<0.01$ \\
\hline Left hemicolectomy & 1.00 & & & 1.00 & & & 1.00 & & \\
\hline Ileocecal resection & 2.79 & $0.46-17.03$ & 0.27 & 2.11 & $0.98-4.53$ & 0.06 & 1.56 & $0.95-2.56$ & 0.08 \\
\hline Right hemicolectomy & 1.54 & $0.44-5.36$ & 0.50 & 1.51 & $0.94-2.43$ & 0.09 & 1.70 & $1.25-2.32$ & $<0.01$ \\
\hline Transverse resection & 0.75 & $0.08-7.42$ & 0.81 & 0.50 & $0.15-1.68$ & 0.26 & 0.91 & $0.54-1.52$ & 0.71 \\
\hline Sigmoidal resection & 1.35 & $0.34-5.34$ & 0.67 & 1.27 & $0.75-2.13$ & 0.37 & 1.26 & $0.89-1.79$ & 0.19 \\
\hline Low anterior resection & 1.14 & $0.24-5.48$ & 0.87 & 1.23 & $0.68-2.22$ & 0.48 & 1.43 & $0.96-2.13$ & 0.08 \\
\hline (Sub)total colectomy & 3.49 & $0.65-18.6$ & 0.14 & 1.90 & $0.87-4.13$ & 0.11 & 1.40 & $0.76-2.58$ & 0.28 \\
\hline Surgical approach & & & 0.19 & & & 0.22 & & & $<0.01$ \\
\hline Open & 1.00 & & & 1.00 & & & 1.00 & & \\
\hline Minimally invasive & 0.47 & $0.21-1.08$ & 0.07 & 0.83 & $0.63-1.10$ & 0.18 & 0.73 & $0.61-0.89$ & $<0.01$ \\
\hline Converted & 0.64 & $0.15-2.76$ & 0.55 & 1.20 & $0.76-1.89$ & 0.44 & 1.15 & $0.84-1.59$ & 0.38 \\
\hline Tumour stage (UICC) & & & $<0.01$ & & & $<0.01$ & & & $<0.01$ \\
\hline Stage I & 1.00 & & & 1.00 & & & 1.00 & & \\
\hline Stage II & 4.82 & $0.61-38.39$ & 0.14 & 2.28 & $1.43-3.65$ & $<0.01$ & 1.47 & $1.14-1.89$ & $<0.01$ \\
\hline Stage III & 6.49 & $1.97-10.02$ & $<0.01$ & 6.27 & $4.04-9.72$ & $<0.01$ & 2.08 & $1.62-2.67$ & $<0.01$ \\
\hline Stage IV & 8.47 & $3.13-14.76$ & $<0.01$ & $*$ & & & 6.09 & $4.59-8.09$ & $<0.01$ \\
\hline Bowel obstruction & & & 0.64 & & & $<0.01$ & & & $<0.01$ \\
\hline No & 1.00 & & & 1.00 & & & 1.00 & & \\
\hline Yes & 1.24 & $0.50-3.08$ & & 1.79 & $1.26-2.55$ & & 1.79 & $1.44-2.27$ & \\
\hline
\end{tabular}

Comorbidity scale: American Society of Anesthesiologists (ASA); Tumour stadium scale: Union for International Cancer Control (UICC); na: not applicable. 


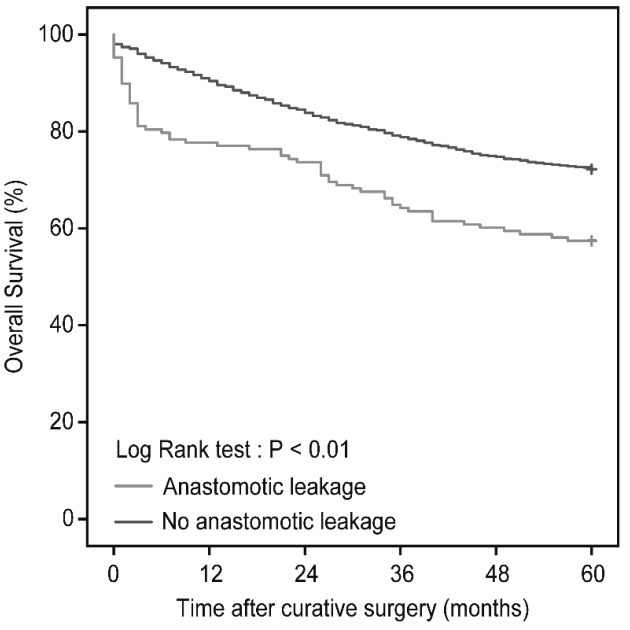

\section{Numbers at risk}

$\begin{array}{lllllll}\text { Anastomotic leakage } & 148 & 115 & 109 & 95 & 89 & 85\end{array}$

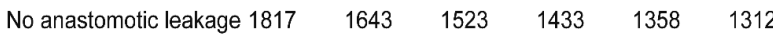

Figure 3 Overall survival in patients with (grey line) and without AL (black line) after curative surgery for CRC (log rank test: $\mathrm{P}<0.01)$.

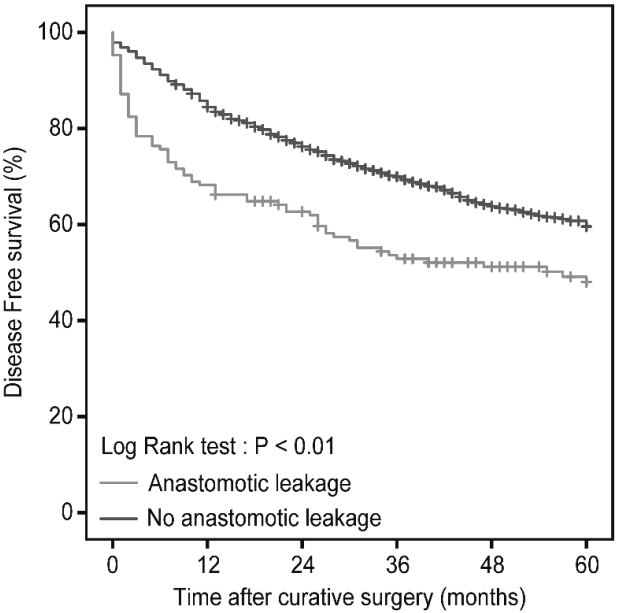

Numbers at risk

$\begin{array}{lllllll}\text { Anastomotic leakage } & 148 & 101 & 93 & 78 & 75 & 71\end{array}$

No anastomotic leakage $\begin{array}{llllll}1817 & 1534 & 1391 & 1298 & 1221 & 1177\end{array}$

Figure $4 \quad 5$ Year disease free survival in patients with AL (grey line) and without AL (black line) after curative surgery for CRC (log rank test: $P<0.01$ ). 
$A L$ was significantly associated with increased overall mortality [HR=1.69 $(95 \% \mathrm{Cl}$ : 1.32-2.18) $\mathrm{P}<0.01$ ]. Covariates that also reached statistical significance were age, ASAclassification, type of surgical procedure, surgical approach, tumour stage and bowel obstruction (Table 3). Local recurrence [HR=1.93 (95\% Cl: 1.11-3.36) $\mathrm{P}=0.02$ ], distant recurrence $[\mathrm{HR}=2.53(95 \% \mathrm{Cl}: 1.52-4.21) \mathrm{P}<0.01]$, and both local and distant recurrence [HR=2.91 $(95 \% \mathrm{Cl} 2.39-3.53) \quad \mathrm{P}<0.01]$ after anastomotic leakage were significantly associated with impaired overall mortality in the multivariate analyses compared to patients without any type of disease recurrence (Figure 5).

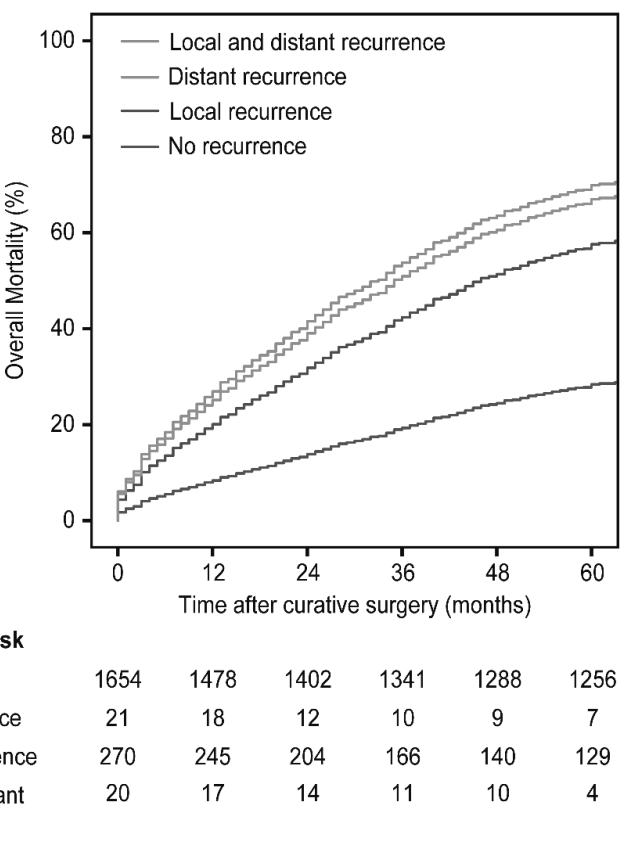

Figure $5 \quad$ Kaplan-Meier plots illustrating overall mortality in patients after curative surgery for colorectal cancer. Mortality was increased in patients with local recurrence, distant metastases and patients with both local recurrence and distant metastases $(P<0.01)$.

\section{Discussion}

In this single-centre observational study, we determined the impact of anastomotic leakage on local and distant recurrence and overall survival in patients who underwent surgery for CRC. The principal finding was that anastomotic leakage was associated with an increased rate of local recurrence. However statistical significance was not found between $A L$ and an increased rate of distant metastases. Local recurrence, distant 
metastasis and patients with both local recurrence and distant recurrence had an inferior impact on overall survival.

That $A L$ after curative surgery for $C R C$ was associated with increased rates of local recurrence and the lack of association between $A L$ and distant recurrence, are in agreement with three recently published meta-analyses ${ }^{9,22,34}$. However, Lu et al. only included articles on AL after rectal carcinoma, while $\mathrm{Ha}$ et al. and Mirnezami et al. included articles on both colonic and rectal cancer. However, Mirnezami et al. distinguished between colon and rectal anastomosis, and both were associated with increased rates of local recurrence. Ha et al. provided a comprehensive updated literature review of local and distant recurrence rates and survival after $A L$ in these patients. They found reduced overall and disease-free survival, similar to our survival results. They performed additional subgroup analyses to assess oncological outcomes. Differences in oncological outcomes were identified in patients who received colon or rectal anastomoses, a distinction we did not make.

Concerning distant metastases after $\mathrm{AL}$, a difference was found but was not significant. Nevertheless, the analyses did demonstrate a non-significant trend towards an increased rate of distant metastases after AL. A large Danish multi-centre study with data merged from three different population-based national registers did find a significantly increased rate of distant metastases after $A L$ [HR=1.42 (95\% Cl:1.13-1.78 $\mathrm{P}=0.003)]^{30}$. Interestingly, they found no significant association between $\mathrm{AL}$ and increased local recurrence, which was completely the opposite of our results and the three fore mentioned meta-analyses. This study by Krarup et al. was one of the limited studies, which only evaluated AL after surgery for colonic carcinoma. Based on the results of Krarup et al., it is understandable to suspect there is an association between $\mathrm{AL}$ and developing distant metastasis. The Danish study had a larger study population than our cohort study and therefore more power to attain statistical significance. This could be precedent for a multicentre Dutch cohort study with sufficient patients to attain this power and possibly the same outcomes. Another subtle dissimilarity between our results and to those of Krarup et al. could lie in the definition of recurrence. In our cohort, patients with both local and distant recurrence were included in both the local recurrence and distant recurrence groups. In agreement with the classification of Goto et al. The Danish cohort of 8589 included patients defined patients with both local and distant recurrence as distant recurrence, leading to an underestimation of the local recurrence rate.

The pathophysiology of developing local and distant recurrence after AL for CRC remains unclear, but several mechanisms have been reported. Microperforation before or during surgery could occur, which has been associated with significant higher local recurrence rates ${ }^{35,36}$. Vital malignant cells have been detected intraluminally and on staple and suture lines during surgery. In vitro and experimental animal studies have 
shown growth of these cells and their ability to metastasize $e^{37-41}$. These findings combined might explain cellular levels caused to AL leading to extra-luminal infiltration of exfoliated malignant cells from intraluminally. Moreover, after AL has occurred, it will slow the healing process of the mucosa which is a gateway for intraluminally viable tumour cells to implant in the peritoneum or pelvis, with a higher risk for developing local recurrence ${ }^{42,43}$. Another and related explanation of the pathway from AL to cancer recurrence is the role of inflammation. Abdominal sepsis extends the inflammatory response from acute to chronic, leading to continued exposure of proinflammatory biomarkers associated with tumour proliferation and evolution to distant metastasis $^{44-48}$. Two studies have even proved that extensive systemic inflammatory responses with significant elevated $C$ reactive protein (CRP) and other stress markers are independent predictors of higher recurrence rates and impaired disease-free survival in patients with $\mathrm{CRC}^{49,50}$. In mouse models, Bohle et al. proved that postoperative intra-abdominal bacterial infection stimulates neo angiogenesis, resulting in a higher likelihood of disease recurrence ${ }^{51}$. In contrast to rectal cancer, colon cancer is known for lower local recurrence rates, which might be explained by colon cancer remaining undiagnosed until symptomatic systemic metastases develop ${ }^{52}$. A more surgery related explanation could be that margins for resection of colonic cancer are more radical than the margins for rectal cancer. Vital tumour cells located elsewhere in the lumen of the bowel than the actual tumour might have been removed with the tumour specimens ${ }^{42}$. The chance of local recurrence in patients having surgery for colonic cancer is therefore lower than for patient who had surgery for rectal cancer.

Clearly, there were several limitations of the present study. First and foremost was the retrospective design of this cohort study, although we strived to reduce this bias with a multivariate Cox regression analysis. Second, we did not make a distinction of $\mathrm{AL}$ between patients with colon and rectal cancer. In the current literature opposing results could have been reported because of inconsistencies in the use of the definitions of anastomotic leakage, which could explain these discrepancies. Like Hain et al. we distinguished asymptomatic from symptomatic anastomotic leakage. However, in contrast to the study of Hain et al. no significant difference in local recurrence was found. The dissimilarity between the results may be caused by the fact that they only included patients with rectal cancer and we included both colon and rectal cancer.

Another explanation could be the high incidence of anastomotic leakage in the French study $(28 \%)^{53}$. A few studies have distinguished between the severity in levels of anastomotic leakage. The International Study Group of Rectal Cancer used a grading system based on clinical management methods: no change in management (grade A); active therapeutic intervention without re-laparotomy (grade $\mathrm{B}$ ); and re-laparotomy required (grade $\mathrm{C})^{54}$. The only drawback of this classification is that it is only usable after management has been completed. Lim et al. introduced an anastomotic leakage 
classification according to its clinical presentation: generalized peritonitis (type I); localized peritonitis (type II); and fistula of the chronic sinus (type III) ${ }^{23}$. Unfortunately, this classification has some overlap in definitions between the several grades rendering it unreliable for drawing conclusions. The initiative of the categorization of different types of anastomotic leakage is certainly necessary for the differentiation in the severity of this major complication and its oncological outcomes.

The literature has shown that there is evidence for increased local recurrence rates in patients with anastomotic leakage after surgery for $\mathrm{CRC}[\mathrm{HR}=2.9(95 \% \mathrm{Cl}: 1.78-4.71$ $\mathrm{P}<0.001)$ ], [HR=1.3 (95\% Cl: 1.04-1.62 $\mathrm{P}<0.05)$ ] and [HR=1.9 (95\% $\left.\left.\mathrm{Cl}: 1.48-2.44 \mathrm{I}^{2}=78 \%\right)\right]$, as summarized in the three aforementioned meta-analyses ${ }^{9,22,34}$. In our study we showed that this finding was accompanied by significantly impaired overall survival. Patients who survive abdominal sepsis in the acute phase after anastomotic leakage are exposed to a significant hazard of developing local recurrence. A logical possible next step in acknowledging this problem would be to deliberate over therapeutic options after anastomotic leakage to reduce this hazard. Treating patients with adjuvant chemotherapy or radiation after anastomotic leakage will raise many questions, especially on ethical grounds, indicating that even patients with tumour stage I or II are potential candidates for adjuvant therapy after anastomotic leakage, while such therapy is initially not indicated in their pTNM stages. This fact might be an incentive for the required future studies. However, before this proposal could be investigated, there must be consensus and recognition first of the increased hazard for local recurrence after anastomotic leakage.

In conclusion, this study provided evidence that $A L$ in patients after surgery for CRC is associated with increased local recurrence rates. Therefore, it will be crucial to strictly follow these patients. Further research is required for minimize anastomotic leakage rates and guidelines to treat and follow-up patients after anastomotic leakage to improve oncologic outcomes. An association between anastomotic leakage and distant recurrence was not found. 


\section{References}

1. Kube R, Mroczkowski P, Granowski D, Benedix F, Sahm M, Schmidt U, et al. Anastomotic leakage after colon cancer surgery: a predictor of significant morbidity and hospital mortality, and diminished tumour-free survival. Eur J Surg Oncol. 2010;36:120-124.

2. Khan AA, Wheeler JM, Cunningham C, George B, Kettlewell M, Mortensen NJ. The management and outcome of anastomotic leaks in colorectal surgery. Colorectal Dis. 2008;10:587-592.

3. Matthiessen P, Hallböök $O$, Rutegård J, Sjödahl R. Population-based study of risk factors for postoperative death after anterior resection of the rectum. Br J Surg. 2006;93:498-503.

4. Nesbakken A, Nygaard K, Lunde OC. Outcome and late functional results after anastomotic leakage following mesorectal excision for rectal cancer. Br J Surg. 2001;88:400-404.

5. Marra F, Steffen T, Kalak N, Warschkow R, Tarantino I, Lange J, et al. Anastomotic leakage as a risk factor for the long-term outcome after curative resection of colon cancer. Eur J Surg Oncol. 2009;35:1060-1064.

6. Hammond j, Lim s, Wan y, Gao x, Patkar A. The burden of gastrointestinal anastomotic leaks: an evaluation of clinical and economic outcomes. J Gastrointest Surg. 2014;18:1176-1185.

7. McDermott FD, Heeney A, Kelly ME, Steele RJ, Carlson GL, Winter DC. Systematic review of preoperative, intraoperative and postoperative risk factors for colorectal anastomotic leaks. Br J Surg. 2015;102:462-479.

8. Bruce J, Krukowski ZH, Al-Khairy G, Russell EM, Park KG. Systematic review of the definition and measurement of anastomotic leak after gastrointestinal surgery. Br J Surg. 2001;88:1157-1168.

9. Mirnezami A, Mirnezami R, Chandrakumaran K, Sasapu K, Sagar P, Finan P. Increased local recurrence and reduced survival from colorectal cancer following anastomotic leak: systematic review and metaanalysis. Ann Surg. 2011;253:890-899.

10. Law WL, Choi HK, Lee YM, Ho JW, Seto CL. Anastomotic leakage is associated with poor long-term outcome in patients after curative colorectal resection for malignancy. J Gastrointest Surg. 2007;11:815.

11. Rullier E, Laurent C, Garrelon JL, Michel P, Saric J, Parneix M. Risk factors for anastomotic leakage after resection of rectal cancer. Br J Surg. 1998;85:355-358.

12. Heald RJ, Moran BJ, Ryall RD, Sexton R, MacFarlane JK. Rectal cancer: the Basingstoke experience of total mesorectal excision, 1978-1997. Arch. Surg. 1998;133:894-899.

13. Vignali A, Fazio VW, Lavery IC, Milsom JW, Church JM, Hull TL, et al. Factors associated with the occurrence of leaks in stapled rectal anastomoses: a review of 1,014 patients, J Am Coll Surg. 1997;85:105-113.

14. Matthiessen P, Hallböök O, Andersson M, Rutegård J, Sjödahl R. Risk factors for anastomotic leakage after anterior resection of the rectum. Colorectal Dis. 2004;6:462-469.

15. Kulu Y, Tarantio I, Warschkow R, Kny S, Schneider M, Schmied BM, et al. Anastomotic leakage is associated with impaired overall and disease-free survival after curative rectal cancer resection: a propensity score analysis. Ann Surg Oncol. 2015;22:2059-2067.

16. Smith JD, Paty PB, Guillem JG, Temple LK, Weiser MR, Nash GM. Anastomotic leak is not associated with oncologic outcome in patients undergoing low anterior resection for rectal cancer. Ann. Surg. 2012;256:1034-1038.

17. Branagan G, Finnis D. Prognosis after anastomotic leakage in colorectal surgery. Dis Colon Rectum. 2005;48:1021-1026.

18. Bell SW, Walker KG, Rickard MJ, Sinclair G, Dent OF, Chapuis PH, et al. Anastomotic leakage after curative anterior resection results in a higher prevalence of local recurrence. Br J Surg. 2003;90: 1261-1266.

19. Petersen S, Freitag M, Hellmich G, Ludwig K. Anastomotic leakage: impact on local recurrence and survival in surgery of colorectal cancer. Int J Colorectal Dis. 1998;13;160-163.

20. Hain E, Maggiori L, Manceau G, Mongin C, Prost À la Denise J, Panis Y. Oncological impact of anastomotic leakage after laparoscopic mesorectal excision. Br J Surg. 2017;104:288-295.

21. Goto S, Hasegawa S, Hida K, Uozumi R, Kanemitsu Y, Watanabe T, et al. Multicenter analysis of impact of anastomotic leakage on long-term oncologic outcomes after curative resection of colon cancer. Surgery. 2017;162:317-324. 
22. Lu ZR, Rajendran N, Lynch AC, Heriot AG, Warrier SK. Anastomotic leaks after restorative resections for rectal cancer compromise cancer outcomes and survival. Dis Colon Rectum. 2016;59:236-244.

23. Lim SB, Yu CS, Kim CW, Yoon YS, Park IJ, Kim JC. The types of anastomotic leakage that develop following anterior resection for rectal cancer demonstrate distinct characteristics and oncologic outcomes. Int J Colorectal Dis. 2015;30:1533-1540.

24. Ebinger SM, Warschkow R, Tarantino I, Schmied BM, Marti L. Anastomotic leakage after curative rectal cancer resection has no impact on long-term survival: a propensity score analysis. Int J Colorectal Dis. 2015;30:1667-1675.

25. Jörgren F, Johansson R, Damber L, Lindmark G. Anastomotic leakage after surgery for rectal cancer: a risk factor for local recurrence, distant metastasis and reduced cancer-specific survival? Colorectal Dis. 2011;13:272-283.

26. Bertelsen CA, Andreasen AH, Jørgensen T, Harling H. Danish Colorectal Cancer Group. Anastomotic leakage after curative anterior resection for rectal cancer: short and long-term outcome. Colorectal Dis. 2010;12:e76-e81.

27. den Dulk M, Marijnen CA, Collette L, Putter H, Påhlman L, Folkesson J, et al. Multicentre analysis of oncological and survival outcomes following anastomotic leakage after rectal cancer surgery. Br J Surg. 2009;96:1066-1075.

28. Eberhardt JM, Kiran RP, Lavery IC. The impact of anastomotic leak and intraabdominal abscess on cancer-related outcomes after resection for colorectal cancer: a case control study. Dis Colon Rectum. 2009;52:380-386.

29. Nachiappan S, Askari A, Malietzis G, Giacometti M, White I, Jenkins JT, et al. The impact of anastomotic leak and its treatment on cancer recurrence and survival following elective colorectal cancer resection. World J Surg. 2015;39:1052-1058.

30. Krarup PM, Nordholm-Carstensen A, Jorgensen LN, Harling H. Anastomotic leak increases distant recurrence and long-term mortality after curative resection for colonic cancer: a nationwide cohort study. Ann Surg. 2014;249:930-938.

31. Wang S, Liu J, Wang S, Zhao H, Ge S, Wang W. Adverse effects of anastomotic leakage on local recurrence and survival after curative anterior resection for rectal cancer: a systematic review and meta-analysis. World J Surg. 2017;41:277-284.

32. Noh GT, Ann YS, Cheong C, Han J, Cho MS, Hur H, et al. Impact of anastomotic leakage on long-term oncologic outcome and its related factors in rectal cancer. Medicine. 2016;95:e4367.

33. National Collaborating Centre for Cancer (UK). Colorectal cancer: the diagnosis and management of colorectal cancer. http://www.ncbi.nlm.nih.gov/books/NBK116633/.

34. Ha GW, Kim JH, Lee MR. Oncologic impact of anastomotic leakage following colorectal cancer surgery: a systematic review and meta-analysis. Ann Surg Oncol. 2017;24:3289-3299.

35. Slanetz Jr CA. The effect of inadvertent intraoperative perforation on survival and recurrence in colorectal cancer. Dis Colon Rectum. 1984;27:792-797.

36. Eriksen MT, Wibe A, Syse A, Haffner J, Wiig JN. Norwegian Rectal Cancer Group, et al. Inadvertent perforation during rectal cancer resection in Norway. Br J Surg. 2004;91:210-216.

37. Umpleby HC, Fermor B, Symes MO, Williamson RC. Viability of exfoliated colorectal carcinoma cells. Br J Surg. 1984;71:659-663.

38. Symes MO, Fermor B, Umpleby HC, Tribe CR, Williamson RC. Cells exfoliated from colorectal cancers can proliferate In immune deprived mice. Br J Cancer. 1984;50:423-425.

39. Fermor B, Umpleby HC, Lever JV, Symes MO, Williamson RC. Proliferative and metastatic potential of exfoliated colorectal cancer cells. J Natl Cancer Inst. 1986;76:347-349.

40. Gertsch P, Baer HU, Kraft R, Maddern GJ, Altermatt HJ. Malignant cells are collected on circular staplers. Dis Colon Rectum. 1992;35:238-241.

41. van den Tol PM, van Rossen EE, van Eijck CH, Bonthuis F, Marquet RL, Jeekel H. Reduction of peritoneal trauma by using nonsurgical gauze leads to less implantation metastasis of spilled tumor cells. Ann Surg. 1998;227:242-248.

42. Skipper D, Cooper AJ, Marston JE, Taylor I. Exfoliated cells and in vitro growth in colorectal cancer. Br J Surg. 1987;74:1049-1052.

43. Baskaranathan S, Philips J, McCredden P, Solomon MJ. Free colorectal cancer cells on the peritoneal surface: correlation with pathologic variables and survival. Dis Colon Rectum. 2004;47:2076-2079. 
44. Aggarwal BB, Vijayalekshmi RV, Sung B. Targeting inflammatory pathways for prevention and therapy of cancer: short-term friend, long-term foe. Clin Cancer Res. 2009;15:425-430.

45. Wu Y, Zhou BP. Inflammation: a driving force speeds cancer metastasis. Cell Cycle. 2009;8:3267-3273.

46. Mantovani A, Allavena P, Sica A, Balkwill F. Cancer-related inflammation. Nature. 2008;454:436-444.

47. Karin M. Nuclear factor-kappaB in cancer development and progression. Nature. 2006;441:431-436.

48. Coussens LM, Werb Z. Inflammation and cancer. Nature. 2002;420:860-867.

49. McMillan DC, Canna K, McArdle CS. Systemic inflammatory response predicts survival following curative resection of colorectal cancer. Br J Surg. 2003;90:215-219.

50. Canna K, McMillan DC, McKee RF, McNicol AM, Horgan PG, McArdle CS. Evaluation of a cumulative prognostic score based on the systemic inflammatory response in patients undergoing potentially curative surgery for colorectal cancer. Br J Cancer. 2004;90:1707-1709.

51. Bohle B, Pera M, Pascual M, Alonso S, Mayol X, Salvado M, et al. Postoperative intra-abdominal infection increases angiogenesis and tumor recurrence after surgical excision of colon cancer in mice. Surgery. 2010;147:120-126.

52. Abulafi AM, Williams NS. Local recurrence of colorectal cancer: the problem, mechanisms, management and adjuvant therapy. Br J Surg. 1994;81:7-19.

53. Hain E, Maggiori L, Manceau G, Mongin C, Prost à la Denise J, Panis Y. Oncological impact of anastomotic leakage after laparoscopic mesorectal excision. Br J Surg. 2017;104:288-295.

54. Rahbari NN, Weitz J, Hohenberger W, Heald RJ, Moran B, Ulrich A, et al. Definition and grading of anastomotic leakage following anterior resection of the rectum: a proposal by the International Study Group of Rectal Cancer, Surgery. 2010;147:339-351. 


\section{Chapter 8

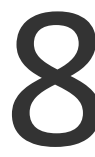

Fluorescence imaging with indocyanine green during robot-assisted surgery in rectal cancer patients

Rogier M.P.H. Crolla*

Winesh Ramphal*

George P. van der Schelling

Jan H. Wijsman

Jennifer M.J. Schreinemakers

Paul D. Gobardhan

Under construction

* Both authors contributed equally to this manuscript 


\section{Abstract}

\section{Background}

To determine whether the use of intraoperative fluorescence imaging with Indocyanine green (ICG) under Near Infra-red (NIR) during robot-assisted laparoscopic surgery in patients with rectal cancer could reduce the number of anastomotic leakages and diverting ileostomies.

\section{Materials and methods}

This single centre retrospective cohort study included patients who had undergone robot-assisted surgery for rectal cancer between 2012 and 2017. Patients with the intraoperative usage of ICG-NIR were compared to patients without the usage of ICGNIR of the same cohort. A sub analyses was performed for patients with rectal cancer who received neoadjuvant chemo radiation or $5 \times 5$ Gy radiation.

\section{Results}

A total of 278 patients were included for analysis, of whom 168 (60.4\%) underwent surgery with intraoperative usage of ICG-NIR. No significant difference was found in the number of anastomotic leakages in the ICG-NIR group compared to the control group (7.1\% vs. $4.5 \%, \mathrm{P}=0.38$ ). However, a significant difference was found in the number of diverting ileostomies $(32.1 \%$ vs. $67.2 \% \mathrm{P}<0.01)$. The number of diverting ileostomies was significant lower in patients with rectal cancer who received neoadjuvant chemo radiation or $5 \times 5$ Gy radiation in the fluorescence group $(P=0.03$ and $P<0.001)$.

\section{Conclusion}

Fluorescence angiography with ICG-NIR during robot-assisted surgery in patients with rectal cancer did not lower the rate of anastomotic leakages. However, we did find a significant lower number of diverting ileostomies in patients in the fluorescence group. ICG-NIR is an innovative technique in RAL rectal surgery and has the potential to become a tool in intraoperative decision making. 


\section{Introduction}

Anastomotic leakage $(\mathrm{AL})$ remains the most severe postoperative complication in colorectal surgery. It causes increased morbidity and mortality and it raises the healthcare costs and economic costs ${ }^{1-7}$. Oncologic outcome is also worse after AL with an increased local recurrence and lower long term survival rates ${ }^{8-11}$. Prevention of $A L$ has to be based on understanding pathophysiology of $A L$ and on knowledge of risk factors. Unfortunately the pathophysiology of AL is not completely understood and probably multifactorial. Factors involved are mechanical, ischaemic, bacterial and inflammatory ${ }^{12-15}$. Many risk factors are known, such as male gender, high body mass index (BMI), malnutrition, use of non-steroidal anti-inflammatory (NSAIDs) drugs, chronic steroid use, preoperative radiation therapy, perioperative blood transfusion, prolonged operation time, distal colorectal anastomosis and surgeon ${ }^{16-22}$.

Strategies to reduce the incidence of $A L$ often focus on reducing the risk factors before, during and after the operation. During the operation the surgeon may reduce the risk of $A L$ by measures that reduce tension of the anastomoses, that ascertain an adequate bowel perfusion and by diversion of the faecal passage by creating a temporary ileostomy. Assessment of the bowel perfusion and the indication for a diverting ileostomy are not very well defined and depend on the judgment of the surgeon. An adequately perfused bowel on the level of the anastomosis is important to obtain enough oxygen supply for optimal healing ${ }^{23-27}$. During surgery several checks are performed to determine perfusion, such as examination of the colour of the bowel wall, visible peristalsis, palpable pulsation and bleeding from the marginal arteries. However, these are subjective checks and based on experience of the surgeon and can lead to misinterpretation ${ }^{28,29}$. An old technique used in ophthalmology to assess blood supply is fluorescence angiography with Indocyanine green (ICG) under near-infrared (NIR) light.

Only recently it has been introduced in colorectal surgery. Reports have shown a great potential in detecting insufficient bowel perfusion ${ }^{30-32}$. ICG is a water-soluble, tricarbocyanine molecule and after intravenous injection, ICG rapidly and extensively binds to plasma proteins and is confined to the intravascular compartment. ICG has the ability to become fluorescent under NIR light which provides a real-time confirmation of intestinal perfusion. In some early studies fluorescence angiography with ICG-NIR in colorectal surgery was associated with lower AL rates ${ }^{33-37}$. In the Amphia we perform robot-assisted laparoscopic (RAL) colorectal surgery since 2012. In 2015 we started to use ICG-NIR during robotic operations routinely. The aim of this study was to determine whether intraoperative ICG-NIR fluorescence imaging to assess bowel perfusion during RAL rectal cancer surgery affected the rates of $A L$ and diverting ileostomies. This was done by comparing the outcomes of robot assisted low anterior resections with and without the use of ICG-NIR fluorescence. 


\section{Methods}

This was a single-centre retrospective observational study with prospectively collected data of patients who underwent robot-assisted rectal cancer surgery between March 2012 and December 2017. All data were collected by three experienced surgeons who performed the RAL procedures. The three surgeons are colorectal surgeons with 22, 20 and 15 years of experience. The treatment of all patients had been discussed in an obligatory multidisciplinary colorectal team of gastroenterologists, oncologic and colorectal surgeons, radiologists, a nuclear medicine doctor, pathologists, radiotherapists, oncologists and case managers. From April 2014 the Dutch guidelines changed to a more restricted use of neoadjuvant radiotherapy ${ }^{38}$. Between 2012 and 2014 the majority of rectal cancer patients in the hospital were operated with robotic assistance and from then on all cases were done robotic assisted. The decision to create a diverting ileostomy was made by the surgeon after performing the low anterior anastomosis. There is no institutional policy dictating the creation of a diverting stoma. Perioperative care was based on ERAS protocol which was introduced in 2005 in our hospital. During the study period there were no changes in the protocol except for the introduction of a three day preoperative course of oral antibiotic prophylaxis (OAP) in 2013. The protocol includes measuring leucocytes and C-reactive protein (CRP) on postoperative days 1, 3 and 5 .

The prospective database included patient characteristics, pre-operative diagnostic data and data of neoadjuvant treatment, surgery, anaesthesia and post-operative data. Operative time was defined as time from incision until closure. Height of the anastomosis from the anal verge was documented in the operation reports. Postoperative care was provided the first night in a medium care unit and afterwards in a surgical colorectal ward according to the ERAS protocol. Postoperative complications were graded according to the Clavien-Dindo classification ${ }^{39}$. Ileus was defined as reinsertion of a gastric tube post operatively. Anastomotic leakage was defined as any radiologic or operative sign of a defect of the anastomosis, or communication between the intra- and extra- luminal compartments, including deep abscesses next to the anastomosis. Clinical suspicion was based on signs of peritonitis, fever (temperature above $38.5^{\circ} \mathrm{C}$ ) or the discharge of pus or faeces from the abdominal drain. Clinical or biochemical suspicion (increased leucocytes and CRP) of AL prompted to early CT assessment. In case of a negative CT assessment clinical suspicion prevailed over radiology to determine treatment. This policy was based on a former study on the role of $\mathrm{CT}$ in $\mathrm{AL}$ in our hospital ${ }^{40}$. Surgical site infections (SSI) were recorded during 30 days or during hospital stay if longer than 30 days. SSI were defined according to the Centers for Disease Control and Prevention (CDC) criteria and were prospectively double checked by dedicated and specifically trained infection control personnel of the laboratory for Microbiology and Infection Control ${ }^{41}$. Discharge criteria were predefined and based on ERAS protocol. Length of stay (LOS) was defined as post-operative length 
of stay in days. Mortality was defined as 30 day or in-hospital mortality. Since introduction of ICG-NIR consequential decisions and actions were documented except for the decision to create a diverting stoma. Pathology results were classified according to The TNM classification, 5 th edition ${ }^{42}$.

\section{ICG-NIR during surgery}

Surgery was performed with the da Vinci $\mathrm{Si}^{\circledR}$ high-definition (HD) vision system. In 2015 an ICG-NIR system (Firefly ${ }^{\mathrm{TM}}$ ) was integrated. The mesentery and marginal vessels were divided at a point appropriate for the proximal margin and in case of a partial mesorectal resection this was also done on the level of the distal rectal resection marge. Then approximately $5 \mathrm{ml}$ ICG $(2.5 \mathrm{mg} / \mathrm{ml})$ was injected intravenously and perfusion of the proximal colon and distal rectum was assessed using a NIR camera system. The combined camera system can switch from white light camera to fluorescence, so the extra operative time due to the use of fluorescence was restricted to the time between injection and maximum fluorescence (less than two minutes). The surgeon then made a qualitative judgement of perfusion based on the fluorescence image. If fluorescence imaging was interpreted as hypoperfusion at the intended point of dissection, the dissection point was changed to the closest location with an appropriate intestinal perfusion. In case of total mesorectal excision the distal resection sometimes was performed before injection of the ICG. Finally colorectal, or coloanal anastomosis was performed with a double-stapling technique or in a very few cases handsewn.

\section{Ethical approval}

For ethical approval, we consulted the national institutional review board Medical Research Ethics Committees United (MEC-U). Referring to this study (reference number W18.018) confirmation was received that the Medical Research Involving Human Subject Act (WMO) does not apply; therefore, official approval of this study by the MEC-U was not required under the WMO. We also consulted the institutional review board of the Amphia Hospital (AMOA) and it confirmed that no formal written waiver for the need of ethics approval was required, because of the retrospective design of the study.

\section{Statistics}

The Kolmogorov-Smirnov test was used to define whether data was normally distributed. Data are reported as means and SDs for normally distributed data and medians and interquartile ranges (IQRs) for non-normally distributed data. The Pearson's $\chi^{2}$ test was used to compare categorical variables. When the expected values in any of the cells of a contingency table are below 5, the Fisher's exact test was used to compare categorical variables. A two sided P-value less than 0.05 was used to indicate 
statistical significance. All of the data analyses were performed with the IBM SPSS statistics software program, version 24 .

\section{Results}

A total of 474 patients with colorectal cancer had undergone RAL surgery in the Amphia Hospital between 2012 and 2017. Eighty-two patients were excluded because of colonic cancer. Of the remaining 392 patients with rectal cancer 114 patients (29.1\%) had to be excluded because of a permanent ostomy and no primary anastomosis. The remaining 278 patients were included for analysis (Figure 1), 176 (63.3\%) of them were male and the median age was 67 years (IQR $60-74)$.

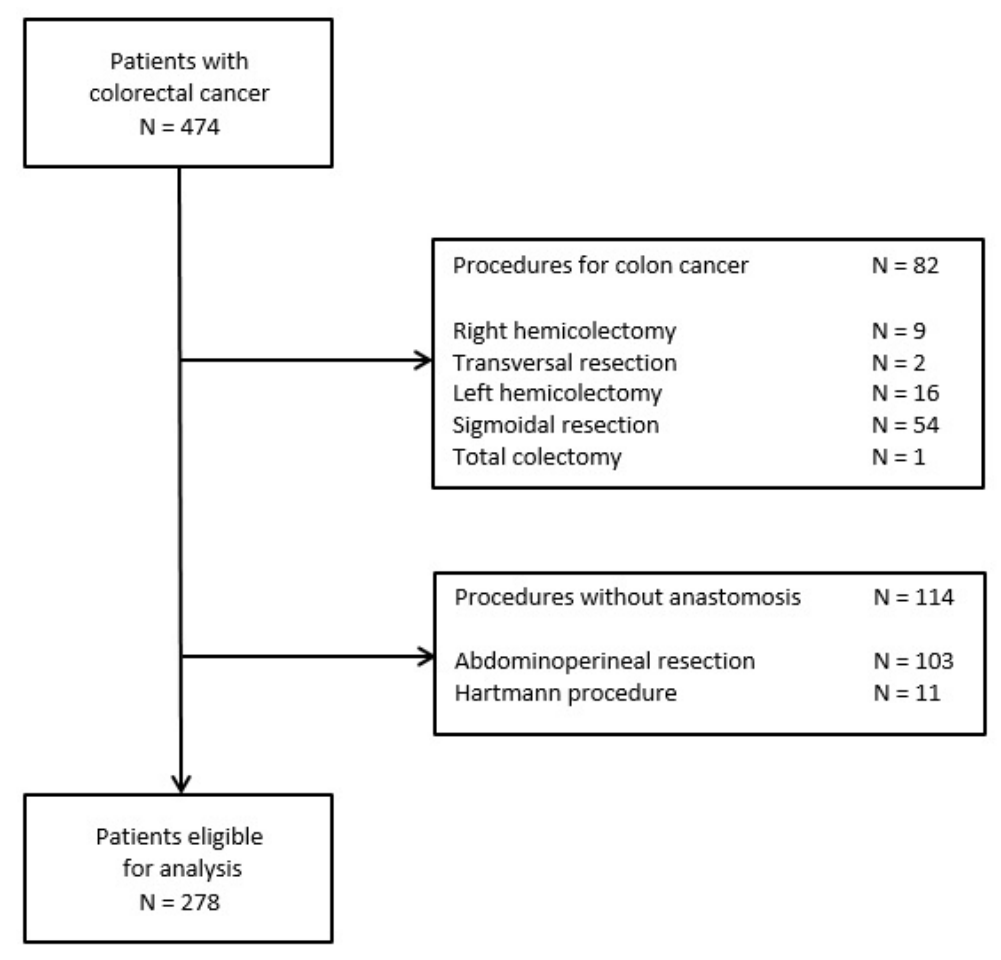

Figure $1 \quad$ Flow-chart of included patients who had undergone robot-assisted surgery for rectal cancer and had a primary anastomosis.

ICG-NIR enhanced fluorescence imaging was used to assess bowel perfusion in 168 (60.4\%) patients. Demographic data and clinical characteristics of the groups with and without ICG-NIR are summarized in Table 1. Patient characteristics and pathologic tumour stage in both groups didn't differ. A difference was found in the percentage of 
patients receiving preoperative $5 \times 5$ Gy short course radiotherapy (SCRT). In the former no ICG-NIR group $31.8 \%$ of patients had SCRT, while this was $18.5 \%$ in the latter ICG-NIR group (Table 1). This difference reflects the more restricted use of neoadjuvant radiotherapy since the introduction of the new guidelines in the Netherlands in 2014.

Table 1 Demographic data and patients characteristics of included patients.

\begin{tabular}{|c|c|c|c|}
\hline Variables & $\begin{array}{c}\text { Patients with } \\
\text { ICG-NIR ( } N=168)\end{array}$ & $\begin{array}{l}\text { Patients without } \\
\text { ICG-NIR }(\mathrm{N}=110)\end{array}$ & P-value \\
\hline Sex & & & 0.34 \\
\hline Male & $100(59.5 \%)$ & $76(69.1 \%)$ & \\
\hline Female & $68(40.5 \%)$ & $34(30.9 \%)$ & \\
\hline Median age in years (IQR) & $67(61-73)$ & $66(60-75)$ & 0.81 \\
\hline \multicolumn{4}{|l|}{ Co-morbidity scale (ASA) } \\
\hline ASA I & $34(20.2 \%)$ & $22(20 \%)$ & 0.96 \\
\hline ASA II & $105(62.5 \%)$ & $75(68.2 \%)$ & 0.33 \\
\hline ASA III & $28(16.7 \%)$ & $13(11.8 \%)$ & 0.26 \\
\hline ASA IV & $1(0.6 \%)$ & $0(0 \%)$ & 1.0 \\
\hline \multicolumn{4}{|l|}{ BMI $\left(\mathrm{kg} / \mathrm{m}^{2}\right)$} \\
\hline$<20$ & $8(4.8 \%)$ & $4(3.7 \%)$ & 0.77 \\
\hline $20-25$ & $71(42.3 \%)$ & $46(41.8 \%)$ & 0.94 \\
\hline $25.1-30$ & $64(38.1 \%)$ & $46(41.8 \%)$ & 0.53 \\
\hline$>30$ & $25(14.8 \%)$ & $14(12.7 \%)$ & 0.61 \\
\hline \multicolumn{4}{|l|}{ Anastomosis from anal verge } \\
\hline$>5 \mathrm{~cm}$ & $68(40.5 \%)$ & $44(40.0 \%)$ & 0.94 \\
\hline $5-10 \mathrm{~cm}$ & $71(42.3 \%)$ & $52(47.3 \%)$ & 0.41 \\
\hline$>10 \mathrm{~cm}$ & $29(17.2 \%)$ & $14(12.7 \%)$ & 0.31 \\
\hline \multicolumn{4}{|l|}{ Tumour stage UICC } \\
\hline Stage I & $55(32.7 \%)$ & $33(30 \%)$ & 0.63 \\
\hline Stage II & $52(31.0 \%)$ & $35(31.8 \%)$ & 0.88 \\
\hline Stage III & $47(28.0 \%)$ & $32(29.1 \%)$ & 0.84 \\
\hline Stage IV & $9(5.3 \%)$ & $3(2.7 \%)$ & 0.29 \\
\hline No vital tumour cells & $5(3.0 \%)$ & $7(6.4 \%)$ & 0.17 \\
\hline \multicolumn{4}{|l|}{ Neo-adjuvant therapy } \\
\hline Chemoradiation & 32 (19.0\%) & $21(19.1 \%)$ & 0.97 \\
\hline $5 \times 5$ Radiation & $31(18.5 \%)$ & $35(31.8 \%)$ & $<0.01$ \\
\hline Diverting ileostomy & $54(32.1 \%)$ & $74(67.2 \%)$ & $<0.01$ \\
\hline Conversion to open surgery & $0(0 \%)$ & $3(2.7 \%)$ & 0.01 \\
\hline Median admission days (IQR) & $4(4-7)$ & $6(5-10)$ & 0.02 \\
\hline Median operation time in min (IQR) & $197(162-237)$ & $220(180-250)$ & 0.03 \\
\hline
\end{tabular}

IQR: Interquartile range; ASA: American Society of Anaesthesiologists; BMI: Body mass index; UICC: Union for International Cancer Control.

There were some differences in outcome. Median operation time was significantly shortened in the ICG-NIR group compared to the group without ICG-NIR ( $P=0.03)$. The initial surgical plan was influenced by fluorescence imaging with ICG-NIR in 26 (9.3\%) patients. In 24 of them the bowel was judged to be insufficiently perfused during the procedure which resulted in a more proximal transection site in 21 and a more distal transection in 3 patients. In one patient the mesenteric inferior artery was resected 
higher and in the other patient a sigmoidal artery branch was spared because of the absence of the left colic artery. Despite the more proximally transection site, anastomotic leakage occurred in two patients. Finally, one patient had an adverse reaction during surgery approximately two minutes after administration of ICG. Because of hypotension and severe bronchospasms, surgery had to be discontinued to support patient hemodynamically with steroids, extra fluids and an adrenaline pump. This anaphylactic shock was probably caused by the iodine component in ICG.

A difference was found in the number of diverting ileostomies in the ICG-NIR group compared to the group without the usage of ICG-NIR (31.9\% vs $67.2 \% \mathrm{P}<0.01$ ), Table 1 ). The subjective decision to make a diverting ileostomy in patients who had undergone surgery for rectal cancer is usually influenced by high risk factors. One of these risk factors is neoadjuvant treatment with chemo radiation or SCRT. Neoadjuvant chemo radiation had been performed in 53 patients. In $21(39.6 \%)$ of these patients no intraoperative ICG-NIR fluorescence was used, while in 32 (60.4\%) patients fluorescence was used. A diverting ileostomy was made in 19/21 (90.5\%) patients in the no ICG- NIR group compared to $19 / 32$ (59.3\%) patients in the ICG-NIR group ( $P=0.03$, Table 2a). There were 66 patients treated preoperatively with SCRT. Surgery with the use of intraoperative ICG-NIR occurred in 31 (47\%) SCRT patients. A diverting ileostomy was made in 14 patients in the ICG-NIR group and 31 in the no ICG-NIR group $(45.2 \%$ vs. 88.6\% $\mathrm{P}<0.01$ ) (Table $2 \mathrm{~b}$ ).

Table 2a Patients with rectal cancer who received neoadjuvant chemo radiation therapy.

\begin{tabular}{lccc}
\hline & $\begin{array}{c}\text { Patients with } \\
\text { ICG-NIR (N=32) }\end{array}$ & $\begin{array}{c}\text { Patients without } \\
\text { ICG-NIR (N=21) }\end{array}$ & P-value* $^{*}$ \\
\hline Anastomotic leakage & $4(12.5 \%)$ & $1(4.8 \%)$ & 0.64 \\
Diverting ileostomy & $19(59.3 \%)$ & $19(90.5 \%)$ & 0.03 \\
\hline
\end{tabular}

* Fisher's exact test.

Table $2 b \quad$ Patients with rectal cancer who received neoadjuvant 5 x 5 Gy radiation therapy.

\begin{tabular}{lccc}
\hline & $\begin{array}{c}\text { Patients with } \\
\text { ICG-NIR (N=31) }\end{array}$ & $\begin{array}{c}\text { Patients without } \\
\text { ICG-NIR (N=35) }\end{array}$ & P-value* \\
\hline Anastomotic leakage & $2(6.5 \%)$ & $3(8.6 \%)$ & 0.99 \\
Diverting ileostomy & $14(45.2 \%)$ & $31(88.6 \%)$ & $<0.001$ \\
\hline
\end{tabular}

* Fisher's exact test.

Postoperatively there were a few differences between both groups. Median length of stay (LOS) for patients with intraoperative usage of ICG-NIR was 4 days (IOR $4-7$ ) and 6 days (IQR $5-10)$ in the group without ICG-NIR ( $P=0.02$, Table 1). Anastomotic leakage occurred in 17 (6.1\%) patients. No statistical difference was found between the ICG-NIR and the control group. ( $7.1 \%$ vs $4.5 \%, \mathrm{P}=0.38$, Table 3 ). Also in higher risk groups as patients after SCRT or CRT no significant difference was found in the number of AL with or without ICG-NIR(Table 2a and 2b). 
Unfortunately five patients (1.8\%) died, all in the ICG-NIR group (Table 3). One patient because of respiratory insufficiency due to a severe pneumosepsis, one patients because of lung embolisms and one patient because of multi organ failure (MOF) based on a Fasciitis necroticans infection. Two patients died because of the consequences of postoperative irreversible ischemic bowel, in one of them, there was delayed perfusion of the bowel with ICG during the initial procedure due to extensive mesenteric atherosclerosis. No patient died because of the consequences of anastomotic leakage.

Table 3 Postoperative comorbidity of included patients.

\begin{tabular}{lccc}
\hline Postoperative complications & $\begin{array}{c}\text { Patients with } \\
\text { ICG-NIR (N=168) }\end{array}$ & $\begin{array}{c}\text { Patients without } \\
\text { ICG-NIR (N=110) }\end{array}$ & P-value \\
\hline Surgical complications & & & $5(4.5 \%)$ \\
$\quad$ Anastomotic leakage & $12(7.1 \%)$ & $2(1.8 \%)$ & 0.38 \\
Ileus requiring surgery & - & $2(1.8 \%)$ & $0.15^{*}$ \\
Abscess & $3(1.8 \%)$ & $1(0.9 \%)$ & $0.99^{*}$ \\
Perforation & - & $2(1.8 \%)$ & $0.39^{*}$ \\
Re-bleeding & $2(1.2 \%)$ & $1(0.9 \%)$ & $0.64^{*}$ \\
Ischaemic bowel & $2(1.2 \%)$ & $1(0.9 \%)$ & $0.99^{*}$ \\
Trocar site hernia & $1(0.6 \%)$ & - & $0.99^{*}$ \\
Fasciitis & $1(0.6 \%)$ & $1(0.9 \%)$ & $0.99^{*}$ \\
Septic (no cause found) & - & $1(0.9 \%)$ & $0.39^{*}$ \\
Surgical site infection & $1(0.6 \%)$ & $29(26.4 \%)$ & $0.99^{*}$ \\
Non-surgical complications & $30(17.8 \%)$ & & 0.09 \\
Clavien-Dindo complication scale ** & & $24(21.8 \%)$ & 0.10 \\
I + II (minor complications) & $24(14.2 \%)$ & $17(15.5 \%)$ & 0.31 \\
III + IV (major complications) & $19(11.2 \%)$ & - & $0.16^{*}$ \\
V (mortality) & $5(3.0 \%)$ & $13(11.8 \%)$ & 0.42 \\
Re-admission & $15(8.9 \%)$ & $14(12.7 \%)$ & 0.48 \\
Re-operation & $17(10.1 \%)$ & & \\
\hline
\end{tabular}

* Fisher Exact test; ** Some of the patients had 2 or more complications. The complication with the highest Clavien Dindo-scale score was documented.

\section{Discussion}

The aim of this study was to determine the results of introducing ICG-NIR fluorescence in the surgery of patients who had undergone robot assisted laparoscopic resections of rectal cancer. The first effect was a lowered mean operation time in the ICG-NIR group. There may be several reasons for this. First of all there may be two factors that lengthen operation time: the time to perform fluorescence and the time to perform an extra resection due to the findings after fluorescence. Then there are factors that may shorten the operation time. One of them may be the learning curve, as the non-ICG group was operated earlier in the series. As they already were experienced laparoscopic surgeons at the start of the study we think the effect of the overall operative learning curve for a low anterior resection was small or absent. But there may be a robotic learning curve, which is reflected in a significant lower median 
operation time and no conversion in the ICG-NIR group compared to three conversions in the control group. However, more important, less ileostomies were made in the ICG group. Median operative time for patients with an ileostomy was $247 \mathrm{~min}$ in the ICGNIR group and $224 \mathrm{~min}$ in the control group. Median operative time for patients without an ileostomy was $176 \mathrm{~min}$ in the ICG-NIR group and $211 \mathrm{~min}$ in the control group. The significant lower overall median operative time in the fluorescence group could therefore be explained by the significant lower rate of diverting ileostomies, requiring less time to complete the surgical procedure.

Fluorescence did not alter the anastomotic leakage rate, which is not in line with previous studies ${ }^{31,33-37,46}$. These studies did find a significant lower $A L$ rate in the fluorescence group. However, as our study, all these studies have their limitations. All are retrospective case-matched studies, except for the PILLAR II study. Jafari et al. conducted the only prospective, multicentre clinical trial that assessed the feasibility and utility of fluorescence angiography for intraoperative perfusion assessment during left sided colectomy and anterior resection (PILLAR II) ${ }^{31}$. Among the other studies there is a broad spectrum of study populations. Our study only included patients with rectal cancer, which is in line with other cohort studies ${ }^{34,36,37,45}$. Other authors also included patients with benign pathology such as diverticulitis ${ }^{31,46}$. Hellan et al. included patients with left sided malignancies ${ }^{35}$. Only two other studies did not find a significant lower $\mathrm{AL}$ rate in the fluorescence group ${ }^{45,47}$. In both studies the small sample size was acknowledged as limitation in this non-significant reduction in anastomotic leaks. Moreover, the retrospective nature and the different time period between the two groups that were compared, were corroborated as additional factors of limitation. These implications apply for our study as well. The much needed PILLAR III study, a randomized controlled trial, was terminated in June 2017 because of slow recruitment. So the level of evidence in the literature remains $\operatorname{low}^{48}$. A recently published systematic review and meta-analysis drew similar conclusions because of the absence of large well-designed RCT's to provide evidence for its routine use in oncologic colorectal surgery ${ }^{49}$.

ICG-NIR influenced our operative strategy in $9.3 \%$ of cases. Nevertheless two AL's occurred in 21 patients $(9.5 \%)$ in whom the transection site was moved to a more proximally better perfused intestine. Combined with an anastomotic leakage rate not lower in the fluorescence group, our study suggests that the assessment of perfusion by fluorescence has its flaws. Fluorescence during surgery is a one-time appreciation of the perfusion, while perfusion changes during and after surgery and venous congestion might occur. More important: adequate perfused bowel is not the only major prerequisite for a sufficient healing of anastomoses.

Perioperative factors such as tension on the anastomoses and technical failure of operation devices have been recognized as potential risk factors for developing $\mathrm{AL}^{12,50-52}$. Recently there is more interest in the role of bacteria in $\mathrm{AL}^{53,54}$. Bacterial 
contamination of the anastomotic region, caused either by intraoperative faecal spillage or by leakage through the anastomoses has long been known as a risk factor ${ }^{53}$. Bachmann et al. provided comprehensive insight in the theory that microbiome has a strong influence on the healing process of an intestinal anastomosis ${ }^{56}$. Several experimental and clinical trials showed significant changes in the anastomotic tissueassociated microbiota as a result of changes in local environmental conditions. These conditions can have virulence potential in anastomotic break-down ${ }^{57-62}$.

The unaffected percentage of $\mathrm{AL}$ while the percentage of diverting ileostomies lowered adds to the argument that perfusion is not the key factor in AL. This is the first series that determined the number of protecting ileostomies and showed a significant decreased rate in the fluorescence group. This was even found in patients who had received neoadjuvant treatment with chemo radiation therapy or SCRT. In general neoadjuvant treatment is considered to be a risk factor for AL. Diverting ileostomies are considered to lower the $A L$ or at least the consequences of $A L^{63-67}$. The exact mechanism why diverting ileostomies prevent $A L$ is unknown. Less motility of the bowel distal to the ileostomy could be an explanation. As a result of this lack of knowledge there is insufficient knowledge on when to divert or not. This is reflected in practice where some centres don't divert at all, while others divert in $100 \%$ of low anterior cases. Nevertheless, unnecessary ileostomies should be prevented because of the associated morbidity, decreased quality of life, surgeries and even permanent ileostomies $^{68,69}$. In the Netherlands there is a trend to apply less diverting ileostomies. In our study the three experienced surgeons proved to be more comfortable after fluorescence to disregard from a diverting stoma and our percentage of diversion lowered from $67.2 \%$ to $31.9 \%$. The decision to divert is a highly subjective one and, at least in our hospital, not a decision based on an institutional guideline. The decision is also multifactorial and there is no reliable methodology to quantify the influence of the separate factors on the decision. So we didn't record the subjective interpretation of influence of fluorescence on the decision process by the surgeons whether to create a diverting ileostomy or not. The fact that the decrease of diverting ileostomies was far more than the national trend, suggests that fluorescence played an important role in the decision making. Despite the subjective estimation of the surgeon, it was the right decision not to create a protective ileostomy as the percentage of $A L$ didn't rise. The shortened LOS in the group with ICG-NIR probably can be explained by the lower number of ileostomies.

In one patient a life threatening anaphylactic shock occurred within two minutes after injection of the dye (0.36\%). The allergic component of ICG solution is iodine. This patient had not been known to have an iodine allergy. The surgical and anaesthesiology team have to be aware of the potential allergic reactions in case of administration of ICG. In this study, the use of fluorescence imaging with ICG-NIR diminishes the need for the surgeon to perform an ileostomy without more anastomotic leakages. We feel that 
in our hands fluorescence lowers the number of second operations to reverse the ileostomy with the additional risks and lowers the ultimate percentage of permanent stomata. This will without any doubt lower the morbidity, re-operation rate and costs.

The limitation of fluorescence imaging with ICG-NIR is that the interpretation of the fluorescence signal is still subjective and depending on the surgeon's judgment. This might be influenced by several technical factors such as ICG-dosage, distance between the tip of the endoscope and the bowel, light cable quality, near-infrared light intensity, and patient characteristics such as BMI and blood pressure. Sherwinter et al. and a systematic review of Degett et al. used a quantification score system with five categories to realize a more objective perfusion assessment ${ }^{46,70}$. However, the quantification system did not lead to a cut off value in any of these two studies, which is needed to minimize the intra- and inter observatory differences ${ }^{58}$. Kim et al. also used a five step of transparency system to objectify intraoperative colorectal perfusion. Perfusion time was closely correlated with intensity, suggesting these 2 parameters are useful indicators for vascularity, vascular patency, and the perfusion status of the bowel $^{37}$.

Our study has several limitations. Most important is the retrospective non-randomized design of the study. Moreover we also did not use a quantification score system to objectify perfusion. One of the questions that remain after our study is: would there have been less AL if we had created more ileostomies in the ICG-NIR group? Without knowing the exact pathophysiology of $A L$ and the influence of all risk factors and even the mechanism how an ileostomy prevents $A L$ there will be no good answer on this question. For now we welcome the fluorescence technique in our hands as a useful instrument to lower the overall burden of rectal cancer surgery. As in our study, almost every study determining the usage and feasibility of fluorescence imaging with ICG-NIR in patients who had undergone (robot-assisted) colorectal surgery is based on a retrospective design with a case-matched control group. Only the PILLAR II study was a multicentre prospective study with a heterogeneous study population. We think that ICG-NIR has the potential to become a tool in intraoperative decision making. It is of crucial need to have multicentre randomised controlled data to assess the impact of this innovative technology on colorectal surgery in homogeneous study populations.

\section{Conclusion}

In our series, fluorescence angiography with ICG-NIR during robot-assisted surgery in patients with rectal cancer did not lower the rate of anastomotic leakages. However, we did find a significant lower number of diverting ileostomies in patients in the ICGNIR group, also those who had received neoadjuvant treatment. Correlated to this, the median LOS was lower in the ICG-NIR group. To understand the future role of fluorescence more knowledge has to be gathered on the significance of a lot of 
unknown aspects of fluorescence and on the pathophysiology of anastomotic leakages. In the meantime fluorescence may support the decision making of colorectal surgeons during surgery. 


\section{References}

1. Kube R, Mroczkowski P, Granowski D, Benedix F, Sahm M, Schmidt U, Gastinger I, Lippert H. Study group (Quality assurance in primary colorectal carcinoma). Anastomotic leakage after colon cancer surgery: a predictor of significant morbidity and hospital mortality, and diminished tumour-free survival. Eur J Surg Oncol. 2010;36:120-124.

2. Khan AA, Wheeler JM, Cunningham C, George B, Kettlewell M, Mortensen NJ. The management and outcome of anastomotic leaks in colorectal surgery. Colorectal Dis. 2008;10:587-592.

3 Matthiessen P, Hallböök O, Rutegård J, Sjödahl R. Population-based study of risk factors for postoperative death after anterior resection of the rectum. Br J Surg 2006;93:498-503.

4 Nesbakken A, Nygaard K, Lunde OC. Outcome and late functional results after anastomotic leakage following mesorectal excision for rectal cancer. Br J Surg. 2001;88:400-404.

5 Marra F, Steffen T, Kalak N, Warschkow R, Tarantino I, Lange J et al. Anastomotic leakage as a risk factor for the long-term outcome after curative resection of colon cancer. Eur J Surg Oncol. 2009;35:10601064.

6 Hammond J, Lim S, Wan Y, Gao X, Patkar A. The burden of gastrointestinal anastomotic leaks: an evaluation of clinical and economic outcomes. J Gastrointest Surg. 2014;18:1176-1185.

7 McDermott FD, Heeney A, Kelly ME, Steele RJ, Carlson GL, Winter DC. Systematic review of preoperative, intraoperative and postoperative risk factors for colorectal anastomotic leaks. Br J Surg. 2015;102:462-479.

8. Mirnezami A, Mirnezami R, Chandrakumaran K, Sasapu K, Sagar P, Finan P. Increased local recurrence and reduced survival from colorectal cancer following anastomotic leak: systematic review and metaanalysis. Ann Surg. 2011;253:890-899.

9. Lu ZR, Rajendran N, Lynch AC, Heriot AG, Warrier SK. Anastomotic Leaks After Restorative Resections for Rectal Cancer Compromise Cancer Outcomes and Survival. Dis Colon Rectum. 2016 Mar;59(3): 236-244.

10. Kang J, Choi GS, Oh JH, Kim NK, Park JS, Kim MJ, Lee KY, Baik SH. Multicenter Analysis of Long-Term Oncologic Impact of Anastomotic Leakage After Laparoscopic Total Mesorectal Excision: The Korean Laparoscopic Colorectal Surgery Study Group. Medicine (Baltimore). 2015;94(29):e1202.

11. Wang S, Liu J, Wang S, Zhao H, Ge S, Wang W. Adverse Effects of Anastomotic Leakage on Local Recurrence and Survival After Curative Anterior Resection for Rectal Cancer: A Systematic Review and Meta-analysis. World J Surg. 2017;Jan;41(1):277-284.

12. Park JS, Choi GS, Kim SH, Kim HR, Kim NK, Lee KY, Kang SB, Kim JY, Lee KY, Kim BC, Bae BN, Son GM, Lee $\mathrm{SI}$, Kang $\mathrm{H}$. Multicenter analysis of risk factors for anastomotic Leakage after laparoscopic rectal cancer excision: the Korean laparoscopic colorectal surgery study group. Ann Surg. 2013;257(4):665-671.

13. Peeters KC, Tollenaar RA, Marijnen CA, Klein Kranenbarg E, Steup WH, Wiggers T, Rutten HJ, van de Velde CJ; Dutch Colorectal Cancer Group. Risk factors for anastomotic failure after total mesorectal excision of rectal cancer. Br J Surg. 2005;92:211-216.

14. Karanjia ND, Corder AP, Bearn P, Heald RJ. Leakage from stapled low anastomosis after total mesorectal excision for carcinoma of the rectum. Br J Surg. 1994;81:1224-1226.

15. Wu Z, Vakalopoulos KA, Kroese LF, Boersema GS, Kleinrensink GJ, Jeekel J, Lange JF. Reducing anastomotic leakage by reinforcement of colorectal anastomosis with cyanoacrylate glue. Eur Surg Res. 2013;50(3-4):255-261.

16. Frouws MA, Snijders HS, Malm SH, Liefers GJ, Van de Velde CJH, Neijenhuis PA, Kroon HM. Clinical Relevance of a Grading System for Anastomotic Leakage After Low Anterior Resection: Analysis From a National Cohort Database. Dis Colon Rectum. 2017;Jul;60(7):706-713.

17. García-Granero E, Navarro F, Cerdán Santacruz C, Frasson M, García-Granero A, Marinello F, FlorLorente B, Espí A. Individual surgeon is an independent risk factor for leak after double-stapled colorectal anastomosis: An institutional analysis of 800 patients. Surgery. 2017;162(5):1006-1016.

18. Qin Q, Ma T, Deng Y, Zheng J, Zhou Z, Wang H, Wang L, Wang J. Impact of Preoperative Radiotherapy on Anastomotic Leakage and Stenosis After Rectal Cancer Resection: Post Hoc Analysis of a Randomized Controlled Trial. Dis Colon Rectum. 2016;59(10):934-942. 
19. Hu MH, Huang RK, Zhao RS, Yang KL, Wang H. Does neoadjuvant therapy increase the incidence of anastomotic leakage after anterior resection for mid and low rectal cancer? A systematic review and meta-analysis. Colorectal Dis. 2017;19(1):16-26.

20. Qu H, Liu Y, Bi DS. Clinical risk factors for anastomotic leakage after laparoscopic anterior resection for rectal cancer: a systematic review and meta-analysis. Surg Endosc. 2015;29(12):3608-3617.

21. Cauchy F, Abdalla S, Penna C, Angliviel B, Lambert B, Costaglioli B, Brouquet A, Benoist S. The small height of an anastomotic colonic doughnut is an independent risk factor of anastomotic leakage following colorectal resection: results of a prospective study on 154 consecutive cases Int J Colorectal Dis. 2017;32(5):699-707.

22. Bakker N, Deelder JD, Richir MC, Cakir H, Doodeman HJ, Schreurs WH, Houdijk AP. Risk of anastomotic leakage with nonsteroidal anti-inflammatory drugs within an enhanced recovery program. J Gastrointest Surg. 2016;20(4):776-82.

23. Trencheva K, Morrissey KP, Wells M, Mancuso CA, Lee SW, Sonoda T, Michelassi F, Charlson ME, Milsom JW. Identifying important predictors for anastomotic leak after colon and rectal resection: prospective study on 616 patients. Ann Surg. 2013;257:108-13.

24. Vignali A, Gianotti L, Braga M, Radaelli G, Malvezzi L, Di Carlo V. Altered microperfusion at the rectal stump is predictive for rectal anastomotic leak. Dis Colon Rectum. 2000;43:76-82.

25. Sheridan WG, Lowndes RH, Young HL. Tissue oxygen tension as a predictor of colonic anastomotic healing. Dis Colon Rectum. 1987;30:867-871.

26. Kologlu M, Yorganci K, Renda N, Sayek I. Effect of local and remote ischemia- reperfusion injury on healing of colonic anastomoses. Surgery. 2000;128:99-104.

27. Boersema GS, Wu Z, Kroese LF, Vennix S, Bastiaansen-Jenniskens YM, van Neck JW, Lam KH, Kleinrensink GJ, Jeekel J, Lange JF. Hyperbaric oxygen therapy improves colorectal anastomotic healing. Int J Colorectal Dis. 2016;31(5):1031-1038.

28. Karliczek A, Harlaar NJ, Zeebregts CJ, Wiggers T, Baas PC, van Dam GM. Surgeons lack predictive accuracy for anastomotic leakage in gastrointestinal surgery. Int J Colorectal Dis. 2009;24:569-576.

29. Markus PM, Martell J, Leister I, Horstmann O, Brinker J, Becker H. Predicting postoperative morbidity by clinical assessment. Br J Surg. 2005;92:101-106.

30. Diana M, Noll E, Diemunsch P, Dallemagne B, Benahmed MA, Agnus V, Soler L, Barry B, Namer IJ, Demartines N, Charles AL, Geny B, Marescaux J. Enhanced-reality video fluorescence: a real-time assessment of intestinal viability. Ann Surg. 2014;259(4):700-707.

31. Jafari MD, Wexner SD, Martz JE, McLemore EC, Margolin DA, Sherwinter DA, Lee SW, Senagore AJ, Phelan MJ, Stamos MJ. Perfusion assessment in laparoscopic left sided/anterior resection (PILLAR II): a multi-institutional study. J Am Coll Surg. 2015;220(1):828-92e8.

32. Boni L, David G, Dionigi G, Rausei S, Cassinotti E, Fingerhut A. Indocyanine greencenhanced fluorescence to assess bowel perfusion during laparoscopic colorectal resection. Surg Endosc. 2016;30(7):2736-2742.

33. Kudszus S, Roesel C, Schachtrupp A, Hoer JJ. Intraoperative laser fluorescence angiography in colorectal surgery: a noninvasive analysis to reduce the rate of anastomotic leakage. Langenbecks Arch Surg. 2010;395:1025-1030.

34. Jafari MD, Lee KH, Halabi WJ, Mills SD, Carmichael JC, Stamos MJ, Pigazzi A. The use of indocyanine green fluorescence to assess anastomotic perfusion during robotic assisted laparoscopic rectal surgery. Surg Endosc. 2013;27:3003-3008

35. Hellan M, Spinoglio G, Pigazzi A, Lagares-Garcia JA. The influence of fluorescence imaging on the location of bowel transection during robotic left-sided colorectal surgery. Surg Endosc. 2014;28: 1695-1702.

36. Kim JC, Lee JL, Yoon YS, Alotaibi AM, Kim J. Utility of indocyanine-green fluorescent imaging during robot-assisted sphincter-saving surgery on rectal cancer patients. Int J Med Robotics Comput Assist Surg. 2016;12:710-717.

37. Kim JC, Lee JL, Park SH. Interpretative Guidelines and Possible Indications for Indocyanine Green Fluorescence Imaging in Robot-Assisted Sphincter-Saving Operations. Dis Colon Rectum. 2017;60: 376-384.

38. National guidelines Integraal kankercentrum Nederland (IKNL). Landelijke werkgroep Gastro Intestinale Tumoren versie 3.0. (consulted on 09 June 2018) https://www.oncoline.nl/index.php?pagina=/richtlijn/ item/pagina.php\&id=37085\&richtlijn_id=933 
39. Dindo D, Demartines N, Clavien PA. Classification of surgical complications a new proposal with evaluation in a cohortof 6336 patients and results of a survey. Ann Surg. 2004;240:205-213.

40. Khoury W, Ben-Yehuda A, Ben-Haim M, Klausner JM, Szold O. Abdominal computed tomography for diagnosing postoperative lower gastrointestinal tract leaks. J Gastrointest Surg. 2009;13(8):1454-1458.

41. O'Hara LM, Thom KA, Preas MA. Update to the Centers for Disease Control and Prevention and the Healthcare Infection Control Practices Advisory Committee Guideline for the Prevention of Surgical Site Infection (2017): A summary, review, and strategies for implementation. Am J Infect Control. 2018;46(6):602-609.

42. Clinical Guideline: Colorectal Cancer: The Diagnosis and Management of Colorectal Cancer. Full Guideline. http://www.nice.org.uk/guidance/cg131/resources/colorectalcancer-full-guideline2, 2015.

43. Alander JT, Kaartinen I, Laakso A, Pätilä T, Spillmann T, Tuchin VV, Venermo M, Välisuo P. A review of indocyanine green fluorescent imaging in surgery. Int J Biomed Imaging. 2012:940585.

44. Cahill RA, Ris F, Mortensen NJ. Near-infrared laparoscopyfor real-time intra-operative arterial and lymphatic perfusion imaging. Colorectal Dis. 2011;13(Suppl 7):12-17.

45. Boni L, Fingerhut A, Marzorati A, Rausei S, Dionigi G, Cassinotti E. Indocyanine green fluorescence angiography during laparoscopic low anterior resection: results of a case-matched study. Surg Endosc. 2017;31:1836-1840.

46. Sherwinter DA, Gallagher J, Donkar T. Intra-operative transanal near infrared imaging of colorectal anastomotic perfusion: a feasibility study. Colorectal Dis. 2013;15:91-96.

47. Kin C, Vo H, Welton L, Welton M. Equivocal effect of intraoperative fluorescence angiography on colorectal anastomotic leaks. Dis Colon Rectum. 2015;58(6):582-587.

48. U.S. National Library of Medicine ClinicalTrials .gov. A study assessing perfusion outcomes with PINPOINT near infrared fluorescence imaging in low anterior resection (PILLAR III) https://clinicaltrials.gov/ct2/show/NCT02205307

49. Blanco-Colino R, Espin-Basany E. Intraoperative use of ICG fluorescence imaging to reduce the risk of anastomotic leakage in colorectal surgery: a systematic review and meta-analysis. Techniques in Coloproctology. 2018;22:15-23.

50. Kingham TP, Pachter HL. Colonic anastomotic leak: risk factors, diagnosis, and treatment. J Am Coll Surg. 2009;208(2):269-278.

51. Kim MJ, Shin R, Oh HK, Park JW, Jeong SY, Park JG. The impact of heavy smoking on anastomotic leakage and stricture after low anterior resection in rectal cancer patients. World J Surg. 2011;35(12):2806-2810.

52. Thompson SK, Chang EY, Jobe BA. Clinical review: healing in gastrointestinal anastomoses, part I. Microsurgery. 2006;26(3):131-136.

53. Gaines S, Shao C, Hyman N, Alverdy JC. Gut microbiome influences on anastomotic leak and recurrence rates following colorectal cancer surgery. Br J Surg. 2018;105(2):e131-e141.

54. Alverdy JC, Hyoju SK, Weigerinck M, Gilbert JA. The gut microbiome and the mechanism of surgical infection. Br J Surg. 2017;104(2):e14-e23

55. Törnqvist A. Jiborn H. Zederfeldt B. Forsgren A. Peroperative contamination and anastomotic leakage after resection for left colon stenosis. Int J Colorect Dis. 1990;5:164-166.

56. Bachmann R, Leonard D, Delzenne N, Kartheuser A, Cani PD. Novel insight into the role of microbiota in colorectal surgery. Gut. 2017;66:738-749.

57. Cohn I Jr, Rives JD. Antibiotic protection of colon anastomoses. Ann Surg. 1955;141:707-717.

58. Komen N, Slieker J, Willemsen P, Mannaerts G, Pattyn P, Karsten T, de Wilt H, van der Harst E, van Leeuwen W, Decaestecker C, Jeekel H, Lange JF. Polymerase chain reaction for Enterococcus faecalis in drain fluid: the first screening test for symptomatic colorectal anastomotic leakage. The Appeal-study: analysis of parameters predictive for evident anastomotic leakage. Int J Colorectal Dis. 2014;29:15-21.

59. Okada M, Bothin C, Kanazawa K, Midtvedt T. Experimental study of the influence of intestinal flora on the healing of intestinal anastomoses. Br J Surg. 1999;86:961-965.

60. Schardey HM, Joosten U, Finke U, Schauer R, Staubach KH, Exner H, Schildberg FW. Cost savings by disinfection for prevention of surgical wound dehiscence after gastrectomy. Chirurg. 1997;68:416-424.

61. Wu L, Zaborina O, Zaborin A, Chang EB, Musch M, Holbrook C, Shapiro J, Turner JR, Wu G, Lee KY, Alverdy JC. High-molecular-weight polyethylene glycol prevents lethal sepsis due to intestinal Pseudomonas aeruginosa. Gastroenterology. 2004;126:488-498. 
62. Krezalek MA, Skowron KB, Guyton KL, Shakhsheer B, Hyoju S, Alverdy JC. The intestinal microbiome and surgical disease. Curr Probl Surg. 2016;53:257-293.

63. Mrak K, Uranitsch S, Pedross F, Heuberger A, Klingler A, Jagoditsch M, Weihs D, Eberl T, Tschmelitsch J. Diverting ileostomy versus no diversion after low anterior resection for rectal cancer: A prospective, randomized, multicenter trial. Surgery. 2016. Apr;(4):1129-1139.

64. Wu S, Ma CC, Yang Y. Role of protective stoma in low anterior resection for rectal cancer: A metaanalysis. World J Gastroenterol. 2014;21;20(47):18031-18037.

65. Hanna $\mathrm{MH}$, Vinci A, Pigazzi A. Diverting ileostomy in colorectal surgery: when is it necessary? Langenbecks Arch Sur. 2015;400:145-152.

66. Gu W, Wu S. Meta-analysis of defunctioning stoma in low anterior resection with total mesorectal excision for rectal cancer: evidence based on thirteen studies. World Journal of Surgical Oncology. 2015;13:9

67. Jonker FHW, Tanis PJ, Coene PPLO, Gietelink L, van der Harst E and Dutch Surgical Colorectal Audit Group. Comparison of a low Hartmann's procedure with low colorectal anastomosis with and without defunctioning ileostomy after radiotherapy for rectal cancer: results from a national registry. Colorectal Disease. 2016;18:785-794.

68. Ihnát $\mathrm{P}$, Guňková $\mathrm{P}$, Peteja $\mathrm{M}$, Vávra $\mathrm{P}$, Pelikán $\mathrm{A}$, Zonča P. Diverting ileostomy in laparoscopic rectal cancer surgery: high price of protection. Surgical Endoscopy. 2016;30(11):4809-4816.

69. Herrle F, Sandra-Petrescu F, Weiss C, Post S, Runkel N, Kienle P. Quality of Life and Timing of Stoma Closure in Patients With Rectal Cancer Undergoing Low Anterior Resection With Diverting Stoma: A Multicenter Longitudinal Observational Study. Dis Colon Rectum. 2016;59(4):281-90.

70. Degett TH, Andersen HS, Gögenur I. Indocyanine green fluorescence angiography for intraoperative assessment of gastrointestinal anastomotic perfusion: a systematic review of clinical trials. Langenbecks Arch Surg. 2016;401:767-775. 

Part III

General discussion, future perspectives and summary 



\section{Chapter 9}

General discussion and future perspectives 



\section{General discussion}

\section{Colonoscopy after uncomplicated diverticulitis}

The Dutch guidelines and Dutch Society of Surgeons in the Netherlands recommend to limit the indication for colonoscopy only to symptomatic patients ${ }^{1,2}$. In contrast, the guidelines of the European Association for Endoscopic Surgery and the American Society of Colon and Rectal Surgeons recommend routine colonoscopy ${ }^{3,4}$. Several authors recommend a colonoscopy several weeks after resolution of symptoms to confirm the diagnosis of diverticular disease and rule out other pathology of the colon such as a malignancy ${ }^{3,5,6}$. However, this was not based on actual evidence. Not only do the Dutch guidelines advise not to perform a colonoscopy on a routine basis, but other studies also have shown that colonoscopy is only indicated when diagnosis is uncertain on a CT scan in case the patient present with alarm symptoms and/or has risk factors for colorectal cancer such as a positive family history ${ }^{7}$. In addition, two published studies (a meta-analysis and a review) concluded that colonoscopy is only indicated when the patient presents with alarm symptoms or has a complicated episode of acute diverticulitis $^{8,9}$. In these high-risk patients, the benefits of potentially diagnosing neoplasia or malignancy would most definitely outweigh the risks of colonoscopy ${ }^{8}$. The risk of colorectal cancer after a radiologically proven episode of acute uncomplicated diverticulitis is low ${ }^{7}$. Until now, there was limited evidence to perform a colonoscopy on a routine basis after an episode of acute diverticulitis in asymptomatic patients to exclude other pathology of the colon. To differentiate for colorectal cancer, our advice would be, based on our own cohort, that only patients with alarm symptoms for CRC should have the diagnostic work-up through colonoscopy. This would result in less patient burden and possibly less colonoscopy-related risks and complications. Also, national health care costs could be reduced. However, there are few large colonoscopy series and no previous series to describe tumour characteristics for these patients. Nonetheless, this thesis describes these patients with colorectal cancer and the accompanied alarm symptoms. In summary, in the case of these alarm symptoms, a diagnostic colonoscopy appears to be indicated after a first episode of uncomplicated diverticulitis. If a concomitant CRC is found, it is often an advanced T-stage and located on the left colon and sigmoid.

\section{Quality management after curative surgery in colorectal cancer patients}

As stated in the introduction, surgery remains the cornerstone in treating CRC. The affected malignant tumour(s) and any nearby lymph nodes will be removed, to reduce the risk of the cancer spreading in the (near) future. Not all patients who will undergo surgery present with the same symptoms such as rectal blood loss, change in bowel habits, unintentional weight loss and/or anaemia. Some of the patients with CRC present with symptoms of an acute obstruction or an ileus. The definition of ileus varies in the published literature, and without a universally accepted definition, tumour 
locations causing an ileus will continue to vary in future publications. In our study, an ileus was defined as a clinical finding that could be confirmed with radiological findings. Other authors define an ileus as a clinical finding, and when symptoms are vague, obstruction is then defined as colorectal disease requiring emergency surgery ${ }^{10}$. Differences in definition lead to misunderstanding and heterogeneous study populations. Previous studies have shown that obstructing CRC is associated with increased rates of distant metastases; this is confirmed in our data ${ }^{11-13}$. Surveillance of patients after obstructing CRC, however, has a specific importance because of the higher incidence in distant metastases. Patients with obstructive CRC after curative surgery might benefit from a more intensive surveillance programme. Several authors have determined and shown the advantage of an intensive surveillance programme ${ }^{14-17}$. This study provides evidence that patients with obstructive CRC have not only worse short-term survival but also decreased long-term survival compared to patients who do not present with acute obstruction of the colon. A more intensive surveillance programme could be beneficial for patients who survive the short term post-operative phase.

For detecting colorectal cancer, there are many potential screening modalities. However, the major clinical guidelines all recommend colonoscopy as the preferred test because it detects both cancers as well as precancerous lesions with high reliability ${ }^{18}$. Also, after curative surgery, a colonoscopy is indicated to detect recurrent luminal disease. If a preoperative colonoscopy was incomplete or not even performed, a postoperative or completing colonoscopy should be performed within 3 months after resection to detect synchronous neoplasia ${ }^{19}$. If appropriate endoscopic removal of premalignant lesions is performed at the time of diagnosis of the primary tumour, any lesions found during following colonoscopies are categorized as metachronous ${ }^{20}$. However, it is possible that some of these synchronous lesions were missed during preoperative colonoscopy, meaning this index colonoscopy should be classified as incomplete. These colonoscopies could be of questionable quality due to poor intestinal preparation (up to $25 \%$ of the patients in some clinics) or because of the presence of flat adenomas or depressed lesions, which have a fairly high malignant potential $^{21,22}$. This provides another reason to perform the first postoperative surveillance colonoscopy one year after curative surgery. The frequency and interval of postoperative colonoscopies vary among different clinics and institutions. In some cases, the physicians discourage surveillance colonoscopy in patients for whom the potential benefit of surveillance is low due to advanced age and/or co-morbidities, which increases the risk of death. It is very challenging to determine the frequency and time interval of postoperative endoscopic follow-up to improve a (disease-free) survival benefit in CRC patients. Several trials have been conducted, but they have too many methodological inconsistencies, which makes comparing these studies even more challenging ${ }^{23-26}$. However, they all concluded that endoscopic surveillance alone would not be useful enough for patients with local recurrence, because of the extra luminal 
development; therefore, other imaging techniques should be part of a surveillance programme $e^{27,28}$. To evaluate and determine efficient surveillance colonoscopy intervals, current colonoscopy guidelines should be evaluated by an RCT in which patients, who undergo colonoscopy early after 3-6 months postoperatively are compared with those undergoing normal surveillance colonoscopy after 1, 3 and 5 years.

In our study cohort, a preoperative elevated CEA measurement of $>5 \mu \mathrm{g} / \mathrm{L}$ has a sensitivity of $40 \%$ for detecting colorectal cancer. Lowering the threshold would cause a higher rate of false positives. On the other hand, increasing the threshold would cause a higher rate of false negatives. During follow-up, CEA measurements are common because its increase could correlate with cancer recurrence. In some patients, it remains unclear how to interpret an elevated follow-up serum CEA level and its accuracy in detecting metastatic disease. It is also unclear whether postoperative CEA levels should be monitored in patients with recurrence who had normal preoperative serum CEA levels. Elevated postoperative CEA levels could lead to false positives, causing unnecessary additional imaging, radiation exposure, and longer waiting lists. Along with serum CEA, information from the patient's medical history and physical examination are needed to decide whether to perform additional imaging. A recently published randomized controlled trial (RCT) evaluated the role of CEA in predicting recurrence and outcomes of surgical treatment with curative intent. The Follow-up after Colorectal Surgery (FACS) trial concluded that CEA testing should not be used as a single triage test ${ }^{29}$.

$\mathrm{AL}$ remains one of the most devastating complications after colorectal surgery, resulting in high morbidity and mortality rates ${ }^{30-32}$. There are conflicting reports concerning the oncologic outcomes in patients with anastomotic leakage after curative surgery for colorectal cancer. Increased rates of local recurrence and the development of systemic disease after anastomotic leakage have been reported ${ }^{33,34}$. In our study population, AL was associated with the development of local recurrence. However, no association was found between anastomotic leakage and the development of distant metastasis. The pathophysiology of developing local and distant recurrence after anastomotic leakage for colorectal cancer remains unclear, but several mechanisms have been reported such as micro perforation before or during surgery and abdominal sepsis, which is accompanied by (chronic) inflammation ${ }^{35,36}$. In our study, we showed that this finding was accompanied by significantly impaired overall survival. Patients who survive abdominal sepsis in the acute phase after anastomotic leakage are exposed to a significant hazard of developing local recurrence. A logical possible next step in acknowledging this problem would be to deliberate over therapeutic options after anastomotic leakage to reduce this hazard and increase the frequency of surveillance moments. Treating patients with adjuvant chemotherapy or radiation after anastomotic leakage will raise many questions, especially on ethical grounds, indicating that even patients with tumour stage I or II are potential candidates for adjuvant 
therapy after anastomotic leakage, while such therapy is initially not indicated in their pTNM stages. This fact might be an incentive for the required future studies. However, before this proposal can be investigated, there must first be consensus and recognition of the increased hazard for local recurrence after AL.

During the operation, the surgeon might reduce the risk of anastomotic leakage by measures that reduce tension of the anastomoses, which ascertain an adequate bowel perfusion and diversion of the faecal passage by creating a temporary ileostomy. Indocyanine green in combination with near infra-red light is a promising tool in intraoperative decision making.

In this study fluorescence angiography with ICG-NIR during robot-assisted surgery in patients with rectal cancer did not lower the rate of anastomotic leakages. However, more importantly, less ileostomies were made in the ICG group and influenced the operative strategy in $9.3 \%$ of the cases. We conducted the first series that determined the number of protecting ileostomies and showed a significant decreased rate in the fluorescence group. Diverting ileostomies are considered to lower the anastomotic leakage or at least the consequences of anastomotic leakage ${ }^{37,38}$. As a result of this lack of knowledge, there is insufficient knowledge on when to divert or not. Nevertheless, unnecessary ileostomies should be prevented because of the associated morbidity, decreased quality of life, surgeries and even permanent ileostomies ${ }^{39,40}$. Combined with an anastomotic leakage rate not lower in the fluorescence group, our study suggests that the assessment of perfusion by fluorescence has its flaws. More importantly, adequate perfused bowel is not the only major prerequisite for sufficient healing of anastomoses. Perioperative factors such as tension on the anastomoses and technical failure of operation devices have been recognized as potential risk factors for developing anastomotic leakage $\mathrm{H1}^{43}$. The only limitation of ICG-NIR is that the interpretation of the fluorescence signal is still subjective and depends on the surgeon's judgment. A quantification score system is needed to realize a more objective perfusion assessment $^{44}$. To understand the future role of fluorescence, more knowledge must be gathered on the significance of many unknown aspects of fluorescence and on the pathophysiology of anastomotic leakages. In the meantime, fluorescence might support the decision-making of colorectal surgeons during robot-assisted surgery.

\section{Future perspectives}

Recently there has been a change in the surgical treatment of recurrent diverticulitis and perforated diverticulitis with purulent or faecal peritonitis. The DIRECT-trial conclude that elective sigmoidectomy, despite the inherent risk of complications, leads to improved quality of life compared to conservative management in patients with recurrent and persisting abdominal complaints after an episode of left-sided diverticulitis ${ }^{45}$. Moreover, the LADIES-trial found that primary anastomosis was superior 
to Hartmann's procedure for the treatment of perforated diverticulitis with regard to 12-month stoma free-survival and overall morbidity after stoma reversal ${ }^{46}$. These two RCT's brought up a major shift towards a more daring surgical treatment compared to the current wait and see, and more conservative treatment. Until recently, if surgery was the treatment of choice, the consideration of a temporary stoma was quickly made in both cases of recurrent diverticulitis and in patients with perforated left-sided diverticulitis. However, future research should be conducted within the field of endoscopic follow-up in patients who developed an episode of uncomplicated diverticulitis. Current literature on this topic is mainly based on retrospective cohorts or on nation-wide case control studies with lack of an adequate control group or low quality of colonoscopies. A definitive study would require a large prospective multicentre cohort of patients with colonoscopy after an episode of acute diverticulitis compared to an asymptomatic screening cohort with an appropriate power analysis and colonoscopies that are performed within criteria of quality guidelines. A more refined approach to the general recommendation of colonoscopy after imaging proven diagnosis of acute diverticulitis may be considered. The follow-up colonoscopy will only be targeted to high risk patients. These are the cases with complicated diverticulitis, suspicious radiologic findings or alarm symptoms for colorectal cancer.

Over the past decades we have learned a lot about colorectal cancer. Because of innovation and modernization, surgical treatment has made enormous steps forward in optimizing patient care. A well-known example is the benefit of laparoscopic surgery compared to open surgery in patients undergoing elective surgery. However, seeking for progression and the development of better equipment and tools in diagnostics and surgical treatment are still the main goal to improve (cancer free) survival. Robotassisted surgery is another example of modernization in surgical approach. On the long term, advantages of this relatively new approach should lead to shorter hospitalization, reduced pain and wound infections, and faster recovery time which leads to patients' return to normal activities. A very interesting tool, which has been described previously in this thesis, is intraoperative usage of near infrared light combined with fluorescence to assess bowel perfusion. Fluorescence guided surgery seems to be of value in other purposes as well. Several studies demonstrated that intraoperative near-infrared fluorescence imaging using indocyanine green identifies (sub)capsular colorectal liver metastases, which are missed by other techniques ${ }^{47,48}$. Another example is intraoperative tumour-targeted fluorescence imaging which has the potential to advance current practice of oncological surgery by selectively highlighting malignant tissue during surgery. CEA is overexpressed in the majority (90\%) of colorectal cancers and is a target in imaging with a fluorescent anti-CEA monoclonal antibody. This could eventually influence clinical decision making during the surgical procedure for patients with colorectal cancer ${ }^{49}$. 
Over the past decade, advances in molecular biology and genomics techniques have revolutionized the diagnosis and treatment of cancer. Also in the field of tumour markers, there has been some new insights. Recently, advancements from molecular studies have provided the opportunity to test novel tumour markers ${ }^{50}$. Additional methods for authentication of new tumour biomarkers and multicentre RCTs are necessary. Moreover, a next step towards a more accurate diagnosis of primary gastrointestinal and liver neoplasms will be possible. Application of immunohistochemistry in gastrointestinal and liver tumours continues to evolve. New tumourspecific markers constantly emerge and help pathologists to further improve diagnostic accuracy. Assessment of predictive and prognostic markers by immunohistochemistry in routine pathologic diagnosis is a new trend and will greatly facilitate the advancement of personalized cancer therapy ${ }^{51}$.

Tissue biopsy remains the gold standard for the establishment of a cancer diagnosis. It provides information for tumour classification, assessment of invasiveness and degree of differentiation, characterization of genetic makeup and mutational status, and provides insight into prognosis. Such information can help guide and personalize treatment strategy. However, tissue biopsies are invasive, costly, and not without complications; sometimes, tissue is not amenable to biopsy due to anatomic location or an underlying coagulopathy. Moreover, tissue biopsies only offer a snapshot of a tumour at one particular time-point and may not always reflect the complete genetic makeup of a neoplasm which is undergoing constant evolution. Liquid biopsy is the sampling of any biological fluid in an effort to enrich and analyse a tumours genetic material. Peripheral blood remains the most studied liquid biopsy material, with circulating tumour cells (CTC's) and circulating tumour DNA (ctDNA) allowing the examination and longitudinal monitoring of a tumours genetic landscape ${ }^{52}$. Liquid biopsy has the potential to significantly impact cancer diagnostics and treatment paradigms. With applications in cancer screening, prognostic stratification, therapy selection and disease surveillance, liquid biopsy represents an exciting new paradigm in the field of cancer diagnostics which can lead to improved patient outcomes and survival $^{53}$.

As mentioned before, patients undergo surveillance colonoscopy as they are at risk for recurrent and metachronous CRC. There are even new theories regarding the cause and development of metachronous colorectal cancer. Other different causes for metachronous CRC have been suggested such as incomplete polypectomies or missed lesions. The causative processes involved are yet still not fully understood. Previous studies have shown that tumour cells exfoliate from CRC into the intestinal lumen, especially when the tumour is manipulated ${ }^{54,55}$. A recently published proof principle study found that primary tumour cells might be seeded in a new location after biopsy of the primary tumour ${ }^{56}$. The molecular findings support the hypothesis that tumour seeding can occur during colonoscopy via the working channel of the endoscope. The 
possibility of iatrogenic seeding seems low. However, this study provides evidence and should compel awareness on this potentially preventable cause of metachronous CRC. Future studies are necessary to increase knowledge in preventing tumour seeding.

In conclusion, we have arrived in the era of precision medicine. However, a considerable amount of progress needs to be made prior to the widespread clinical implementation of these new implications in colorectal cancer care. Elevated tumour markers, complicated course after curative surgery and obstructive colorectal cancer are risk factors for disease recurrence. They may benefit from a more intensive surveillance programme. Specifically, additional prospective, multi-center studies must validate preliminary findings for patients with colorectal cancer. Moreover, further development of clinically implementable technologies such as cost-effective and sensitive assays for detecting and analyzing genetic alterations are needed. Improving patient selection and advances in knowledge of tumor biology and mechanisms will eventually have significantly impact in cancer diagnostics and treatment paradigms in colorectal cancer patients. 


\section{References}

1. Dutch Society of Surgery. Diagnostic and treatment of acute diverticulitis of the colon. Dutch guidelines diagnostics and treatment of acute colonic diverticulitis. 2012. Available at: http://www.mdl.nl/ uploads/240/1137/Acute-diverticulitis-van-hetcolon-2012.pdf.

2. Vennix S, Morton DG, Hahnloser D, Lange JF, Bemelman WA; Research Committee of the European Society of Coloproctocology. Systematic review of evidence and consensus on diverticulitis: an analysis of national and international guidelines. Colorectal Dis. 2014;24:866-878.

3. Stollman NH, Raskin JB. Diagnosis and management of diverticular disease of the colon in adults. Ad Hoc Practice Parameters Committee of the American College of Gastroenterology. Am J Gastroenterol. 1999;94:3110-3121.

4. O'Neill S, Ross P, McGarry P. Latest diagnosis and management of diverticulitis. Br J Med Pract. 2011;4:a443-a450.

5. Westwood DA, Eglinton TW, Frizelle FA. Routine colonoscopy following acute uncomplicated diverticulitis. Br J Surg. 2011;98:1630-1634.

6. Beckham $\mathrm{H}$, Whitlow $\mathrm{CB}$. The medical and nonoperative treatment of diverticulitis. Clin Colon Rectal Surg. 2009;22:156-160.

7. Lecleire S, Nahon S, Alatawi A, Antonietti M, Chaput U, Di-Fiore A, Alhameedi R, Marteau P, Ducrotté $P$, Dray X. Diagnostic impact of routine colonoscopy following acute diverticulitis: a multicentre study in 808 patients and controls. United European Gastroenterol J. 2014;2:301-306.

8. Sharma PV, Eglinton T, Hider P, Frizelle F. Systematic review and meta-analysis of the role of routine colonic evaluation after radiologically confirmed acute diverticulits. Ann Surg. 2014;256:263-272.

9. Agarwal AK, Karanjawala BE, Maykel JA, Johnson EK, Steele SR. Routine colonic endoscopic evaluation following resolution of acute diverticultis: is it necessary? World J Gastroenterol. 2014;20: 12509-12516.

10. Moolla Z, Madiba TE. Trends in demographics and management of obstructing colorectal cancer. World J Surg. 2014;38:2466-2470.

11. Smothers L, Hynan L, Fleming J, Turnage R, Simmang C, Anthony T. Emergency surgery for colon carcinoma. Dis Colon Rectum. 2003;46:24-30.

12. CortetM, Grimault A, Cheynel N, Lepage C, Bouvier AM, Faivre J. Patterns of recurrence of obstructing colon cancers after surgery for cure: a population-based study. Color Dis. 2013;15:1100-1106.

13. Umpleby HC, Williamson RC. Survival in acute obstructing colorectal carcinoma. Dis Colon Rectum. 1984;27:299-304.

14. Renehan AG, Egger M, Saunders MP, O’Dwyer ST. Impact on survival of intensive follow up after curative resection for colorectal cancer: systematic review and meta-analysis of randomised trials. BMJ. 2002;324:813.

15. Scholefield JH, Robinson MH, Mangham CM, Hardcastle JD. Screening for colorectal cancer reduces emergency admissions. Eur J Surg Oncol. 1998;24:47-50.

16. RosatiG, Ambrosini G, Barni S, Andreoni B, Corradini G, Luchena G, Daniele B, Gaion F, Oliverio G, Duro M, Martignoni G, Pinna N, Sozzi P, Pancera G, Solina G, Pavia G, Pignata S, Johnson F, Labianca R, Apolone G, Zaniboni A, Monteforte M, Negri E, Torri V, Mosconi P, Fossati R. A randomized trial of intensive versus minimal surveillance of patients with resected Dukes B2-C colorectal carcinoma. Ann Oncol. 2016;27:274-280.

17. Glover C, Douse P, Kane P, Karani J,Meire H, Mohammadtaghi S, Allen-Mersh TG. Accuracy of investigations for asymptomatic colorectal liver metastases. Dis Colon Rectum. $2002 ; 45: 476-484$.

18. Young PE, Womeldorph CM. Colonoscopy for Colorectal Cancer Screening. J Cancer. 2013;4(3):217-226.

19. Dutch Guidelines colonoscopy surveillance. Nederlandse Vereninging van Maag-, Darm en Leverartsen in samenwerking met Nederlandse Vereniging van Pathologie. https://www.mdl.nl/sites/ www.mdl.nl/ files/richlijnen/Richtlijn_Coloscopie_Surveillance_definitief_2013.pdf

20. Rex DK, Kahi CJ, Levin B, Smith RA, Bond JH, Brooks D, et al. Guidelines for colonoscopy surveillance after cancer resection: a consensus update by the American Cancer Society and the US Multi-Society Task Force on Colorectal Cancer. Gastroenterology. 2006;130:1865-71. 
21. Soetikno RM, Kaltenbach T, Rouse RV, Park W, Maheshwari A, Sato T, et al. Prevalence of nonpolypoid (flat and depressed) colorectal neoplasms in asymptomatic and symptomatic adults. JAMA. 2008;299:1027-35.

22. Matsuda T, Saito Y, Hotta K, Sano Y, Fujii T. Prevalence and clinicopathological features of nonpolypoid colorectal neoplasms: should we pay more attention to identifying flat and depressed lesions? Dig Endosc. 2010;22:57-62.

23. Schoemaker D, Black R, Giles L, Toouli J. Yearly colonoscopy, liver CT, and chest radiography do not influence 5-year survival of colorectal cancer patients. Gastroenterology. 1998;114:7-14.

24. Kjeldsen BJ, Kronborg O, Fenger C, Jørgensen OD. A prospective randomized study of follow-up after radical surgery for colorectal cancer. Br J Surg. 1997;84:666-9.

25. Renehan AG, Egger M, Saunders MP, O'Dwyer ST. Impact on survival of intensive follow up after curative resection for colorectal cancer: systematic review and meta-analysis of randomised trials. BMJ. 2002;324:813.

26. Figueredo A, Rumble RB, Maroun J, Earle CC, Cummings B, McLeod R, Zuraw L, Zwaal C; Gastrointestinal Cancer Disease Site Group of Cancer Care Ontario's Program in Evidence-based Care. Follow-up of patients with curatively resected colorectal cancer: a practice guideline. BMC Cancer. 2003;3:26.

27. Barkin JS, Cohen ME, Flaxman M, Lindblad AS,Mayer RJ, Kalser MH, Steinberg SM. Value of a routine follow-up endoscopy programfor the detection of recurrent colorectal carcinoma. Am J Gastroenterol. 1988;83:1355-60.

28. Kronborg O. Optimal follow-up in colorectal cancer patients: what tests and how often? Semin Surg Oncol. 1994;10:217-24.

29. Shinkins $B$, Nicholson $B D$, James $T$, et al. What carcinoembryonic antigen level should trigger further investigation during colorectal cancer follow-up? A systematic review and secondary analysis of a randomised controlled trial. Health Technol Assess. 2017;21:1-60.

30. McDermott FD, Heeney A, Kelly ME, Steele RJ, Carlson GL, Winter DC. Systematic review of preoperative, intraoperative and postoperative risk factors for colorectal anastomotic leaks, Br J Surg. 2015;102:462-479.

31. Matthiessen P, Hallböök O, Rutegård J, Sjödahl R. Population-based study of risk factors for postoperative death after anterior resection of the rectum, Br J Surg. 2006;93:498-503.

32. Marra F, Steffen T, Kalak N, Warschkow R, Tarantino I, Lange J. Zünd M. Anastomotic leakage as a risk factor for the long-term outcome after curative resection of colon cancer, Eur J Surg Oncol. 2009; 35:1060-1064.

33. Kulu Y, Tarantio I, Warschkow R, Kny S, Schneider M, Schmied BM, Büchler MW, Ulrich A. Anastomotic leakage is associated with impaired overall and disease-free survival after curative rectal cancer resection: a propensity score analysis, Ann Surg Oncol. 2015;22:2059-2067.

34. Smith JD, Paty PB, Guillem JG, Temple LK, Weiser MR, Nash GM. Anastomotic leak is not associated with oncologic outcome in patients undergoing low anterior resection for rectal cancer. Ann Surg. 2012;256:1034-1038.

35. Slanetz Jr CA. The effect of inadvertent intraoperative perforation on survival and recurrence in colorectal cancer, Dis. Colon Rectum. 1984;27:792-797.

36. Aggarwal BB, Vijayalekshmi RV, Sung B. Targeting inflammatory pathways for prevention and therapy of cancer: short-term friend, long-term foe. Clin Cancer Res. 2009;15:425-430.

37. Jonker FHW, Tanis PJ, Coene PPLO, Gietelink L, van der Harst E and Dutch Surgical Colorectal Audit Group. Comparison of a low Hartmann's procedure with low colorectal anastomosis with and without defunctioning ileostomy after radiotherapy for rectal cancer: results from a national registry. Colorec Dis. 2016;18:785-794.

38. Gu W, Wu S. Meta-analysis of defunctioning stoma in low anterior resection with total mesorectal excision for rectal cancer: evidence based on thirteen studies. Wor J of Sur Onc. 2015;13:9

39. Ihnát $\mathrm{P}$, Guňková $\mathrm{P}$, Peteja $\mathrm{M}$, Vávra $\mathrm{P}$, Pelikán $\mathrm{A}$, Zonča P. Diverting ileostomy in laparoscopic rectal cancer surgery: high price of protection. Surg Endosc. 2016;30(11):4809-4816.

40. Herrle F, Sandra-Petrescu F, Weiss C, Post S, Runkel N, Kienle P. Quality of Life and Timing of Stoma Closure in Patients With Rectal Cancer Undergoing Low Anterior Resection With Diverting Stoma: A Multicenter Longitudinal Observational Study. Dis Colon Rectum. 2016;59(4):281-290. 
41. Park JS, Choi GS, Kim SH, Kim HR, Kim NK, Lee KY, Kang SB, Kim JY, Lee KY, Kim BC, Bae BN, Son GM, Lee $\mathrm{SI}$, Kang $\mathrm{H}$. Multicenter analysis of risk factors for anastomotic leakage after laparoscopic rectal cancer excision: the Korean laparoscopic colorectal surgery study group. Ann Surg. 2013;257(4):665-671.

42. Kingham TP, Pachter HL. Colonic anastomotic leak: risk factors, diagnosis, and treatment. J Am Coll Surg. 2009;208(2):269-278.

43. Alverdy JC, Hyoju SK, Weigerinck M, Gilbert JA. The gut microbiome and the mechanism of surgical infection. Br J Surg. 2017;104(2):e14-e23.

44. Degett TH, Andersen HS, Gögenur I. Indocyanine green fluorescence angiography for intraoperative assessment of gastrointestinal anastomotic perfusion: a systematic review of clinical trials. Langenbecks Arch Surg. 2016;401:767-775.

45. Bolkenstein HE, Consten ECJ, van der Palen J, van de Wall BJM, Broeders IAMJ, Bemelman WA, Lange JF, Boermeester MA, Draaisma WA; Dutch Diverticular Disease (3D) Collaborative Study Group. Longterm outcome of surgery versus Conservative management for recurrent and ongoing complaints after an episode of Diverticulitis. 5-year follow-up results of a multicenter randomized controlled trial (Direct-trial). Ann Surg. 2019;269(4):612-620.

46. Lambrichts DPV, Vennix S, Musters GD, Mulder IM, Swank HA, Hoofwijk AGM, Belgers EHJ, Stockmann HBAC, Eijsbouts QAJ, Gerhards MF, van Wagensveld BA, van Geloven AAW, Crolla RMPH, Nienhuijs SW, Govaert MJPM, di Saverio S, D'Hoore AJL, Consten ECJ, van Grevenstein WMU, Pierik REGJM, Kruyt PM, van der Hoeven JAB, Steup WH, Catena F, Konsten JLM, Vermeulen J, van Dieren S, Bemelman WA, Lange JF; LADIES trial collaborators.. Hartmann's procedure versus sigmoidectomy with primary anastomosis for perforated diverticulitis with purulent or faecal peritonitis (LADIES): a multicentre, parallel-group, randomised, open-label, superiority trial.Lancet Gastroenterol Hepatol. 2019;4(8): 599-610.

47. Handgraaf HJM, Boogerd LSF, Höppener DJ, Peloso A, Sibinga Mulder BG, Hoogstins CES, Hartgrink HH, van de Velde $\mathrm{CJH}$, Mieog JSD, Swijnenburg RJ, Putter H, Maestri M, Braat AE, Frangioni JV, Vahrmeijer AL. Long-term follow-up after near-infrared fluorescence-guided resection of colorectal liver metastases: a retrospective multicenter analysis. Eur J Surg Oncol. 2017;43(8):1463-1471.

48. Boogerd LSF, Handgraaf HJM, Lam HD. Laparoscopic detection and resection of occult liver tumors of multiple cancer types using real-time near-infrared fluorescence guidance. Surg Endosc. 2017;31: 952-961.

49. Boogerd LSF, Hoogstins CWA, Schaap DP, Kusters M, Handgraaf HJM, van der Valk MJM, Hilling DE, Holman FA, Peeters KCMJ, Mieog JSD1 van de Velde CJH, Farina-Sarasqueta A, van Lijnschoten I, Framery B, Pèlegrin A, Gutowski M, Nienhuijs SW, de Hingh IHJT, Nieuwenhuijzen GAP, Rutten HJT, Cailler F, Burggraaf J, Vahrmeijer AL. Safety and effectiveness of SGM-101, a fluorescent antibody targeting carcinoembryonic antigen, for intraoperative detection of colorectal cancer: a dose-escalation pilot study. Lancet Gastroenterol Hepatol. 2018;3(3):181-191.

50. Berretta M, Alessandrini L, de Divitiis C, Nasti G, Lleshi A, Di Francia R, Facchini G, Cavaliere C, Buonerba C, Canzonieri V. Serum and tissue markers in colorectal cancer: state of art. Crit Rev Oncol Hematol. 2017;111:103-116.

51. Chen ZE, Lin F. Application of Immunohistochemistry in Gastrointestinal and Liver Neoplasms. Arch Pathol Lab Med. 2015;139:14-23.

52. Aroujo DV, Bratman SV, Siu LL. Designing circulating tumor DNA-based interventional clinical trials in oncology. Genome Medicine 2019;11:22.

53. Saini A, Pershad Y, Albadawi H, Kuo M, Alzubaidi S, Naidu S, Knuttinen MG, Oklu R. Liquid Biopsy in Gastrointestinal Cancers. Diagnostics 2018, 8, 75; doi:10.3390/diagnostics8040075.

54. Inoue T, Fujii H, Koyama F, Nakamura S, Ueda T, Nishigori N, Kawasaki K, Obara S, Nakamoto T, Uchimoto K, Morita K, Nishikawa T, Ohbayashi C, Nakajima Y. Intraluminal lavage to remove exfoliated tumor cells after colorectal endoscopic submucosal dissection. Surg Endosc. 2016;30:2773-2778.

55. Loktionov A. Cell exfoliation in the human colon: myth, reality and implications for Colorectal cancer screening. Int J Cancer. 2007;120:2281-2289.

56. Backes Y, Seerden TCJ, van Gestel RSFE, Kranenburg O, Ubink I, Schiffelers RM, van Straten D, van der Capellen MS, van de Weerd S, de Leng WWJ5, Siersema PD, Offerhaus GJA, Morsink FH, Ramphal W, Terhaar Sive Droste JS, van Lent AUG, Geesing JMJ, Vleggaar FP, Elias SG, Lacle MM5, Moons LMG. Tumor Seeding During Colonoscopy as a Possible Cause for Metachronous Colorectal Cancer. Gastroenterology. 2019;13. pii: S0016-5085(19)41229-8. doi: 10.1053/j.gastro.2019.07.062. 


\section{Chapter 10}

Summary 



\section{Summary}

This thesis addressed clinical situations during follow-up in patients with an uncomplicated diverticulitis and patient who had undergone curative surgery for colorectal cancer. In the first part we determined the necessity of endoscopic follow up by means of colonoscopy in patients who were treated conservatively for uncomplicated diverticulitis to rule out a malignant neoplasm of the large intestines. In the second part we investigated several clinical results after curative surgery for colorectal cancer in order to optimize and improve quality management during followup in these patients.

In Chapter $\mathbf{2}$ we determined the risk of colorectal cancer after an episode of acute uncomplicated diverticulitis in conservatively treated patients with or without antibiotics. This was investigated in a group of 645 patients who had undergone colonoscopy during follow-up. The outcome of the presence of colorectal cancer found by colonoscopy was analysed according to patients' presentation of alarm symptoms (rectal blood loss, unintentional weight loss and/or persistent abdominal pain) for colorectal cancer. Alarm symptoms were present in 205 patients. A total of 9 patients were diagnosed with colorectal cancer $(4.4 \%)$ versus 1 patient $(0.2 \%, P=0.0002)$ in the group without alarm symptoms. Concluding, this study confirms that routine colonoscopy is not indicated after acute diverticulitis which has been treated conservatively. Only in case of alarm symptoms a colonoscopy is obligated.

A subsequent study, based on the same cohort is provided in Chapter 3 . In this observational study we investigated the tumour characteristics of patients diagnosed with colorectal cancer after been treated for an episode of acute uncomplicated diverticulitis. As stated in chapter 2, a total of 10 patients were diagnosed with colorectal cancer after a conservatively treated episode of acute uncomplicated diverticulitis of whom 9 with alarm symptoms. One patient was diagnosed with stage I disease, 4 patients had stage II disease and 5 patients had stage III disease. In 9 of 10 patients, the tumour was found in the left colon (sigmoid) compared to 1 tumour in the hepatic flexure. Also this study strongly suggests that even though colorectal cancer is rare after uncomplicated diverticulitis, in cases of alarm symptoms, a subsequent colonoscopy needs to be performed. If a concomitant colorectal cancer is found, it is often advanced with a higher TNM stage and poor prognosis.

In Chapter 4 we assessed the long-term survival of patients with acute obstructive colorectal cancer causing an ileus compared to patients without obstructive colorectal cancer. Ileus occurred in 178 patients (14.4\%). The 5-year survival for patients with an ileus was $32 \%$ and without $60 \%(P<0.01)$. No significant difference was found in patients with synchronous metastases. Survival at 5 years in this subgroup was 10 and $12 \%$ for patients with and without an ileus, respectively $(P=0.705)$.Patients with 
obstructive colorectal cancer have a reduced short-term overall survival. Also, longterm overall survival is impaired in patients who present witch acute obstructive CRC compared to patients without obstruction.

The optimal interval of surveillance colonoscopy after curative surgery for colorectal cancer was investigated in Chapter 5. In our cohort, 1644 of 2420 patients after curative surgery for colorectal cancer underwent at least one postoperative colonoscopy (67.9\%). In 1087 patients, colonoscopy was performed in the first 18 months after surgery, which detected 34 (3.1\%) instances of metachronous colorectal tumours or anastomotic recurrence. We concluded that patients with a history of colorectal cancer have an increased risk for a second colorectal tumour. Therefore, we recommend a colonoscopic surveillance programme with the first colonoscopy performed one year after curative surgery, which is in accordance with national guidelines

In Chapter 6 we determined the value of elevated pre- and postoperative serum carcinoembryonic antigen as an independent prognostic factor for locoregional and distant recurrence in patients who underwent curative surgery for colorectal cancer. A total of 2093 patients with CEA level measurements were included. We did not find a significant association between an elevated preoperative serum CEA and locoregional recurrence (adjusted $\mathrm{HR}=1.29$ (95\% Cl 0.91, 1.84; $\mathrm{P}=0.26)$ ). However, we did find a significant association between an elevated preoperative serum CEA and systemic recurrence (adjusted $\mathrm{HR}=1.58(95 \% \mathrm{Cl} 1.25,2.00 ; \mathrm{P}<0.01)$ ). Moreover, the five-year disease free survival was lower in patients with elevated preoperative serum CEA levels $(P<0.01)$. In conclusion, the preoperative serum CEA level is an independent prognostic factor for systemic metastasis after curative surgery for colorectal cancer in patients with stage I-III disease.

Chapter 7 determined the impact of anastomotic leakage on local recurrence and distant recurrence rates, disease-free survival and overall mortality in 1984 patients who underwent curative surgery for colorectal cancer. The overall incidence of anastomotic leakage was $7.5 \%$. In 41 (2.1\%) patients local recurrence was diagnosed, associated with anastomotic leakage [adjusted $\mathrm{HR}=2.25(95 \% \mathrm{Cl}: 1.14-5.29 ; \mathrm{P}=0.03)$ ). Distant recurrence developed in $291(14.8 \%)$ patients with no association with anastomotic leakage (adjusted $\mathrm{HR}=1.30$ (95\% Cl: 0.85-1.97) $\mathrm{P}=0.23$ ). Moreover, five year disease-free survival was significantly decreased in patients with anastomotic leakage, (log rank test $\mathrm{P}<0.01$ ). In conclusion, anastomotic leakage was significantly associated with increased rates of local recurrence, impaired disease free-survival and overall mortality. Associations of anastomotic leakage with distant recurrence was not found. 
The usage of intraoperative fluorescence angiography with indocyanine green in combination with near infrared light was investigated in Chapter 8. We determined whether the assessment of bowel perfusion during robot assisted laparoscopic rectal cancer surgery affected the rates of anastomotic leakage and diverting ileostomies in rectal cancer patients. A total of 278 patients were included for analysis, of whom 168 $(60.4 \%)$ underwent surgery with intraoperative usage of ICG-NIR. No significant difference was found in the number of anastomotic leakages in the ICG-NIR group compared to the control group $(7.1 \%$ vs. $4.5 \%, \mathrm{P}=0.38)$. However, a significant difference was found in the number of diverting ileostomies $(32.1 \%$ vs. $67.2 \% \mathrm{P}<0.01)$. The number of diverting ileostomies was significant lower in patients with rectal cancer who received neoadjuvant chemo radiation or $5 \times 5$ Gy radiation in the fluorescence group $(\mathrm{P}=0.03$ and $\mathrm{P}<0.001)$. Fluorescence angiography with ICG-NIR during robotassisted surgery in patients with rectal cancer did not lower the rate of anastomotic leakages. However, we did find a significant lower number of diverting ileostomies in patients in the fluorescence group. ICG-NIR is an innovative technique in RAL rectal surgery and has the potential to become a tool in intraoperative decision making. 



\section{Chapter 11}

Summary in Dutch/Samenvatting in het Nederlands 



\section{Samenvatting}

Dit proefschrift heeft aspecten belicht met betrekking tot de endoscopische follow-up in patiënten met een acute ongecompliceerde diverticulitis en patiënten die een curatieve resectie hebben ondergaan voor het colorectaal carcinoom. In de eerste sectie wordt de noodzaak onderzocht van endoscopische controle bij patiënten die conservatief zijn behandeld voor een ongecompliceerde diverticulitis, dit om een colorectale maligniteit uit te sluiten. In de tweede sectie worden verschillende klinische vraagstukken onderzocht die betrekking hebben tot patiënten die een curatieve operatie hebben ondergaan voor het colorectaal carcinoom. Het uiteindelijke doel van dit onderzoek is om meer inzicht te krijgen in de follow-up voor patiënten met het colorectaal carcinoom, om uiteindelijk kwaliteitsmanagement in deze patiëntengroep te verbeteren en te optimaliseren.

In hoofdstuk 2 wordt het risico bepaald op het colorectaal carcinoom bij patiënten die met of zonder antibiotica, conservatief zijn behandeld voor een episode van een acute ongecompliceerde diverticulitis. Dit werd onderzocht in een groep van 645 patiënten die gedurende de follow-up een colonoscopie hebben ondergaan. Onder de patiënten bij wie het colorectaal carcinoom werd geconstateerd, werd geanalyseerd of alarmsymptomen voor het colorectaal carcinoom aanwezig waren. De alarmsymptomen bestonden uit rectaal bloedverlies, onbedoeld gewichtsverlies en/of persisterende buikpijn klachten. Alarmsymptomen waren aanwezig in 205 patiënten. In totaal werden 9 (4.4\%) patiënten gediagnosticeerd met het colorectaal carcinoom tegen $1(0.2 \%)$ patiënt in de groep zonder alarmsymptomen $(P=0.0002)$. Concluderend, deze studie bevestigt dat het routinematig uitvoeren van een colonoscopie niet is geïndiceerd bij patiënten die conservatief zijn behandeld voor een episode van een acute ongecompliceerde diverticulitis. Alleen bij de aanwezigheid van alarmsymptomen voor het colorectaal carcinoom, is het verrichten van een colonoscopie verplicht.

Een vervolgstudie, gebaseerd op hetzelfde cohort gepresenteerd in hoofdstuk 2, wordt besproken in hoofdstuk 3. In deze observationele studie werden de tumorkarakteristieken van patiënten met het colorectaal carcinoom onderzocht, nadat ze initieel werden behandeld voor een episode van acute ongecompliceerde diverticulitis. Zoals vermeld in hoofdstuk 2 werden in totaal 10 patiënten gediagnosticeerd met het colorectaal carcinoom van wie 9 met de aanwezigheid van alarmsymptomen. Eén patiënt werd gediagnosticeerd met stadium I ziekte, 4 patiënten hadden stadium II ziekte en 5 patiënten werden gediagnosticeerd met stadium III ziekte. In 9 van de 10 gevallen werd de maligniteit gevonden in het linker gedeelte van het colon, namelijk het colon sigmoïdeum, vergeleken met 1 tumor in de flexura hepatica. Hoewel het colorectaal carcinoom zeer zeldzaam is na een acute ongecompliceerde diverticulitis, suggereert ook deze studie dat een colonoscopie alleen uitgevoerd hoort te worden indien alarmsymptomen voor het colorectaal carcinoom aanwezig zijn. Indien deze 
tumor wordt gevonden, dan is de ziekte vergevorderd met een hoog TNM stadium en slechte prognose.

In hoofdstuk 4 werd onderzocht wat de lange termijn overleving is van patiënten met een ileus op basis van het colorectaal carcinoom vergeleken met patiënten zonder acute obstructie. Een Ileus op basis van het colorectaal carcinoom werd geconstateerd in 178 patiënten (14.4\%). De 5-jaars overleving voor patiënten met een acute obstructie op basis van het colorectaal carcinoom was $32 \%$ vergeleken met $60 \%$ voor patiënten zonder acute obstructie $(P<0.01)$. Er werd geen statistisch significant verschil gezien in patiënten met synchrone metastases. De 5 -jaars overleving in deze subgroep voor patiënten met en zonder een ileus waren respectievelijk $10 \%$ en $12 \%$ ( $P=0.705)$. Concluderend, deze studie bevestigt dat de korte termijn overleving is verlaagd in patiënten met een acute obstructie vergeleken met patiënten zonder acute obstructie. Deze studie laat echter ook zien dat de lange termijn overleving significant is gereduceerd in de patiënten die zich presenteren met een ileus op basis van een colorectale maligniteit.

Het optimale interval van de surveillance colonoscopie na curatieve resectie voor het colorectaal carcinoom werd onderzocht in hoofdstuk 5. In dit cohort hebben 1644 van de 2420 (67.9\%) patiënten minstens 1 colonoscopie ondergaan na de curatieve resectie. In 1087 patiënten werd een colonoscopie in de eerste 18 maanden verricht na de operatie. Hier werden 34 (3.1\%) metachrone colorectale tumoren of naadrecidieven gevonden. Patiënten met een medische voorgeschiedenis van het colorectaal carcinoom hebben een hoger risico op het ontwikkelen van een tweede colorectale tumor ten opzichte van patiënten zonder het colorectaal carcinoom. Concluderend, wij adviseren een surveillance colonoscopie programma waarbij de eerste surveillance hoort plaats te vinden één jaar na de curatieve resectie, dit komt overeen met de huidige Nederlandse richtlijnen.

In hoofdstuk 6 werd de waarde van verhoogd pre- en postoperatief carcinoembryonaal antigeen bepaald, als prognostische factor voor het ontwikkelen van een locoregionaal recidief en voor metastase op afstand bij patiënten die een curatieve resectie hebben ondergaan voor het colorectaal carcinoom. In deze studie werd een totaal van 2093 patiënten met CEA bepalingen geïncludeerd. Er werd geen significante associatie gevonden tussen een verhoogd preoperatief serum CEA en het ontwikkelen van een locoregionaal recidief (gecorrigeerde $\mathrm{HR}=1.29$ (95\% $\mathrm{Cl} 0.91,1.84 ; \mathrm{P}=0.26)$ ). Een statistisch significante associatie werd wel gevonden tussen een verhoogd preoperatieve CEA en het ontwikkelen van metastase op afstand (gecorrigeerde $\mathrm{HR}=$ 1.58 (95\% Cl 1.25, 2.00; $\mathrm{P}<0.01)$ ). Bovendien was de vijf jaar ziekte vrije overleving lager in patiënten met een verhoogd preoperatief serum CEA dan bij patiënten met een normaal serum CEA waarde $(P<0.01)$. Uit deze studie werd geconcludeerd dat een verhoogd preoperatieve CEA waarde een onafhankelijke prognostische factor is voor 
systemische ziekte na curatieve chirurgie bij patiënten met het colorectaal carcinoom stadium I-III.

In hoofdstuk 7 werd bepaald wat de impact was van een naadlekkage op het ontwikkelen van een lokaal recidief, metastasering op afstand, de ziekte vrije overleving en totale overleving in 1984 patiënten die een curatieve resectie hebben ondergaan voor het colorectaal carcinoom. De incidentie van een naadlekkage was $7.5 \%$. In totaal ontwikkelden 41 (2.1\%) patiënten een lokaal recidief, welke geassocieerd was met een naadlekkage (gecorrigeerde $\mathrm{HR}=2.25(95 \% \mathrm{Cl}: 1.14-5.29 ; \mathrm{P}=0.03)$ ). Metastase op afstand werd geconstateerd in 291 patiënten (14.8\%). Hier werd geen associatie gevonden met een naadlekkage (gecorrigeerde $\mathrm{HR}=1.30(95 \% \mathrm{Cl}: 0.85-1.97) \mathrm{P}=0.23$ ). De vijf-jaars overleving was significant verlaagd in patiënten met een naadlekkage (logrank test $\mathrm{P}<0.01)$. Concluderend, een naadlekkage is geassocieerd met het ontwikkelen op een lokaal recidief, een verlaagde ziekte vrije- en totale overleving. Een associatie tussen een naadlekkage en het ontwikkelen van metastase op afstand werd niet gevonden.

Het gebruik van intra-operatieve fluorescentie angiografie met indocayanine groen in combinatie met nabij infra rood licht werd onderzocht in hoofdstuk 8. Hier werd beoordeeld of het objectiveren van de darmperfusie met ICG-NIR, effect heeft op de incidentie naadlekkages of het aantal deviërende ileostoma's bij patiënten die een robot geassisteerde laparoscopische resectie ondergaan voor het rectumcarcinoom. In totaal weren 278 patiënten geïncludeerd voor analyse waarvan 168 (60.4\%) een resectie hebben ondergaan met het gebruik van intra-operatieve fluorescentie. Er werd geen significant verschil gevonden in het aantal naadlekkages tussen de ICG-NIR groep en de controle groep. (7.1\% vs. 4.5\%, $\mathrm{P}=0.38)$. Er werd een significant verschil gevonden in het aantal ileostoma's, welke minder waren in de fluorescentie groep $(32.1 \%$ vs. $67.2 \% \mathrm{P}<0.01)$. Dit was eveneens het geval voor de patiënten in de fluorescentiegroep die neo-adjuvant zijn behandeld met chemoradiatie of $5 \times 5 \mathrm{~Gy}$ bestraling $(\mathrm{P}=0.03$ en $P<0.001)$. Fluorescentie angiografie met ICG-NIR tijdens een robot geassisteerde laparoscopische low anterior resectie laat geen reductie zien in het aantal naadlekkages, maar wel een significant lager aantal deviërende ileostoma's. Concluderend, ICG-NIR is een innovatieve techniek binnen de robot geassisteerde laparoscopische rectumchirurgie en heeft de potentie om een bruikbare tool te worden gedurende de intra-operatieve besluitvorming.

\section{Toekomstperspectieven}

Recentelijk heeft er een verschuiving plaatsgevonden in de chirurgische behandeling voor patiënten met recidiverende diverticulitiden en patiënten met een geperforeerde diverticulitis met purulente of fecale peritonitis. Uit de resultaten van de Nederlandse 
DIRECT-trial wordt geconcludeerd dat een electieve sigmoïdresectie, ondanks het inherente risico op complicaties, leidt tot een betere kwaliteit van leven, vergeleken met patiënten die conservatief worden behandeld voor recidiverende episodes van linkszijdige diverticulitis.

Daarnaast kan uit de eveneens Nederlandse LADIES-trial geconcludeerd worden dat een primaire anastomose gerechtvaardigd is bij patiënten met een geperforeerde diverticulitis in vergelijking met de Hartman procedure. De 1-jaars stoma vrije overleving en morbiditeit na het opheffen van het stoma waren hierin de primaire uitkomstmaten. Deze twee gerandomiseerde gecontroleerde trials hebben een enorme verschuiving teweeg gebracht richting de operatieve ingreep vergeleken met de huidige 'wait and see' en dus meer conservatieve behandeling. Tot voor kort, wanneer voor een chirurgische behandeling werd gekozen, was de overweging om een tijdelijk stoma aan te leggen snel en eenvoudig gemaakt. Dit gold voor zowel patiënten met recidiverende diverticulitis als patiënten met een geperforeerde diverticulitis. Echter, meer onderzoek is nodig als het gaat om de endoscopische follow-up in patiënten na een episode van een ongecompliceerde diverticulitis. De huidige literatuur op dit vlak is voornamelijk gebaseerd op retrospectieve studies of op landelijke case-controlled studies met een gebrek aan adequate controle groepen en colonoscopie (verslagen) van matige kwaliteit. Een grote prospectieve multicenter studie is nodig met patiënten die een colonoscopie ondergaan na een ongecompliceerde acute diverticulitis welke worden vergeleken met een asymptomatische screening populatie met een accurate poweranalyse. Daarnaast dient de colonoscopie van hoge kwaliteit te zijn en volgens strikte criteria vanuit de huidige richtlijnen uitgevoerd te worden met een complete verslaglegging. Een verfijnde benadering tot een aanbeveling van een colonoscopie na een bewezen acute diverticulitis kan alleen op die manier overwogen worden. Een follow-up colonoscopie wordt alleen verricht in een hoog risico populatie. Dit zijn patiënten met een gecompliceerde diverticulitis, verdachte radiologische afwijkingen en/of de aanwezigheid van alarmsymptomen voor het colorectaal carcinoom.

In de laatste decennia is de kennis over het colorectaal carcinoom progressief toegenomen. Door innovatie en modernisatie heeft de chirurgische behandeling voor dit ziektebeeld enorme stappen gemaakt in het optimaliseren van patiëntenzorg. Een zeer bekend voorbeeld hiervan is het voordeel van laparoscopische ingrepen vergeleken met open buikoperaties in patiënten die een electieve operatie ondergaan. Het voortdurend zoeken naar progressie en ontwikkeling van innovatieve tools in diagnostiek en chirurgische behandelingen zijn immer primaire doelen om (ziekte vrije) overleving te verbeteren in patiënten met dikke darm- endeldarm kanker. Robot geassisteerde chirurgie is een ander voorbeeld in de modernisatie als het gaat om chirurgische benadering. Op de lange termijn zouden de voordelen van deze benadering moeten leiden tot kortere ziekenhuis opnames, minder pijn, minder wondinfecties en kortere hersteltijd waardoor patiënten weer zo snel mogelijk terug kunnen naar hun dagelijkse activiteiten. Een interessante tool binnen de robot 
geassisteerde chirurgie is het intra-operatief gebruik van nabij infrarood licht gecombineerd met fluorescentie om darmperfusie te objectiveren en te beoordelen. Fluorescentie geleide chirurgie heeft reeds zijn voordelen laten zien in andere oncologische operatieve ingrepen. Verschillende studies hebben laten zien dat het intra operatief gebruik van nabij infrarood licht en fluorescentie (sub)capsulaire colorectale levermetastases kan identificeren die normaliter gemist worden met andere gestandaardiseerde radiologische technieken. Een ander voorbeeld is intra-operatieve tumor-target fluorescentie imaging techniek, deze techniek heeft de potentie om de huidige chirurgische technieken te verbeteren door zeer selectief kwaadaardige cellen aan te kleuren tijdens een buikoperatie. Het carcino embryogeen antigeen (CEA) laat overexpressie zien in de meerderheid van de colorectaal carcinomen (90\%) en is hiermee een doelwit bij het afbeelden van de tumor met fluorescerende monoklonale antilichamen van CEA. Uiteindelijk kan dit in potentie invloed uitoefenen op de intra operatieve beslissingen tijdens een resectie bij patiënten met het colorectaal carcinoom.

In de laatste tien jaar hebben vooruitgang in de moleculaire biologie en technieken in genomics een revolutie teweeg gebracht binnen de diagnostiek en behandeling voor kanker. Ook op het gebied van tumormarkers ontstaan verscheidende nieuwe inzichten. Onlangs hebben nieuwe moleculaire studies de mogelijkheid gehad om deze nieuw tumor markers te testen. Aanvullende methoden zijn nodig voor de authenticatie van deze nieuwe tumor markers waarbij ze getest moeten worden in multi centrische gerandomiseerde studies voordat ze daadwerkelijk in de kliniek toegepast kunnen worden in oncologie patiënten. Daarnaast gaat een accuratere diagnose van primaire gastro-intestinale- en lever tumoren behoren tot de mogelijkheden. De applicatie van immunohistochemie in gastro-intestinale- en levertumoren blijven evolueren. Nieuwe tumor specifieke markers komen continu in opkomst waarbij pathologen worden geholpen om steeds nauwkeuriger diagnoses op histologische en immunohistochemische wijze te kunnen bevestigen. De beoordeling van voorspellende en prognostische markers met immunohistochemie in de hedendaagse pathologische diagnostiek is een nieuwe trend en zal de vooruitgang in gepersonaliseerde kankertherapie steeds beter kunnen faciliteren.

Weefselbiopsie blijft de gouden standaard voor het diagnosticeren van een colorectale maligniteit of zelfs een uitzaaiing hiervan. Het voorziet de specialist informatie in tumorclassificatie, een accurate schatting van invasie, mate van differentiatie, genetische informatie, mutatiestatus en het biedt inzicht in de prognose van de patiënt. Dergelijke informatie kan de behandelstrategie helpen begeleiden en personaliseren. Echter, zijn weefsel biopsieën invasief, duur en gaan ze niet altijd zonder complicaties. In sommige gevallen is het weefsel niet toereikend voor biopsie vanwege de anatomische ligging of een onderliggende coagulopathie waardoor het bloedingsrisico te hoog is. Daarnaast geeft weefselbiopsie een snapshot van de tumor op een bepaald 
moment en is daarom niet altijd representatief voor de complete genetische samenstelling van een neoplasma, welke een constante evolutie doormaakt. Vloeibare biopsie is de bemonstering van elke biologische vloeistof in een poging om het genetische materiaal van een tumor te verrijken en te analyseren. Perifere bloedafname blijft het meest bestudeerde vloeibare biopsiemateriaal met circulerende tumorcellen en circulerend tumor DNA. Hiermee kan het genetisch landschap van tumoren longitudinaal onderzocht worden. Vloeibare biopsie kan de diagnostiek en behandelstrategieën in oncologie patiënten aanzienlijk beïnvloeden. Met toepassingen in kankerscreening, prognostische stratificatie, therapieselectie en ziektesurveillance vormt vloeibare biopsie een nieuw paradigma op het gebied van oncologische diagnostiek die kan leiden tot verbeterde patiënt uitkomsten en uiteindelijk overleving.

Zoals eerder vermeld, komen patiënten na een curatieve resectie in aanmerking voor een surveillance programma omdat zij een hoger risico lopen op metachrone colorectale tumoren. Er bestaan nieuwe theorieën over de oorzaak en ontwikkeling van metachrone colorectale tumoren. Verschillende oorzaken zijn gesuggereerd, zoals incomplete poliepectomieën of gemiste premaligne laesies gedurende de index colonoscopie. De processen die onderliggend zijn aan de oorzaak hiervan worden nog steeds niet volledig begrepen. Eerdere studies hebben aangetoond dat tumorcellen exfoliëren van de colorectale tumor naar elders in het darmlumen, vooral wanneer de tumor wordt gemanipuleerd tijdens een colonoscopie of een operatieve ingreep. Een recent gepubliceerd principle proof study toonde aan dat primaire tumorcellen op een nieuwe locatie in het darmlumen gezaaid kunnen worden na biopsie van de primaire tumor, dit wordt iatrogene tumortranslocatie genoemd. De moleculaire bevindingen ondersteunen de hypothese dat iatrogene tumortranslocatie plaatsvindt via het werkkanaal van de endoscoop. De potentiele mogelijkheid van iatrogene enting lijkt laag. Deze studie levert echter bewijs en zou bewustwording moeten geven over deze potentieel te voorkomen oorzaak van metachrone colorectale tumoren. Toekomstige studies zijn nodig om de kennis te vergroten om luminale iatrogene tumortranslocaties te voorkomen.

Concluderend, we zijn gearriveerd in het tijdperk van precisiegeneeskunde. Er moet echter een aanzienlijke hoeveelheid vooruitgang worden geboekt voordat de nieuwe implicaties in de zorg voor patiënten met het colorectaal carcinoom algemeen toegepast kunnen worden.

Verhoogde specifieke tumormarkers, een gecompliceerd beloop na curatieve chirurgie en obstructieve colorectale tumoren zijn risicofactoren voor het recidiveren van oncologische ziekte. Mogelijkerwijs kan deze specifieke patiëntengroep baat hebben bij een intensievere surveillance programma. Voornamelijk aanvullende prospectieve, multi gecentreerde onderzoeken horen de eerder genoemde bevindingen te valideren. Bovendien is verdere ontwikkeling van klinisch implementeerbare technologieën nodig, waaronder kosteneffectieve en gevoelige testen, om genetische verandering verder te 
kunnen analyseren. Het optimaliseren van patiëntselectie, vooruitgang in kennis in tumorbiologie en mechanismen zullen uiteindelijk een positief effect hebben op kankerdiagnostiek en behandelingsstrategieën in patiënten met het colorectaal carcinoom. 



\section{Chapter 12}

Valorisation 



\section{Valorisation}

\section{Introduction}

Diverticulosis is considered as the most common disease of the large intestines in the Western world and is an important cause of hospital admissions and a significant contributor to healthcare costs in these industrialized societies. In the Netherlands the incidence and prevalence of diverticulosis and diverticulitis together is 0.7 and 1.8 per 1000 patients respectively, per year. The incidence of diverticulitis has increased over time and increases with age. Approximately $20 \%$ of patients with incident diverticulitis have at least one recurrence. Recent changes in understanding its natural history have substantially modified follow-up regimes and treatment paradigms.

Colorectal cancer is the third most commonly diagnosed cancer in males and second in females with a total of 1.8 million new cases and almost 861,000 deaths in 2018 according to the World Health Organization. Globally, the regional incidence of colorectal cancer varies over 10 -fold. The highest incidence rates are reported in Western countries and in the Netherlands 13,597 new patients were diagnosed with colorectal cancer in 2018. Due to its increasing and high incidence, colorectal cancer has an important social and economic impact in the Netherlands. Survival rates in colorectal cancer are still increasing, with a current 5 -year overall survival of $65 \%$, owing to better multidisciplinary treatment. Treatment consists of resection of the primary tumour and corresponding lymph nodes, and if indicated follow by a treatment with chemotherapy. Because of the chance of disease recurrence a follow-up regime after surgery is needed. On the other hand, quality of life of patients after curative surgery could be affected by morbidity caused by this treatment. Consequently, it is important to select patients that will benefit from a follow-up programme to detect disease recurrence in an early stage.

\section{Social relevance of scientific results in this thesis}

The first topic this thesis addressed was on endoscopic follow-up in patients who have been treated conservatively for an episode of uncomplicated diverticulitis. It used to be common practice to perform a follow-up colonoscopy to exclude a colorectal neoplasm after an episode of uncomplicated diverticulitis. However, only in case of alarm symptoms a colonoscopy may be justified. This would result in less unnecessary colonoscopies and therefore shorter waiting list for patients who are in need of a colonoscopy. This would result in less patient burden as colonoscopy is not without risk, let alone, the discomfort of the preparation and the procedure itself for the patient. This would also mean less colonoscopy-related risks and complications which can be mild or severe, requiring emergency surgery, which is also accompanied by possible lethal complications. Finally, national health care costs could be reduced. 
The second topic addressed several clinical aspects after curative surgery in colorectal cancer patients. Patients with obstructing colorectal has a specific importance because of the higher incidence in distant metastases. Moreover, preoperative serum CEA level is a prognostic factor for systemic recurrence in patients who previously had curative surgery for colorectal cancer. Also, patients who developed anastomotic leakage after curative surgery have an increased risk in developing local recurrence. This specific patient group has an increased risk in developing disease recurrence. Therefore, it will be crucial to strictly follow these patients. They may benefit from a more intensive surveillance programme. Recurrent disease would be diagnosed at an early stage which is preferable to maintain a surgical treatment with curative intentions to improve survival. It will be very challenging to test this hypothesis in a well-designed clinical trial. Indocyanine green in combination with near infra-red light is a promising tool in intraoperative decision making during robot-assisted rectal cancer surgery. It does not affect the anastomotic leakage rate, however, less ileostomies were made. With intraoperative fluorescence usage, unnecessary ileostomies could be prevented, which has an enormous patient benefit. This would lower the associated patient morbidity rate, increase quality of life, and prevent a second surgery which is accompanied with risks and complications or even permanent ileostomies.

\section{Target population}

The results of this thesis are relevant for patients who develop a first episode of uncomplicated diverticulitis of the colon. Moreover, the results are also relevant for patients who are diagnosed with colorectal cancer and are planned to undergo curative surgery. Furthermore, it offers additional information for patients presenting with obstructing colorectal cancer. It also provides information on several clinical aspects after surgery regarding surveillance colonoscopy, interpretation of CEA measurements and the oncological impact of anastomotic leakage.

\section{Innovation and future}

There are some promising perspectives in the near future within the field of diagnostics and surgical treatment of patients with colorectal cancer. Modern and less invasive techniques will significantly contribute to a new era in personalized cancer therapy. Robot-assisted surgery in combination with intraoperative fluorescence imaging is an example which already is implemented in some clinics in the Netherlands. Our knowledge in tumour biology and genetics will increase. This should lead to a more extended spectrum in specific diagnostic techniques to find cancer, or even systemic disease at an early stage. Additional studies will have to elucidate the role of these new techniques before clinical implementation. Furthermore, with these applications in cancer screening, prognostic stratification specific therapy selection, and disease surveillance will facilitate personalized cancer therapy. Finally, elevated tumour markers, complicated course after curative surgery and obstructive colorectal cancer 
are risk factors for disease recurrence. Clinical outcome studies are needed to understand if this specific patient group would benefit from a more intensive surveillance programme in order to improve survival. 

Part IV

Appendices 



\section{Chapter 13}

List of publications 



\section{List of publications}

Ramphal W, Schreinemakers JMJ, Seerden TCJ, Crolla RMPH, Rijken AM, Gobardhan PD. What is the Risk of Colorectal Cancer After an Episode of Acute Diverticulitis in Conservatively Treated Patients? Journal of Clinical Gastroenterology. 2016;50(4): e35-39.

Ramphal W, van der Laan L, Vos LD, Veen EJ. Chirurgische behandeling van een type II endoleak vanwege een groeiende aneurysmazak na een EVAR-procedure. Nederlands Tijdschrift voor Heelkunde 2018 Maart Jaargang 27 Nummer 2.

Ramphal W, Schreinemakers JMJ, Seerden TCJ, Gobardhan PD. Tumor characteristics of patients with colorectal cancer after a first episode of acute uncomplicated diverticulitis. Digestive Diseases. 2018;36(5):362-368.

Ramphal W, Mus M, Nuytinck HKS, van Heerde MJ, Verduin CM, Gobardhan PD. Sepsis caused by acute phlegmonous gastritis based on a group A Streptococcus. Journal of Surgical Case Reports 2018 Aug 4;2018(8):rjy188.

Boeding JRE, Ramphal W, Crolla RMPH, Boonman - de Winter LM , Gobardhan PD, Schreinemakers JMJ. Ileus caused by obstructing colorectal cancer - Impact on Long term survival. International Journal of Colorectal Disease. 2018 Oct;33(10):1393-1400.

Ramphal W, Raaijmakers NJ, van der Klift M, Wijsman JH, Kluytmans JAJW, Veen EJ. Mycotic aneurysm caused by a Clostridium septicum in a patient with colorectal cancer. Infection 2018 Oct;46(5):711-716.

Ramphal W, Boeding JRE, Gobardhan PD, Crolla RMPH, Rutten HJT, de Winter LMB, Crolla RMPH, Schreinemakers JMJ. Oncologic outcome and recurrence rate following anastomotic leakage after curative resection for colorectal cancer. Surgical Oncology 2018 Dec;27(4):730-736.

Ramphal W, Boeding JRE, van Iwaarden M, Schreinemakers JMJ, Rutten HJT, Crolla RMPH, Gobardhan PD. Serum carcinoembryonic antigen to predict recurrence in the follow-up of patients with colorectal cancer. International Journal of Biological Markers 2019 Mar;34(1):60-68.

Ramphal W, Elsten LEPM, Gobardhan PD, Vreuls CPH, ten Tije AJ. Een zwelling van de mamma; niet altijd wat het lijkt. Nederlands Tijdschrift voor de Oncologie 2019 Mei 3 (16) 104-108. 
Ramphal W, Mus M, Nuytinck HKS, Verduin CM, Gobardhan PD. Totale maagresectie vanwege een acute flegmoneuze gastritis op basis van een hemolytische groep $A$ streptococcus. Nederlands Tijdschrift voor Heelkunde 2019 Mei Jaargang 28 Nummer 3

Peters CML, Ramphal W, Buimer MG, Veen EJ. Stent graft treatment as a bridge to surgery for a secondary aortoduodenal fistula. European Journal of Cardiothoracic Surgery. 2019 Jun 1;55(6):1225-1227.

Ramphal W, Boeding JRE, Schreinemakers JMJ, Gobardhan PD, Rutten HJT, Crolla RMPH. Colonoscopy surveillance after colorectal cancer: The optimal interval for followup. Journal of Gastrointestinal Cancer (Accepted) Doi: 10.1007/s12029-019-00254-5. (Epub ahead of print).

Backes Y, Seerden TCJ, van Gestel RSFE, Kranenburg O, Ubink I, Schiffelers RM, van Straten D, van der Capellen MS, van der Weerd S, de Leng WWJ, Siersema PD, Offerhaus GJA, Morsink FH, Ramphal W, Terhaar Sive Droste JS, van Lent AUG, Geesing JMJ, Vleggaar FP, Elias SG, Lacle MM, Moons. Tumor Seeding During Colonoscopy as a Possible Cause for Metachronous Colorectal Cancer. Gastroenterology. 2019;157(5): 1222-1232.

Boeding JRE, Ramphal W, Crolla RMPH, Gobardhan PD, Schreinemakers JMJ. Differences in Metastatic Pattern in Patients Presenting With or Without Obstructing Colorectal Cancer: A Retrospective Observational Study of 2595 Patients. Annals of Surgical Oncology. 2020 Apr;27(4):1048-1055. 
Acknowledgements / Dankwoord 



\section{Dankwoord}

Promoveren tijdens mijn assistentschap was een enorme uitdaging, gelukkig stond ik er niet alleen voor. Zonder de hulp van enkele mensen was mij dit niet gelukt. Aan hen ben ik dan ook enorm veel dank verschuldigd. ledereen die heeft bijgedragen aan de totstandkoming van dit proefschrift wil ik graag middels deze weg enorm bedanken, met een aantal personen in het bijzonder.

Prof. dr. H.J.T. Rutten (promotor). Beste Harm, ten eerste wil ik u ontzettend bedanken voor de kans die u mij heeft gegeven om bij $u$ te mogen promoveren. De eerste ontmoeting in het Catharina Ziekenhuis vond ik ontzettend spannend, maar $u$ was direct enthousiast, betrokken en had nieuwe ideeën en adviezen over dit project. Ook in de kliniek heb ik fijn met u samen gewerkt. Vooral op de operatiekamer toen u zei: "Hier, dan kan jij de darmnaad maken" terwijl u de instrumenten aan me overhandigde, maar u loosde me er wel doorheen net zoals bij dit proefschrift. Ik kijk met trots terug op onze samenwerking.

Dr. Paul D. Gobardhan (copromotor). Beste Paul, wat ben ik blij dat ik in de zomer van 2012 tijdens mijn Chirurgie coschap aan jou werd gekoppeld. Je zag het in me zitten en het bleek de fundering te zijn van een mooie samenwerking. Op een of andere manier heb jij het wetenschappelijk vuurtje in mij weten te ontbranden waarvan ik niet had gedacht dat ik die had. Promoveren naast een assistentschap was niet altijd een pretje maar jij wist me altijd een hart onder de riem te steken. Vanaf de eerste dag heb je me met alles enorm geholpen en heb jij het contact met Harm gelegd. In de kliniek ben je altijd toegankelijk geweest en ik heb bewondering voor hoe je de wetenschap weet te combineren met je sociale leven en je leven als chirurg in een perifere kliniek. Je bent absoluut een voorbeeld voor me. Ik hoop dat onze samenwerking niet bij deze promotie blijft en Ik wil je ontzettend bedanken voor wat je zowel binnen als buiten de kliniek voor me hebt gedaan. Misschien dat ik in de toekomst je weer mag imiteren tijdens het kerstcabaret.

Dr. Jennifer M.J. Schreinemakers (copromotor). Lieve Jen, een week nadat ik met Paul om de tafel had gezeten voor het diverticulitis onderzoek, ontmoette ik jou op de endoscopiekamers. Het eerste wat jij zei: "Wat heb jij gave schoenen zeg! Hoi, ik ben Jennifer". Ik dacht: "Wat een relaxe oudste assistent", totdat ik binnen 2 uur mijn eerste manuscript, waar ik de afgelopen maanden zo hard aan had gewerkt, volledig in het rood van je terugkreeg. Het moest ook z.s.m. weer naar je terug, want je was met zwangerschapsverlof. Een link die ik destijds niet helemaal snapte. Maar hoe beter ik je leerde kennen, hoe logischer het werd, want dit karakteriseert jou. Je bent een ware machine, het ene idee wordt gevolgd door het andere, je bent soms niet te stoppen. Jij was ook de eerste die tegen me zei: "Winesh, jij gaat promoveren". Mede door jouw input en enthousiasme heb ik dit weten te bereiken. Wat ben ik trots dat jij mijn 
copromotor bent en dat ik deel uitmaak van de basis van het Amphia onderzoeks imperium van jou, Rogier en Paul.

Beoordelingscommissie: Geachte prof. dr. L.P.S. Stassen, prof. dr. I.H.M. Borel Rinkes, prof. dr. I.J.H.T. de Hingh en dr. D.K. Wasowicz, leden van de leescommissie, ik wil jullie allen danken voor het kritisch lezen en beoordelen van mijn proefschrift en voor het aanvaarden van de positie in de beoordelingscommissie. Tevens wil ik de overige leden bedanken voor hun bereidheid om als opponent zitting te nemen in de promotiecommissie. Het is een eer om met jullie over dit proefschrift van gedachte te wisselen.

Prof. dr. I.J.H.T. de Hingh (chirurg Catharina Ziekenhuis Eindhoven): beste Ignace, dat jij in de beoordelingscommissie plaats neemt maakt het wel speciaal. Ik heb veel van je geleerd tijdens mijn assistentschap en heb de samenwerking in het Catharina Ziekenhuis als zeer prettig ervaren.

Drs. Rogier. M.P.H. Crolla (chirurg Amphia Ziekenhuis). Beste Rogier, Ik kan me je mailtje als de dag van gisteren herinneren. "Het is aardig om na te gaan wat de opbrengst is van de 1-jaars colonoscopie na colonresectie wegens maligniteit, we hoesten zo 2000 casus op, hoef je je niet te vervelen". Bedankt hiervoor, ik heb me kostelijk vermaakt! Maar wat kunnen we trots zijn op wat we hieruit hebben voortgebracht. Ik wil je graag bedanken voor je adviezen en het commentaar bij de geschreven hoofdstukken want met jouw visie kreeg elk artikel een extra dimensie. In de kliniek heb ik je leren kennen als een gedreven en zeer toegankelijke collega. Ook daarbuiten hebben we fijn samengewerkt met als hoogtepunt het EAES congres in Frankfurt. We weten allebei dat ik die technology award had moeten winnen. Ik hoop dat onze samenwerking niet eindigt bij deze promotie en dat we in de nabije toekomst als 2 doctors samen een biertje kunnen drinken...hint.

Jeske Boeding: Lieve Jes, ik had me geen betere research-partner in crime kunnen wensen. Die verschrikkelijke database was niet alleen het begin van onze samenwerking, maar belangrijker nog, het begin van een hechte vriendschap. Met jouw doorzettingsvermogen, energie en soms (het moet toch vermeld worden) koppigheid, heb ik dit onderzoek kunnen afronden. Ik wens je het allerbeste toe in het vervolg van je carrière en ik kijk uit naar het vervolg van onze samenwerking. Wij zijn natuurlijk nog niet klaar, op naar de volgende mijlpaal: jouw proefschrift! Misschien dat we ooit nog in de toekomst een case-report kunnen schrijven over het dubbel-sigmoïd.

Tom C. J. Seerden (maag- darm- leverarts Amphia Ziekenenhuis). Beste Tom, dank voor je input bij de geschreven stukken over endoscopische follow-up na diverticulitis. Als MDL-arts keek je vanuit een andere ooghoek naar het manuscript, dit gaf het artikel een completer beeld. Daarnaast wil ik je bedanken dat je mij betrokken hebt in het 
'iatrogene tumortranslocatie' manuscript, hadden we toch bijna een NEJM publicatie te pakken.

Co-auteurs: Publiceren doe je natuurlijk niet alleen, harstikke bedankt voor jullie inzet en bijdrage aan de publicaties.

Amphia Academie: Dank voor jullie bijdrage aan dit proefschrift.

Jan van Trier (bibliothecaris Amphia Ziekenhuis). Beste Jan, dank dat ik 24-7 van alle faciliteiten gebruik heb mogen maken in de bibliotheek en voor het zoeken van artikelen die ik zelf niet kon vinden. De achtergelaten dienbladen waren van mij, nogmaals mijn excuses.

Dianne Backelandt (stomaverpleegkundige Amphia Ziekenhuis): Ik zat nog op de middelbare school toen jij al bezig was met het opzetten van de database. De basis heb jij destijds gelegd, ontzettend bedankt hiervoor.

Jacqueline Rasenberg (moederoverste). Lieve Jacqueline, door jou voelde ik me sinds dag 1 thuis in het Amphia Ziekenhuis. Mijn dag begon altijd goed door een compliment over mijn schoenen of mijn outfit. Elke keer als ik in het Amphia ben, mis ik je wel. Ik ben je ontzettend dankbaar voor de korte babbeltjes en adviezen in de afgelopen jaren.

Assistenten Amphia Ziekenhuis Breda. Dank voor de collegialiteit en samenwerking tijdens mijn eerste jaren als dokter, ze waren ontzettend leerzaam, deze zullen je altijd bijblijven. Daarnaast was het altijd lachen in circus ( $r$ Amphia.

Assistenten Catharina Ziekenhuis Eindhoven. Ook jullie ontzettend bedankt voor de leerzame en vooral leuke periode. Eindhoven was al mijn hometown, maar jullie hebben me vanaf het begin thuis laten voelen.

Monique Heij, Paul van Winden en Tiny Wouters. Bedankt voor jullie hulp bij het verspreiden, drukken en opmaken van dit proefschrift.

Kutterij en dergelijke. Beste Bart, Wisse, Maarten, Thomas, Tim, Tom, Boyd en Vincent, sommigen van jullie ken ik toch al langer dan 25 jaar. Ik denk niet dat veel vrienden van onze leeftijd dat kunnen zeggen. Ondanks dat we verspreid door het land zitten, spreken we vrij eenvoudig met elkaar af, en zo hoort het ook. Een hechte vriendengroep waar ik altijd op kan terugvallen. Ik hoop dan ook echt dat we volgend jaar onze eerste wintersport mogen meemaken. Oh ja, en Vince, wanneer kom je definitief terug naar Nederland? 
Rotkoppen: Beste Thomas, Chris, Jelle, Stijn, Victor en Tim, zoals jullie weten, heb ik dit werk geleverd in mijn vrije tijd naast mijn baan als arts. Ik ben jullie ontzettend dankbaar dat jullie hier nooit moeilijk over deden wanneer ik ergens niet bij kon zijn... Desalniettemin hebben we in de afgelopen jaren mooie feestjes kunnen pakken. Daarnaast hebben we nog altijd de sinterklaasavonden met legendarische gedichten, de vele zinloze discussies, harde grappen, voetbalopinies en niet te vergeten, de roulerende you-go-girl Victor. Blommert, ik hoop dat we nu wat vaker samen naar ons cluppie Ajax kunnen kijken.

Urologen IJsselland Ziekenhuis. Beste Marique, Eltjo, Berend en Robin, dank voor de nieuwe kans die jullie mij hebben geboden.

Sarika en Kiran Dayal-Ramsoedh: Lieve Sarika, Kiran (en Rohan). Ik heb jullie de afgelopen tijd wat minder vaak gezien, ik heb jullie daardoor wel gemist. Ik denk oprecht dat jullie het sterkste koppel zijn dat ik ken, zeker na wat jullie al hebben meegemaakt. Sarika, ik zie je toch als mijn grote zus en Kiran jij blijft voor altijd mijn superheld, dat weet je. Misschien wordt het weer eens tijd voor een dikke Cubaanse sigaar en een goed glas whiskey.

Girjasing family: Lieve Sarika, Amit, Shaam, Dinesh, Sonny, Anil, Reshwan, Chandni en Dheeraj. Ik heb jullie nooit in detail verteld waar ik me mee bezig heb gehouden de afgelopen jaren, maar het resultaat ligt hier voor jullie. Dit ging weleens ten koste van een verjaardag of een ander feestje, waardoor ik jullie eigenlijk nog minder zag dan normaal. Jullie blijven mijn familie en ik houd ontzettend veel van jullie. Misschien wordt het weer eens tijd om de videobanden uit de jaren 90 uit de kast te halen voor een avondje schaterlachen.

Chitradebie Ramsoedh-Girjasing + : Lieve Chitra mausi, wat had ik graag gewild dat u hierbij zou zijn. Helaas mocht dit niet zo zijn en heeft de tijd $u$ ingehaald. $U$ was als een tweede moeder voor mij.

Marnix Mus. Beste Marnix, jij kwam als oudste coassistent bij mij op de afdeling in het Amphia Ziekenhuis. Met verve en bravoure zwaaiden wij met de scepter op de traumaunit. Schotwonden en 12 weken oude tuberculum majus fracturen, het kon allemaal op Unit 41. Daarna werden we collegae. SEH-diensten met jou waren een feest, 'madness' maar ook altijd onder controle. Domino's en Pom Lai draaiden juist de overuren. Af en toe een balletje trappen als de rust was wedergekeerd, vele panna's heb jij hier mogen ontvangen, zo gaat dat. Maar daarnaast hebben wij ook 2 publicaties, toch iets om trots op te zijn. Ik heb enorm veel bewondering hoe jij je pad hebt gekozen en ik ben benieuwd in welk volgend avontuur je terecht gaat komen. Ik kijk uit naar het weekendje Engeland met jou, Beek en Stino. Of toch een middagje Ajax, zie je een keer een echte club voetballen. 
Dr. Stijn Steunenberg. Beste Stino, wij zijn samen als 2 groene onderzoekers begonnen in het Amphia. Jij op de vaatchirurgie en ik op de gastro-intestinale chirurgie. We zaten snel op 1 lijn omdat we allebei niet goed door hadden waar we mee bezig waren. Gelukkig hadden we wel snel door dat we verstand van voetbal hadden en konden we eindeloos wedstrijden, goals en spelers terughalen van de mooiste club van Nederland, Ajax. Daarna werden we collegae en op de werkvloer stonden we direct klaar voor elkaar. Ik vind het enorm knap hoe jij je onderzoek hebt aangepakt en hoe jij als dokter functioneert. Je bent dan ook één van de fijnste collega's om mee te werken, Het is dan ook niet meer dat terecht dat jij in opleiding bent gekomen.

Dr. Jasper van der Slegt en dr. Maarten Beek. Beste Slegt en Beek, jullie hebben mij als jonge onderzoeker ontvangen in het Amphia en mij geholpen waar nodig. Ook als beginnende assistent gaven jullie mij advies hoe dit het beste te combineren met je werk als arts. Ik had enorm veel respect voor hoe jullie tot in de late uurtjes aan je onderzoek zaten om een deadline te halen of een artikel te publiceren. Ironisch hoe die dingen lopen, want een aantal maanden later deed ik exact hetzelfde. Het was een feest om met jullie te werken en jullie worden ongetwijfeld uitstekende chirurgen.

Dr. Maxim Mulder. Beste Max, samen met Joeri zijn jullie mijn Geneeskunde maatjes. Ik weet niet hoe vaak wij de slappe lach hebben gehad tijdens een college. Maar we waren ook serieus wanneer we ons hadden opgesloten in de bieb voor een tentamen, om daarna dronken door Witte de With te slenteren. In Rotterdam hebben we mooie dingen meegemaakt. Ik denk nog wel eens terug aan die zomerse dag in de Oude Haven, Nederland-Brazilië en de ontploffing na de legendarische kopbal van Wesley Sneijder. Ik vind het mooi hoe jij je enthousiasme over echt elk willekeurig onderwerp kan overbrengen en hoe jij als oudere broer met je zusjes en broertje omgaat. Je bent een dierbare vriend op wie ik altijd kan rekenen en je wordt net als Laus een mooie Neuroloog.

Richard en Luke Peters. Lieve Ric en Luke. Vanaf het begin heb ik me welkom gevoeld bij jullie en ik wil jullie daarom ook bedanken voor jullie adviezen en wijsheden de afgelopen jaren. De eerste vakantie met jullie in Toscane was ontzettend spannend, dat mogen jullie best weten, maar wat heb ik toen genoten. Ric, ontzettend bedankt voor de ski lessen, er komt vast een moment dat ik je voorbij ski en dat ik met een goedkeurend knikje terug kan kijken op de piste. Ik kijk nu al uit naar onze volgende ski vakantie.

Tim Carel Kuijpers (paranimf). Beste Carel, waar moet ik beginnen? Eigenlijk heel eenvoudig, groep 2 van de Driestam. Sindsdien beste vrienden. Ik moest daarom niet lang nadenken wie mijn paranimf zou zijn. Ik kan altijd bij je terecht en ik weet dat ik op je kan bouwen. We hebben bijna alle klassen van de basisschool en het begin van de middelbare school naast elkaar gezeten. We hebben samen ontzettend veel 
meegemaakt, roemruchtige verhalen zijn dit, een aantal hiervan kan ik hier beter niet delen. Bij elkaar spelen op de woensdagmiddag, de ontelbare potjes 10-en, het onnavolgbare geklooi op het van Maerlant Lyceum en de vele festivals, onvergetelijk. Des te mooier dat jij straks aan mijn zijde staat bij de verdediging. Hopelijk kan jij dit jaar ook een mijlpaal bereiken met het behalen van je afstudeerscriptie, hopelijk is dit inhoudelijk van hoger niveau dan je spreekbeurt over epilepsie.

Joeri van Boxtel (paranimf): Beste Joeri, het was voor mij niet moeilijk wie aan mijn andere zijde als paranimf zou moeten plaatsnemen. Tijdens de studie kwamen we er snel achter dat we dezelfde interesses deelden. We hadden allebei ambities in een snijdend vak en dat werd bij elk coschap weer eens bevestigd. Ik vind het toch knap hoe jij je studie gehaald hebt omdat je de colleges altijd met je ogen dicht volgde. Het is ontzettend mooi hoe jij je doel inmiddels hebt weten te bereiken, hier heb ik nooit aan getwijfeld. Maar ik weet ook van je bestuurlijke ambities, ik ben dan ook zeer benieuwd wanneer je een bestuurlijke functie gaat bekleden in wat voor instelling dan ook. Ongetwijfeld ga jij je weg hier ook in vinden.

Papa en mama. Lieve papa en mama, zonder jullie liefde en steun had ik dit nooit kunnen doen. Jullie staan altijd voor me klaar, hebben altijd interesse getoond in de vorderingen van het onderzoek en boden altijd een luisterend oor als het niet soepel liep. Vanaf mijn jeugd hebben jullie me vrij gelaten in mijn keuzes en dat gaf me het vertrouwen om de juiste stappen te zetten. Daarnaast hebben jullie mij geleerd dat hard werken en doorzetten de basis is van succes. Uiteindelijk resulteerde dit in een groepsknuffel in de zomer van 2008 toen ik hoorde dat ik was geselecteerd voor de Geneeskunde studie, een moment om nooit te vergeten. Met jullie levenslessen en mentaliteit heb ik dit onderzoek aangepakt, het resultaat ligt nu eindelijk voor jullie. Papa, jij hebt het als eerste toch goed gezien. Jij zei net na mijn geboorte dat ik doctor/dokter zou worden, je hebt in beide gevallen gelijk gekregen.

Shanila. Lieve bolletje, allerliefste zusje, dank je wel dat je altijd voor mij klaar stond, mijn gezeur aanhoorde en mijn getreiter pikte. Maar dit siert je ook ontzettend, dit laat zien hoe lief en attent je bent geweest voor mij. Ik vind het mooi hoe ik jou volwassen heb zien worden. Tegenwoordig laat jij zien hoe ik tegen bepaalde dingen aan kan kijken in plaats van andersom. Dan laat je toch weer zien hoeveel menselijk inzicht jij hebt. Vooral wanneer mijn mening weer eens te zwart-wit is, of wanneer ik te kort door de bocht ben, weet jij dit weer te rationaliseren. Bedankt voor alle zinloze gesprekken, domme dansjes in de keuken, je bolle wangen en je adviezen. "Zeg gewoon dat er meer onderzoek gedaan moet worden" is toch wel je beste advies geweest wanneer ik vastliep met een artikel. Ik ben enorm trots hoe jij je Psychologie studie bijna hebt afgerond, nog heel even! Ik had me geen beter zusje kunnen wensen om mee samen onze papa en mama trots te maken. 
Chloé: Lieve Chloé, de liefde van mijn leven. Zonder jou had ik dit niet kunnen afronden. Je weet als geen ander hoe de afgelopen jaren zijn verlopen en hoe ik die heb beleefd. Vanaf het begin bleef je betrokken en bleef je aan mijn zijde staan, dat zal ik nooit vergeten. Net zoals ik nooit zal vergeten hoe jij mij versierd hebt op de kerstborrel van 2016. Ik kijk met een glimlach terug op de ontelbare romantische weekendjes weg in het Amphia. Maar ik werd pas echt verliefd op je in de sneeuw in Zell am See. Ik kan me inmiddels geen leven meer voorstellen waar jij niet in voorkomt. $\mathrm{Nu}$ ben je mijn alles, maar we moeten niet vergeten dat we natuurlijk ook collegae zijn geweest. Toen heb ik al kunnen zien dat je toewijding, je professionaliteit en intelligentie jou een uitstekend dokter maken. Ik ben enorm trots hoe jij nu de opleiding tot chirurg aanpakt en ben benieuwd waar jij je uiteindelijk in gaat differentiëren, maar stiekem weet ik dit al. Ik hoop dat we samen snel meer duidelijkheid hebben, zodat we ons imperium verder kunnen uitbreiden. Ik hoop dat we in de toekomst nog vele pistes mogen trotseren. Ik houd ontzettend veel van je en ik laat je nooit meer gaan, voor altijd samen, just the two of us. 

Curriculum vitae 



\section{Curriculum vitae}

The author of this Thesis, Winesh Ramphal was born on the $28^{\text {th }}$ of August 1987 in Eindhoven, the Netherlands. He graduated from high school at the van Maerlant Lyceum (Atheneum) in 2006. After his third application, he finally got accepted at the Faculty of Medicine of the Erasmus University in Rotterdam. During his surgical internship at the Amphia Hospital Breda he started his research project in endoscopic follow-up after diverticulitis under supervision of dr. P.D. Gobardhan and dr. J.M.J. Schreinemakers. This project was the foundation of this thesis and he got rewarded with the "Pieter Stijnen science award" in 2014. In March 2015 he graduated from Medical school and started working as a resident at the Surgery Department at the Amphia Hospital in Breda where he combined his clinical work with his PhD research in patients with diverticulitis and colorectal cancer. In 2018 he went to Eindhoven to work as a surgical resident at the Catharina Hospital Eindhoven and finish his medical research under supervision of prof. dr. H.J.T. Rutten. The main aim of his PhD project was to describe various clinical situations in patients with diverticulitis and patients with colorectal cancer to improve quality management after curative surgery. The results are presented in this thesis. Currently he is working as a resident at the Urology department.

De auteur van dit proefschrift, Winesh Ramphal, werd op 28 augustus 1987 geboren in Eindhoven, Nederland. In 2006 slaagde hij voor het eindexamen Atheneum op het van Maerlant Lyceum in Eindhoven. Na drie keer loten, werd hij via de decentrale selectie aangenomen voor de studie Geneeskunde aan de Erasmus Universiteit in Rotterdam. Gedurende zijn Chirurgie co-schap in het Amphia Ziekenhuis begon hij met zijn onderzoek naar de endoscopische follow-up bij patiënten met een diverticulitis onder supervisie van dr. P.D. Gobardhan en dr. J.M.J. Schreinemakers. Dit project was de fundering van deze dissertatie en hiermee won hij de Pieter Stijnen wetenschapsprijs in 2014. In maart 2015 studeerde hij af in de Geneeskunde en begon hij als arts-assistent op de afdeling Chirurgie van het Amphia waar hij zijn werkzaamheden in de kliniek combineerde met zijn PhD onderzoek naar diverticulitis en het colorectaal carcinoom. In mei 2018 begon hij als arts assistent Chirurgie in het Catharina Ziekenhuis Eindhoven waar hij zijn onderzoek afrondde onder supervisie van zijn promotor prof. dr. H.J.T. Rutten. In dit PhD onderzoek worden verschillende klinische situaties in de endoscopische follow-up na een ongecompliceerde diverticulitis onderzocht. Daarnaast worden verschillende klinische vraagstukken beantwoord over patiënten die een curatieve resectie ondergaan voor het colorectaal carcinoom met als doel het kwaliteitsmanagement te bevorderen. De resultaten worden gepresenteerd in dit proefschrift. Momenteel is hij werkzaam als arts-assistent op de afdeling Urologie. 


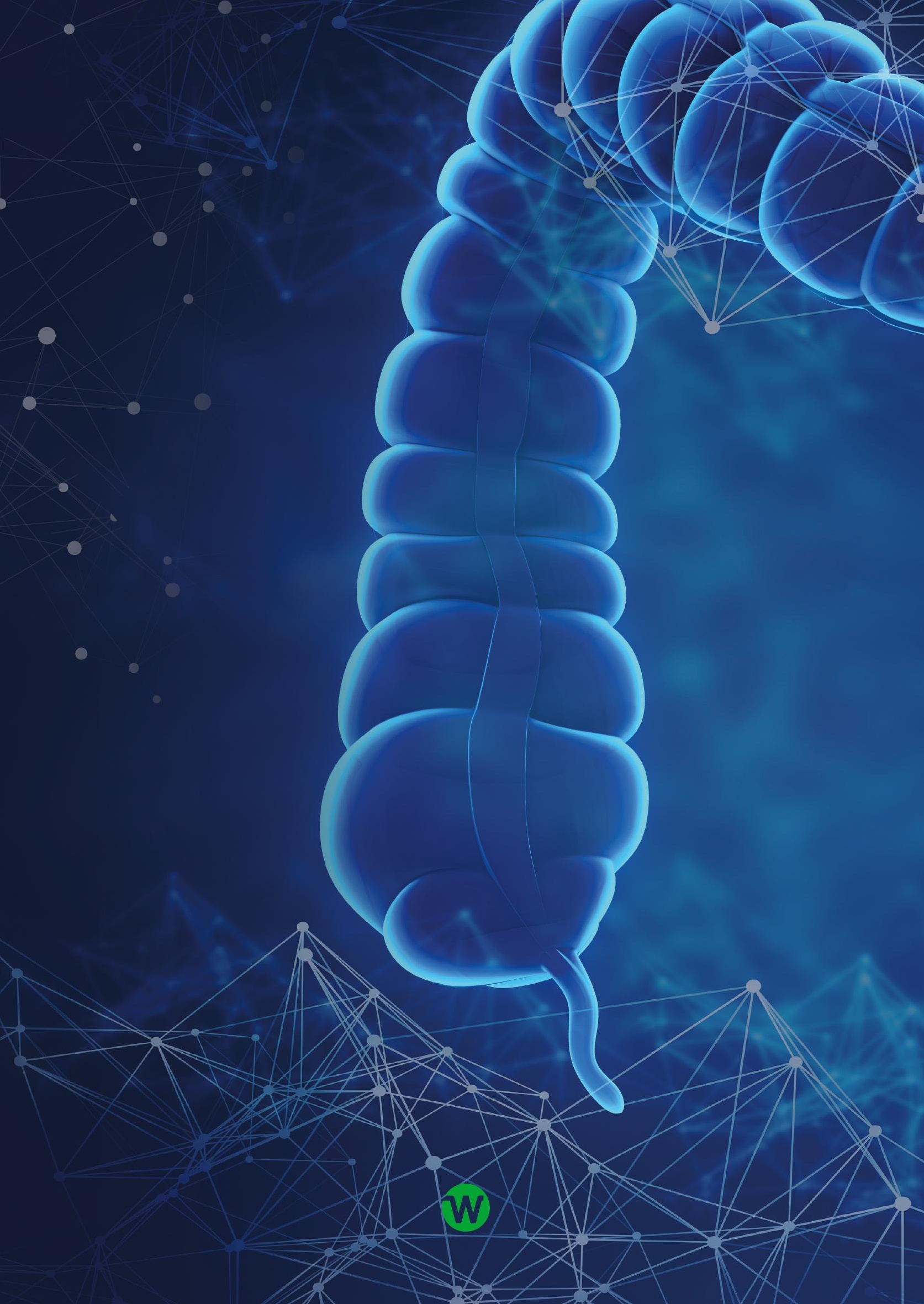

